\title{
CONTROLE ROBUSTO DE SUSPENSÃO SEMI-ATIVA PARA CAMINHONETES UTILIZANDO AMORTECEDORES MAGNETO-REOLÓGICOS
}

Tese apresentada à Escola Politécnica da Universidade de São Paulo para obtenção do Título de Doutor em Engenharia.

v.1 



\section{CONTROLE ROBUSTO DE SUSPENSÃO SEMI-ATIVA PARA CAMINHONETES UTILIZANDO AMORTECEDORES MAGNETO-REOLÓGICOS}

Tese apresentada à Escola Politécnica da Universidade de São Paulo para obtenção do Título de Doutor em Engenharia.

Área de Concentração:

Engenharia Mecânica

Orientador:

Prof. Doutor Décio Crisol Donha Co-orientador:

Prof. Doutor Edilson Hiroshi Tamai

v.1 
Este exemplar foi revisado e alterado em relação à versão original, sob responsabilidade única do autor e com a anuência de seu orientador.

São Paulo, 17 de dezembro de 2008.

Assinatura do autor

Assinatura do orientador

\section{FICHA CATALOGRÁFICA}

Crivellaro, Cláudio

Controle robusto de suspensão semi-ativa para caminhonetes utilizando amortecedores magneto-reológicos / C. Crivellaro. -- ed.rev. -- São Paulo, 2008.

439 p.

Tese (Doutorado) - Escola Politécnica da Universidade de São Paulo. Departamento de Engenharia Mecânica.

1.Mecânica automotiva 2.Amortecedores 3.Suspensão mecânica I.Universidade de São Paulo. Escola Politécnica. Departamento de Engenharia Mecânica II.t. 
Dedico este trabalho aos meus pais, à minha esposa Regiane e ao meu filho Enzo. 


\section{AGRADECIMENTOS}

Agradeço primeiramente a Deus, por ter me dado inspiração, coragem, otimismo e disposição para conduzir e finalizar este trabalho, com qual eu aprendi muito mais do que podia imaginar.

À minha esposa, Regiane, pelo apoio e incentivo, e principalmente pela sua paciência e cumplicidade. Também ao meu filho, Enzo, que com sua alegria e criatividade é uma grande fonte de inspiração para mim.

Aos meus pais, pelo apoio, pelo suporte, e, sem dúvida, pela educação que me proporcionaram.

Ao meu orientador Prof. Dr. Décio Crisol Donha, pela sua perspicácia nas correções, pelas críticas enriquecedoras, e pelo apoio e orientação neste trabalho.

Ao meu co-orientador Prof. Dr. Edilson Hiroshi Tamai, por contribuir com materiais imprescindíveis à execução deste trabalho, e pelo suporte no laboratório de dinâmica.

Ao Prof. Dr. Antônio Bombard da UNIFEI de Itajubá, MG, primeiramente pela amizade que construímos, pelos conselhos e dicas, e também por fornecer o fluido magneto-reológico para os protótipos, e pelos artigos e patentes sobre o assunto.

Ao Prof. Dr. José Roberto Cardoso, pela utilização do software Flux2D ${ }^{\circledR}$ no laboratório LMAG do departamento de Engenharia Elétrica da Escola Politécnica da USP, e pela sua orientação nas análises de elementos finitos magnetostática da válvula do amortecedor magneto-reológico.

Ao Prof. Dr. Jaime da Cruz, pela amizade, pelo incentivo e pelas dicas que me foram muito úteis.

À Prof. ${ }^{\text {a }}$ Doutora Denise Consonni, pela utilização do seu laboratório para testes do circuito eletrônico de acionamento do amortecedor magneto-reológico.

À Silvia Della Torre, pelas orientações e dicas quanto à organização do texto, organização da bibliografia e às normas e procedimentos das bibliotecas da USP.

Ao Eng. ${ }^{\circ}$ e Mestre Núncio Perrella, pelo valiosíssimo suporte em relação ao "hardware" do DSP da Texas Instruments, e pela amizade que iniciamos.

À DANA por proporcionar a oportunidade da construção e testes do amortecedor magnetoreológico.

Ao Eng. ${ }^{\circ}$ Eduardo Carlos Alves e Eng. ${ }^{\circ}$ Hideo Matsuzaki da Affinia Automotive Group, pelo apoio na construção dos protótipos do amortecedor magneto-reológico.

Ao Eng. ${ }^{\circ}$ Eduardo Prelog, pela ajuda nos trabalhos de instalação dos equipamentos no veículo e auxílio nos testes experimentais, e pelos finais de semana que deixou de estar com a família para me ajudar. E ao seu pai, Sr. Slavko Prelog, por ceder gentilmente a garagem de sua casa para ser nossa oficina.

Ao futuro Eng. ${ }^{\circ}$ Ricardo dos Santos Lima, pelo seu excepcional trabalho de ferramentaria na construção dos componentes mais importantes dos amortecedores magneto-reológicos, e também pelos seus conselhos e dicas.

A todos os colegas da DANA, da Affinia e da USP que direta ou indiretamente colaboraram na execução deste trabalho. 
"Nunca andes pelo caminho traçado, pois ele conduz somente aonde outros já foram".

(Alexander Graham Bell) 


\section{RESUMO}

A utilização de sistemas semi-ativos no controle de movimento e vibração vem crescendo muito nos últimos anos, e está se firmando como a opção mais econômica em muitas aplicações. Os sistemas de controle semi-ativos baseados em fluidos magneto-reológicos (MR) já são empregados no controle de vibrações desde máquinas de lavar a grandes pontes suspensas, e até mesmo no controle de vibração de edifícios sujeitos a abalos sísmicos. No controle de movimento, eles têm sido aplicados em aparelhos de fisioterapia, próteses de joelho humano e embreagens. No setor automobilístico, os sistemas semi-ativos são empregados em sistemas de controle da suspensão e sistemas anti-rolagem, e também no controle de sistemas de torque e tração. Visto a crescente importância dos sistemas de controle semi-ativo, este trabalho aborda este assunto dividindo-o em duas partes: a primeira, apresentada no volume 1, trata do projeto de atuadores magneto-reológicos e do seu modelamento dinâmico voltado para projetos de controle; e a segunda parte, apresentada no volume 2, trata de projeto de controladores para sistemas semi-ativos, mais especificamente voltados para o controle de suspensão veicular semi-ativa, buscando a melhoria do desempenho em conforto, segurança e dirigibilidade do veículo. Na primeira parte, a maior contribuição deste trabalho está em preencher uma lacuna na literatura no que diz respeito a uma técnica sistemática de projeto de atuadores magneto-reológicos e da forma mais adequada de sua representação dinâmica para projetos de controle, que é feita a partir de dados experimentais. Na segunda parte deste trabalho buscou-se desenvolver um sistema de controle economicamente viável para veículos utilitários (caminhonetes principalmente). Estes são os veículos que mais carecem de sistemas de suspensão capazes de atender a uma grande variedade de situações (variação de pista, variação de carga), e cujo mercado exige uma relação custo/benefício melhor que aquela dos mercados de carros de luxo, onde estes sistemas são empregados atualmente. Como resultados mais importantes deste trabalho têmse: uma proposição para o uso da lei de controle LQG/LTR em sistemas não estritamente próprios; um modelo de um veículo utilitário completo com sete graus de liberdade e capaz de representar as situações mais importantes do comportamento dinâmico deste tipo de veículo; o desenvolvimento de uma estratégia de controle robusto baseado na técnica LQG/LTR, adequada para trabalhar com atuadores semi-ativos, e que utiliza sensores de custo compatível com a aplicação. O sistema de controle proposto foi capaz de melhorar o desempenho em conforto e segurança, evitando situações de perda de aderência dos pneus e comportamentos dinâmicos indesejáveis destes veículos, que foi verificado experimentalmente e através de simulações em computador.

Palavras chave: suspensão veicular, caminhonetes, magneto-reológico, controle robusto, LQG/LTR, semi-ativo, modelo Bouc-Wen discreto. 


\begin{abstract}
The application of semi-active systems to motion and vibration control has significantly grown during the last years, and it is becoming an economically viable option for several applications. Semi-active systems based on magneto-rheological (MR) fluids were applied to vibration control ranging from washing machines to suspended bridges, and also in vibration control of buildings under seismic tremors. Regarding the movement control, they have been used in gym apparati, human knee prosthesis and clutches. More specifically in the automotive industry, semi-active systems have been applied in suspension and anti-roll systems, and also in torque and traction control systems. This work treats this subject dividing it into two parts: the first one, presented in volume 1, deals with the design of semi-active actuators based on magneto-rheological fluids and dynamic modeling; and the second one, presented in volume 2, deals with the design of semi-active control for vehicular suspension systems. The control main objective is the performance improvement in comfort, safety and handling features of a vehicle. In the first part, the main contribution of this work is to fulfill a literature gap regarding a systematic procedure for design of magneto-rheological actuators and to find a better representation for the dynamic behavior regarding the control system development, which is done based on experimental data analysis. The second part of this work leaded with the development of a vehicular suspension system for utility vehicles (for SUVs, and mainly for light trucks), which need suspension systems able to face a great number of situations (road variation, load variation, etc.), and which present stability problems due to its high gravity center height. Important results of this work are: the development of a robust control strategy based on LQG/LTR techniques for non-strictly proper systems, the development of a dynamic model for light trucks and SUVs with seven degrees of freedom; the development of a robust control strategy based on the LQG/LTR synthesis, suit to work with semi-active actuators, and using sensors with costs compatible to the application. The proposed control system was able to improve the performance of comfort and safety, avoiding the loss of adherence between tires and the ground and other undesirable dynamic behaviors of these vehicles, that was verified experimentally and through computer simulations.
\end{abstract}

Key words: car suspension, pickup trucks, magneto-rheological, robust control, LQG/LTR, semi-active, Bouc-Wen discrete-time model. 


\section{LISTA DE FIGURAS}

Figura 1.1 - Exemplo de uso de atuadores MR em máquinas de lavar................................26

Figura 1.2 - Intervalos críticos ao longo do programa automático de lavagem.................... 27

Figura 1.3 - Comparação entre os sistemas passivos com baixo e alto amortecimento e o sistema de controle semi-ativo em malha fechada............................................ 27

Figura 1.4 - Corvette edição especial de aniversário do $50^{\circ}$ ano da marca............................ 28

Figura 1.5 - Detalhes e cortes do amortecedor MR do utilizado no Corvette........................ 28

Figura 1.6 - Exemplo de um prédio equipado com atuadores MR que atenuam a sua

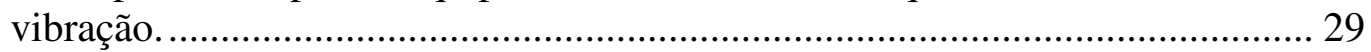

Figura 1.7 - Experimento da Universidade de Notre Dame- http://www.nd.edu/ ................ 30

Figura 1.8 - Ponte pênsil sobre o lago Dongting, na província de Hunan, China. Esta ponte tem um comprimento total de $800 \mathrm{~m}$ e os vãos livres principais chegam a 310m. Um par de atuadores MR foi colocado em cada um dos seus cabos de aço de sustentação (KO et al., 2003).

Figura 1.9 - Prótese de perna mecânica Magnetix ${ }^{\mathrm{TM}}$ da MOTHEC baseado em atuadores MR.

Figura 1.10 - Próteses semi-ativas MR em amputados trans-femoral................................... 31

Figura 2.1 - Amostra de fluido MR ao natural (imagem à esquerda) e sob campo magnético (imagem à direita).

Figura 2.2 - Micrografia eletrônica de varredura de partículas de pó de ferro carbonilo da

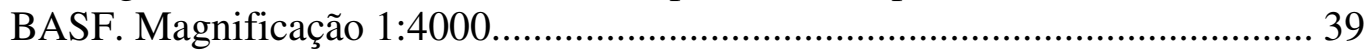

Figura 2.3 - Válvula MR com esponja de poliuretano saturada............................................ 44

Figura 2.4 - Válvula MR utilizada no amortecedor do Corvette (HALVERSON, 2003)..... 45

Figura 2.5 - Válvula MR desenvolvida para a Visteon pelo Virginia Tech ......................... 46

Figura 2.6 - Modelo Bingham de um amortecedor MR (Stanway, op. cit.) ........................... 47

Figura 2.7 - Modelo proposto por Gamota e Filisko (1991).................................................. 48

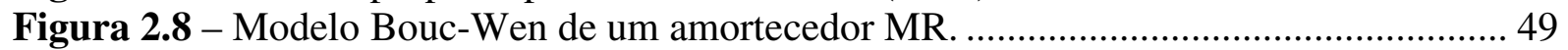

Figura 2.9 - Modelo proposto por Spencer et al. (1996)................................................... 50

Figura 3.1 - Volume infinitesimal de fluido e suas tensões: (a) 2D, (b) 3D. ........................ 53

Figura 3.2 - Curva da tensão de cisalhamento do fluido MRF 132-AD da Lord em função da taxa de cisalhamento. Esta curva pode ser representada por uma reta, aproximando-a por um modelo newtoniano com viscosidade constante............ 55

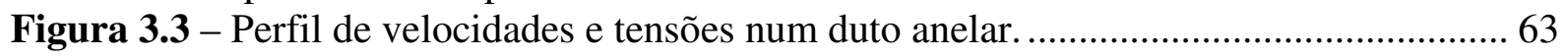

Figura 3.4 - Perfil de velocidades e tensões num fluxo entre placas paralelas. ..................... 64

Figura 3.5 - Ilustração da margem de força controlável num amortecedor MR. ................... 69

Figura 3.6 - Modos operacionais básicos para dispositivos MR: (a) modo de fluxo gerado por pressão, e (b) modo de cisalhamento direto....................................................... 70

Figura 4.1 - Exemplo da divisão de espaço em um amortecedor monotubular (valores em

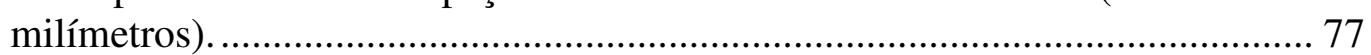

Figura 4.2 - Gráfico do "Product Bulletin" do fluido MRF-132AD ..................................... 81

Figura 4.3 - Geometria adotada para a válvula MR .......................................................... 84

Figura 4.4 - Modelo de elementos finitos e sua condição de contorno............................... 87

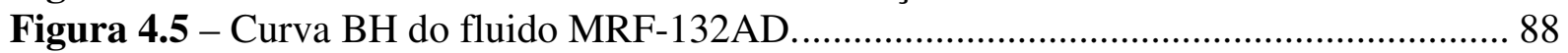

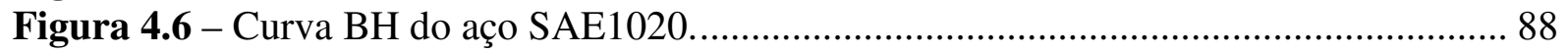

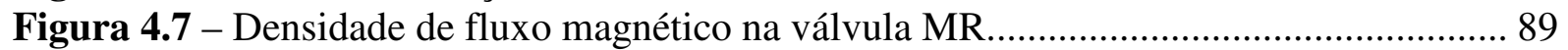

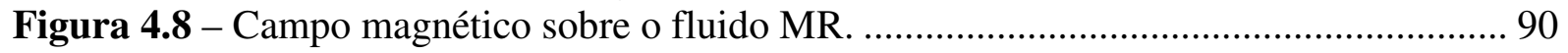

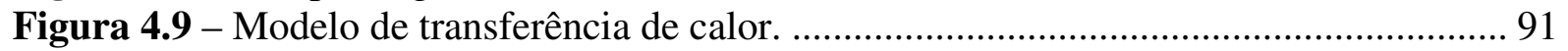

Figura 4.10 - Componentes de vedação e mancal da haste .................................................. 94 


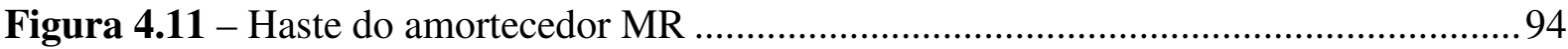

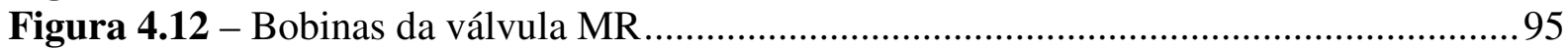

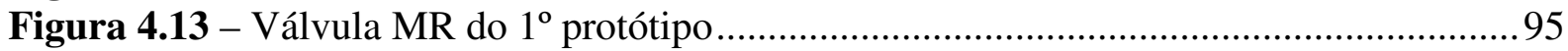

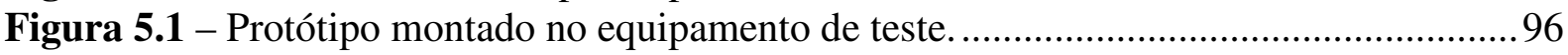

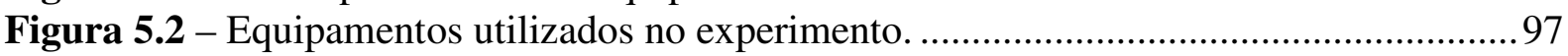

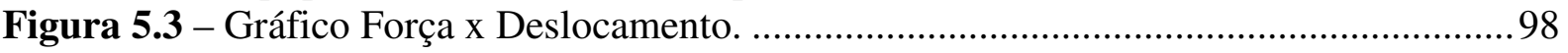

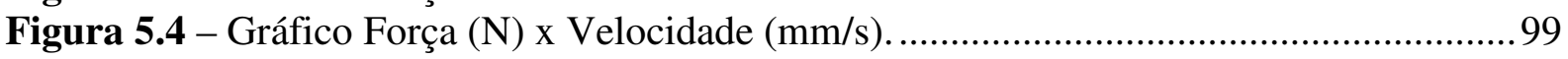

Figura 5.5 - Destaque dos patamares de força para cada nível de tensão de excitação ........ 100

Figura 5.6 - Fluxograma do procedimento de projeto de dispositivos MR ..........................104

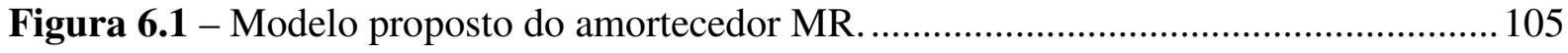

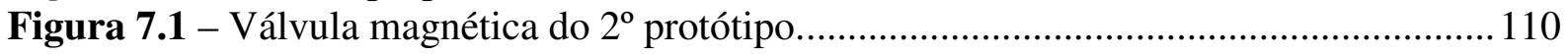

Figura 7.2 - Modelo em CAD 3D do amortecedor MR para caminhonete Ranger.............. 112

Figura 7.3 - Modelo Conjunto de peças do $2^{\circ}$ protótipo do amortecedor MR. ..................... 112

Figura 7.4 - Comparação do amortecedor original com o novo amortecedor MR............... 113

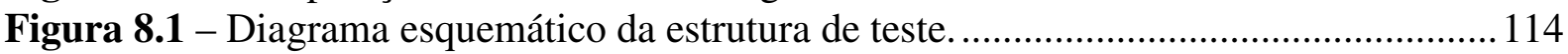

Figura 8.2 - Realização física da estrutura de teste (Laboratório da Dana Nakata). ............. 115

Figura 8.3 - Equipamentos MTS utilizado no experimento............................................ 116

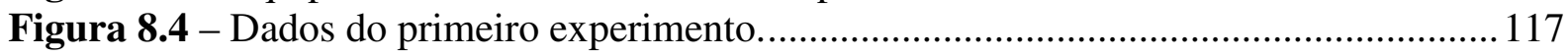

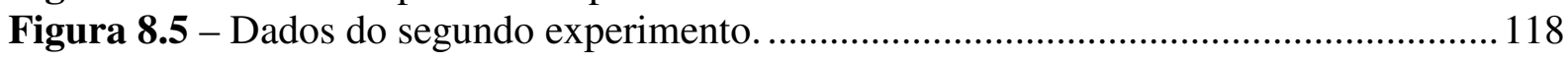

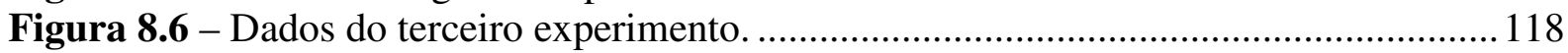

Figura 8.7 - Gráfico de Força x Deslocamento - $1^{\circ}$ experimento. ........................................ 122

Figura 8.8 - Gráfico de Força x Velocidade - $1^{\circ}$ experimento.......................................... 122

Figura 8.9 - Gráficos de Força x Tempo e Erro de força - $1^{\circ}$ experimento. ......................... 123

Figura 8.10 - Gráfico de Força x Deslocamento - $2^{\circ}$ experimento. ....................................... 123

Figura 8.11 - Gráfico de Força x Velocidade - $2^{\circ}$ experimento. ......................................... 124

Figura 8.12 - Gráficos de Força x Tempo e Erro de força - $2^{\circ}$ experimento......................... 124

Figura 8.13 - Gráfico de Força x Deslocamento - $3^{\circ}$ experimento. ..................................... 125

Figura 8.14 - Gráfico de Força x Velocidade - $3^{\circ}$ experimento........................................... 125

Figura 8.15 - Gráficos de Força x Tempo e Erro de força - $3^{\circ}$ experimento......................... 126

Figura 8.16 - Processo proposto para identificação do modelo............................................ 129

Figura 8.17 - Estimativa do tempo de resposta a partir dos dados do segundo experimento.

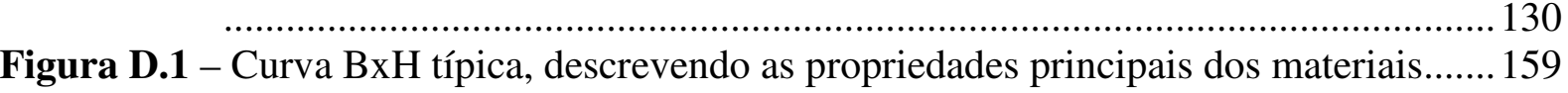

Figura D.2 - Coercividade e magnetização de saturação de materiais magnéticos (Chin apud

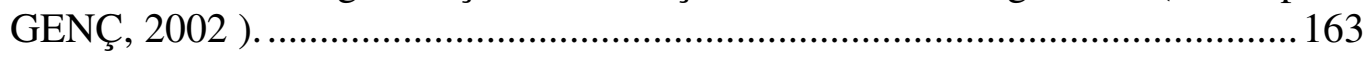




\section{LISTA DE TABELAS}

Tabela 4.1: Resumo dos requisitos e restrições do projeto do amortecedor MR....................78

Tabela 4.2: Dados técnicos sobre o fluido MRF-132AD ......................................................91

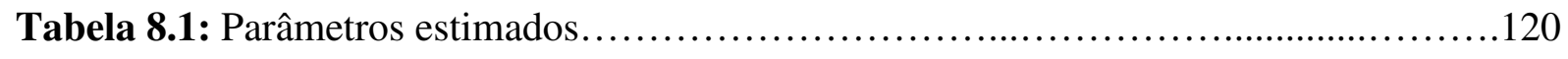

Tabela D.1: Suscetibilidade e permeabilidade relativa dos materiais..................................159

Tabela D.2: Materiais ferromagnéticos doces típicos (MORRISH,1965)............................161

Tabela An.1:Composição básica e densidade de fluidos MR comerciais (1998)..................169

Tabela An.2: Tensão de escoamento e viscosidade aparente de fluidos MR comerciais......170 


\section{LISTA DE SÍMBOLOS}

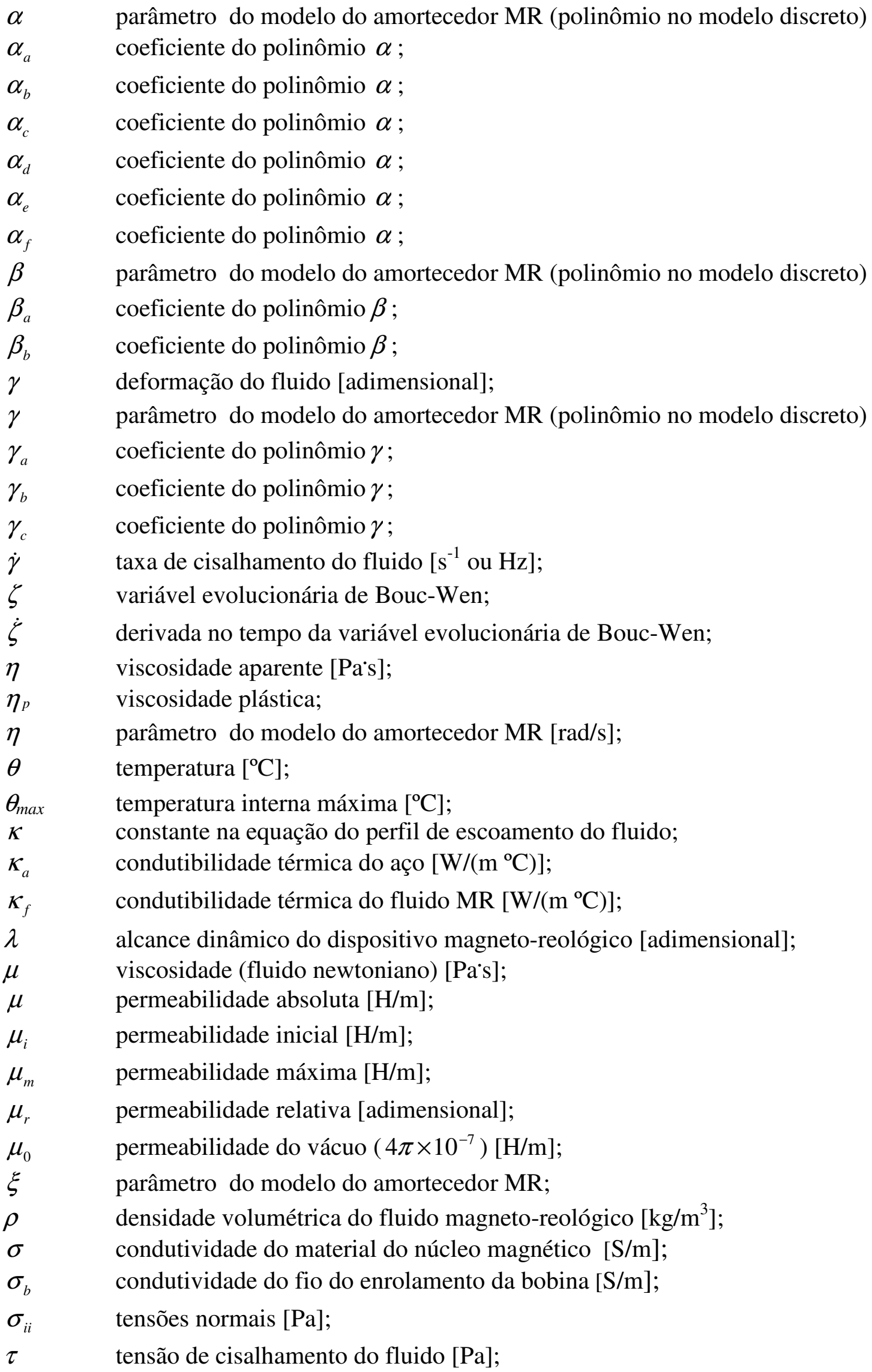



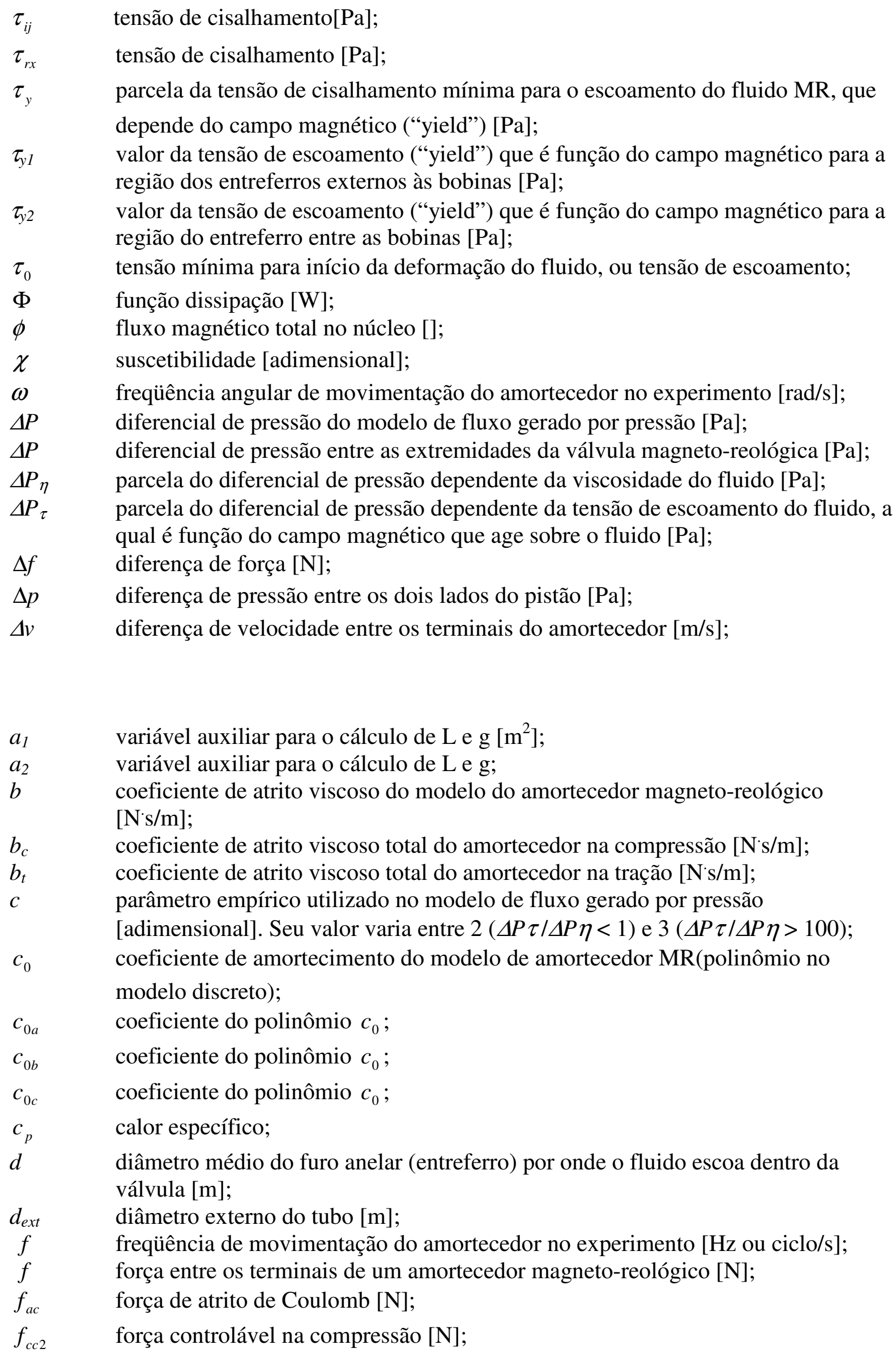


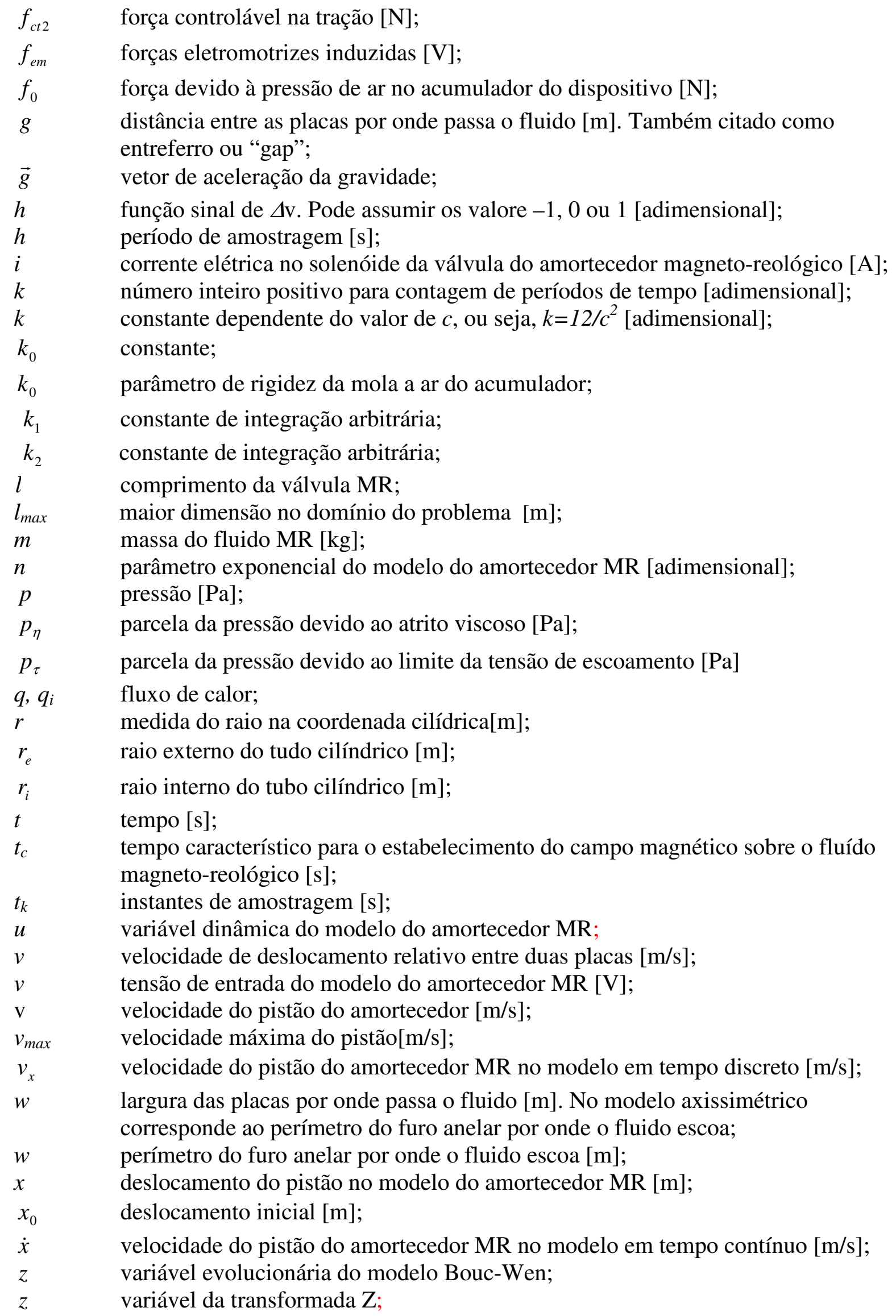


A

A

$A_{a}$

$A_{b}$

$A_{c}$

$A_{c}$

$A_{d}$

$A_{\text {desl }}$.

$A_{p}$

$A_{t}$

$A_{v}$

$A_{\text {vel. }}$.

$\vec{A}$

$B=|\vec{B}|$

$B_{r}$

$\vec{B}$

C

$C_{T}$

D

D

$D_{\text {haste }}$

$\vec{E}$

F

F

$F_{C}$

$F_{\text {max }}$

$F_{\text {min }}$

$F_{\eta}$

$F_{\tau}$

$F_{1}$

$F_{2}$

$F_{3}$

G

$H=|\vec{H}|$

$H_{c}$

$\vec{H}$

I

I

$I_{\max }$

$I_{p}$

$J$

área através da qual o pistão do amortecedor aplica força sobre o fluido $\left[\mathrm{m}^{2}\right]$; parâmetro do modelo do amortecedor MR (polinômio no modelo discreto); coeficiente do polinômio $A$;

coeficiente do polinômio $A$;

coeficiente do polinômio $A$;

área do pistão que exerce pressão na compressão do amortecedor $\left[\mathrm{m}^{2}\right]$;

amplitude do deslocamento da haste do amortecedor no experimento [mm];

amplitude do deslocamento [m];

área da seção transversal do pistão do amortecedor $\left[\mathrm{m}^{2}\right]$;

área do pistão que exerce pressão na tração do amortecedor $\left[\mathrm{m}^{2}\right]$;

amplitude da velocidade da haste do amortecedor no experimento [mm/s];

amplitude da velocidade $[\mathrm{m} / \mathrm{s}]$;

vetor potencial magnético;

intensidade do vetor densidade de fluxo magnético [Tesla $\left.\equiv \mathrm{Wb} / \mathrm{m}^{2}\right]$;

remanência $\left[\right.$ Tesla $\left.\equiv \mathrm{Wb} / \mathrm{m}^{2}\right]$;

vetor densidade de fluxo magnético $\left[\right.$ Tesla $\left.\equiv \mathrm{Wb} / \mathrm{m}^{2}\right]$;

velocidade da luz;

capacitância térmica;

diâmetro interno do tubo do amortecedor [m];

tensor de velocidade de deformação ou taxa de deformação;

diâmetro da haste do amortecedor do amortecedor [m];

vetor campo elétrico;

força necessária para gerar um movimento relativo entre as placas com velocidade $v$ no modelo de cisalhamento direto $[\mathrm{N}]$

força de reação do amortecedor em função da imposição do deslocamento [N];

força de atrito de Coulomb "residual" [N];

força axial máxima controlável gerada pelo amortecedor magneto-reológico $[\mathrm{N}]$;

força mínima gerada pelo amortecedor magneto-reológico [N];

parcela da força dependente da viscosidade do fluido [N];

parcela da força dependente da tensão de escoamento do fluido, a qual é função do

campo magnético que age sobre o fluido $[\mathrm{N}]$;

fator de mérito para dispositivos magneto-reológicos $[\mathrm{Pa} / \mathrm{s}]$;

fator de mérito para dispositivos magneto-reológicos $\left[\mathrm{m}^{2} / \mathrm{s}^{3}\right]$;

fator de mérito para dispositivos magneto-reológicos $[\mathrm{N} \cdot \mathrm{m} / \mathrm{Wb} \mathrm{A}]$;

módulo de elasticidade complexo do fluido $[\mathrm{Pa}]$;

intensidade do vetor campo magnético $[\mathrm{A} / \mathrm{m}]$;

coercividade $[\mathrm{A} / \mathrm{m}]$;

vetor campo magnético $[\mathrm{A} / \mathrm{m}]$;

corrente no solenóide $[\mathrm{A}]$;

matriz identidade;

corrente máxima no solenóide da válvula do dispositivo magneto-reológico [A];

corrente elétrica de pico [A];

densidade de corrente elétrica na área da secção de cada bobina do solenóide

$\left[\mathrm{A} / \mathrm{m}^{2}\right]$;

$J_{e} \quad$ densidade de correntes parasitas no núcleo magnético $\left[\mathrm{A} / \mathrm{m}^{2}\right]$; 


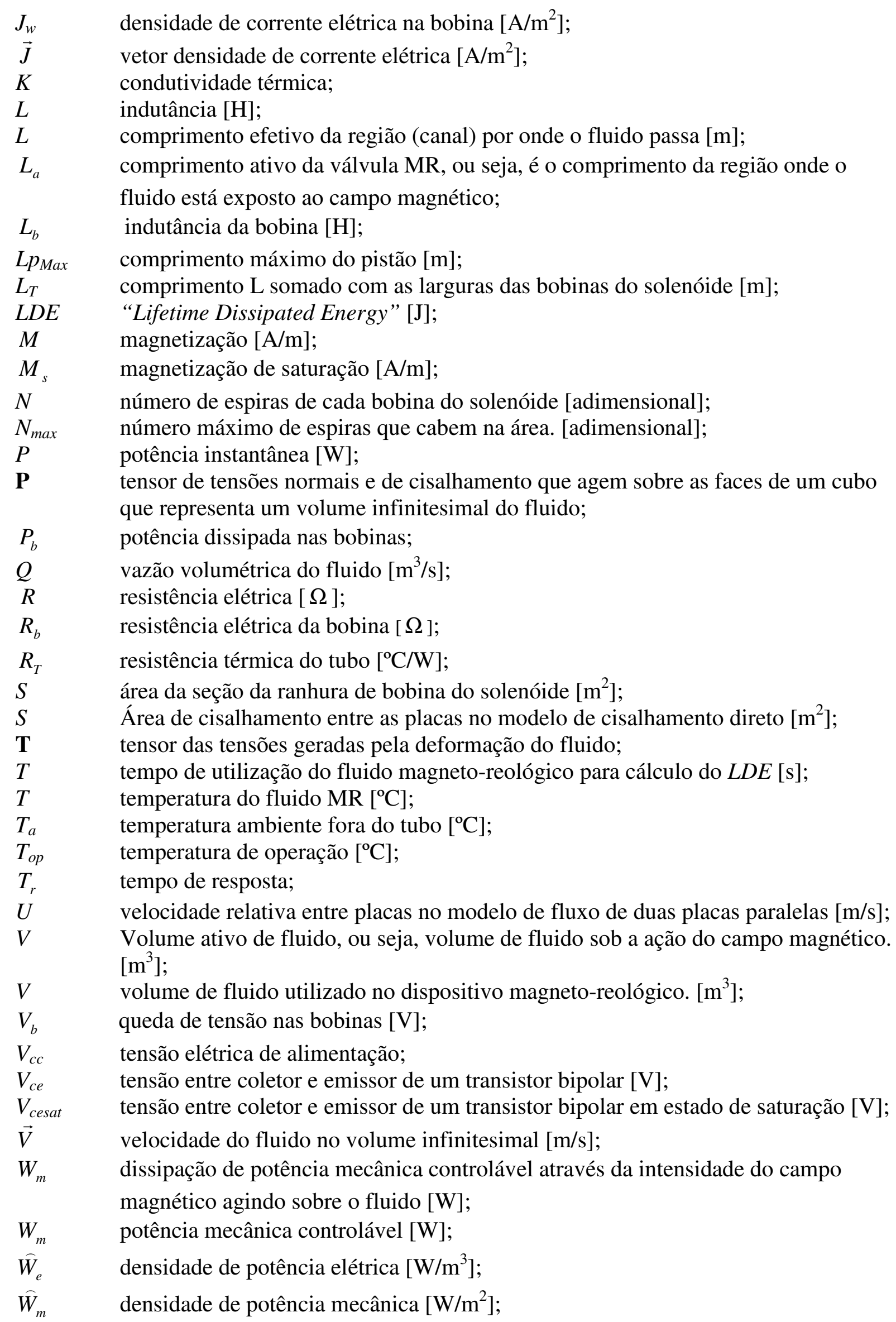




\title{
Operadores
}

\author{
$(\bullet)^{T} \quad$ operador de transposição de matriz; \\ $(\bullet)^{-1} \quad$ operação de inversão de matriz; \\ $(\bullet)^{\perp} \quad$ operação de pseudo inversão de matriz; \\ - $\quad$ indica estimativa de variável; \\ - $\quad$ indica derivada em relação ao tempo; \\ $E\{\bullet\} \quad$ valor esperado de variável estocástica; \\ $\|\bullet\|_{1} \quad$ norma 1 ; \\ $\| \bullet \quad$ norma 2; \\ $\|\bullet\|_{F} \quad$ norma de Frobenius; \\ $\nabla \bullet \quad$ operador gradiente; \\ $\nabla \cdot \vec{\bullet} \quad$ operador divergente; \\ $\nabla \times \vec{\bullet} \quad$ operador rotacional; \\ $\nabla^{2} \vec{\bullet} \quad$ operador laplaceano.
}




\section{LISTA DE ABREVIATURAS E SIGLAS}

\begin{tabular}{|c|c|}
\hline BFGS & Broyden-Fletcher-Goldfarb-Shanno \\
\hline CAD & "computer aided design" \\
\hline CAE & "computer aided engineering" \\
\hline CMM & compósitos magnéticos moles \\
\hline ER & eletro-reológico \\
\hline FEMM & "finite element method magnetics" \\
\hline IUT & "in-use-thickening" \\
\hline LDE & "lifetime dissipated energy" \\
\hline MR & magneto-reológico \\
\hline $\mathrm{MEF}$ & método dos elementos finitos \\
\hline SMC & "soft magnetic composities" \\
\hline SMR & suspensões magneto-reológicas \\
\hline PG & problema geral \\
\hline PL & programação linear \\
\hline PQ & programação quadrática \\
\hline PQS & programação quadrática seqüencial \\
\hline PTFE & poli-tetrafluoroetileno \\
\hline SQP & "sequential quadratic programming" \\
\hline $3 \mathrm{D}$ & três dimensões \\
\hline
\end{tabular}




\section{SUMÁRIO}

PARTE 1 PROJETO DO AMORTECEDOR MAGNETO-REOLÓGICO................23

1 INTRODUÇÃO

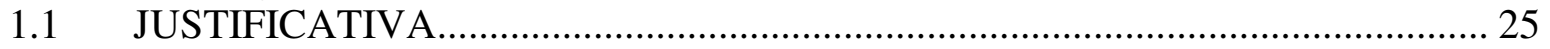

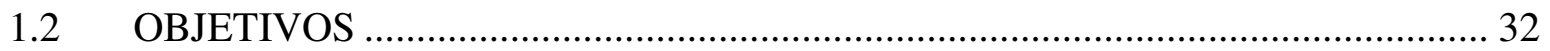

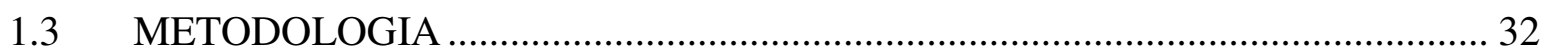

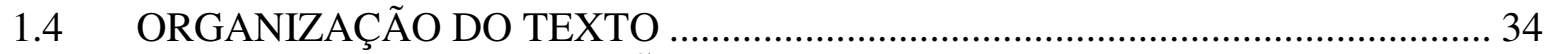

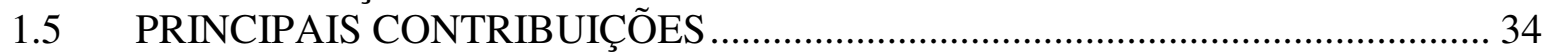

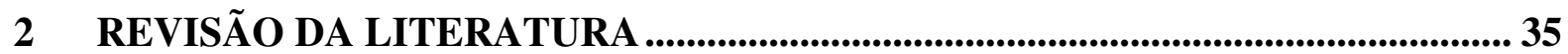

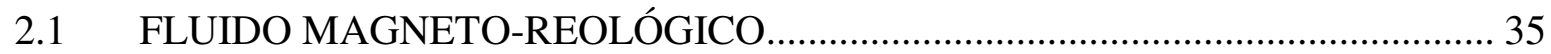

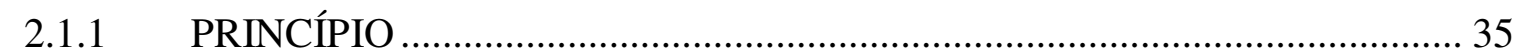

2.1.2 COMPOSIÇÃO QUÍMICA ........................................................................ 37

2.1.3 HISTÓRICO DO DESENVOLVIMENTO DOS FLUIDOS MR/ER.............. 40

2.2 DISPOSITIVOS MAGNETO-REOLÓGICOS ……………………………….... 41

2.2.1 COMO FAZER DISPOSITIVOS MR DE ALTO DESEMPENHO ................. 41

2.2.2 MATERIAIS FERROMAGNÉTICOS EM DISPOSITIVOS MR.................. 42

2.2.3 EXEMPLOS DE VÁLVULAS MAGNÉTICAS DE DISPOSITIVOS MR ... 43

2.3 MODELAGEM DO COMPORTAMENTO DINÂMICO ………………………... 47

2.4 COMENTÁRIOS GERAIS ........................................................................ 51

3 BASE TEÓRICA PARA O PROJETO DE ATUADORES MR ……........................52

$3.1 \quad$ ATUADORES MAGNETO-REOLÓGICOS ……………………..................... 52

3.1.1 DESCRIÇÃO DO PROBLEMA ACOPLADO............................................. 52

3.1.2 SIMPLIFICAÇÕES DO FENÔMENO ACOPLADO ……………………….......... 60

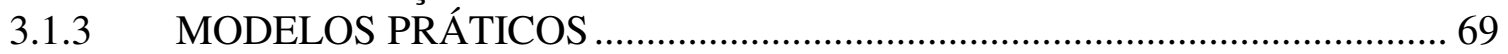

3.2 VOLUME DE FLUIDO ATIVO E ALCANCE DINÂMICO ……………………........ 71

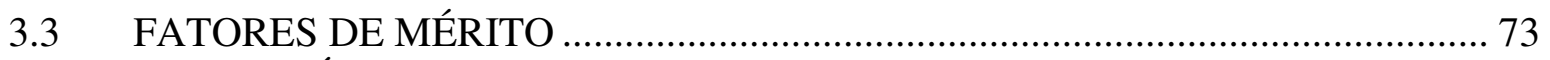

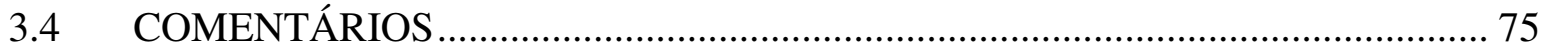

4 PROJETO E CONSTRUÇÃO DO $1^{\circ}$ PROTÓTIPO ................................................... 76

4.1 REQUISITOS E RESTRIÇÕES DE PROJETO …………………………........... 76

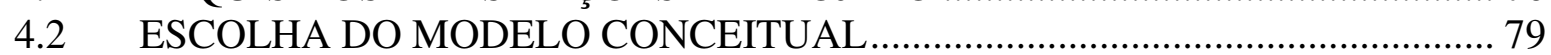

4.3 ESCOLHA DO FLUIDO MR............................................................................ 79

4.4 CÁLCULO DE PARÂMETROS BÁSICOS......................................................... 80

4.5 DEFINIÇÃO DA MAGNETIZAÇÃO MÁXIMA DO FLUIDO............................. 81

4.6 CÁLCULO DOS PARÂMETROS GEOMÉTRICOS ………………………......... 82

4.7 DEFINIÇÃO DA GEOMETRIA DA VÁLVULA MR ………………………....... 83

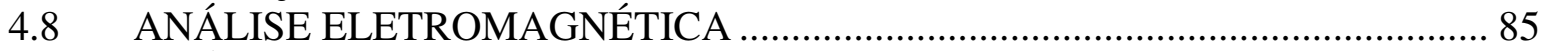

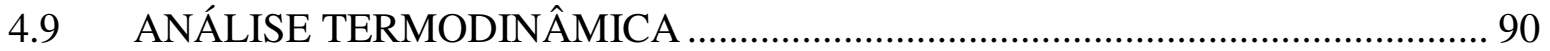

4.10 COMENTÁRIO SOBRE O PROJETO …………………………………........... 93

4.11 CONSTRUÇÃO DO PRIMEIRO PROTÓTIPO..................................................... 94

5 RESULTADOS E DISCUSSÃO - $1^{\circ}$ PROTÓTIPO..................................................96

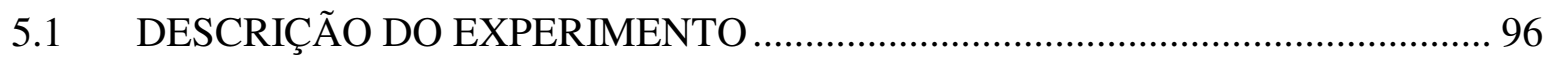

5.2 RESULTADOS EXPERIMENTAIS …………….......................................... 98

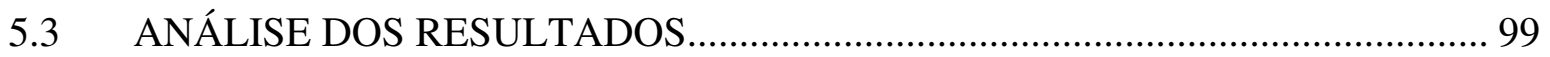

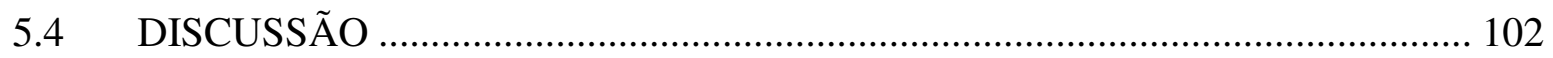


6 NOVO MODELO DINÂMICO DISCRETIZADO .................................................105

7 CONSTRUÇÃO DO $2^{\circ}$ PROTÓTIPO ..................................................................110

8 TESTE EXPERIMENTAL DO $2^{\circ}$ PROTÓTIPO ....................................................... 114

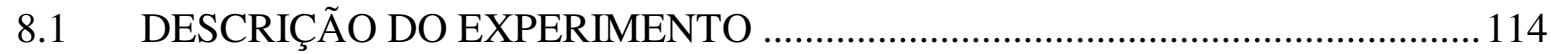

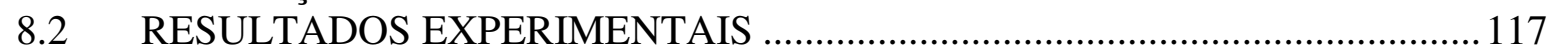

8.3 ESTIMAÇÃO DOS PARÂMETROS DO MODELO .......................................... 119

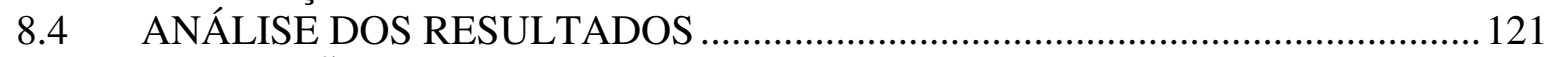

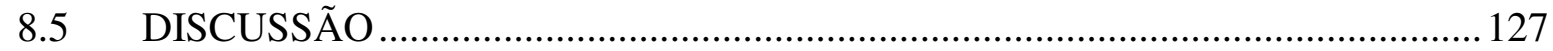

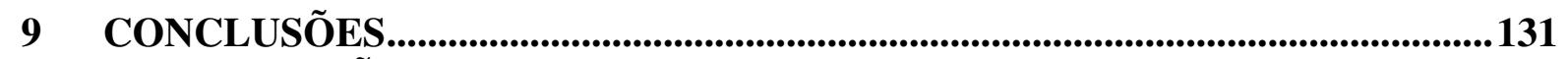

9.1 SUGESTÕES PARA TRABALHOS FUTUROS .......................................... 133

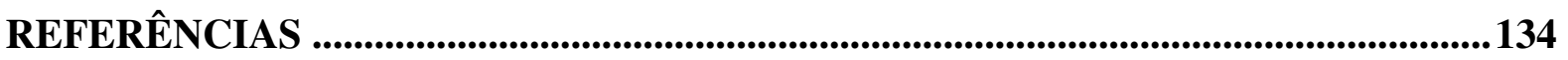

APÊNDICE A - REVISÃO SOBRE VISCOSIDADE .....................................................148

APÊNDICE B - MR VERSUS ER..............................................................................153

APÊNDICE C - CARACTERÍSTICAS DE UM FLUIDO MR ......................................154

APÊNDICE D - MATERIAIS FERROMAGNÉTICOS ..............................................158

APÊNDICE E - EQUAÇÕ ÕES DAS TENSÕES SOBRE UM FLUIDO .........................164

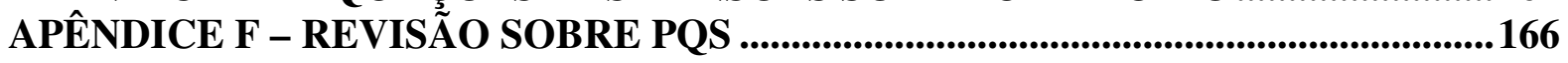

ANEXO A - EXEMPLO DE FLUIDOS MR COMERCIAIS ....................................169

ANEXO B - EXEMPLOS DE FERRAMENTAS DE CAE .......................................171

ANEXO C - DIMENSIONAMENTO DE CIRCUITOS MAGNÉTICOS .......................172

PARTE 2 PROJETO DO SISTEMA DE SUSPENSÃO SEMI-ATIVO...................193

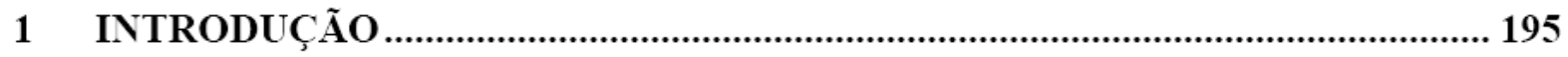

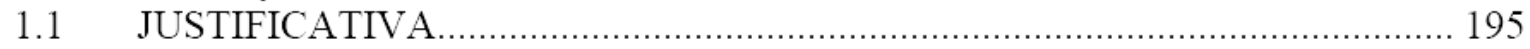

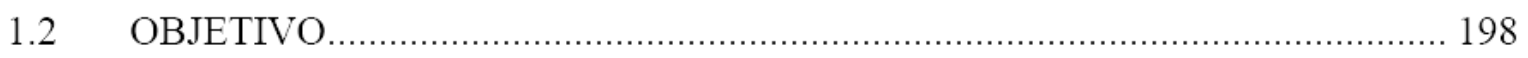

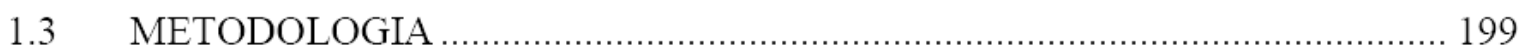

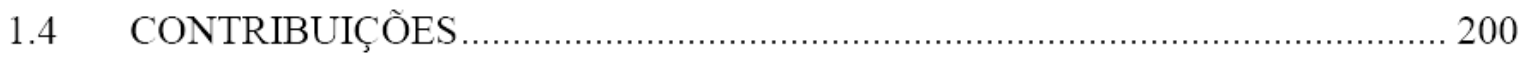

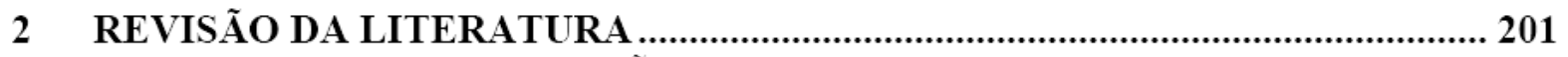

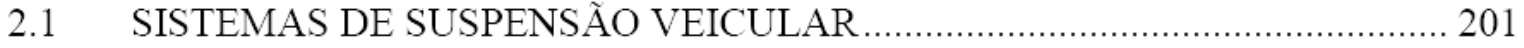

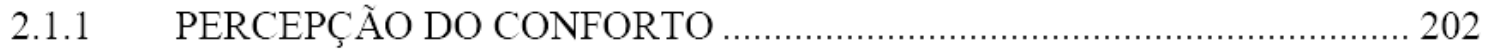

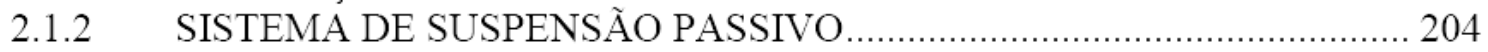

2.2 SISTEMAS DE CONTROLE DA SUSPENSÃO …............................................ 205

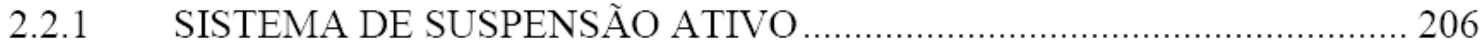

2.2.2 SISTEMA DE SUSPENSÃO SEMI-ATIVO …............................................ 208 
2.2.3 HISTÓRICO DA EVOLUÇÃO DOS SISTEMAS SEMI-ATIVOS .............209

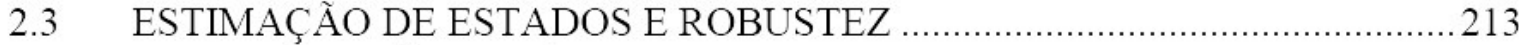

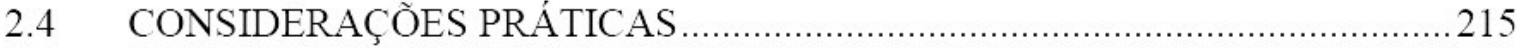

2.4.1 REPRESENTAÇÃO APROPRIADA DOS DISTÚBIOS EXÓGENOS ......215

2.4.2 CRITÉRIOS DE CONFORTO E O "JERK” …............................................2 217

2.4 .3 OS CRITÉRIOS PARA PROJETO DO CONTROLADOR ….......................222

2.4.4 REFERÊNCIA PARA COMPARAÇÃO DE DESEMPENHO …..................222

2.4.5 TIPOS DE SENSORES PARA SISTEMAS MECÂNICOS ….......................2230

2.4.6 POSIÇÃO DOS SENSORES NO VEÍCULO …............................................ 232

2.4.7 AS NÃO-LINEARIDADES DOS ATUADORES .........................................2 234

$2.4 .8 \quad$ FLEXIBILIDADE DO CHASSI DE CAMINHONETES ….........................234

2.4.9 AMORTECIMENTOS INERENTES À SUSPENSÃO …...........................2236

2.4.10 RESSONÂNCIA NO EIXO TRASEIRO E SEUS EFEITOS ........................238

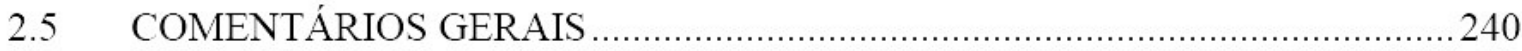

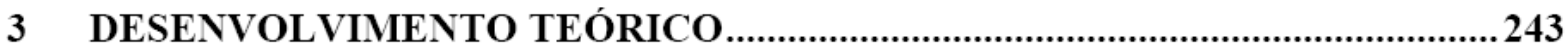

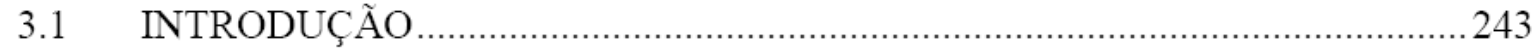

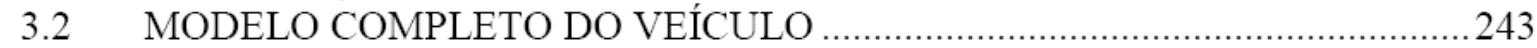

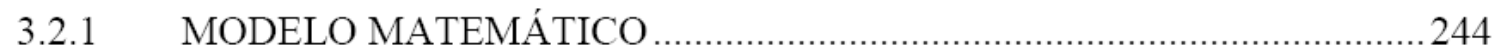

3.2.2 DEFINIÇÃO DAS ENTRADAS DE CONTROLE ......................................248

3.2.3 REPRESENTAÇÃO EM ESPAÇO DE ESTADOS ......................................2 250

3.2.4 SEPARAÇÃO DOS MODOS DE CORPO RÍGIDO E TORÇÃO ................252

3.3 APERFEIÇOAMENTO DA TÉCNICA LQG/LTR ….......................................25

3.3.1 FORMA CONVENCIONAL DA TÉCNICA LQG/LTR …........................256

3.3.2 TÉCNICA LQG/LTR ADAPTADA AO CONTROLE SA ...........................263

3.3.3 RLQ EM SISTEMAS NÃO-ESTRITAMENTE PRÓPRIOS .......................269

3.3.4 TEOREMA FUNDAMENTAL “LTR” ESTENDIDO …...........................276

3.3.5 GENERALIZAÇÃO TEOREMA ESTENDIDO ….....................................28

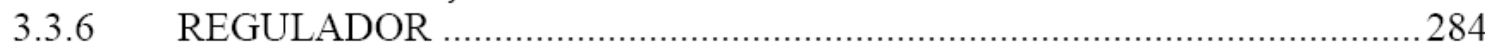

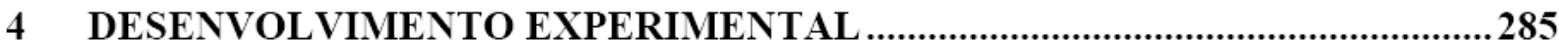

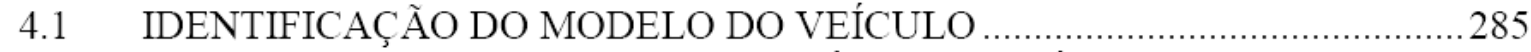

4.1.1 ESTIMATIVA INICIAL DOS PARÂMETROS FÍSICOS …......................28

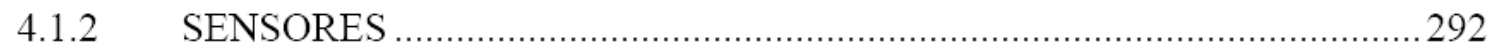

4.1.3 EQUIPAMENTO PARA AQUISIÇÃO DE DADOS E CONTROLE ..........296

4.1.4 APLICATIVOS PARA AQUISIÇÃO DE DADOS …...................................29

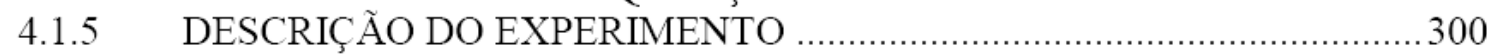

4.1.6 ANÁLISE DOS DADOS E IDENTIFICAÇÃO DO MODELO …....................302

4.1.7 RESUMO DOS RESULTADOS - IDENTIFICAÇÃO DO MODELO ...........320

4.2 ATUADORES MAGNETO REOLÓGICOS ........................................................ 321

4.2.1 ATRITO DE COULOMB E MAGNETIZAÇÃO DA VÁLVULA MR ........333

4.2.2 INSTALAÇÃO DOS ATUADORES NO VEÍCULO …................................. 335

4.2.3 MODELO DO VEÍCULO COM OS ATUADORES …................................. 336

4.2.4 RESUMO DOS RESULTADOS - ATUADORES MAGNETO

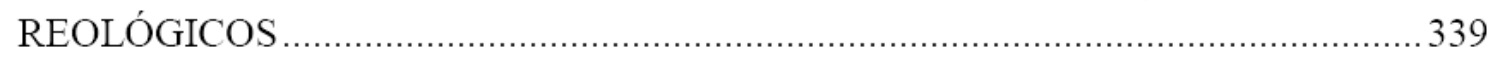

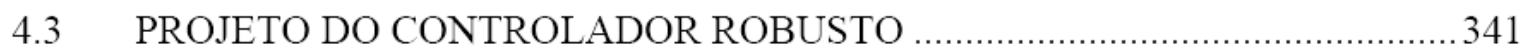

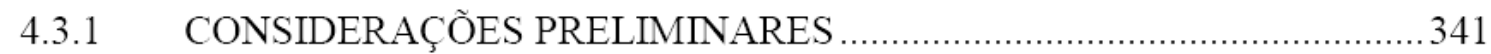

4.3.2 AVALIAÇÃO DAS INCERTEZAS DO MODELO …................................... 342

4.3.3 PÓLOS, ZEROS DE TRANSMISSÃO E OBSERVABILIDADE …..............345

4.3.4 ELIMINAÇÃO DO MODO DE TORÇÃO …............................................... 346 
4.3.5 CRITÉRIOS DE DESEMPENHO E PONDERAÇÃO DAS SAÍDAS .......... 348

4.3.6 REDUÇÃO, BALANCEAMENTO E NORMALIZAÇÃO DO MODELO 351

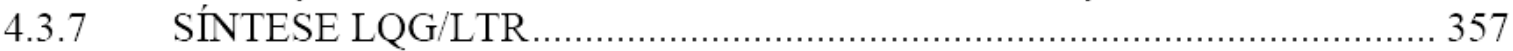

4.3.8 GRAMPEADOR DE SINAL PARA O ATUADOR SEMI-ATIVO ............ 370

4.3.9 REDUÇÃO DO TEMPO DE RESPOSTA DO ATUADOR SEMI-ATIVO 372

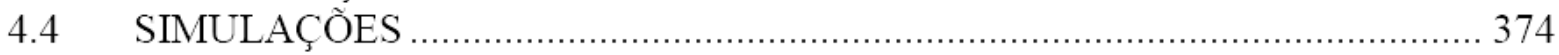

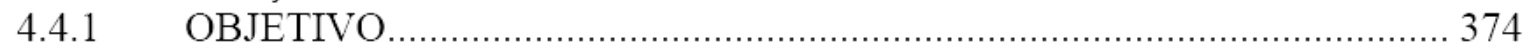

4.4.2 DEFINIÇÃO DO MODELO PARA SIMULAÇÃO …............................... 374

4.4.3 DEFINIÇÃO DOS SINAIS DE ENTRADA PARA SIMULAÇÃO .............. 375

4.4.4 DEFINIÇÃO DOS RUÍDOS DE MEDIDA PARA SIMULAÇÃO …........... 377

4.4.5 AVALIAÇÃO DO "JERK" E DO DESEMPENHO EM SEGURANÇA .... 377

4.4.6 SIMULAÇÃO DO CONTROLADOR ATIVO ….................................. 378

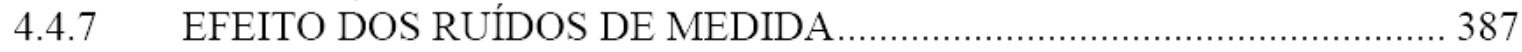

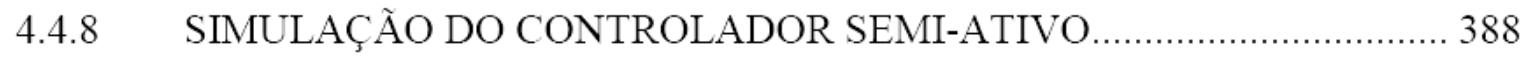

4.4.9 TESTE DAS PROPOSTAS PARA MELHORIA DE DESEMPENHO ........ 393

4.4.10 ESCOLHA DA MELHOR CONFIGURAÇÃO DO CONTROLADOR ....... 397

4.4.11 DEFINIÇÃO DOS EXPERIMENTOS E INDICADORES …....................... 398

4.5 TESTES EXPERIMENTAIS DA SUSPENSÃO SEMI-ATIVA …...................... 401

4.5.1 ELETRÔNICA DE POTÊNCIA ……........................................................ 401

4.5.2 ALGORITMO DE CONTROLE NO SIMULINK .................................... 402

4.5 .3 DESCRIÇÃO DO EXPERIMENTO ….................................................. 403

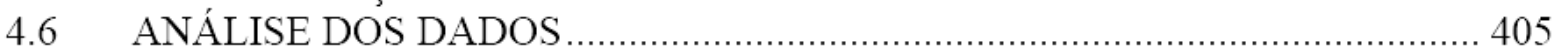

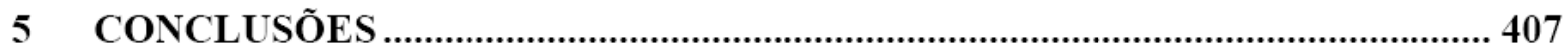

5.1 SUGESTÕES PARA TRABALHOS FUTUROS …........................................ 409

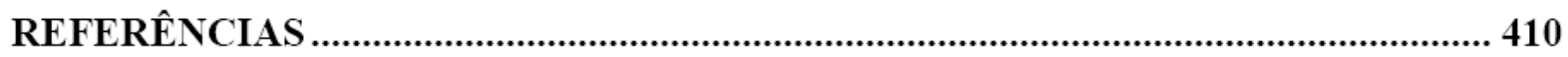

APÊNDICE A - SOLUÇÃO RLQ PARA SISTEMA DE 1 GRAU DE LIBERDADE. 424

APÊNDICE B - IDENTIDADES DE ÁLGEBRA MATRICIAL ….............................428

B. 1 - LEMA 1 (LEMA DA INVERSÃO MATRICIAL-LIM) …................................. 428

B. 2 - LEMA 2 (DECORRENTE DO LEMA 1) ....................................................... 428

APÊNDICE C - CONSTRUÇÃO E CALIBRAÇÃO DOS SENSORES ........................ 429

APÊNDICE D - PROGRAMA MATLAB PARA USO DO RTDX............................... 437

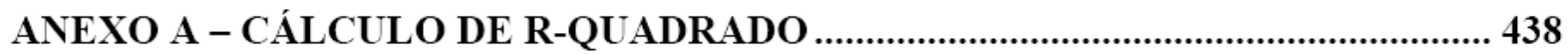




\section{PARTE 1}

PROJETO DO AMORTECEDOR

MAGNETO-REOLÓGICO 


\section{INTRODUÇÃO}

O propósito desta introdução é apresentar a justificativa e os objetivos desta primeira parte do trabalho, e também apresentar uma breve descrição da metodologia, da organização e quais são as suas principais contribuições.

\subsection{JUSTIFICATIVA}

O controle de movimentos e atenuação de vibrações são problemas comuns na engenharia, que aparece em pequenos sistemas, como numa máquina de lavar, ou em grandes sistemas, como em viadutos e pontes. Nem sempre a utilização de componentes passivos é suficiente para contrapor a grande variedade de perturbações e situações de uso de certos sistemas mecânicos, e por isso surge a necessidade de controladores mais sofisticados.

Quando se parte para o controle de movimento ou vibração de um sistema mecânico, é comum o engenheiro projetista considerar atuadores de força ativos, como cilindros hidráulicos ou pneumáticos, eletroímãs, servos-motores, células piezo-elétricas, etc. Estes atuadores são capazes de produzir força através da transformação da energia armazenada no sistema ou disponível a partir de uma fonte externa. Contudo nem sempre esta fonte de energia está disponível, ou há um custo injustificável para a sua utilização em razão dos benefícios que podem ser alcançados. Nestes casos surge a alternativa do emprego de atuadores semi-ativos.

Os atuadores semi-ativos são dispositivos capazes de gerar apenas forças dissipativas, ou seja, ele é capaz de controlar apenas as forças que se opõem ao movimento. No caso de restrição ou transmissão de um movimento, ou atenuação de vibrações, as forças dissipativas são predominantes, o que torna os atuadores semi-ativos atrativos, pois além de serem em geral mais baratos que os atuadores ativos, utilizam pouca energia para sua operação. Entre os atuadores semi-ativos destacam-se aqueles baseados em fluidos magneto-reológicos (MR), devido principalmente às suas características de controle por corrente elétrica de baixa potência e baixos níveis de tensão elétrica, confiabilidade e estabilidade. Os fluidos MR são suspensões cujo comportamento reológico é fortemente influenciado por um campo 
magnético, por isso são também chamadas de suspensões MR (SMR) (BOMBARD, 2005). Requerendo somente de 20 a 50 watts de potência, os atuadores MR podem ser operados com uma bateria convencional, eliminando a necessidade de grandes fontes de potência e geradores. Como as forças geradas nestes dispositivos são ajustadas através da variação da intensidade de um campo magnético, nenhuma válvula mecânica é necessária, o que os torna bastante confiáveis. Adicionalmente, o fluido MR responde em milisegundos a uma variação do campo magnético, o que permite o desenvolvimento de dispositivos com uma ampla banda de resposta em freqüência.

As aplicações comerciais de atuadores MR são muitas e distribuídas por diversas áreas, como na indústria automobilística, engenharia civil, medicina, indústria de eletroeletrônicos, máquinas industriais, e indústria aeroespacial (PHILLIPS, 2003). A seguir são apresentados vários exemplos de aplicações comerciais de atuadores semi-ativos.

Como exemplos de atuadores MR para o controle de vibração já existem aplicações em sistemas de suspensão de assentos de motorista de ônibus e caminhões pesados (suspensões secundárias) (CARLSON et al., 1999), suspensão de máquinas de lavar roupa (CHRZAN e CALSON, 2001) e suspensão de bicicletas tipo "Mountain-bike" (BREESE e GORDANINEJAD, 2003).

A figura 1.1 apresenta uma ilustração dos atuadores MR utilizados em uma máquina de lavar roupas. Nesta aplicação os amortecedores MR atuam apenas em uma faixa de freqüências de rotação, especificamente quando a câmara de lavagem acelera para alcançar a velocidade de rotação no modo de centrifugação, ou quando desacelera ao terminar esta operação. Esta região de operação, que se encontra entre as velocidades A e C de rotação, está destacada na figura 1.2.

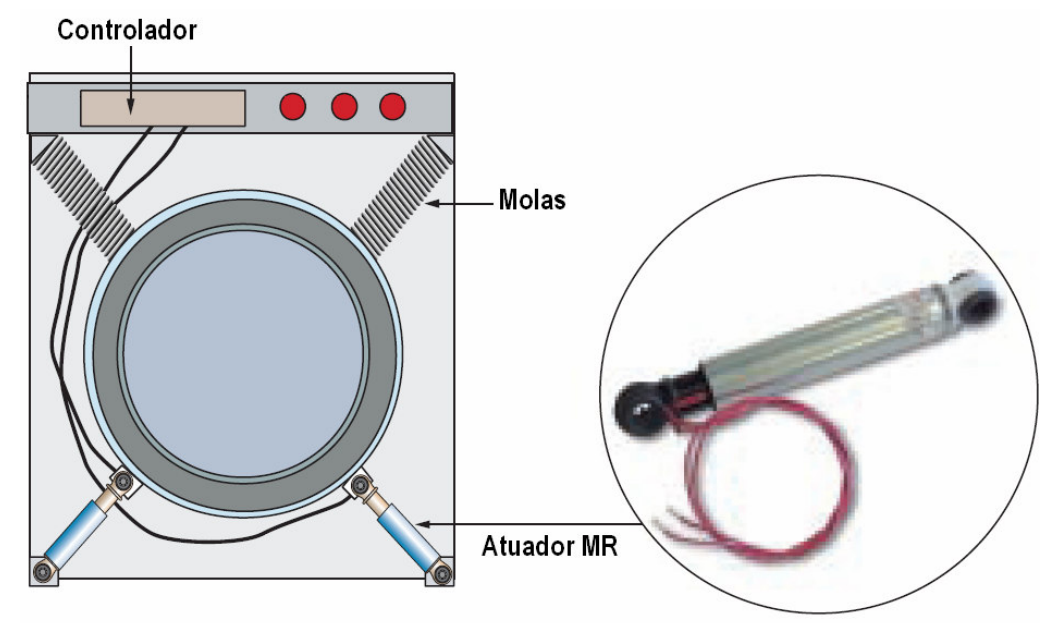

Figura 1.1 - Exemplo de uso de atuadores MR em máquinas de lavar. 


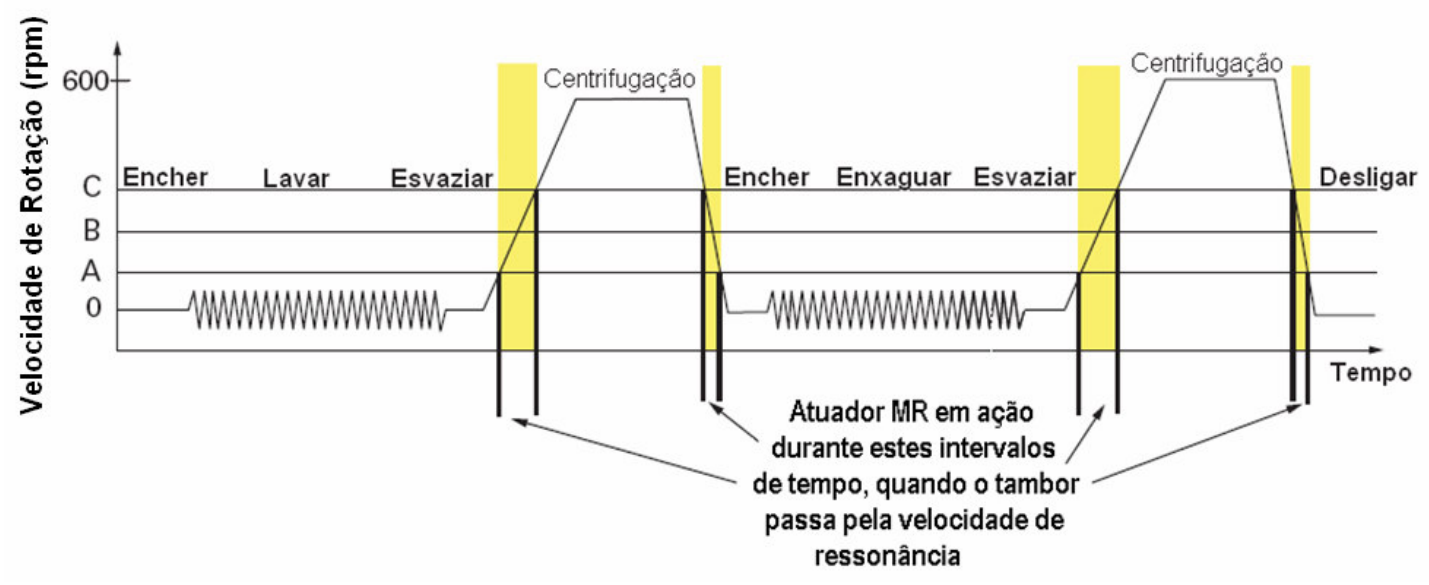

Figura 1.2 - Intervalos críticos ao longo do programa automático de lavagem.

Na figura 1.3 há uma comparação do comportamento da força transmitida da câmara de lavagem para carcaça externa da máquina em função da sua velocidade de rotação em três situações:

- baixo amortecimento, em que ocorre ressonância na região crítica, porém com baixa transferência nas altas freqüências de centrifugação;

- alto amortecimento, em que o efeito da ressonância é reduzido, porém ocorre maior transferência de forças nas altas freqüências; e

- com o controle semi-ativo em malha fechada, que apresenta o melhor desempenho tanto na região critica quanto nas altas rotações.

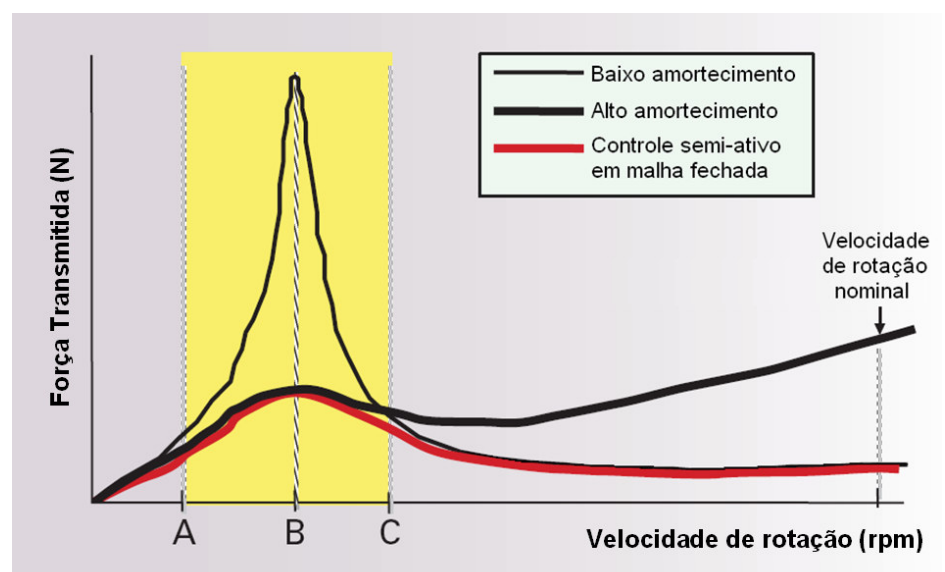

Figura 1.3 - Comparação entre os sistemas passivos com baixo e alto amortecimento e o sistema de controle semi-ativo em malha fechada. 
Também já existem amortecedores automobilísticos comerciais, utilizados em carros como o Corvette (HALVERSON, 2003), mostrado na figura 1.4, e nos Cadillac Seville STS a partir de 2002 (GILBERT e JACKSON, 2002; GEHM, 2001). Na figura 1.5 é possível observar vistas em corte de detalhes da válvula magnética e da instalação do amortecedor MR no veículo. Os amortecedores MR têm também algumas aplicações no mercado automobilístico de competição (CARRERA, 2003).

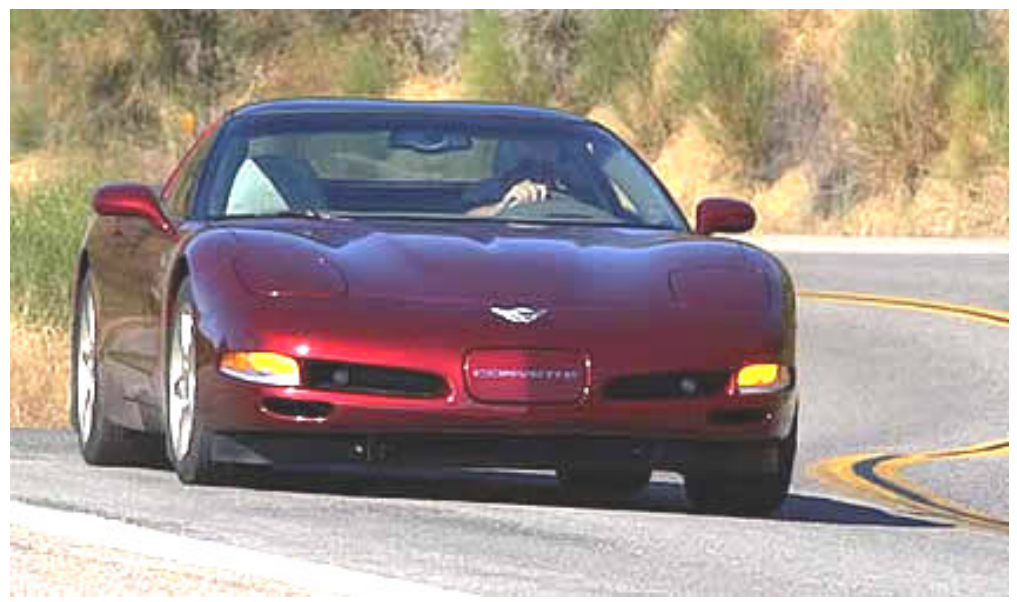

Figura 1.4 - Corvette edição especial de aniversário do $50^{\circ}$ ano da marca.

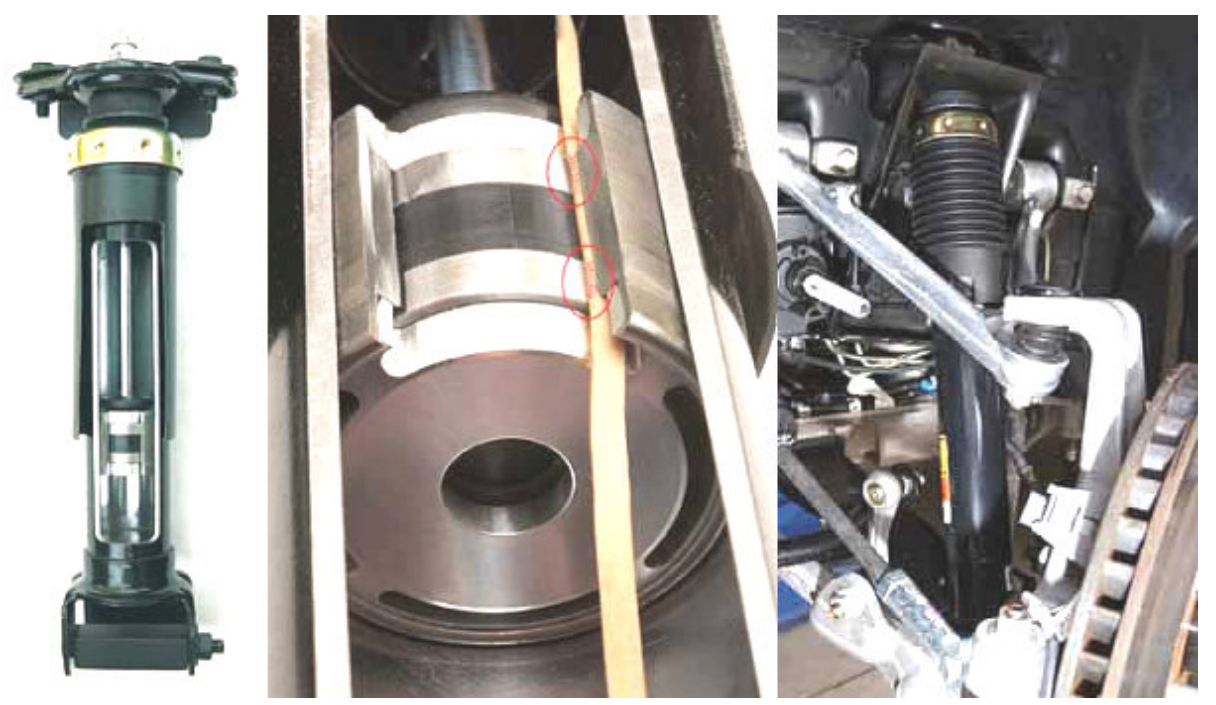

Figura 1.5 - Detalhes e cortes do amortecedor MR do utilizado no Corvette.

No caso de dispositivos magneto-reológicos que fazem transmissão de movimentos há o exemplo de uma embreagem magneto-reológica (LAMPE e GRUNDMANN, 2000), que se distingue da embreagem convencional por sua excelente controlabilidade de transmissão de torque, tempo de reação bastante curto e pequeno desgaste. A vantagem fundamental em 
relação à embreagem tradicional consiste em sua habilidade de processar informações elétricas de controle diretamente, isto é, sem qualquer elo mecânico. Há também o projeto de um motor hidráulico não convencional, chamado de motor viscoso de fluxo laminar (SILVA, 1998), utilizando fluido magneto-reológico. Este motor visa o acionamento do eixo de uma máquina-ferramenta de ultraprecisão, substituindo motores elétricos e hidráulicos convencionais que apresentam problemas de vibração e instabilidade térmica.

Na construção civil, já se estuda há algum tempo a utilização de atuadores MR em prédios visando à atenuação de vibrações causadas por abalos sísmicos (DIKE at al., 1996; SPENCER at al., 1998; YOSHIOKA at al., 2002). Como pode ser observado no exemplo da figura 1.6, os atuadores MR são colocados em todos os andares do edifício, de forma a gerar forças entre as lajes dos andares adjacentes até uma intensidade de $200 \mathrm{kN}$ ( 20 ton), e desta forma poder atuar reduzindo a amplitude das vibrações geradas por um terremoto. A figura 1.7 mostra um experimento com este tipo de atuadores MR realizado na Universidade de Notre Dame nos EUA. Este experimento consiste numa montagem do atuador MR em série com uma célula de carga e um atuador hidráulico com capacidade de $250 \mathrm{kN}$, onde o atuador MR apresenta um curso de movimentação da sua haste de $\pm 8 \mathrm{~cm}$, um diâmetro interno de $20,3 \mathrm{~cm}$, uma massa de $250 \mathrm{~kg}$, e utiliza 5 litros de fluido MR, dos quais apenas $90 \mathrm{ml}$ ficam sob a ação do campo magnético num dado instante.

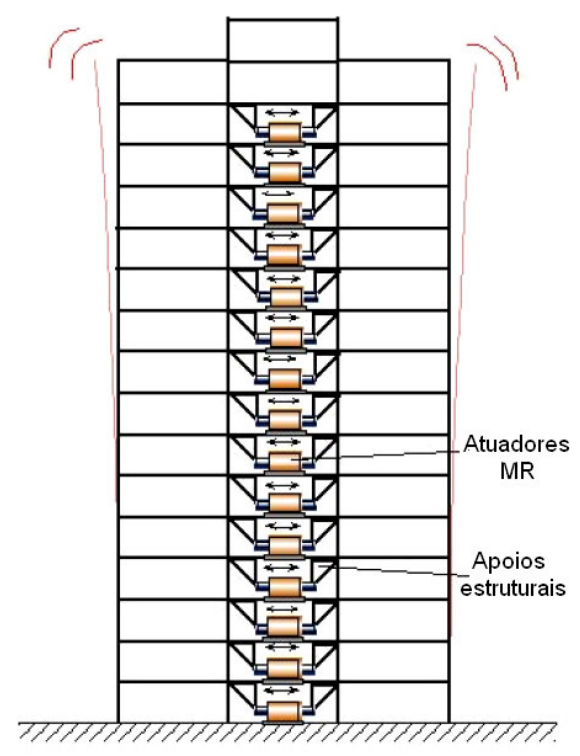

Figura 1.6 - Exemplo de um prédio equipado com atuadores MR que atenuam a sua vibração. 


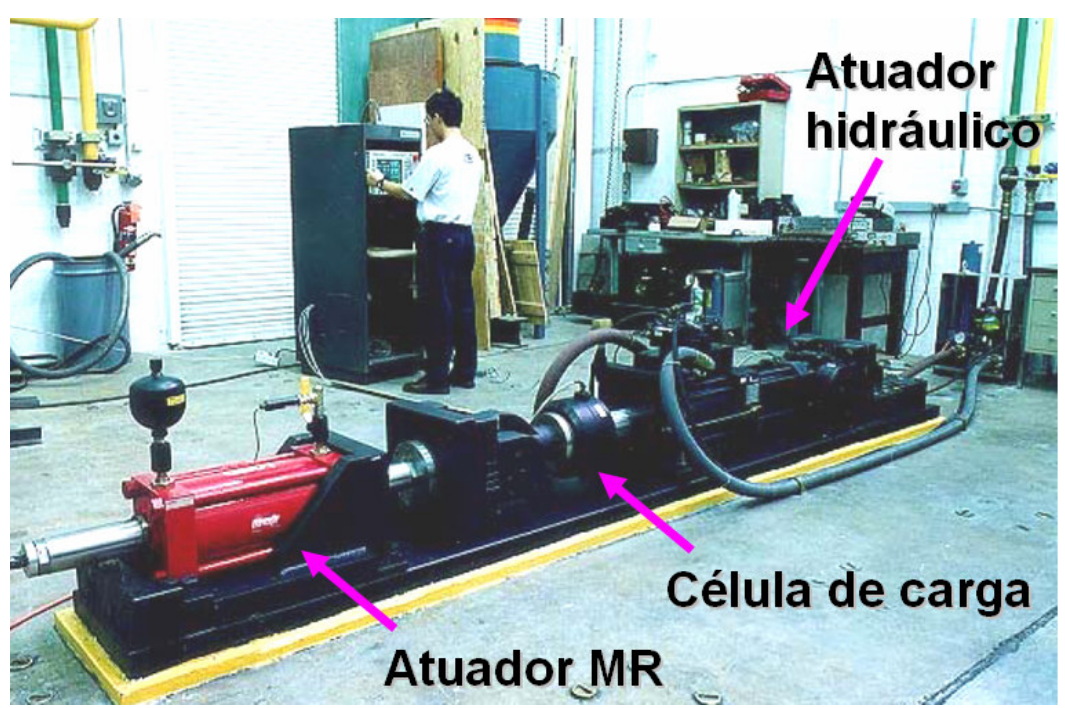

Figura 1.7 - Experimento da Universidade de Notre Dame- http://www.nd.edu/

Outra aplicação na engenharia civil é apresentada na figura 1.8. Este exemplo mostra a ponte pênsil construída sobre o lago Dongting, na província de Hunan, China (KO et al., 2003). Desde sua abertura para o tráfego no final de 2000, a ponte vinha apresentando vibrações severas em seus cabos sob a ação de ventos de baixa velocidade e chuva moderada. Esta situação de risco elevado (lembrar o desabamento da ponte Takoma Narrows em 1947) levou a adoção de um sistema inteligente de atenuação da vibração, baseado em atuadores MR e controle semi-ativo.
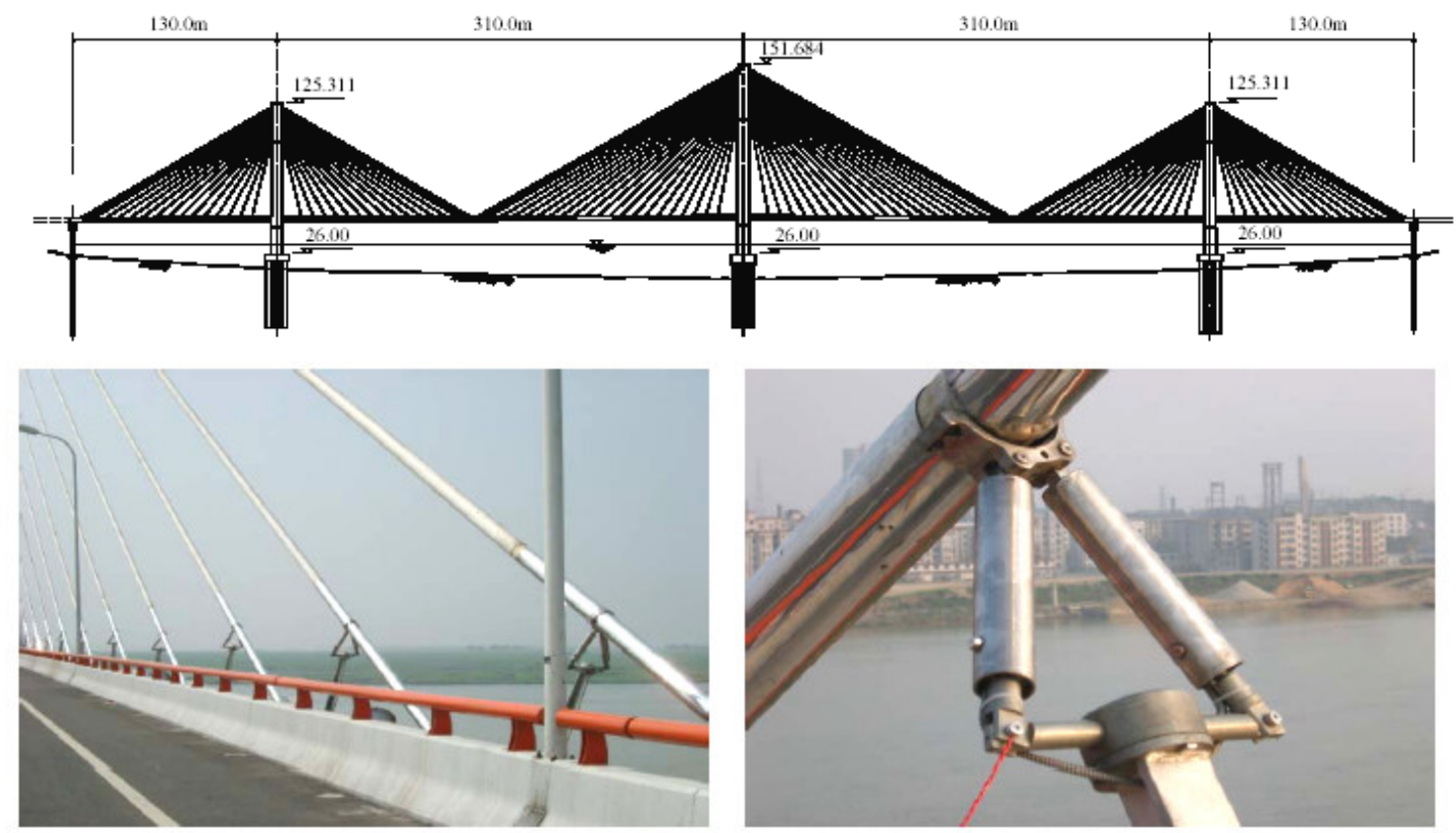

Figura 1.8 - Ponte pênsil sobre o lago Dongting, na província de Hunan, China. Esta ponte tem um comprimento total de $800 \mathrm{~m}$ e os vãos livres principais chegam a $310 \mathrm{~m}$. Um par de atuadores MR foi colocado em cada um dos seus cabos de aço de sustentação (KO et al., 2003). 
Outra área promissora é a de fisioterapia, bem como aparelhos para atividade física (musculação), dada a maior precisão com que as cargas podem ser aplicadas, além do que os esforços solicitados pelo equipamento podem seguir um comportamento pré-estabelecido ou podem se adaptar automaticamente às necessidades do usuário. Também na área da medicina, os atuadores MR estão sendo utilizados com excelentes resultados na construção de próteses inteligentes (HERR et al. 2003), como o exemplo apresentado nas figuras 1.9 e 1.10 que ilustra uma prótese de joelho.

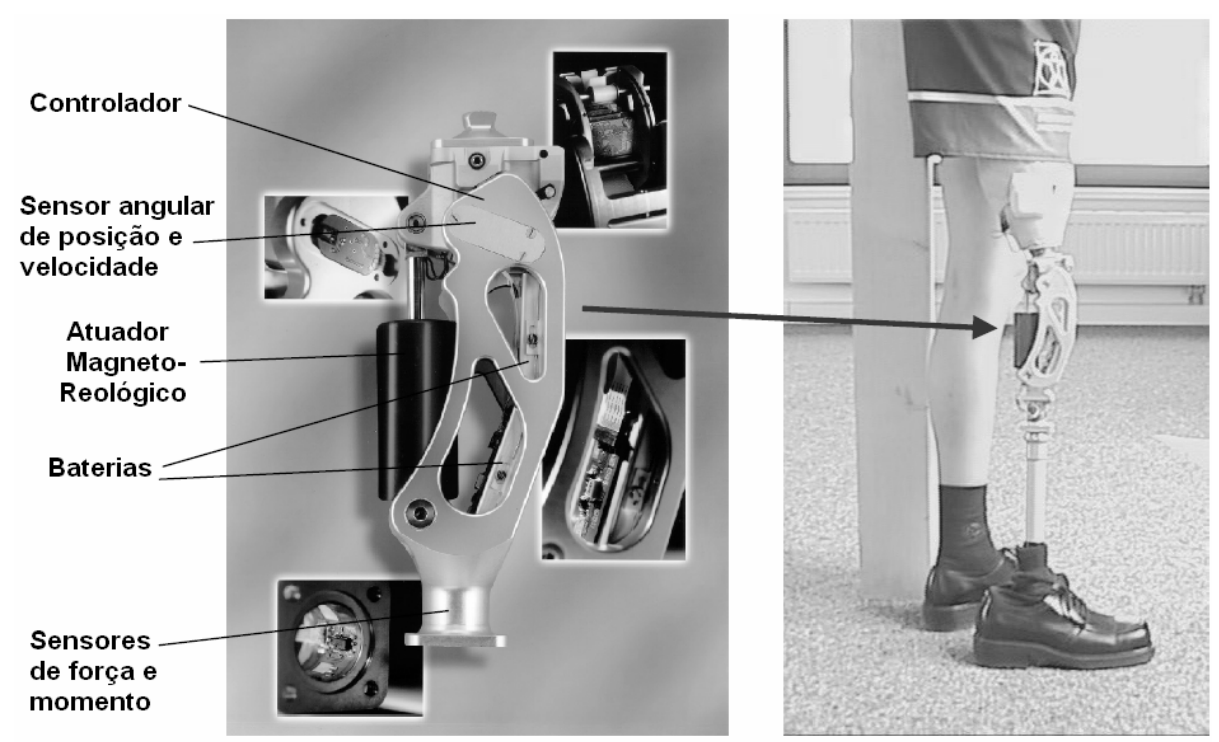

Figura 1.9 - Prótese de perna mecânica Magnetix ${ }^{\mathrm{TM}}$ da MOTHEC baseado em atuadores MR.

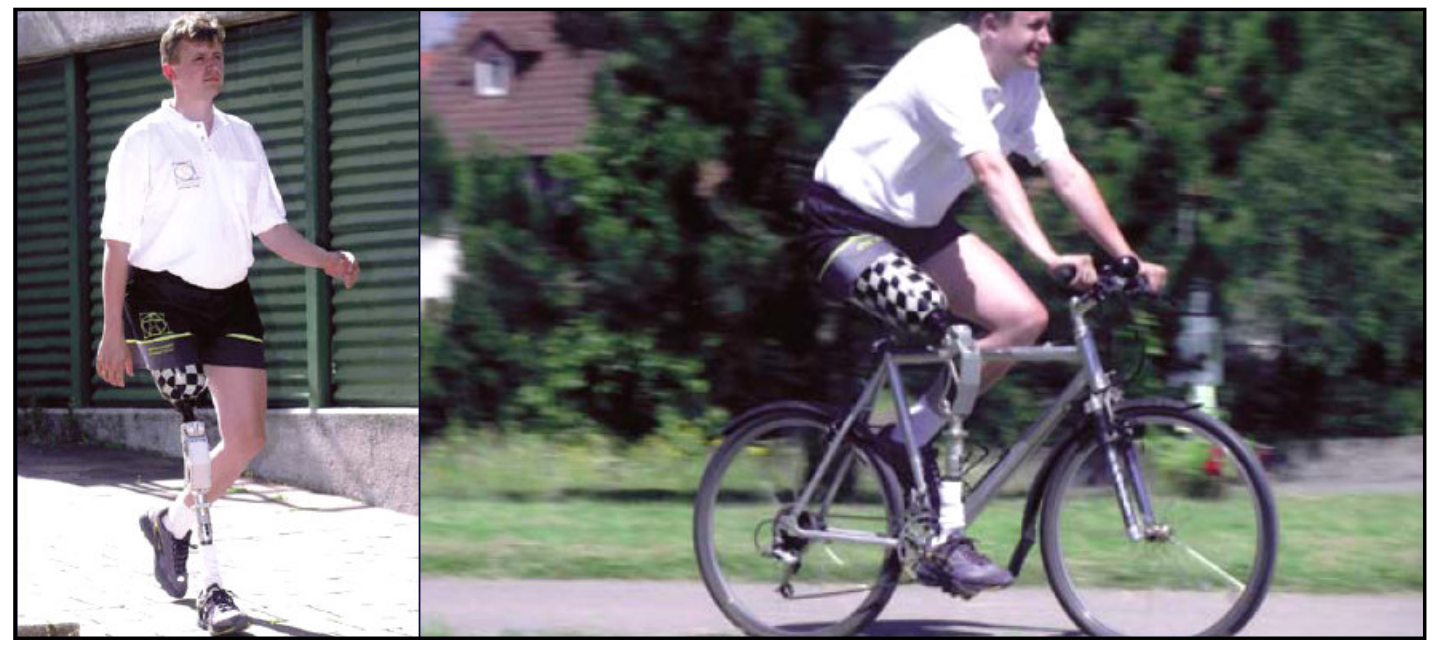

Figura 1.10 - Próteses semi-ativas MR em amputados trans-femoral. 
De fato, a utilização de atuadores MR no controle de movimentos e vibrações deve ser uma opção a ser considerada pelos engenheiros, visto que além das vantagens de menor complexidade e maior confiabilidade sobre os sistemas ativos, existe hoje uma grande variedade de produtos comerciais e pesquisas em diversos tipos de aplicações.

Como atualmente na indústria automobilística as exigências dos usuários de veículos são cada vez maiores com relação ao conforto e segurança, é um caminho natural que sistemas de controle mais sofisticados sejam aplicados neste campo. Neste cenário, os controladores semi-ativos baseados em atuadores MR passam a ser uma excelente opção, e por esse motivo esta aplicação é o foco deste trabalho.

\subsection{OBJETIVOS}

Os objetivos principais desta primeira parte do trabalho são:

1. Estudar o processo para o projeto de amortecedores MR a partir de um melhor entendimento de toda a teoria envolvida ( fluido MR e dispositivos baseados nestes fluidos), naturalmente levando em consideração os requisitos básicos da aplicação de forma a garantir um processo mais sistemático de projeto.

2. Desenvolver formas de modelagem de um atuador MR visando obter informações importantes sobre o dispositivo, bem como oferecer um modelo matemático eficiente e robusto para simulações em computador de sistemas semi-ativos complexos, e também para ser utilizado como modelo-referência numa malha de controle.

3. Desenvolver um procedimento para estimação dos parâmetros do modelo proposto, a partir de dados experimentais obtidos de testes definidos especificamente para esta finalidade.

\subsection{METODOLOGIA}

Para alcançar os objetivos propostos, parte-se de uma vasta pesquisa englobando os seguintes assuntos: fluidos MR, materiais magnéticos, dispositivos baseados nos fluidos MR, mecânica de fluidos não newtonianos, tipos mais comuns de válvulas magnéticas, modelos dinâmicos de dispositivos MR, e projeto de amortecedores automobilísticos. 
Com a finalidade de se elaborar um procedimento sistemático de projeto de atuadores MR, partiu-se de uma descrição detalhada do problema hidrodinâmico acoplado eletromagnética e termicamente. Com a adoção de simplificações deste modelo, chegou-se a soluções de onde foi possível estabelecer fórmulas práticas de projeto. Um conceito de otimização, chamado de "volume ativo mínimo", foi aplicado para levar a um método de projeto que utilize a menor quantidade possível de fluido para uma dada especificação de projeto.

Para a análise magnetostática foi utilizado um aplicativo de prateleira baseado no método dos elementos finitos (MEF) para dimensionamento do circuito magnético responsável pela aplicação do campo magnético sobre o fluído. Diferentes formas construtivas de válvulas magnéticas obtidas na literatura foram consideradas como opções de projeto.

Um protótipo de amortecedor MR foi projetado segundo as formulações práticas obtidas, utilizando como ponto de partida as especificações de uma aplicação real. Outro aplicativo $\mathrm{CAD} / \mathrm{CAE}$ de prateleira foi utilizado para o projeto mecânico deste protótipo. $\mathrm{O}$ protótipo foi testado em laboratório com o uso de atuadores hidráulicos, células de carga, sensores de deslocamento e equipamento de aquisição de dados. A análise destes resultados levou à confirmação do desempenho esperado para o atuador e a validação da proposta de uma nova metodologia de projeto para dispositivos MR.

Para a obtenção de um modelo dinâmico de um amortecedor MR que pudesse ser simulado rapidamente e utilizado em controladores digitais (como modelo de referência, por exemplo), desenvolveu-se adicionalmente um modelo em tempo discreto.

Para aplicação numa caminhoneta real, foi necessário construir outro protótipo que também serviu para o desenvolvimento de outra concepção de válvula, e adicionalmente para a obtenção de dados experimentais para a identificação de parâmetros do modelo dinâmico proposto.

Para a identificação do modelo foi proposto um procedimento que utiliza um algoritmo de otimização MiniMax baseado em Programação Quadrática Seqüencial (PQS), que ajusta os parâmetros do modelo para minimizar um critério de erro médio quadrado entre os dados experimentais e os obtidos pelo modelo. 


\subsection{ORGANIZAÇÃO DO TEXTO}

A seção 2 apresenta uma revisão da literatura sobre os fluidos, materiais magnéticos e dispositivos magneto-reológicos. Também é apresentada uma revisão sobre as principais formas de modelagem matemática dos dispositivos MR. A seção 3 apresenta uma base teórica para o projeto de atuadores MR, mostrando uma descrição aprofundada da teoria que está por trás destes dispositivos, a qual resulta na formulação de modelos simples que podem ser utilizados em procedimentos de projeto. Na seção 4 é desenvolvida uma proposta de processo de projeto de dispositivos MR, a partir da construção de um protótipo preliminar. A verificação do projeto é feita a partir da comparação de dados experimentais com o resultado teórico, apresentada na seção 5. A seção 6 apresenta uma nova proposta para o modelo dinâmico do atuador MR utilizando equações de diferenças. Na seção 7 é apresentado o projeto e construção de um segundo protótipo, onde se utilizou outro conceito de válvula. Além de exercitar o processo sistemático de projeto, este segundo protótipo serviu para coleta de dados para a identificação do modelo matemático do amortecedor MR, que é apresentado na seção 8. Nesta seção também se apresenta a descrição do experimento realizado no segundo protótipo e dos dados utilizados processo de estimação dos parâmetros do modelo. As conclusões e comentários finais desta parte da tese são expostos na seção 9.

\subsection{PRINCIPAIS CONTRIBUIÇÕES}

As principais contribuições desta primeira parte do trabalho são:

1 - a proposição de uma metodologia prática e eficaz para projeto de dispositivos MR, em especial de amortecedores MR, a qual foi verificada com a construção de um protótipo.

2 - a proposição de um novo modelo matemático em tempo-discreto para representação do comportamento dinâmico de atuadores semi-ativos baseados em fluidos MR. O modelo foi validado por meio de dados experimentais de um amortecedor MR real. Este modelo, além de permitir uma estimativa bastante boa de várias propriedades do dispositivo, é de processamento rápido e diretamente implementável em sistemas digitais.

3 - a proposição de um método para estimação dos parâmetros do modelo matemático em tempo-discreto de um amortecedor MR, a partir de dados experimentais. O método de estimação proposto foi modelado na forma de um problema de otimização MinMax, e resolvido por meio de algoritmo PQS, que mostrou-se eficiente e de rápida convergência. 


\section{REVISÃO DA LITERATURA}

Esta revisão tem seu foco nos seguintes assuntos:

- o fluido MR: seu princípio, composição química e histórico de desenvolvimento;

- os dispositivos MR: características e desempenho, materiais magnéticos utilizados, e alguns exemplos de válvulas MR apresentadas e desenvolvidas em trabalhos acadêmicos e utilizadas em equipamentos comerciais; e

- formas de modelamento matemático de um atuador MR.

\subsection{FLUIDO MAGNETO-REOLÓGICO}

\subsubsection{PRINCÍPIO}

Fluidos MR, ou "suspensões magneto-reológicas" (SMR), são materiais que respondem a um campo magnético aplicado gerando uma alteração no seu comportamento reológico. Tipicamente, esta alteração se manifesta pelo desenvolvimento de uma resistência ao escoamento (similar a um sólido sob deformação plástica) que varia de forma diretamente proporcional à intensidade de um campo magnético aplicado. O interesse em fluidos magnetoreológicos deriva da sua habilidade em gerar uma resposta rápida (em torno de poucos milisegundos), de forma simples e silenciosa, sob o efeito de campo magnético. Esta característica é útil na construção de dispositivos que transformam impulsos elétricos em forças dissipativas mecânicas, que são capazes de interconectar controles eletrônicos e sistemas mecânicos.

A resposta magneto-reológica dos fluidos MR resulta da polarização induzida nas partículas ferromagnéticas suspensas por meio da aplicação de um campo magnético externo. Esta interação faz com que as partículas se organizem em estruturas colunares, paralelas às linhas de fluxo magnético, conforme pode ser observado na figura 2.1. 

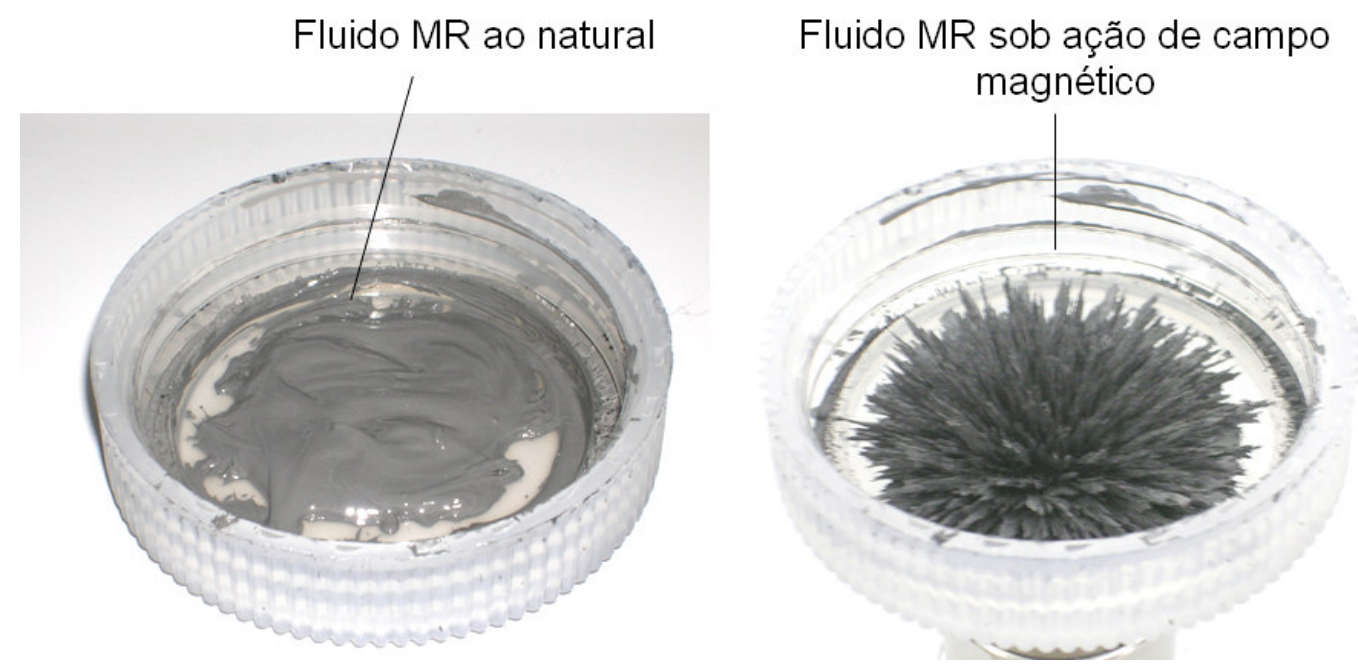

Figura 2.1 - Amostra de fluido MR ao natural (imagem à esquerda) e sob campo magnético (imagem à direita).

Estas estruturas em forma de "correntes" restringem a movimentação do fluido, e assim aumentam a resistência à sua passagem por caminhos onde um campo magnético esteja sendo aplicado. A energia mecânica necessária para romper estas estruturas aumenta com a intensidade do campo magnético aplicado, e é deste processo que deriva a relação direta entre a tensão de escoamento e este campo. Na ausência de um campo magnético, os fluidos MR apresentam um comportamento que se aproxima do newtoniano (ou quasi-newtoniano), com uma viscosidade aparente $^{1}$ relativamente baixa, aproximadamente entre 0,07 e 0,40 Pas. Porém, apresentam um comportamento visco-elástico similar a de um "sólido" quando estão sob a influência de um campo magnético, de forma que o comportamento deste fluido é freqüentemente representado pelo modelo de plástico de Bingham.

Considerando os efeitos viscosidade aparente e do campo magnético no escoamento do fluido MR, a tensão de escoamento é dada pelas seguintes equações:

$$
\tau= \begin{cases}\tau_{y}(H)+\eta \dot{\gamma}, & \tau \geq \tau_{\mathrm{y}} \\ G \gamma & , \tau<\tau_{\mathrm{y}}\end{cases}
$$

onde a tensão $\tau_{y}$ corresponde à tensão de escoamento (variando de $50 \mathrm{~Pa}$ a $50.000 \mathrm{~Pa}$ ) dependente do campo magnético $\mathrm{H}[\mathrm{A} / \mathrm{m}] ; \dot{\gamma}$ é a taxa de cisalhamento $\left[\mathrm{s}^{-1}\right]$, e $\eta$ é a

\footnotetext{
${ }^{1}$ Fluido MR são fluidos não-newtonianos, cuja viscosidade é dependente da sua taxa de deformação (mesmo sem a ação de um campo magnético), e por isso é chamada de viscosidade aparente. Mais detalhes podem ser encontrados no Apêndice A deste volume.
} 
viscosidade aparente [Pas], admitida constante, ou seja, considera-se o fluido como se ele fosse newtoniano.

Abaixo dos níveis de tensão de escoamento, em deformações $\gamma$ da ordem de $10^{-3}$, o material apresenta um comportamento que pode ser aproximado por um modelo puramente elástico, conforme a equação (2.1), onde G [Pa] é o módulo de elasticidade complexo do material, que também é dependente da intensidade do campo magnético (Weiss, Carlson e Nixon, 1994²; Nakano, Yamamoto e Jolly, $1997^{3}$ apud JOLLY, BENDER e CARLSON, 1998).

Embora o modelo plástico de Bingham tenha comprovado sua utilidade no projeto e caracterização de dispositivo baseados nos fluidos MR, estes fluidos na verdade exibem algumas características um pouco diferentes deste modelo simples. Provavelmente, a maior diferença deva-se ao fato de que a viscosidade aparente também depende do campo magnético externo, isto é, $\eta=\eta(\dot{\gamma}, H)$ (Kormann, Laun e Klett, $1994^{4}$ apud JOLLY, BENDER e CARLSON, 1998).

Existem também os fluidos eletro-reológicos (ER) que apresentam uma analogia bastante grande com os fluidos MR. A diferença entre os dois é que enquanto o fluido MR tem seu comportamento reológico alterado por um campo magnético, o fluido ER tem seu comportamento reológico alterado por um campo elétrico.

O fluido MR apresenta uma série de vantagens em relação ao fluido ER. Uma comparação destes dois fluidos é apresentada no Apêndice B deste volume.

\subsubsection{COMPOSIÇÃO QUÍMICA}

Segundo Bombard (2005), a composição química dos fluidos MR pode variar muito. Em linhas gerais, esses fluidos correspondem a suspensões ${ }^{5}$ compostas de:

\footnotetext{
${ }^{2}$ Weiss, K. D.; Carlson, J. D.; Nixon, D. A.; Viscoelastic properties of magneto and eletro-rheological fluids. Journal of Intelligent Materials, Systems and Structures, v. 5, p772-775, 1994.

${ }^{3}$ Nakano, M.; Yamamoto, H.; Jolly, M. R.; Dynamics viscoelasticity of a magnetorheological fuid in oscillatory slit flow; Proceedings of the $6^{\text {th }}$ International Conference on ERF, MRS and Their Applications, Yonezawa, Japão; 22-25 de Julho, 1997.

${ }^{4}$ Kormann, C. M.; Laun, M.; Klett, G.; Actuator 94, Proceedings of the 4th International Conference on New Actuators; editado por: H. Borgmann, K. Lens; Axon Technologies Consult GmbH, 271, 1994.

${ }^{5}$ Os fluidos MR, por constituírem uma suspensão de partículas sólidas em meio líquido, também são chamados de Suspensões Magneto-reológicas (SMR).
} 
- um pó magnético, geralmente ferromagnético, na proporção de 60 a $80 \%$ em massa;

- um líquido não volátil e compatível quimicamente com o pó magnético, geralmente óleos com viscosidade abaixo de $200 \mathrm{mPa}$ s a $20^{\circ} \mathrm{C}$, que corresponde à maior parte da porção líquida;

- um aditivo estabilizante para evitar a agregação das partículas, que corresponde a uma fração de 1 a $10 \%$ do volume líquido; e

- um aditivo tixotrópico para retardar a sedimentação do pó magnético como sílica pirogênica hidrofílica ou hidrofóbica, poli-vinil-pirrolidona, argilas modificadas, etc, na proporção de 1 a $5 \%$ em massa do composto.

O pó magnético utilizado é obtido pela decomposição térmica controlada da substância pentocarbonil ferro zero $\left(\mathrm{Fe}(\mathrm{CO})_{5}\right)$, que apresenta pureza da ordem de 99,8\%. Estes pós são denominados comercialmente por "pós de ferro carbonilo", contudo, a rigor, esta denominação não é correta quanto à nomenclatura química. Todavia, como o termo "pó de ferro carbonilo" é o jargão adotado no meio acadêmico e profissional, este será o termo adotado neste trabalho. Nos fluidos MR são, em geral, utilizados pós com partículas de tamanho entre 1 e $8 \mu \mathrm{m}$, conforme apresentado na figura 2.2. Também existem fluidos MR com partículas entre 20 e $50 \mu \mathrm{m}$, porém estes sedimentam muito rapidamente, o que é uma característica indesejável.

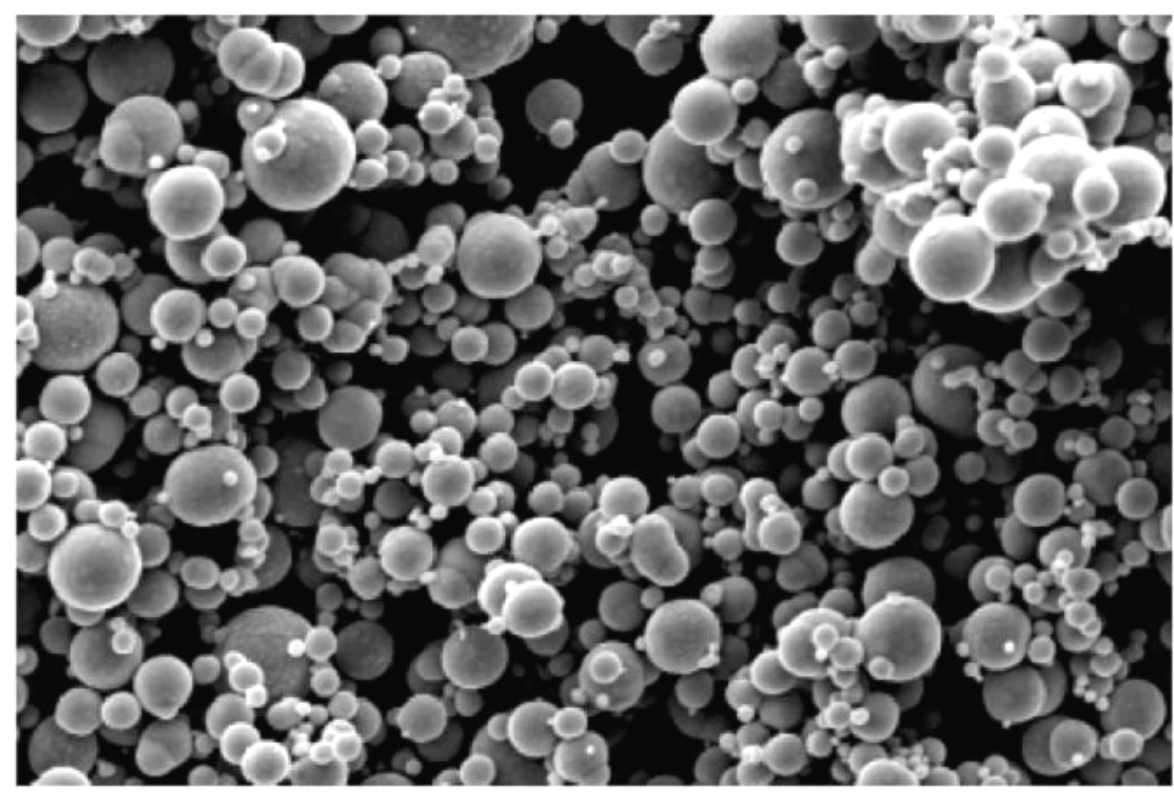


Figura 2.2 - Micrografia eletrônica de varredura de partículas de pó de ferro carbonilo da BASF. Magnificação 1:4000.

Os fluidos MR não devem ser confundidos com os ferrofluidos (também chamados de “colóides magnéticos"). Nos ferrofluidos, as partículas apresentam dimensões coloidais típicas, ou seja, ficam entre 10 e 1000 nanômetros, embora estes limites inferior e superior não sejam rígidos. Diferentemente dos fluidos $\mathrm{MR}$, os ferrofluidos não apresentam sedimentação, e seu comportamento reológico é bastante diferente daquele apresentado pelo fluido MR, principalmente sob a ação de campos magnéticos.

Segundo Genç (2002) e Bombard (2005), os pós de ferro carbonilo são os pós mais utilizados na composição dos fluidos MR, pois a síntese química confere a eles propriedades inigualáveis, impossíveis de se obter por outros meios, como através de processos metalúrgicos ou processos de atomização eletrolítica ou por "spray". As principais características dos pós de ferro carbonilo são:

- apresentam-se como partículas esféricas de ferro com diâmetros entre 1 e 15 micrômetros ${ }^{6}$ e elevada pureza;

- ausência de poros nas partículas;

- baixo teor de impurezas metálicas ou silício;

- controle do teor de carbono dentro de estreita tolerância;

- alto nível de pureza garante grande mobilidade das barreiras de domínio ${ }^{7}$;

- forma esférica que ajuda a minimizar a anisotropia magnética causada por irregularidade na forma e também ajuda a redução da abrasão entre as partículas, melhorando a mobilidade entre elas; e

- alta magnetização de saturação ( 2,1 tesla à temperatura ambiente) e são em geral materiais magnéticos moles.

Também há pós magnéticos de outros materiais magneticamente moles como as ligas de FeCo, que atingem uma magnetização de saturação de até 2,43 T. Embora muitos pesquisadores tenham reportado uma melhoria na tensão de escoamento máxima destes fluidos MR, comparados com aqueles com pós de ferro, há um aumento do problema da

\footnotetext{
${ }^{6}$ Este tamanho, embora reduzido, permite a existência de vários domínios magnéticos em cada partícula.

${ }^{7}$ O conceito de domínio magnético foi introduzido por Weiss em 1929, e ainda hoje é o modelo que se utiliza para explicar os processos de magnetização dos materiais ferromagnéticos. A fronteira entre dois domínios é chamada de barreira de domínio.
} 
sedimentação pois a densidade da liga de $\mathrm{FeCo}(8,1 \mathrm{~g} / \mathrm{cc})$ é maior que a do ferro $(7,8 \mathrm{~g} / \mathrm{cc})$ (GENÇ, 2002).

\subsubsection{HISTÓRICO DO DESENVOLVIMENTO DOS FLUIDOS MR/ER}

A descoberta de fluidos MR e ER remonta à década de 40 (Rabinow, 1948 ; Winslow $1949^{9}$ apud CARLSON; CATANZARITE; CLAIR, 1996). Há relatos de um experimento feito em conjunto por Rabinow e Winslow, onde eles descrevem um dispositivo que apresentava uma área total de cisalhamento de aproximadamente $50 \mathrm{~cm}^{2}$ e era capaz de sustentar o peso de uma mulher $53 \mathrm{~kg}$. Para que esta demonstração tivesse sido bem sucedida, como foi, o fluido MR utilizado precisaria apresentar uma tensão de escoamento de no mínimo $100 \mathrm{kPa}(\mathrm{CARLSON}, 2001)$.

Desde então, os fluidos MR e ER vem sendo estudados, no entanto com uma ênfase maior dada aos fluidos ER, principalmente porque era difícil obter misturas homogêneas e com boa estabilidade para os fluidos MR.

De qualquer forma, os dispositivos ER ou MR só voltaram a despertar um interesse maior de pesquisa nas décadas de 80 e 90, caracterizado pelo grande número de trabalhos publicados neste período, inclusive abordando técnicas de controle utilizando dispositivos semi-ativos como atuadores.

No Brasil foram realizados trabalhos de pesquisa sobre fluidos ER na década de 90, como por exemplo: Mendes (1996), Vieira (1996) e Bombard (1996) realizados na UNICAMP. Mais recentemente têm-se trabalhos focados nos fluidos MR, como, por exemplo, o trabalho de Bombard (2005), também na UNICAMP. O centro de pesquisa da UNIFEI de Itajubá, MG, montou um laboratório voltado para pesquisas de fluidos MR com investimentos do setor privado.

\footnotetext{
${ }^{8}$ RABINOW, J. The Magnetic Fuid Clutch. AIEE Trans., v. 67, p. 1308-1315, 1948.

${ }^{9}$ WINSLOW, W. M. Induced Fibration of Suspensions. J. Appl. Phys., v. 20, p. 1137-1140, 1949.
} 


\subsection{DISPOSITIVOS MAGNETO-REOLÓGICOS}

\subsubsection{COMO FAZER DISPOSITIVOS MR DE ALTO DESEMPENHO}

É relativamente fácil de elaborar um fluido MR que atenda razoavelmente bem às necessidades básicas da maioria dos dispositivos MR. Entretanto, para se obter dispositivos MR altamente eficientes, as pesquisas mais atuais sobre os fluidos MR buscam aprimorar algumas de suas características a fim de atingir desempenhos cada vez melhores (BOMBARD, 2005; GENÇ, 2002). Basicamente são quatro as características fundamentais dos fluidos MR:

- tensão de escoamento;

- viscosidade aparente;

- estabilidade e

- durabilidade

As duas primeiras características estão diretamente ligadas ao desempenho do dispositivo MR (CARLSON, 2001). Quanto mais altas tensões de escoamento sob campo magnético e mais baixos coeficientes de viscosidade aparente um fluido apresentar, melhor será o desempenho do dispositivo MR que utiliza este fluido.

Por outro lado, as duas últimas características estão ligadas a manutenção do desempenho de um dispositivo com o passar do tempo e com o seu uso. A estabilidade do fluido MR garante que um dispositivo que fique sem utilização por longo períodos, ou que tenho pouco uso, mantenha seu desempenho inalterado, ou seja, capaz de recuperá-lo rapidamente. A durabilidade do fluido MR está relacionada a quanta energia o fluido é capaz de suportar ao longo de sua vida útil, sem perder seu desempenho. Esta energia vem das forças de cisalhamento que agem sobre as partículas do fluido, que com o tempo vão se deformando e se quebrando, provocando o espessamento do fluido MR.

O Apêndice $\mathrm{C}$ traz maiores detalhes sobre estas características dos fluidos MR. 


\subsubsection{MATERIAIS FERROMAGNÉTICOS EM DISPOSITIVOS MR}

A construção de dispositivos MR utiliza basicamente materiais ferromagnéticos para os caminhos do fluxo magnético e materiais diamagnéticos para a isolação do circuito magnético. Para mais detalhes sobre as diferenças entre materiais ferromagnéticos e diamagnéticos, além de outras propriedades dos materiais magnéticos, vide Apêndice D.

Aplicações em dispositivos MR, assim como em transformadores, motores e geradores exigem que o material ferromagnético apresente as seguintes propriedades:

- alta magnetização de saturação;

- baixa coercividade;

- alta permeabilidade inicial; e

- baixas perdas energéticas por histerese.

Estas em geral são as características típicas de um material ferromagnético mole ou doce. Um exemplo deste tipo de material é o ferro doce ou o aço SAE1008. No entanto materiais magneticamente "moles" são em geral também mecanicamente moles, apresentando baixa resistência a esforços de tração e compressão. Como em dispositivos MR a resistência mecânica é um fator importante, é comum se utilizar nestas aplicações aços com um pouco mais de carbono, como o SAE1020 (CRAFT, 2003), por exemplo, que é magneticamente um pouco mais duro que o SAE1008, porém apresenta propriedades mecânicas compatíveis com a aplicação.

O Ferro-Cobalto é um dos melhores materiais para utilização em dispositivos MR, pois apresenta entre outras propriedades excepcionais, uma das mais altas magnetizações de saturação (cerca de 2,4T). A sua única desvantagem é o custo, visto que o cobalto não é um material muito abundante na Natureza.

Nos últimos anos, com a busca por materiais magnéticos que permitam construir máquinas elétricas mais rápidas, e mais compactas e eficientes, novos materiais têm sido investigados (SHIMADA et al., 2003; MAEDA et al., 2005). Uma classe destes novos materiais, que pode ser vir a ser estudada para aplicação em dispositivos MR, é obtida a partir de processos de metalurgia do pó, e são conhecidos como compósitos magnéticos moles (CMM) ("Soft magnetic composities" - SMC). Um exemplo desta classe de materiais magnéticos é o SOMALOY 550 
A maior vantagem dos materiais CMM para a construção de dispositivos MR é a facilidade de moldagem de formas complexas de núcleos magnéticos com um volume contínuo, isto é, sem encaixes. Isto permite que possam ser explorados novos conceitos de desenho de válvulas MR que busquem melhores desempenhos a partir de formas mais complexas de fluxo do fluido MR através da válvula e de sua interação com o campo magnético. Estes materiais também apresentam uma boa resistência mecânica e menores custos no processo de fabricação que os materiais convencionais. Além disso, eles apresentam baixa coercividade, e condutividade relativamente baixa (de 500 a $10000 \mathrm{~S} / \mathrm{m}$ ), o que reduz a indução de correntes parasitas no núcleo magnético. Apesar de não alcançar os níveis de magnetização de saturação do ferro, ele apresenta níveis de saturação bem maiores que o das ferritas ( 1,33 Tesla). Contudo a maior desvantagem é a sua baixa permeabilidade relativa (entre 250 a 350), que pode ser um fator proibitivo para este tipo de aplicação.

No caso dos pós de ferro carbonilo, utilizados na composição dos fluidos MR, as propriedades magnéticas mais importantes são a suscetibilidade e a magnetização de saturação. Segundo vários experimentos de Bombard (2005) e Genç (2002) e de outros autores por eles citados, a tensão de escoamento do fluido MR sob a ação de um campo magnético apresenta uma relação direta com a suscetibilidade e a magnetização de saturação do pó magnético que o constitui. Portanto, quanto maiores as suscetibilidades e a magnetização de saturação, maior é o limite máximo da tensão de escoamento que o fluido MR pode atingir.

No entanto, o excesso de suscetibilidade do pó utilizado no fluido MR pode levar a uma saturação do núcleo ferromagnético da válvula, reduzindo a intensidade do campo magnético sobre o fluido. Portanto existe uma solução de compromisso entre as características magnéticas do fluido MR, dos materiais, e da geometria do núcleo ferromagnético.

\subsubsection{EXEMPLOS DE VÁLVULAS MAGNÉTICAS DE DISPOSITIVOS MR}

A válvula magnética é a parte do dispositivo MR que controla o fluxo de fluido MR, que se dá a partir do controle do comportamento reológico do fluido por meio da aplicação de um campo-magnético variável. Existe uma grande variedade de conceitos de válvulas magnéticas, os quais dependem da vazão de fluido que se pretende controlar, da intensidade máxima de força dissipativa que se pretende obter e do tempo de resposta necessário que uma dada aplicação exige. 
A escolha da geometria da válvula depende de como se pretende expor o fluido ao campo magnético, ou seja, da forma como será a interação do fluido MR com o circuito magnético. A seguir são apresentados alguns exemplos que visam ilustrar alguns conceitos construtivos.

O primeiro exemplo é apresentado na figura 2.3, onde no entreferro entre o pistão e o tubo é colocada uma esponja de poliuretano saturado com fluido MR. Este tipo de construção tem a vantagem de usar uma pequena quantidade de fluido (3 a $10 \mathrm{ml})$ e a válvula controla a vazão de ar entre as câmaras. Este tipo de construção é adequado para aplicações onde os esforços máximos são da ordem de $150 \mathrm{~N}$, o que é utilizado em aplicações como máquinas de lavar ou equipamentos de ginástica. A finalidade deste exemplo é ilustrar uma aplicação específica de baixa potência, contudo a modelagem matemática necessária para este tipo de dispositivo diverge da linha abordada neste trabalho, que se baseia na forma mais comum de construção de dispositivos MR.

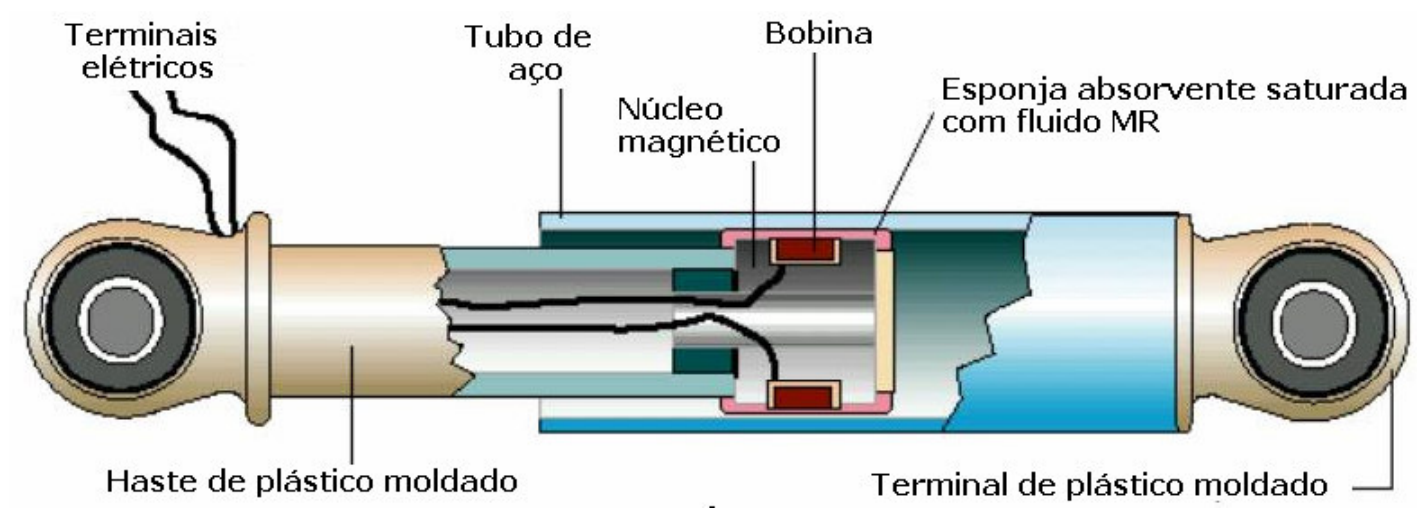

Figura 2.3 - Válvula MR com esponja de poliuretano saturada.

Outro exemplo é apresentado na figura 2.4, é o adotado pela Delphi no amortecedor MR utilizado no Corvette (HALVERSON, 2003). Nesta construção mais complexa, o fluido passa por dentro do pistão móvel (vide a fita que passa pelo canal anelar na fig. 2.4). Portanto, o fluxo magnético fica praticamente todo contido na válvula magnética dispensando um tubo externo com parede espessa (entre 3 e $4 \mathrm{~mm}$ ), como aqueles necessários quando o circuito magnético se fecha pelo tubo. Desta forma, este conceito permite a utilização de materiais magnéticos mais nobres ${ }^{10}$ em qualquer parte do circuito magnético. Nas extremidades da válvula é utilizado material paramagnético (com suscetibilidade $\chi \sim 0$ ) ou diamagnético $(\chi<0)$,

\footnotetext{
${ }^{10}$ Materiais magnéticos que apresentam alta permeabilidade inicial, alta magnetização de saturação, baixa coercividade e baixas perdas energéticas por histerese.
} 
o que evita a fuga de fluxo magnético para fora do circuito magnético e através do fluido MR que preenche o interior do atuador.

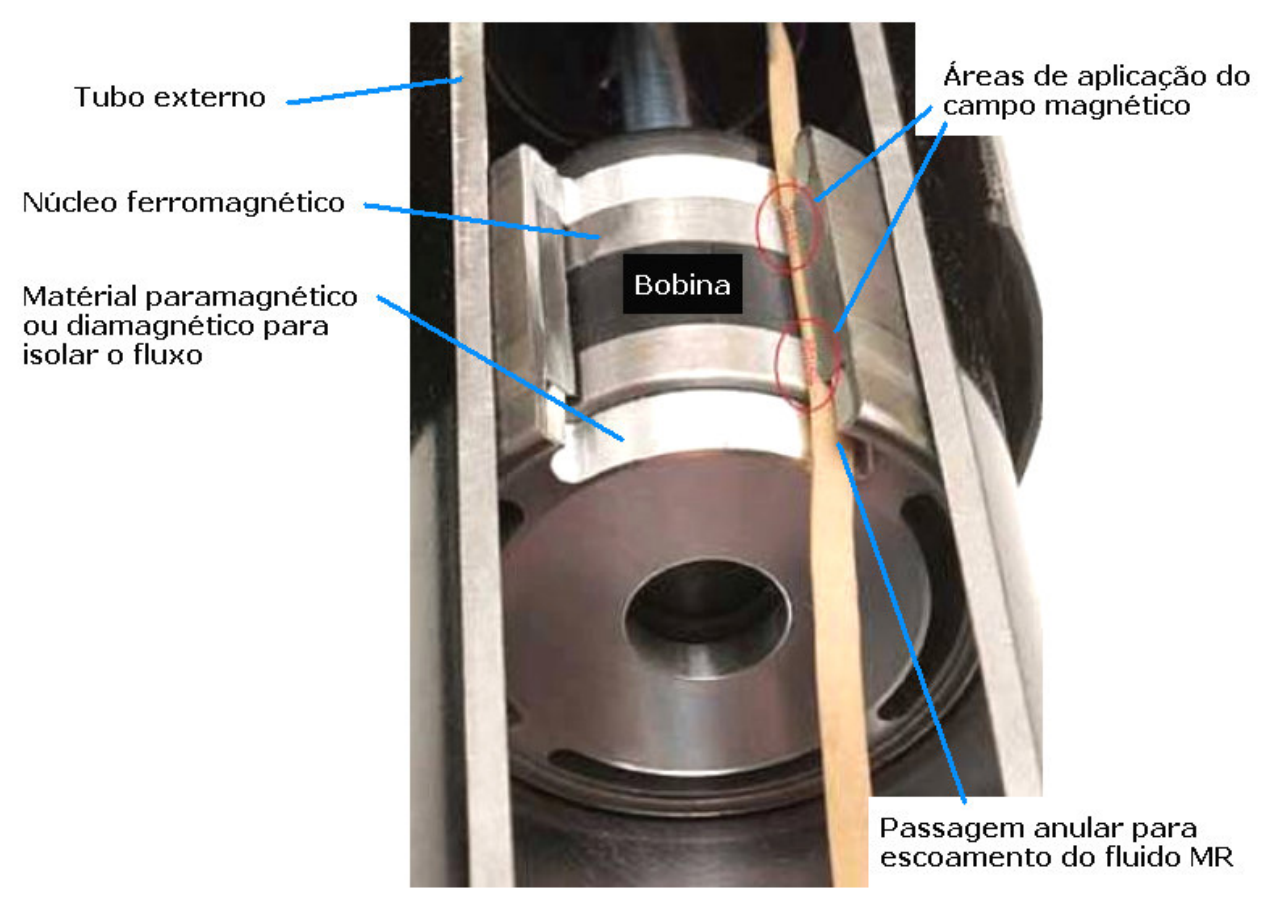

Figura 2.4 - Válvula MR utilizada no amortecedor do Corvette (HALVERSON, 2003).

Por fim, apresenta-se uma terceira opção na figura 2.5, que é uma geometria desenvolvida na Universidade da Virgínia (Virginia Tech) em parceria com a Visteon. Este desenho de válvula magnética apresenta algumas peculiaridades como o fluxo do fluido MR que ocorre entre o pistão e o tubo, e, portanto, as paredes do tubo fazem parte do circuito magnético e devem apresentar uma espessura mínima para comportar a densidade de fluxo magnético necessária para a aplicação. Outra característica é a existência de duas bobinas ao invés de uma, como é o caso dos exemplos anteriores, o que pode resultar em circuitos magnéticos com menor relutância (KELSO, 2001). Como os circuitos magnéticos ficam mais curtos, ocorre uma menor saturação no núcleo ferromagnético. 

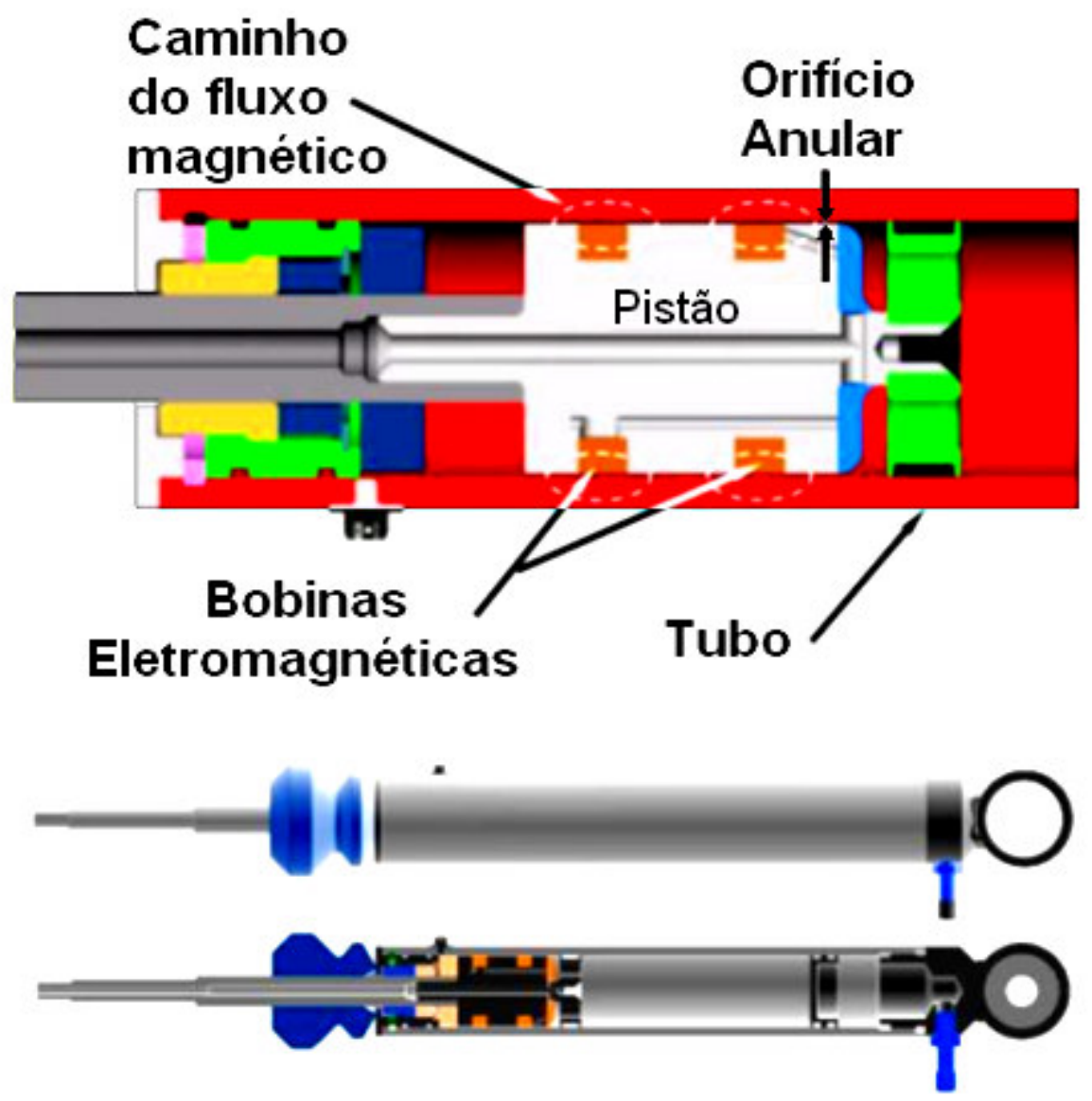

Figura 2.5 - Válvula MR desenvolvida para a Visteon pelo Virginia Tech. 


\subsection{MODELAGEM DO COMPORTAMENTO DINÂMICO}

Para se desenvolver algoritmos de controle capazes de tirar o máximo de vantagens das características dos atuadores semi-ativos, vários pesquisadores têm trabalhado no desenvolvimento de modelos que possam caracterizar de forma adequada o comportamento não-linear intrínseco destes dispositivos.

O trabalho de Spencer et al. (1996) faz um estudo comparando três modelos com um quarto modelo proposto por ele, através de dados experimentais em um protótipo de amortecedor MR. Segue aqui uma breve descrição e comentários destes modelos.

O primeiro e mais básico baseia-se no modelo de plástico de Bingham (equação 2.1, página 36), e foi desenvolvido por Stanway et al. (1985 ${ }^{11}, 1987^{12}$; apud SPENCER et al., 1996). O modelo consiste de um elemento de atrito de Coulomb colocado em paralelo com um amortecedor viscoso ideal, conforme ilustrado na figura 2.6. O foco do trabalho de Stanway (op. cit.) foram os fluidos e dispositivos ER.

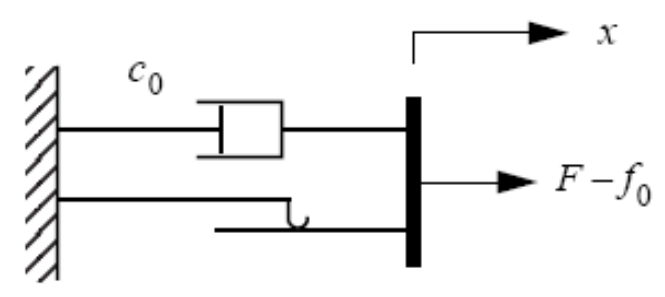

Figura 2.6 - Modelo Bingham de um amortecedor MR (Stanway, op. cit.)

Neste modelo, para velocidade, $\dot{x}$, do pistão diferente de zero, a força gerada pelo dispositivo é dada por:

$$
F=f_{a c} \cdot \operatorname{sgn}(\dot{x})+c_{0} \dot{x}+f_{0}
$$

onde $c_{0}$ é o coeficiente de atrito viscoso, $f_{a c}$ é a força de atrito de Coulomb que varia conforme a tensão elétrica de controle, $f_{0}$ é a força residual devido à pressão de ar no

\footnotetext{
${ }^{11}$ STANWAY, R.; SPROSTON, J. L.; STEVENS, N. G. Non-linear identification of an electro-rheological vibration damper. IFAC Identification and System Parameter Estimation, p. 195-200, 1985

${ }^{12}$ STANWAY, R.; SPROSTON, J. L.; STEVENS, N. G. Non-linear modeling of an electro-rheological vibration damper. J. Electrostatics, v. 20, p. 167-184, 1987
} 
acumulador do dispositivo, e "sgn" é a função sinal. Apesar de representar o comportamento mais importante de um atuador MR, por ser demasiadamente simples ele não é capaz de descrever o comportamento dinâmico transitório deste tipo de dispositivo, que é caracterizado por uma curva de histerese quando ocorre a mudança de sentido da velocidade do pistão.

Outro modelo, que também visava a predizer o comportamento de dispositivos ER, é aquele apresentado no trabalho de Gamota e Filisk ${ }^{13}$ (1991; apud SPENCER et al., 1996), o qual propõe uma extensão do modelo de Bingham proposto por Stanway; que é feita a partir da inclusão de um modelo viscoelástico-plástico em série com o modelo anterior, conforme ilustrado na figura 2.7 .

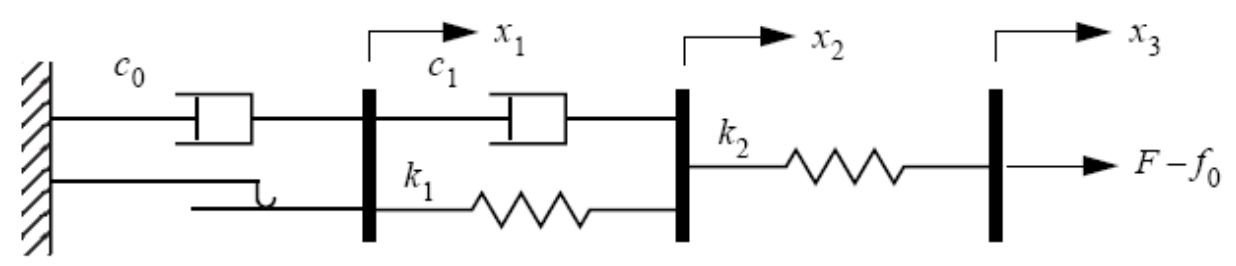

Figura 2.7 - Modelo proposto por Gamota e Filisko (1991).

As equações que governam o comportamento deste modelo são dadas por:

$$
\left.\begin{array}{rl}
F & =k_{1}\left(x_{2}-x_{1}\right)+c_{1}\left(\dot{x}_{2}-\dot{x}_{1}\right)+f_{0} \\
& =f_{c} \cdot \operatorname{sgn}\left(\dot{x}_{1}\right)+c_{0} \dot{x}_{1}+f_{0} \\
& =k_{2}\left(x_{3}-x_{2}\right)+f_{0}
\end{array}\right\},|F|>f_{c}
$$

onde $c_{0}$ é o coeficiente de amortecimento associado com o modelo de Bingham e $k_{1}, k_{2}$ e $c_{1}$ são associados com o material sólido linear. Nota-se que quando $|F| \leq f_{c}, \dot{x}_{1}=0$. Este modelo já consegue representar o comportamento não-linear observado nos experimentos que mostram a relação força versus velocidade conforme a velocidade passa por zero (histerese). Contudo este modelo apresenta um condicionamento numérico ruim, o que leva a se utilizar

\footnotetext{
${ }^{13}$ GAMOTA, D. R.; FILISKO, F. E. Dynamic mechanical studies of electro-rheological materials: moderate frequencies. Journal of Rheology, v. 35, p. 399-425, 1991.
} 
passos de integração muito pequenos para simulá-lo, podendo haver instabilidade gerada por erro numérico. Este problema constitui a principal desvantagem do modelo de Gamota e Filisko, que também foi observada no trabalho de Ehrgott e Masri (1994).

O terceiro modelo, que se baseia no modelo Bouc-Wen (WEN ${ }^{14} 1976$ apud SPENCER et al., 1996), é numericamente tratável e tem sido utilizado extensivamente para modelar o fenômeno de histerese. O modelo Bouc-Wen é bastante versátil e pode exibir uma ampla variedade de comportamentos histeréticos. Este modelo está apresentado na figura 2.8.

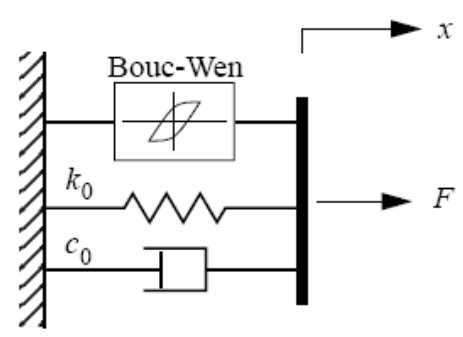

Figura 2.8 - Modelo Bouc-Wen de um amortecedor MR.

A força neste modelo é representada por

$$
F=c_{0} \dot{x}+k_{0}\left(x-x_{0}\right)+\alpha z
$$

onde $f_{0}$ é incorporada a partir de uma deflexão inicial $x_{0}$ na mola linear $k_{0}$. Na equação (2.5), z é uma variável evolucionária que é responsável pelo comportamento histerético, e é governada por:

$$
\dot{z}=-\gamma \cdot|\dot{x}| \cdot z \cdot|z|^{n-1}-\beta \cdot \dot{x} \cdot|z|^{n}+A \cdot \dot{x}
$$

A partir do ajuste dos parâmetros $\gamma, \beta, A$ e $n$, pode-se controlar a forma da transição da curva de histerese.

Um quarto modelo, que foi proposto por Spencer et al. (1996), é mais adequado para descrever o comportamento de dispositivos que apresentam uma rápida queda da força ("rolloff”) quando a velocidade do pistão passa por zero. Segundo a literatura, este comportamento

\footnotetext{
${ }^{14}$ WEN, Y. K. Method of random vibration of hysteretic systems. Journal of Engineering Mechanics Division, ASCE, v. 102, n. EM2, p. 249-263, 1976.
} 
é melhor para aplicações automobilísticas, por diminuir o desconforto vibro-acústico (“harshness") gerado por estes componentes. Este modelo é ilustrado na figura 2.9.

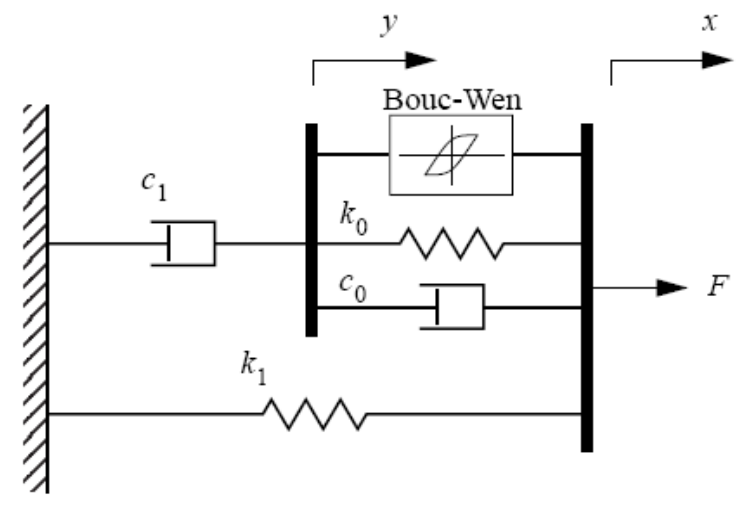

Figura 2.9 - Modelo proposto por Spencer et al. (1996).

As equações que descrevem este modelo estão listadas a seguir:

$$
\begin{aligned}
\dot{y} & =\frac{1}{\left(c_{0}+c_{1}\right)}\left\{\alpha z+c_{0} \dot{x}+k_{0}(x-y)\right\} \\
\dot{z} & =-\gamma|\dot{x}-\dot{y}| z|z|^{n-1}-\beta(\dot{x}-\dot{y})|z|^{n}+A(\dot{x}-\dot{y}) \\
F & =c_{1} \dot{y}+k_{1}\left(x-x_{0}\right)+f_{1} \\
\alpha & =\alpha(u)=\alpha_{a}+\alpha_{b} u \\
c_{1} & =c_{1}(u)=c_{1 a}+c_{1 b} u \\
c_{0} & =c_{0}(u)=c_{0 a}+c_{0 b} u \\
\dot{u} & =-\eta(u-v)
\end{aligned}
$$

Além das equações de equilíbrio de forças e da variável evolucionária $z$, as equações (2.10), (2.11) e (2.12) apresentam parâmetros que são dependentes da variável $u$, que por sua vez é resultante de um filtro de primeira ordem que representa o retardo da corrente do circuito elétrico em relação a tensão de entrada $v$ (equação 2.13).

Há outros modelos que se baseiam em formulações mais complexas, como é o caso do trabalho de Wang e Gordaninejad (2001), que se baseia nas equações constitutivas de Herschel-Bulkley ${ }^{15}$. Porém estes são menos adequados para aplicação em controle, uma vez

\footnotetext{
${ }^{15}$ ALEXANDroU, A. N., MCGILVRVREAY, T. M.; BURGOS, G. Steady Herschel-Bulkley fluid flow in three-dimensional expensions. J. Non-Newtonian Fluid Mech., v. 100, p. 77-96, 2001.
} 
que a sua maior complexidade não traz vantagem significativa para a representação do atuador MR e apresenta um peso computacional maior.

\subsection{COMENTÁRIOS GERAIS}

Esta pesquisa ajudou a identificar os principais aspectos dos fluidos MR e dos materiais magnéticos utilizados na construção de dispositivos MR. Também mostrou que existe uma solução de compromisso entre o fluido MR, o material do núcleo ferromagnético e sua geometria, que define o circuito magnético e sua relutância. Nesse sentido, nota-se a importância de uma análise de elementos finitos magnetostática com a finalidade de se identificar a distribuição do fluxo magnético na válvula do dispositivo MR.

Os três exemplos de válvulas MR apresentados serviram para ilustrar que podem existir diferentes formas e conceitos que podem ser aplicados no controle do fluido MR, cada qual com suas vantagens e desvantagens.

Verificou-se que não há muita literatura, principalmente em língua portuguesa, que explique em detalhes o embasamento teórico das fórmulas práticas utilizadas para descrição de escoamentos simples entre placas paralelas. Um conhecimento maior desta base teórica pode ajudar no desenvolvimento de atuadores MR mais eficientes.

Os modelos fenomenológicos são uma opção bastante interessante para a simulação do comportamento dos fluidos MR, dada a sua simplicidade e efetividade. Contudo, nenhum dos modelos encontrados na literatura consultada apresenta uma forma viável para ser utilizado numa malha de controle digital (tempo discreto), e também não apresentam um processo prático e rápido (apesar de eficiente) para a estimação dos parâmetros do modelo.

A partir um modelo fenomenológico representativo de um dispositivo MR, é possível se obter informações importantes sobre este atuador que podem ser utilizadas como um padrão de referência para comparação entre dois ou mais atuadores deste tipo. 


\section{BASE TEÓRICA PARA O PROJETO DE ATUADORES MR}

\subsection{ATUADORES MAGNETO-REOLÓGICOS}

Atuador magneto-reológico é definido neste trabalho como todo dispositivo mecânico dotado de circuitos elétricos e magnéticos capazes de agir sobre o comportamento reológico de fluidos MR e utilizar esta alteração de comportamento para gerar forças mecânicas dissipativas. Estes dispositivos em geral são utilizados como atuadores em sistemas de controle de movimento e vibração. Esta seção tem por objetivo investigar com profundidade a teoria que está por trás dos atuadores MR, mostrando as considerações e simplificações que levam às fórmulas mais simples e aos procedimentos mais práticos de projeto. Também são analisados o método de otimização por volume mínimo de fluido, e os fatores de mérito para avaliação dos projetos.

\subsubsection{DESCRIÇÃO DO PROBLEMA ACOPLADO}

A descrição de um modelo completo de um atuador MR é bastante complexa, visto que se trata de um fenômeno acoplado de forma eletromagnética, hidrodinâmica, e termodinâmica. O fenômeno observado nos atuadores MR precisa ser analisado em termos de campos. O campo eletromagnético está acoplado, entre outros, ao campo de velocidade do fluido, ao campo de tensão mecânica e ao campo de temperatura. Este acoplamento de campos faz com que a análise deste fenômeno em transdutores seja bastante complicada. $\mathrm{O}$ que o torna um problema ainda mais intricado é o caráter variável destes campos e as nãolinearidades dos fenômenos envolvidos. Até o momento não há uma proposta geral para solução de um fenômeno de campo dependente do tempo.

$\mathrm{Na}$ modelagem desenvolvida, assume-se que o fluido é um meio contínuo, o que pode ser considerado válido para um fluido MR quando se trabalha com volumes com dimensões superiores a 50 mícrons. Para dimensões menores que esta, o tamanho das partículas de ferro carbonilo tornam-se significativas e o modelo não é mais aplicável. Como as menores 
dimensões das regiões de passagem de fluido dos dispositivos MR são em geral superiores a 300 mícrons, isto não é um fator impeditivo. Outra hipótese necessária é que todas as variáveis de interesse tais como pressão, velocidade, densidade, temperatura, etc., sejam diferenciáveis (isto é, não há transição de fase).

Para se descrever o problema, inicia-se pela forma geral da equação de Navier-Stokes para a conservação de momento, apresentada na equação (3.1). Desta equação vetorial resultam três relações escalares que permitem determinar o campo de velocidade do fluido ou o seu campo de pressão em um escoamento de interesse.

$$
\rho \frac{D \vec{V}}{D t}=\nabla \cdot \mathbf{P}+\rho \vec{g}
$$

Na equação (3.1), $\vec{V}$ é o vetor que representa a velocidade do fluido no volume infinitesimal estudado, e $\frac{D}{D t}(\bullet) \equiv \frac{\partial}{\partial t}(\bullet)+\vec{V} \cdot \nabla(\bullet)$ é a derivada substancial ou derivada material, que recebe este nome porque o volume infinitesimal acompanha uma partícula do fluido, ou seja, segue o fluxo da substância (ou material). Esta derivada representa a relação entre a formulação lagrangeana, na qual a quantidade depende do tempo $t$, e a formulação euleriana, na qual a quantidade depende da posição $(x, y$ e $z)$ e do tempo $t$. A matriz $\mathbf{P}$ é o tensor de tensões normais e de cisalhamento que agem sobre as faces de um cubo que representa um volume infinitesimal do fluido, conforme a figura 3.1. O parâmetro $\rho$ é a massa específica do fluido e $\vec{g}$ é o vetor da aceleração da gravidade.

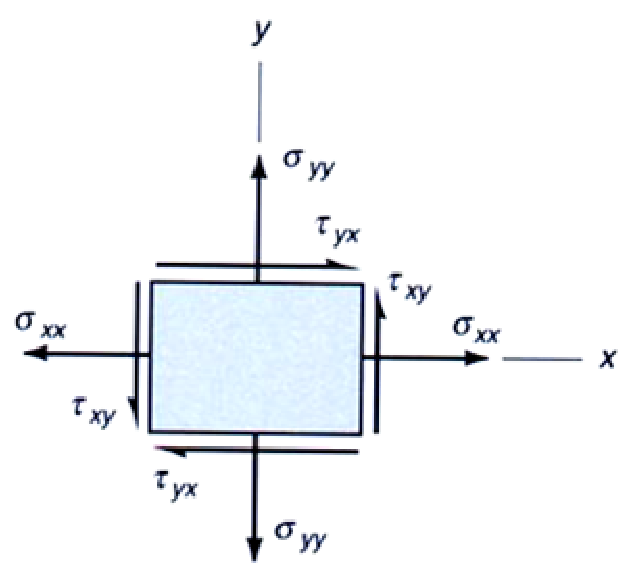

(a)

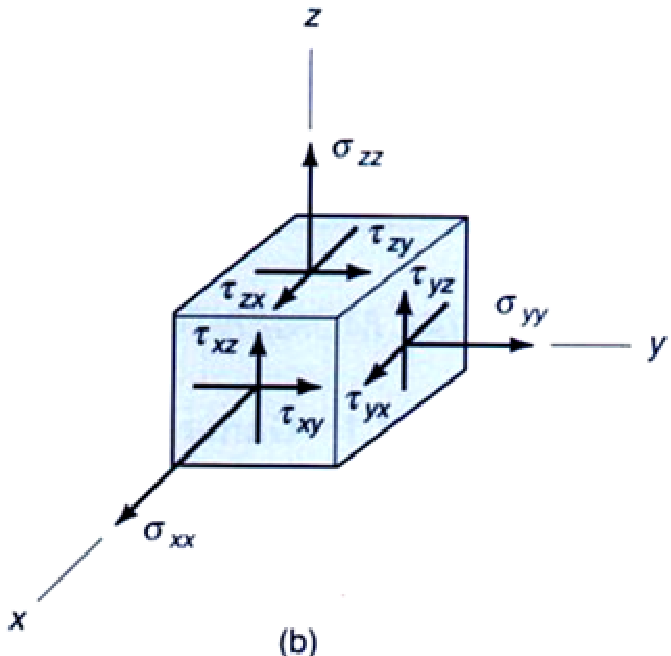

(b)

Figura 3.1 - Volume infinitesimal de fluido e suas tensões: (a) 2D, (b) 3D. 
Conforme a figura 3.1, as tensões $\sigma_{i i}$ são as tensões normais e $\tau_{i j}$ são as tensões de cisalhamento. Assim o tensor $\mathbf{P}$ pode ser representado da seguinte forma:

$$
\mathbf{P}=\left[\begin{array}{ccc}
\sigma_{x x} & \tau_{x y} & \tau_{x z} \\
\tau_{y x} & \sigma_{y y} & \tau_{y z} \\
\tau_{z x} & \tau_{z y} & \sigma_{z z}
\end{array}\right]
$$

A menos que o fluido possua um grau de liberdade de rotação, tal como em um vórtice, $\mathbf{P}$ é um tensor simétrico. No caso de dispositivos MR, na região de interesse onde o fluido estará sob a influência de um campo magnético, esta hipótese será válida uma vez que o escoamento nesta região não deve apresentar vórtices.

No caso de um escoamento incompressível, como ocorre com os fluidos MR, a massa específica do fluido é constante em qualquer ponto. Sendo assim, a equação de Navier-Stokes para a conservação de massa (também conhecida como equação da continuidade) é dada pela expressão abaixo:

$$
\nabla \cdot \vec{V}=0
$$

Para um fluido newtoniano incompressível e isotrópico ${ }^{16}$, o tensor $\mathbf{P}$ é definido pela equação (3.4), que muitas vezes é chamada de equação constitutiva (POTTER e WIGGERT, 1997).

$$
\mathbf{P}=\left[\begin{array}{lll}
\sigma_{x x} & \tau_{x y} & \tau_{x z} \\
\tau_{y x} & \sigma_{y y} & \tau_{y z} \\
\tau_{z x} & \tau_{z y} & \sigma_{z z}
\end{array}\right]=-p \cdot \mathbf{I}+\mu\left(\nabla \vec{V}+(\nabla \vec{V})^{T}\right)=-p \cdot \mathbf{I}+\mu \cdot \mathbf{D}
$$

onde $p$ é a pressão, I é a matriz identidade, $\mu$ é a viscosidade, e $\mathbf{D} \equiv\left(\nabla \vec{V}+(\nabla \vec{V})^{T}\right)$ é o tensor de velocidade de deformação ou taxa de deformação (SZELAG, 2003). Para uma descrição mais detalhada do tensor $\mathbf{P}$, vide Apêndice E.

\footnotetext{
${ }^{16}$ A condição de isotropia existe se as propriedades do fluido são independentes da direção.
} 
Contudo, apesar dos fluidos MR apresentarem um comportamento quasi-newtoniano sem a presença de um campo magnético (vide figura 3.2), sob a ação de um campo magnético o seu comportamento é semelhante a um plástico de Bingham (SZELAG, 2003), e pode ser representado pelo modelo de Bingham (equação 2.1, pág. 36). Para estes fluidos o tensor $\mathbf{P}$ não é mais dependente apenas das taxas de deformação, mas também da densidade de fluxo magnético $(B)$, ou seja, $\mathbf{P}=\mathbf{P}(\mathbf{D}, B)$, e pode ser representado por (LORD, 2001b):

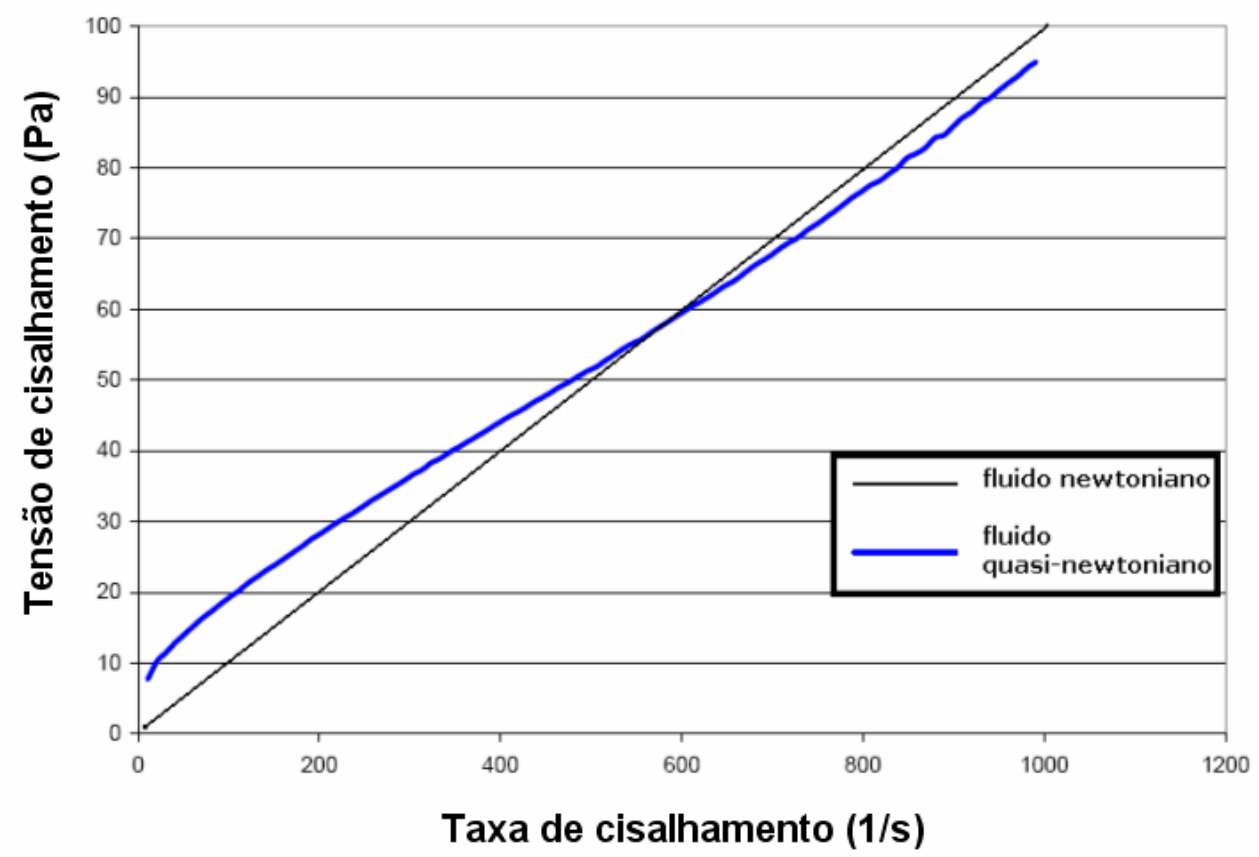

Figura 3.2 - Curva da tensão de cisalhamento do fluido MRF 132-AD da Lord em função da taxa de cisalhamento. Esta curva pode ser representada por uma reta, aproximando-a por um modelo newtoniano com viscosidade constante.

$$
\mathbf{P}=-p \cdot \mathbf{I}+\left(\eta+\frac{\tau_{0}(B)}{\|\mathbf{D}\|}\right) \cdot \mathbf{D} \quad \text { para }(\|\mathbf{P}\|+p)>\tau_{0}(B)
$$

onde $\eta$ é a viscosidade aparente do fluido e $\tau_{0}$ é a tensão mínima para início da deformação do fluido, também chamada de tensão de escoamento, que é dependente da densidade de fluxo magnético $B$ no fluido MR. $\|\mathbf{D}\| \mathrm{e}\|\mathbf{P}\|$ são as normas de Frobenius $^{17}$ ou norma euclidiana dos respectivos tensores. Quando a norma de $\mathbf{P}$ somada à pressão for menor que a tensão de

\footnotetext{
${ }^{17}$ A norma de Frobenius de uma matriz quadrada A é definida por $\|\mathbf{A}\|_{F}=\sqrt{\sum_{i, j}\left|a_{i j}\right|^{2}}=\sqrt{\operatorname{tr}\left(\mathbf{A}^{*} \cdot \mathbf{A}\right)}=\sqrt{\sum_{i} \sigma_{i}^{2}}$, onde $a_{i j}$ são os elementos da matriz $\mathbf{A}$ e $\sigma_{i}$ são os valores singulares da matriz $\mathbf{A}$.
} 
escoamento do fluido, este apresenta o comportamento de um sólido elástico, onde as tensões são função das deformações do volume infinitesimal.

Pode-se então definir uma viscosidade plástica $^{18} \eta_{p}$, tal que:

$$
\mathbf{P}=-p \cdot \mathbf{I}+\eta_{p} \cdot \mathbf{D} \quad \text { para }\|\mathbf{T}\|>\tau_{0}(B)
$$

onde o tensor $\mathbf{T}$ é por definição:

$$
\mathbf{T} \equiv\left(\eta+\frac{\tau_{0}(B)}{\|\mathbf{D}\|}\right) \cdot \mathbf{D}
$$

Dada a similaridade das equações (3.4) e (3.6), a diferença entre o modelo de um fluido newtoniano e um fluido MR pode ficar restrito à definição da viscosidade. Para um fluido newtoniano tem-se uma viscosidade constante e independente da posição $(\mu)$, porém um fluido MR apresenta uma viscosidade plástica, $\eta_{p}$, que não é constante e dependente fundamentalmente da densidade de campo $B$, da viscosidade aparente $\eta$ e do tensor D. A viscosidade plástica é dada por:

$$
\eta_{p}= \begin{cases}\eta+\frac{\tau_{0}(B)}{\|\mathbf{D}\|} & \text { para }\|\mathbf{T}\|>\tau_{0}(B) \\ \infty & \text { para }\|\mathbf{T}\| \leq \tau_{0}(B)\end{cases}
$$

Então, substituindo a equação (3.6) na equação (3.1), tem-se:

$$
\rho \frac{D \vec{V}}{D t}=-\nabla p+\nabla \cdot\left(\eta_{p} \cdot \mathbf{D}\right)+\rho \vec{g}
$$

Aplicando-se a identidade vetorial abaixo:

$$
\nabla \cdot(\alpha \mathbf{M}) \equiv \mathbf{M} \cdot(\nabla \alpha)+\alpha(\nabla \cdot \mathbf{M})
$$

\footnotetext{
${ }^{18}$ Viscosidade plástica, que é o nome dado à viscosidade aparente típica de fluidos que se comportam como plástico de Bingham (vide APÊNDICE A).
} 
A equação 2.15 pode ser escrita como:

$$
\rho \frac{D \vec{V}}{D t}=-\nabla p+\mathbf{D} \cdot\left(\nabla \eta_{p}\right)+\eta_{p}(\nabla \cdot \mathbf{D})+\rho \vec{g}
$$

Admitindo-se a hipótese da continuidade, isto é $\nabla \cdot \vec{V}=0$, a equação (3.11) pode ser simplificada como se segue (vide Apêndice E):

$$
\rho \frac{D \vec{V}}{D t}=-\nabla p+\mathbf{D} \cdot\left(\nabla \eta_{p}\right)+\eta_{p} \nabla^{2} \vec{V}+\rho \vec{g}
$$

Uma vez definida a equação de campo de velocidades do problema hidrodinâmico, parte-se para a modelagem do problema do campo eletromagnético. $\mathrm{O}$ acoplamento destes dois campos ocorre através da viscosidade plástica $\eta_{p}$.

Como a viscosidade aparente depende da densidade de fluxo magnético $B$, é preciso recorrer às equações de Maxwell do eletromagnetismo. Para o problema em análise, é adotado a premissa de campos de "baixa" frequiência, que é o método frequentemente utilizado em análises de máquinas elétricas. Quando o comprimento de onda das ondas eletromagnéticas é muito maior do que o tamanho do domínio do problema, as mudanças do campo elétrico com respeito ao tempo podem ser ignoradas. A condição geral para esta simplificação é:

$$
f<<\frac{C}{l_{\max }}
$$

onde $f$ é a frequiência de operação (em Hz), $C$ é a velocidade da luz (em $\mathrm{m} / \mathrm{s})$, e $l_{\text {max }}$ é a maior dimensão (em metros) no domínio do problema.

Com esta simplificação admite-se que o campo elétrico não tem efeito sobre o campo magnético (o que normalmente ocorre em altas frequiências), enquanto que o campo magnético pode afetar o campo elétrico. Desta forma, apesar da variação no tempo do campo elétrico ser ignorada, esta formulação ainda permite o aparecimento de forças eletromotrizes $\left(f_{e m}\right)$ induzidas, o que é comum em transformadores e motores de indução. No caso dos dispositivos MR, a $f_{e m}$ é responsável pela geração de correntes parasitas no núcleo magnético destes dispositivos, e que pode contribuir com a redução de sua eficiência. Contudo esta questão não faz parte do escopo deste trabalho. 
A descrição do problema eletromagnético começa pela equação a seguir:

$$
\vec{B}=\nabla \times \vec{A}
$$

onde $\vec{A}$ é por definição o potencial vetor magnético (HAYT, 1981).

Conhecidas a relação $\vec{B}=\mu_{0} \mu_{r} \vec{H}$ e a lei circuital de Ampère na forma pontual $\nabla \times \vec{H}=\vec{J}$, pode-se construir a seguinte relação:

$$
\frac{1}{\mu_{0}} \nabla \times\left(\frac{1}{\mu_{r}(\vec{B})} \nabla \times \vec{A}\right)=\vec{J}
$$

onde $\mu_{0}=4 \pi \times 10^{-7}$ é a permeabilidade magnética do vácuo, $\mu_{r}$ é a permeabilidade relativa do meio, $J=|\vec{J}|$ compõe-se da densidade de corrente elétrica na bobina $\left(J_{w}\right)$ mais a densidade de correntes parasitas no núcleo magnético $\left(J_{e}\right)$. A densidade de corrente na bobina, $J_{w}$, depende da tensão $(v)$ aplicada e dos parâmetros do circuito elétrico, como a resistência $(R)$ e a indutância $(L)$, como se segue:

$$
v=R \cdot \frac{\left(J_{w} \cdot S\right)}{N}+\frac{d \phi}{d t}=R \cdot i+\frac{d(L \cdot i)}{d t}
$$

onde, $S$ é a área da seção da bobina $\left(J_{w}=N \cdot i / S\right), N$ é o número de espiras, $\phi$ é o fluxo magnético total no núcleo, e $L$ é a indutância, que não é constante e é dependente da corrente na bobina $(i)$, pois em correntes elevadas pode ocorrer a saturação do núcleo ferromagnético, situação que leva a uma diminuição da indutância. A capacitância do circuito pode ser despresada neste caso, pois somente seria importante em altas freqüências. Por sua vez, a densidade de corrente $\vec{J}_{e}$ pode ser escrita como:

$$
\vec{J}_{e}=\sigma \cdot \vec{E}
$$

onde $\sigma$ é a condutividade do material do núcleo magnético (dada em $\mathrm{S} / \mathrm{m}$ ), e $\vec{E}$ é o campo elétrico, o qual surge no núcleo em função da lei experimental de Faraday (HAYT, 1981): 


$$
\nabla \times \vec{E}=-\frac{\partial \vec{B}}{\partial t}
$$

A equação (2.24) pode ser desenvolvida da seguinte forma:

$$
\nabla \times \vec{E}=-\frac{\partial(\nabla \times \vec{A})}{\partial t}=-\nabla \times\left(\frac{\partial \vec{A}}{\partial t}\right) \Rightarrow \vec{E}=-\frac{\partial \vec{A}}{\partial t}
$$

Desta forma o $2^{\mathrm{o}}$ membro da eq. (3.15) pode ser reescrito da seguinte forma:

$$
\frac{1}{\mu_{0}} \nabla \times\left(\frac{1}{\mu_{r}(\vec{B})} \nabla \times \vec{A}\right)=J_{w}-\sigma \frac{\partial \vec{A}}{\partial t}
$$

Como, na equação (3.15), $\mu_{r}$ é dependente da posição, porque as regiões de saturação do núcleo nem sempre são distribuídas de forma homogênea, este parâmetro não pode ser colocado fora do rotacional.

Em geral a permeabilidade magnética relativa $\mu_{r}$, a condutividade $\sigma$ (na região onde ocorrem as correntes parasitas), a resistência da bobina e a viscosidade dinâmica do fluido são funções da temperatura. Portanto, é preciso descrever como é a distribuição da temperatura, que decorre do balanço de energia do sistema (POTTER e WIGGERT, 1997), conforme a equação:

$$
\rho \cdot c_{p} \frac{D \theta}{D t}=K \nabla^{2} \theta+\Phi
$$

onde $\theta$ é a temperatura, $\rho$ é a massa específica, $c_{p}$ é o calor específico, $K$ é a condutividade térmica, e $\Phi$ é a função dissipação, que é descrita a seguir: 


$$
\Phi= \begin{cases}J_{w}^{2} / \sigma_{b} & \text {, para a bobina. } \\ J_{e}^{2} / \sigma & , \text { para a região de correntes parasitas. } \\ \frac{\eta_{p}}{2} \cdot\|\mathbf{D}\|_{\mathrm{F}}^{2} & , \text { para o fluido MR, onde }\|\bullet\|_{F} \text { é a norma de Frobenius. }\end{cases}
$$

Quando se analisa o desempenho de um dispositivo MR, as equações (3.12), (3.16), (3.20) e (3.21), descrevendo os fenômenos eletromagnético, hidrodinâmico e termodinâmico, devem ser resolvidas em conjunto com a equação da dinâmica de seus elementos móveis, e sujeitos a forças externas. Esta equação resulta da aplicação da $2^{\mathrm{a}}$ Lei de Newton, e sua forma depende muito do tipo de dispositivo MR, isto é, se é um amortecedor, ou um freio, por exemplo. A forma de cálculo da parcela de força referente à ação eletromagnética sobre o fluido MR também depende do tipo de dispositivo, podendo ser uma integral das tensões agindo sobre o fluido em uma determinada área, ou uma integral do diferencial de pressão gerado por um escoamento forçado numa determinada área.

\subsubsection{SIMPLIFICAÇÕES DO FENÔMENO ACOPLADO}

As equações (3.12), (3.16), (3.20) e (3.21) que descrevem o fenômeno acoplado desenvolvidas até aqui são bastante genéricas e aplicáveis a uma ampla gama de problemas baseados em qualquer sistema de coordenadas inercial, seja ele retangular, cilíndrico ou esférico. Estas equações descrevem o fenômeno de forma aproximada já que as seguintes hipóteses foram admitidas:

- O fluido MR é considerado um meio contínuo;

- Todas as variáveis de interesse são diferenciáveis;

- O fluido MR é considerado incompressível, isotrópico e homogêneo;

- O escoamento na região de interesse não apresenta vórtices;

- O fluido MR apresenta um comportamento quasi-newtoniano sem a presença de um campo magnético;

- As variações de $\eta, c_{p}$ e $K$ com a temperatura de trabalho do dispositivo MR podem ser desprezadas. 
Contudo a formulação apresentada ainda está longe de ser aplicável de forma prática e outras hipóteses precisam ser admitidas. Neste sentido, vai se considerar que o campo magnético é aplicado sobre o fluido MR de forma uniforme e que o escoamento do fluido nesta região de aplicação do campo magnético seja permanente e unidirecional, sendo as linhas de correntes perpendiculares às linhas de campo magnético e paralelas às paredes da região de escoamento. Então, fazendo-se algumas considerações adicionais, podem-se adotar as seguintes simplificações:

- A viscosidade aparente $\eta$ e a permeabilidade relativa $\mu_{r}$ do fluido MR passam a ser constantes ao longo da região de interesse;

- Supondo um fluxo do fluido apenas na direção " $x$ ”, o vetor de velocidades simplificase para, por exemplo, $\vec{V}^{T}=\left\{\begin{array}{lll}u & 0 & 0\end{array}\right\}$;

- Admite-se que o escoamento está totalmente desenvolvido na região de interesse, portanto $\partial u / \partial x=0$;

- Como o escoamento é permanente tem-se que $\partial u / \partial t=0$, e considerando as duas hipóteses acima, pode-se admitir a derivada substancial de $\vec{V}$ nula;

- Considera-se que o fluxo de calor está em regime permanente, isto é, $\partial \theta / \partial t=0$;

- A variação da indutância em função da saturação magnética do núcleo e do fluido pode ser desprezada;

- A ação da aceleração da gravidade sobre a massa de fluido na região de interesse pode ser desprezada.

Com estas simplificações as equações do fenômeno acoplado podem ser reescritas da seguinte forma:

$$
\begin{aligned}
& \text { Eq. (3.12) } \Rightarrow \nabla p=\eta_{p} \nabla^{2} \vec{V} \\
& \text { Eq. (3.20) } \Rightarrow \frac{1}{\mu_{0} \mu_{r}} \nabla \times \nabla \times \vec{A}=\frac{1}{\mu_{0} \mu_{r}}\left(\nabla(\nabla \cdot \vec{A})-\nabla^{2} \vec{A}\right)=J_{w}-\sigma \frac{\partial \vec{A}}{\partial t} \\
& \text { Eq. (3.16) } \Rightarrow v=R \cdot i+L \cdot \frac{d i}{d t} \\
& \text { Eq. (3.21) } \Rightarrow K \nabla^{2} \theta=-\Phi
\end{aligned}
$$


Admitindo-se uma condição estática de corrente elétrica $(\nabla \cdot A=0)$ e material magnético isotrópico no núcleo magnético, a equação (3.15) pode ser simplificada para $v=R \cdot i$, e a equação (3.24) também pode ser simplificada para:

$$
-\frac{1}{\mu_{0} \mu_{r}} \nabla^{2} \vec{A}=J_{w}
$$

e pode ser resolvida facilmente aplicando-se o Método de Elementos Finitos (MEF) para problemas magnetostáticos. Como, em geral, o problema apresenta um circuito magnético fechado, admite-se que numa região suficientemente afastada do circuito magnético em análise o vetor $\vec{A}$ é muito próximo de zero, e portanto pode-se utilizar a condição de contorno de Dirichlet $(\vec{A}=\overrightarrow{0})$.

Pode-se conseguir maior simplificação do modelo a partir da adoção deste conceito de dispositivo, e assim se buscar um melhor entendimento do comportamento do fluido MR num escoamento permanente sob campo magnético constante.

Como o interesse maior deste trabalho está nos amortecedores MR, e estes dispositivos, em geral, apresentam uma construção onde o fluido MR é forçado a passar por um duto anelar (figura 3.3), pode-se conseguir maior simplificação do modelo a partir da adoção deste conceito de dispositivo, e assim se buscar um melhor entendimento do comportamento do fluido MR num escoamento permanente sob campo magnético constante.

Conforme o esquema apresentado na figura 3.3, o fluido MR escoa entre duas paredes cilíndricas, sendo a parede interna fixa e a externa móvel em relação a um referencial inercial, e o campo magnético é homogêneo nesta passagem anelar, cortando perpendicularmente as linhas de corrente de velocidade do fluido. O problema pode ser analisado sob simetria axial, onde a velocidade do fluido é não nula apenas na direção $x$ e somente a tensão de cisalhamento $\tau_{r x}$ é diferente de zero. 


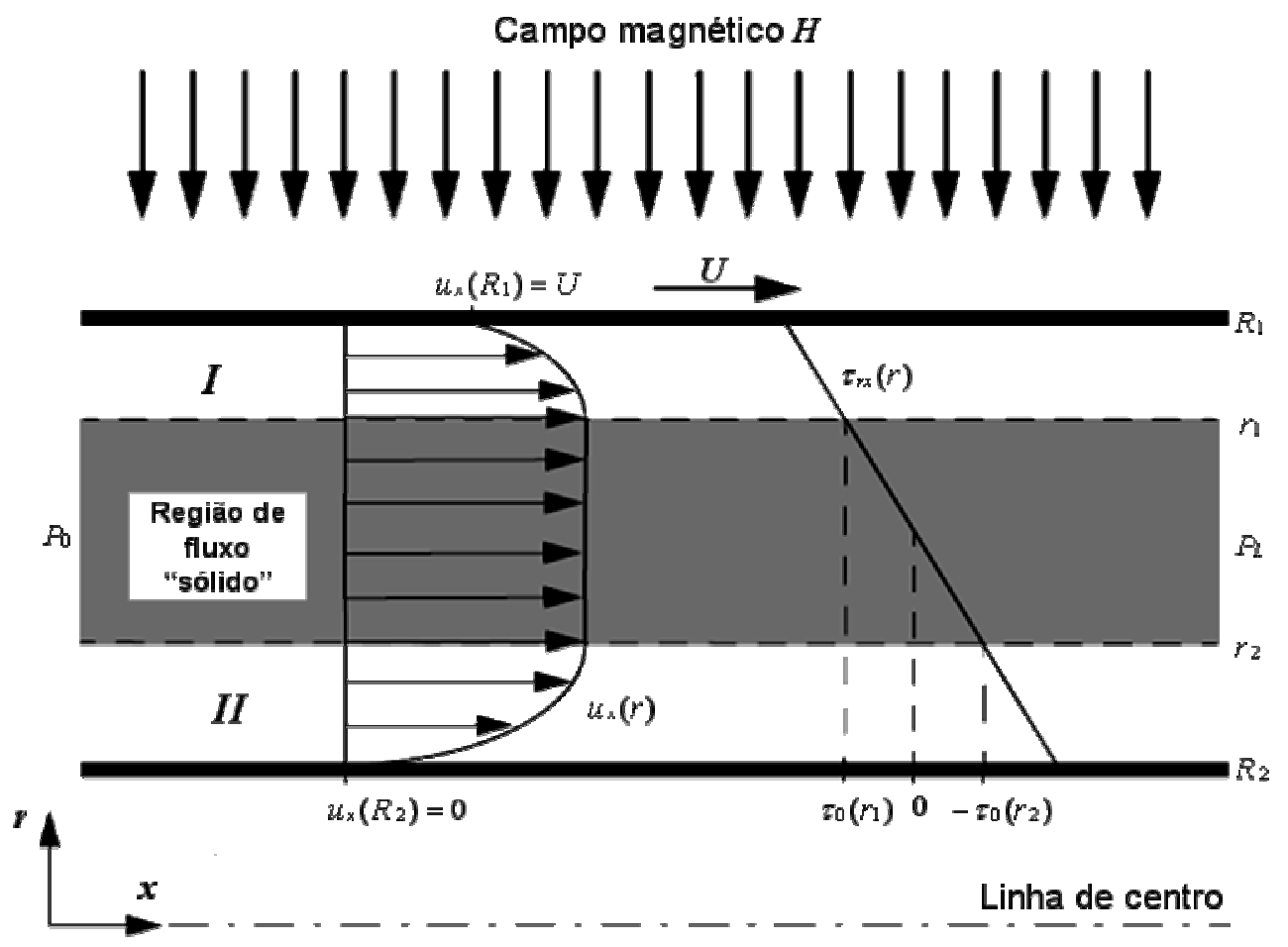

Figura 3.3 - Perfil de velocidades e tensões num duto anelar.

Segundo este conceito de dispositivo e considerando um sistema de coordenadas cilíndrico $^{19}$, a equação (3.23) pode ser simplificada para:

$$
\frac{d p}{d x}=\eta_{p} \cdot \frac{1}{r} \cdot \frac{d}{d r}\left[r \cdot \frac{d}{d r} u_{x}(r)\right]
$$

Conforme a figura 3.3, a tensão de cisalhamento $\tau_{r x}$ é máxima junto às paredes e diminui em direção ao centro do escoamento. Esta situação permite a formação de uma região de fluxo "sólido", isto é, uma região central onde a tensão de cisalhamento é inferior a tensão mínima para deformação do fluido MR.

Segundo o modelo de amortecedor MR da figura 3.3, a força gerada por este dispositivo pode ser calculada da seguinte forma:

$$
F=\Delta p \cdot A_{p}=\left(P_{L}-P_{0}\right) \cdot A_{p}=\frac{d p}{d x} \cdot L \cdot A_{p}
$$

\footnotetext{
${ }^{19}$ Para esta representação foi adotado um sistema de coordenadas cilíndricas ( $\mathrm{r}, \theta, \mathrm{x}$ ). Foi utilizado a utilizada a nomenclatura " $\mathrm{x}$ " ao invés do tradicional " $\mathrm{z}$ " para tornar mais simples a comparação do modelo axissimétrico com o modelo bidimensional.
} 
onde $\Delta p$ é a diferença de pressão entre os dois lados do pistão, $L$ é o comprimento efetivo do canal, e $A_{p}$ é a área da seção transversal do pistão do amortecedor.

Em geral, a tensão de escoamento do fluido, $\tau_{0}(\vec{B})$, no modelo axissimétrico é uma função de " $r$ ". Contudo, conforme o trabalho de Spencer et al. (1998), quando $\left(R_{1}-R_{2}\right)<<R_{2}$, a variação da tensão de escoamento no canal pode ser ignorada, e as equações do modelo podem ser substancialmente simplificadas.

Neste caso pode-se adotar um modelo de fluxo de fluido entre duas placas paralelas de largura infinita e comprimento $L$, as quais são atravessadas perpendicularmente por um campo magnético $H$ uniforme, conforme a figura 3.4. A distância entre as placas é definida como $g=R_{1}-R_{2} \quad$ (ou $g=Y_{1}-Y_{2}$ conforme a figura 3.4), e para fins de cálculo da vazão volumétrica $(Q)$ e para se manter uma analogia com o modelo axissimétrico é definida uma largura $(w)$ do novo duto equivalente à circunferência média do canal anelar, que é calculada por $w=\pi\left(R_{1}+R_{2}\right)$.

Nesta nova condição a equação (3.28) pode ser simplificada como se segue:

$$
\frac{\partial^{2} u}{\partial y^{2}}=\left\{\begin{array}{lll}
0 & \text { para } & \tau_{\mathrm{yx}} \leq\left|\tau_{0}(\vec{B})\right| \\
\frac{1}{\eta_{p}} \cdot \frac{\partial p}{\partial x} & \text { para } & \tau_{\mathrm{yx}}>\left|\tau_{0}(\vec{B})\right|
\end{array}\right.
$$

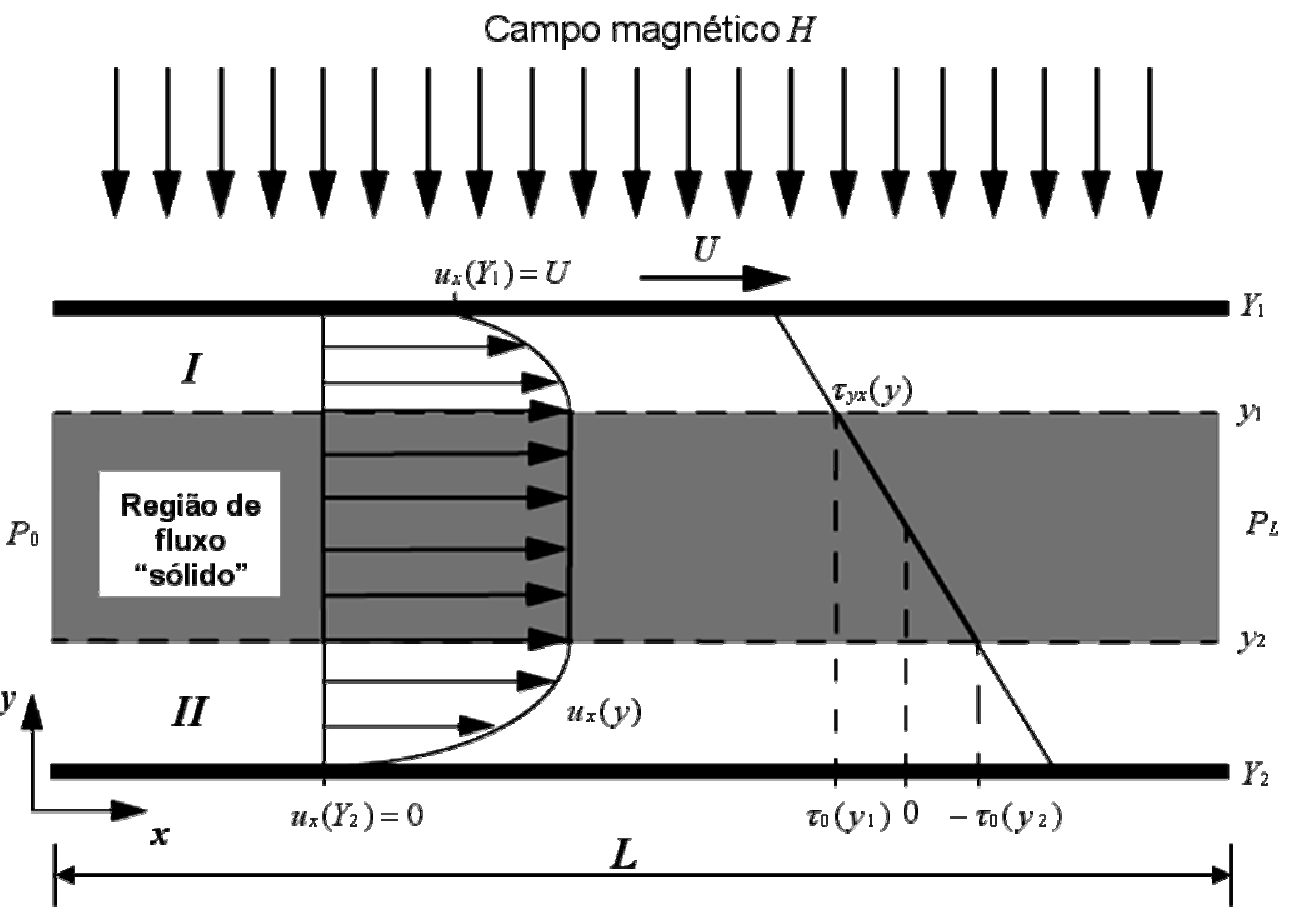

Figura 3.4 - Perfil de velocidades e tensões num fluxo entre placas paralelas. 
A equação (3.30) mostra que o campo de velocidades na região de escoamento "sólido" $\left(\tau_{y x}<\tau_{0}(\vec{B})\right)$ é constante, e divide o escoamento em outras duas regiões, I e II, conforme a figura 3.4. Considerando-se a natureza da viscosidade plástica $\eta_{p}$, que é composta por uma parcela independente e por outra dependente do campo magnético, a equação (3.30) pode ser reescrita da seguinte forma:

$$
\frac{d p}{d x}=\eta \cdot \frac{d^{2} u}{d y^{2}}+\frac{\tau_{0}(\vec{B})}{|d u / d y|} \frac{d^{2} u}{d y^{2}}
$$

A equação (3.31) aplica-se apenas às regiões I e II. Através desta construção, o diferencial de pressão pode ser analisado separadamente em cada uma das parcelas, como segue:

$$
\frac{d p}{d x}=\frac{d p_{\eta}}{d x}+\frac{d p_{\tau}}{d x} \Rightarrow\left\{\begin{array}{l}
\frac{d p_{\eta}}{d x}=\eta \cdot \frac{d^{2} u}{d y^{2}} \quad \text { para as regiões I e II } \\
\frac{d p_{\tau}}{d x}=\frac{\tau_{0}(\vec{B})}{|d u / d y|} \frac{d^{2} u}{d y^{2}} \Rightarrow \begin{cases}\frac{d p_{\tau}}{d x}=\tau_{0}(\vec{B}) \cdot \frac{d u}{d y} & \text { para a região I } \\
\frac{d p_{\tau}}{d x}=-\tau_{0}(\vec{B}) \cdot \frac{d u}{d y} & \text { para a região II }\end{cases}
\end{array}\right.
$$

Para se encontrar uma solução para as equações diferenciais (3.32), pode-se admitir numa primeira análise que $\tau_{0}(\vec{B})=0$, de forma que não exista a região de fluxo "sólido", e calcular apenas a parcela do diferencial de pressão que representa o efeito do atrito viscoso, $d p_{\eta} / d x$. Como nesta parcela, o primeiro membro é apenas uma função de $x$, e o segundo membro é apenas uma função de $y$, pode-se ter a seguinte relação:

$$
\frac{d^{2} u}{d y^{2}}=\frac{1}{\eta} \cdot \frac{d p_{\eta}}{d x} \Rightarrow \frac{d^{2} u}{d y^{2}}=k_{0}
$$


em que $k_{0}$ é uma constante, já que $x$ e $y$ são variáveis independentes. Considerando a mesma condição, a equação (3.33) pode ser integrada duas vezes para resultar na função que descreve a velocidade um em cada ponto da direção y.

$$
u(y)=\frac{\kappa}{2} \cdot y^{2}+k_{1} \cdot y+k_{2} \quad \text { dado } \quad \tau_{0}(\vec{B})=0
$$

onde $k_{1}$ e $k_{2}$ são constantes de integração arbitrárias. Neste caso as condições de contorno para este escoamento são $u\left(Y_{1}=g\right)=U$ e $u\left(Y_{2}=0\right)=0$, e calculam-se as constantes de integração da seguinte forma:

$$
\left\{\begin{array}{l}
u(0)=k_{2}=0 \\
u(g)=\frac{k_{0}}{2} \cdot g^{2}+k_{1} \cdot g=U \Rightarrow k_{1}=\frac{U}{g}-\frac{k_{0} \cdot g}{2}
\end{array}\right.
$$

Utilizando os resultados obtidos acima, pode-se escrever a expressão para a distribuição de velocidades entre as duas placas paralelas com velocidade relativa $U$ como segue:

$$
u(y)=\frac{1}{2 \eta} \cdot \frac{d p_{\eta}}{d x} \cdot\left(y^{2}-g \cdot y\right)+\frac{U \cdot y}{g}
$$

A partir dessa expressão, é possível se calcular a vazão no duto, como sendo:

$$
Q=\int u d S=w \cdot \int_{o}^{g}\left[\frac{1}{2 \eta} \cdot \frac{d p_{\eta}}{d x} \cdot\left(y^{2}-g \cdot y\right)+\frac{U \cdot y}{g}\right] d y=-\frac{w g^{3}}{12 \eta} \cdot \frac{d p_{\eta}}{d x}+\frac{U w g}{2}
$$

Em seguida, calcula-se a queda de pressão, utilizando o fato de que $d p / d x$ é constante para um escoamento totalmente desenvolvido:

$$
-\frac{d p_{\eta}}{d x}=\frac{12 \eta Q}{w g^{3}} \cdot\left(1-\frac{U w g}{2 Q}\right) \cong \frac{p_{L}-p_{0}}{L}=\frac{\Delta \mathrm{p}_{\eta}}{L}
$$


onde $L$ é o comprimento do duto entre as duas placas paralelas. Conforme a equação (3.29) e o resultado da equação (3.38), a força do amortecedor devido apenas à viscosidade $\left(\tau_{0}(\vec{B})=0\right)$ pode ser calculada como:

$$
F_{\eta}=\Delta \mathrm{p}_{\eta} \cdot A_{p}=\left(1-\frac{w g U}{2 Q}\right) \cdot \frac{12 \eta Q L}{w g^{3}} \cdot A_{p}
$$

Voltando à equação (3.32) e admitindo que $\tau_{0}(\vec{B})>0$, dado por um valor de tensão de escoamento já estabelecido e permanente $\tau_{0}(\vec{B})=\hat{\tau}_{0}$, por exemplo. Nesta situação há a formação da região central, chamada de escoamento "sólido", onde o campo de velocidade do fluido é constante na direção y e unidirecional. Admitindo também que a vazão Q seja a mesma do caso que foi analisado anteriormente, obtem-se à seguinte solução para a equação (3.32), considerando-se as novas condições:

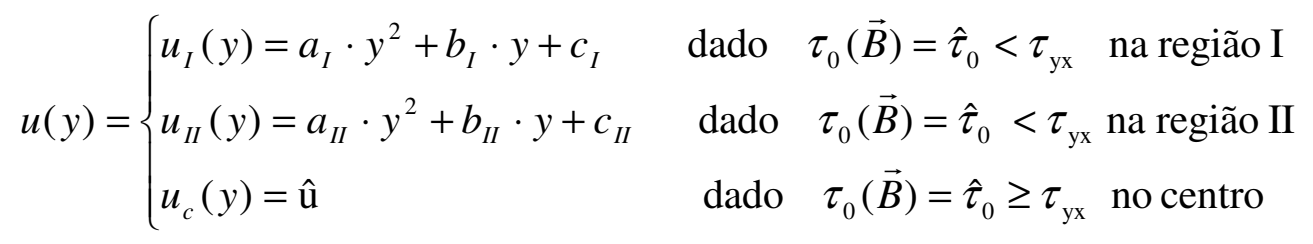

Neste caso, para determinar o perfil de velocidades do escoamento é preciso determinar nove incógnitas: $a_{I}, b_{I}, c_{I}, a_{I I}, b_{I I}, c_{I I}, y_{1}, y_{2}, \hat{\mathrm{u}}$. Para se resolver este problema são necessárias nove equações, das quais oito resultam das condições de contorno apresentadas a seguir:

$$
\left\{\begin{array}{l}
u_{I I}(0)=0 \\
u_{I}(g)=U \\
u_{I}\left(y_{1}\right)=u_{I I}\left(y_{2}\right)=\hat{\mathrm{u}} \\
\frac{d}{d y} u_{I I}(0)=\frac{d}{d y} u_{I}(g) \\
\frac{d}{d y} u_{I}\left(y_{1}\right)=0 \\
\frac{d}{d y} u_{I I}\left(y_{2}\right)=0 \\
Y_{1}-y_{1}=y_{2}-Y_{2}
\end{array}\right.
$$

A nona equação vem da expressão para o cálculo da vazão volumétrica: 


$$
Q=\int u d S=w \cdot\left[\int_{0}^{y_{2}}\left(a_{I} \cdot y^{2}+b_{I} \cdot y+c_{I}\right) d y+\int_{y_{2}}^{y_{1}} \hat{\mathrm{u}} d y+\int_{y_{1}}^{g}\left(a_{I I} \cdot y^{2}+b_{I I} \cdot y+c_{I I}\right) d y\right]
$$

Assim é possível encontrar uma solução para cada valor de $\tau_{0}(\vec{B})>0$, de tal forma que se chega a uma solução para o escoamento.

Segundo Wereley e Pang ${ }^{20}$ (1998) apud Yoo e Wereley (2002), para um perfil de velocidade típico, conforme ilustrado na figura 3.4, o valor da vazão $Q$ segue a seguinte expressão:

$$
Q=-\frac{w g^{3}}{12 \eta L_{a}} \cdot(1-\delta)^{2} \cdot\left(1+\frac{\delta}{2}\right) \cdot \Delta P
$$

onde $\delta=\left(y_{1}-y_{2}\right) / g$ é a espessura adimensional do fluxo "sólido" de fluido MR e $L_{a}$ é o comprimento ativo da válvula MR, ou seja, é o comprimento da região onde o fluido está exposto ao campo magnético. O valor de $\delta$ varia desde zero, quando $\tau_{0}(\vec{B})=0$ e o escoamento é newtoniano, até um, quando a válvula MR está totalmente bloqueada. Com o cálculo de $\delta$ a partir de dados experimentais é possível se ter uma avaliação da eficiência da válvula MR; que será tão melhor quanto mais próximo de 0 e 1 , o valor de $\delta$ estiver alcançando.

Como uma solução para a queda de pressão na válvula MR sob a ação de um campo magnético, Spencer et al. (1998) apresentam a seguinte relação:

$$
-\frac{d p_{\tau}}{d x}=\mathrm{c} \cdot \frac{\tau_{0}(\vec{B})}{g}=\frac{\Delta \mathrm{p}_{\tau}}{L_{a}}
$$

onde $c$ é implicitamente governada pela solução do escoamento quando $\tau_{0}(\vec{B})>0$, e varia conforme a relação $\lambda=\Delta p_{\tau} / \Delta p_{\eta}$. Para o intervalo $0<\lambda<1000$, que compreende a maioria dos projetos de dispositivos, $c$ pode ser aproximado com uma margem de erro de $3 \%$ pela expressão:

\footnotetext{
${ }^{20}$ Wereley, N. M.; Pang, L. Nondimensional analisys of semi-active eletrorheological and magnetorheological dampers using approximate parallel plate models. Smart Materials and Structures, v. 7, n. 5, p. 732-743, 1998.
} 


$$
c=2,07+\frac{1}{1+0,4 \cdot \lambda}
$$

Assim a força gerada no dispositivo MR devido exclusivamente ao efeito do campo magnético sobre o fluido é:

$$
F_{\tau}=\mathrm{c} \cdot \frac{\tau_{0}(\vec{B}) \cdot L_{a} \cdot A_{p}}{g}
$$

O resultado da força total que pode ser gerada pelo dispositivo MR, destacando a margem de força que pode ser controlada pelo campo magnético, é apresentado no gráfico da figura 3.5 .

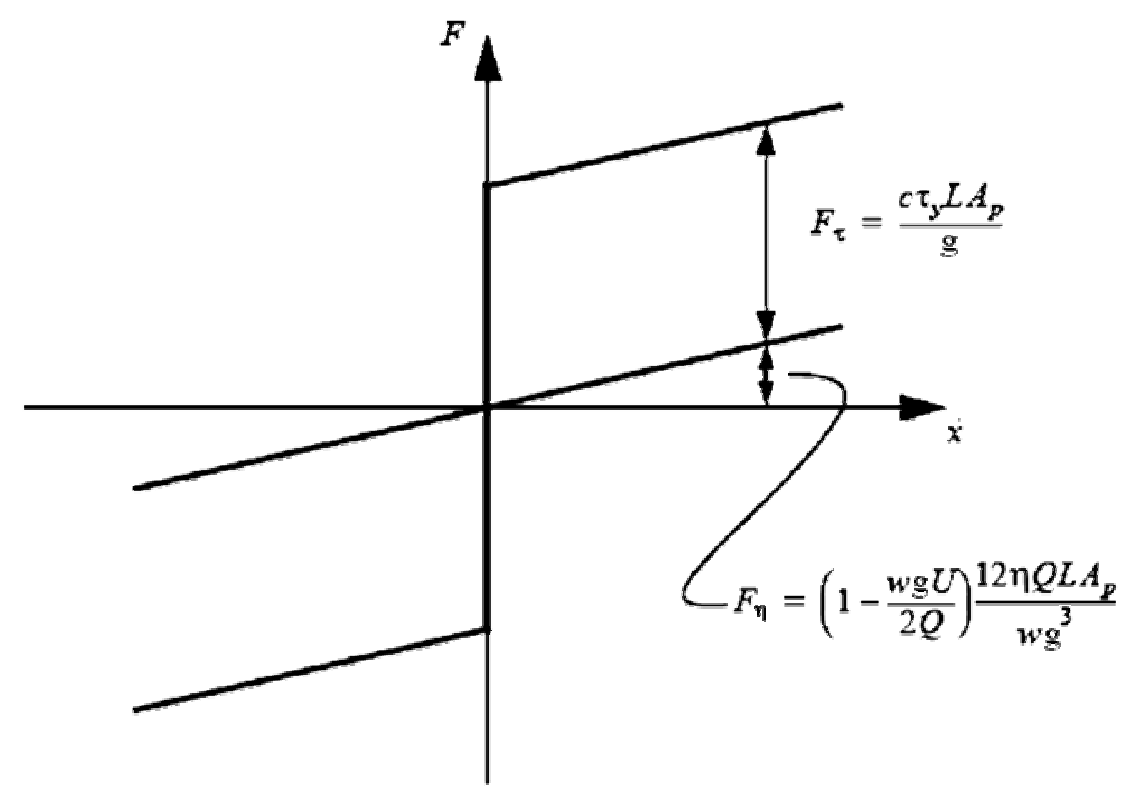

Figura 3.5 - Ilustração da margem de força controlável num amortecedor MR.

\subsubsection{MODELOS PRÁTICOS}

Como um dos objetivos deste trabalho é definir um procedimento sistemático e prático de projeto de dispositivos MR, é necessário que os projetos baseiem-se em fórmulas simples, porém que sejam suficientes para o dimensionamento correto destes dispositivos, dados um conjunto de metas e restrições de projeto. Como resultado das análises feitas até aqui, é 
possível definir dois modelos práticos que são aplicáveis ao projeto da grande maioria dos dispositivos que usam fluidos MR, obtendo uma precisão aceitável. O primeiro modelo caracteriza-se pelo escoamento forçado entre duas placas paralelas fixas, onde o movimento do fluido é devido apenas ao gradiente de pressão, chamado de escoamento de Poiseuille ou modo de fluxo gerado por pressão. O outro modelo caracteriza-se pelo deslocamento relativo de duas placas paralelas, com o fluido MR entre elas, onde o movimento do fluido é devido apenas ao movimento relativo das placas, e é conhecido por escoamento de Couette ou modo de cisalhamento direto. Ilustrações destes dois modos operacionais básicos são mostradas na figura 3.6.

(a)

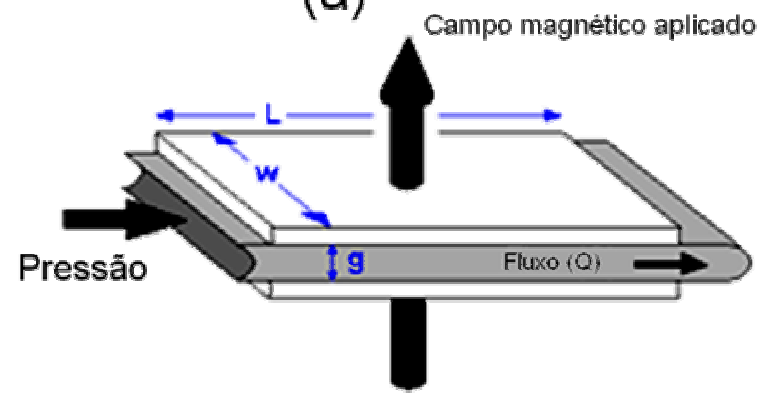

(b)

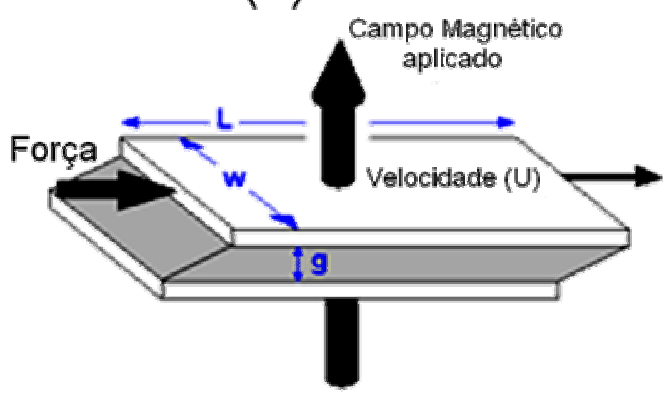

Figura 3.6 - Modos operacionais básicos para dispositivos MR: (a) modo de fluxo gerado por pressão, e (b) modo de cisalhamento direto.

De forma análoga à equação (2.1, página 36), quando $\tau>\tau_{0}$, a queda de pressão desenvolvida num dispositivo baseado no modo de fluxo gerado por pressão é comumente assumida como o resultado da soma de um componente dependente da viscosidade do fluido, $\Delta p_{\eta}$, e de um componente dependente da tensão de escoamento induzida por um campo magnético, $\Delta p_{\tau}$. Assim este diferencial de pressão pode ser aproximado por:

$$
\Delta p=\Delta p_{\eta}+\Delta p_{\tau}=\frac{12 \eta Q L}{g^{3} w}+\frac{c \tau_{0} L}{g}
$$

O parâmetro $c$ da equação (3.47) depende da relação $\lambda=\Delta p_{\tau} / \Delta p_{\eta}$ e varia conforme a equação (3.45). Tipicamente o valor da parâmetro $c$ está entre 2 (para $\lambda$ menor que 1) e 3 (para $\lambda$ maior que 100). 
Da mesma maneira, a força desenvolvida por um dispositivo no modelo de cisalhamento direto é:

$$
F=F_{\eta}+F_{\tau}=\frac{\eta S U}{g}+\tau_{0} S
$$

onde v é a velocidade relativa das placas e $S=L w$ é a área de cisalhamento da placa.

\subsection{VOLUME DE FLUIDO ATIVO E ALCANCE DINÂMICO}

Apesar das equações (3.47) e (3.48) serem úteis no projeto de dispositivos com fluido controláveis, elas freqüentemente não fornecem a melhor sugestão de valor para cada parâmetro, quando se busca o projeto mais eficiente quanto ao uso da energia. Desta forma pode-se utilizar o conceito de volume ativo mínimo de fluido $(V)$, que foi introduzido por JOLLY et al. (1998). Este é o volume de fluido MR exposto a um campo magnético e que proporciona o melhor aproveitamento do efeito magneto-reológico.

Para se chegar à formulação deste volume ativo, é preciso trabalhar algebricamente as equações (3.47) e (3.48). Inicialmente, definem-se algumas variáveis que serão utilizadas como parâmetro de projeto:

a) a razão de controle ou alcance dinâmico como sendo $\lambda=\Delta p_{\tau} / \Delta p_{\eta}$, para fluxo gerado por pressão, ou $\lambda=F_{\tau} / F_{\eta}$, para cisalhamento direto, e

b) o nível de potência mecânica controlável como sendo $W_{m}=Q \cdot \Delta p_{\tau}$, para fluxo gerado por pressão, ou $W_{m}=U \cdot F_{\tau}$, para cisalhamento direto.

Em seguida, faz-se a manipulação algébrica das parcelas da equação (3.47), e assim temse:

$$
\lambda=\frac{\Delta p_{\tau}}{\Delta p_{\eta}}=\frac{\Delta p_{\tau}}{\frac{12 \eta Q L}{g^{3} w}} \cdot \frac{\Delta p_{\tau}}{\Delta p_{\tau}}=\frac{\frac{c^{2} \tau_{0}^{2} L^{2}}{g^{2}}}{\frac{12 \eta W_{m} L}{g^{3} w}} \Rightarrow \frac{12 \lambda \eta W_{m}}{c^{2} \tau_{0}^{2}}=L g w=V
$$


De onde resulta:

$$
V=k \cdot\left(\frac{\eta}{\tau_{0}^{2}}\right) \cdot \lambda \cdot W_{m}
$$

onde $k=12 / c^{2}$.

Da mesma forma, a partir da manipulação das parcelas da expressão (3.48) chega-se a mesma expressão, porém com $k=1$. É importante notar que em ambos os casos o volume de fluido ativo mínimo é proporcional ao produto de três termos: um termo que é função das propriedades do fluido magneto-reológico $\left(\eta / \tau_{0}^{2}\right)$; outro que é a razão de controle desejada ou o alcance dinâmico $(\lambda)$; e a dissipação de potência mecânica controlável $\left(W_{m}\right)$ exigida.

Nota-se que para ambos os casos, na geometria do volume de fluido ativo, tem-se a relação $V=L w g$, portanto a equação (3.49) pode ser novamente manipulada, como segue:

$$
V=L w g=\frac{12}{c^{2}} \cdot\left(\frac{\eta}{\tau_{0}^{2}}\right) \cdot \lambda \cdot Q \cdot \Delta p_{\tau}=\frac{12 \cdot L}{g \cdot c} \cdot\left(\frac{\eta}{\tau_{0}}\right) \cdot \lambda \cdot Q
$$

De onde resulta uma equação de restrição para a situação de fluxo gerado por pressão:

$$
w g^{2}=\frac{12}{c} \cdot\left(\frac{\eta}{\tau_{0}}\right) \cdot \lambda \cdot Q
$$

Da mesma forma para a situação de cisalhamento direto, tem-se a seguinte relação:

$$
g=\left(\frac{\eta}{\tau_{0}}\right) \cdot \lambda \cdot U
$$

Assim, as equações (3.51) e (3.52) fornecem as restrições geométricas e as relações de aspecto dos dispositivos MR baseado em três informações: (a) as propriedades do fluido MR, (b) a razão de controle desejado ou alcance dinâmico, (c) e a velocidade do dispositivo ou vazão de fluido. É interessante observar que enquanto o volume ativo de fluido depende da razão entre viscosidade e tensão de escoamento ao quadrado $\left(\eta / \tau_{0}^{2}\right)$, a restrição geométrica depende da razão $\eta / \tau_{0}$. 


\subsection{FATORES DE MÉRITO}

As densidades de potência mecânica e elétrica de dispositivos MR são dadas respectivamente por:

$$
\begin{aligned}
& \hat{W}_{m}=\tau_{0} \cdot \dot{\gamma} \\
& \hat{W}_{e}=\frac{B \cdot H}{2 \cdot t_{c}}
\end{aligned}
$$

onde $\dot{\gamma}$ é a taxa de cisalhamento do fluido $\left(\dot{\gamma} \cong Q / w g^{2}\right.$ para o modo de fluxo gerado por pressão, ou $\dot{\gamma}=U / g$ para o modo de cisalhamento direto), $B$ e $H$ são respectivamente a densidade de fluxo magnético e $H$ é o campo magnético ( ambos atuando sobre o fluido MR), e $t_{c}$ é o tempo característico para o estabelecimento do campo magnético sobre o fluido.

A partir das equações (3.49), (3.53) e (3.54) é possível conceber alguns fatores de mérito úteis numa avaliação comparativa entre diferentes projetos de dispositivos MR e diferentes qualidades de fluidos MR utilizados.

O primeiro fator de mérito $\left(F_{1}\right)$ vem diretamente da equação (3.49) e está relacionado ao volume ativo de fluido:

$$
F_{1}=\frac{\tau_{0}^{2}}{\eta}
$$

O fator de mérito $F_{1}$ é inversamente proporcional ao mínimo volume ativo de fluido $(V)$ e tem a unidade de $\mathrm{Pa} / \mathrm{s}$. Maximizando este fator de mérito, minimiza-se o tamanho do dispositivo e o consumo de potência elétrica, uma vez que $W_{e}=\hat{W}_{e} \cdot V$. Este fator de mérito também reflete o alcance dinâmico de um dispositivo MR dado que, para um dado volume ativo de fluido, conforme $F_{1}$ cresce, $\lambda$ também cresce. Para aplicações sensíveis ao peso, este fator de mérito pode ser modificado de forma a penalizar a densidade do fluido $(\rho)$ :

$$
F_{2}=\frac{\tau_{0}^{2}}{\eta \cdot \rho}
$$


$\mathrm{O}$ fator de mérito $F_{2}$ é inversamente proporcional à massa ativa do fluido e tem unidade de $\mathrm{m}^{2} / \mathrm{s}^{3}$.

Relacionando-se as equações (3.53) e (3.54) chega-se à outra equação importante no projeto de dispositivos MR que é a razão entre a densidade de potência mecânica e a densidade de potência elétrica, dada pela seguinte expressão:

$$
\frac{\hat{W}_{m}}{\widehat{W}_{e}}=2 \cdot t_{c} \cdot \dot{\gamma} \cdot \frac{\tau_{0}}{B \cdot H}
$$

que está relacionada com a eficiência de transformação de potência do dispositivo MR utilizando um certo fluido MR. Da equação (3.57) pode-se conceber mais um fator de mérito $\left(F_{3}\right)$ para o projeto de dispositivos MR, dado a seguir:

$$
F_{3}=\frac{\tau_{0}}{B \cdot H}
$$

Maximizando este fator de mérito, minimiza-se o consumo de potência elétrica de um dispositivo MR para uma dada demanda de potência mecânica a uma desejada largura de banda de resposta.

Os valores típicos para estes fatores de mérito são (SPENCER et al., 1996):

$$
\begin{aligned}
F_{1} & \sim 10^{9} \mathrm{~Pa} / \mathrm{s} \\
F_{2} & \sim 10^{6} \mathrm{~m}^{2} / \mathrm{s}^{3} \\
F_{3} & \sim 0,5 \mathrm{~N} . \mathrm{m} / \text { Wb.A })
\end{aligned}
$$

Estes três fatores de mérito fornecem formas genéricas de comparação do comportamento nominal de diversos fluidos MR aplicados nos dispositivos MR. Outros fatores tais como estabilidade, durabilidade e margem de temperatura terão um impacto significativo em aplicações particulares de fluidos MR. 


\subsection{COMENTÁRIOS}

A partir deste estudo foi possível verificar que, dada a complexidade e o grande número de variáveis, o projeto de um dispositivo MR pode ser uma tarefa complicada e enfadonha e que pode demandar a construção de muitos protótipos até se chegar a uma condição satisfatória. Contudo, através das formulações práticas dos escoamentos Couette e Poiseuille e dos resultados algébricos, obtidos a partir da consideração do volume ativo de fluido e do alcance dinâmico, é possível se definir um procedimento sistemático de projeto de dispositivos MR.

O estudo do problema de acoplamento de campos que é inerente ao projeto de dispositivos MR, partindo das equações de Navier-Stokes e de Maxwell, contribuiu para o entendimento dos princípios fundamentais de funcionamento destes dispositivos, e constitui um embasamento teórico importante para futuros trabalhos nesta área.

Os fatores de mérito podem ser uma importante ferramenta de verificação do projeto, avaliando tanto o desempenho do fluido quanto a parte eletromagnética do projeto. 


\section{PROJETO E CONSTRUÇÃO DO $1^{\circ}$ PROTÓTIPO}

Esta seção descreve a sequiência de passos utilizada para o projeto do primeiro dos dois protótipos apresentados neste trabalho. Como o tema principal deste trabalho é o projeto de controle para suspensão veicular, o foco de projeto será os amortecedores MR com características voltadas para esta aplicação.

\subsection{REQUISITOS E RESTRIÇÕES DE PROJETO}

Os principais requisitos de projeto de um amortecedor MR são três, conforme descrito a seguir.

- Força máxima controlável: é a maior força que o amortecedor semi-ativo deve alcançar em sua função de filtrar as imperfeições da via e atenuar os movimentos vibratórios da carroceria do veículo devido a manobras, curvas, frenagem e aceleração.

- Alcance dinâmico: é a razão de controle do amortecedor MR, ou seja, a razão entre a força máxima controlável e a força gerada pelo atrito viscoso (força mínima), estabelecidos a uma velocidade de referência. Estes dois níveis de força estabelecem a faixa em que a força pode ser continuamente controlada pelo atuador dentro da sua condição semi-ativa.

- Tempo de resposta: é a constante de tempo de um atraso de primeira ordem que representa o comportamento dinâmico da força em reação a um degrau de tensão aplicado na válvula MR. O tempo de resposta define a largura de banda de resposta em freqüência do atuador MR.

Para este projeto será considerada uma velocidade de referência do pistão do amortecedor igual a $1 \mathrm{~m} / \mathrm{s}$. Baseada nesta condição foi definida uma força máxima controlável de $2400 \mathrm{~N}$ e uma força mínima de $430 \mathrm{~N}$. Estes valores foram assumidos como suficientes para se controlar a suspensão de um veículo com massa de aproximadamente $1000 \mathrm{~kg}$. Em Crivellaro (2003) mostra-se que estes valores limites são suficientes para uma melhoria 
significativa do conforto, utilizando-se controle semi-ativo da suspensão. Como resultado, chega-se a um alcance dinâmico $\lambda \cong 5,58$, que é a razão entre as forças máxima e mínima.

O tempo de resposta pode ser estabelecido indiretamente através da largura de banda do controlador. Segundo HROVAT (1997), para um controle de suspensão englobar tanto o controle da massa suspensa como da massa não suspensa, a largura da banda de resposta em frequiência deve ser superior a $15 \mathrm{~Hz}$. Para atender a este requisito, o tempo de resposta adotado é $T_{r}=10 \mathrm{~ms}$.

Além destes requisitos, como todo projeto de engenharia, há restrições oriundas de limitações físicas e econômicas do projeto.

As primeiras restrições são relacionadas à aplicação automobilística. A suspensão de um veículo apresenta um limite de curso ("rattle space" ou "stroke range") e um espaço físico limitado para o componente amortecedor. Em geral, o curso dos amortecedores está entre 100 e $200 \mathrm{~mm}$, o comprimento está entre 250 a $450 \mathrm{~mm}$ e a largura do tubo entre 35 e $50 \mathrm{~mm}$. Para este projeto adotou-se um curso de $120 \mathrm{~mm}( \pm 60 \mathrm{~mm})$, um comprimento de $350 \mathrm{~mm}$ (totalmente fechado) e a largura do tubo de $38 \mathrm{~mm}$.

Adotando-se o conceito monotubular de amortecedor é possível definir o comprimento máximo da válvula MR, utilizando-se as restrições acima. O esquema da figura 4.1 ilustra como definir o espaço para a válvula MR, dados o comprimento e o curso máximo do amortecedor MR.

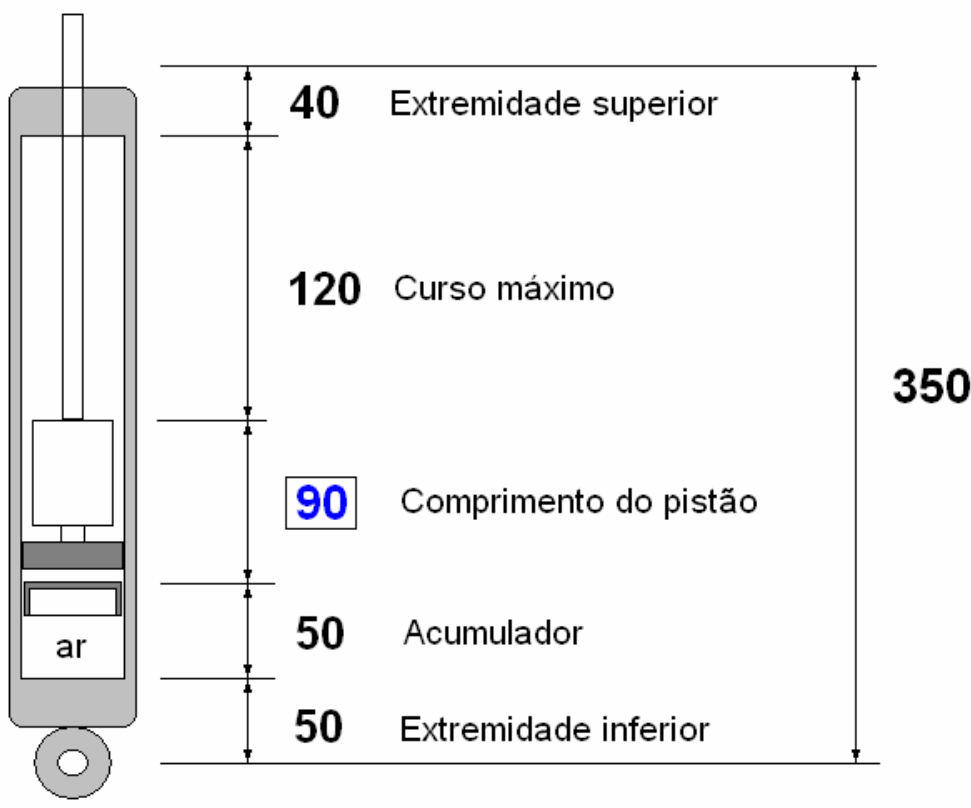

Figura 4.1 - Exemplo da divisão de espaço em um amortecedor monotubular (valores em milímetros). 
Uma restrição importante a se considerar é com relação à fonte de energia elétrica disponível nos veículos. Como a maioria dos veículos utiliza hoje sistemas de 12V/14V, o valor será adotado como restrição para o projeto do amortecedor MR será de $12 \mathrm{~V}$.

Não se pode esquecer da restrição de potência. Nos sistemas veiculares dos carros mais sofisticados do mercado, a potência média consumida por todos os subsistemas elétricos já está na casa dos 2000W (SILVA E PAULA, 2002), o que já sobrecarrega em demasia os sistemas baseados em 12V/14V. No entanto, uma das vantagens dos sistemas semi-ativos é o seu baixo consumo de potência. Desta forma, a potência de pico foi limitada em 36W para este projeto de amortecedor MR, o que resulta em uma corrente de pico de 3A. Portanto, o sistema total com quatro amortecedores MR deverá consumir em média 100W (valores RMS - "root mean square"), um pouco mais que os faróis consomem.

Outra restrição é a temperatura interna do amortecedor. Em função dos limites máximos suportados pelo fluido, elementos vedantes e a cobertura epóxi das bobinas, este valor foi estipulado em $125^{\circ} \mathrm{C}$. Associada a esta restrição está a limitação da velocidade máxima admissível para o pistão do amortecedor. Esta velocidade foi limitada a $2 \mathrm{~m} / \mathrm{s}$, o que resulta numa dissipação de potência de 4800W quando a forma máxima é gerada.

Na tabela 4.1 é apresentado um resumo de todos os valores de requisitos e restrições deste projeto.

Tabela 4.1: Resumo dos requisitos e restrições do projeto do amortecedor MR.

\begin{tabular}{|l|c|c|c|}
\hline \multicolumn{1}{|c|}{ Requisitos e Restrições } & Símbolo & Valor & Unidade \\
\hline Força máxima controlável & $F_{\max }$ & 2400 & $\mathrm{~N}$ \\
\hline Alcance dinâmico & $\lambda$ & 5,581 & --- \\
\hline Tempo de resposta & $T_{r}$ & 0,01 & $\mathrm{~s}$ \\
\hline Comprimento máximo do pistão & $L p_{\max }$ & 0,09 & $\mathrm{~m}$ \\
\hline Diâmetro externo do tubo & $d_{e x t}$ & 0,038 & $\mathrm{~m}$ \\
\hline Tensão elétrica de alimentação & $V_{c c}$ & 12 & $\mathrm{~V}$ \\
\hline Corrente elétrica de pico & $I_{p}$ & 3 & $\mathrm{~A}$ \\
\hline Temperatura interna máxima & $\theta_{\max }$ & 125 & ${ }^{\circ} \mathrm{C}$ \\
\hline Velocidade máxima do pistão & $v_{\max }$ & 2 & $\mathrm{~m} / \mathrm{s}$ \\
\hline
\end{tabular}




\subsection{ESCOLHA DO MODELO CONCEITUAL}

Para se escolher entre os dois conceitos básicos, Poiseuille ou Couette, é preciso definir qual o fenômeno é predominante no comportamento da válvula MR. No caso do amortecedor, em geral há duas opções: uma situação onde o fluido passa por um orifício anelar interno ao pistão, onde ocorre somente o modo de fluxo gerado por pressão, ou uma segunda situação onde o fluido passa entre a superfície externa do pistão e a superfície interna do tubo, onde ocorre uma situação mista dos fenômenos de fluxo gerado por pressão e cisalhamento direto.

Para a construção do protótipo, optou-se pela segunda situação devido a sua forma construtiva mais simples e devido ao diâmetro reduzido do tubo. Para que isso não trouxesse uma complicação maior de projeto, foi avaliada a contribuição de cada um dos modos para a representação do fenômeno físico, e verificou-se que as altas velocidades do fluxo do fluido na passagem entre o pistão e o tubo são muito superiores à velocidade relativa entre o pistão e o tubo. Sendo assim, o projeto considerou apenas o modo de fluxo Poiseuille, e que o erro na modelagem pode alcançar até $5 \%$ das forças resultantes da passagem do fluido pelo pistão.

É claro que se pode considerar nesta fase uma modelagem mais complexa, considerando o efeito dos dois modos em conjunto, contudo como este trabalho busca um processo de projeto prático, optou-se por seguir o caminho de maior simplicidade, porém ciente dos erros gerados por esta simplificação.

\subsection{ESCOLHA DO FLUIDO MR}

Conforme Carlson et al. (1999), o fluido magneto-reológico é tanto melhor para uma aplicação em um amortecedor MR quanto maior "alcance dinâmico" ele proporcionar. Para isso, em geral é mais vantajoso ter-se um fluido com menor viscosidade aparente do que maior tensão de limite de escoamento (vide Anexo A).

Assim, segundo esse critério, pesquisando-se vários tipos de fluidos MR (LORD, 2001a, 2001b, 2001c), a melhor opção foi o MRF-132AD, que apresenta uma razoável tensão de limite de escoamento quando sob a ação de um campo magnético, e uma baixa viscosidade aparente na temperatura de trabalho do amortecedor. 
A escolha do fluido também envolve a questão de se utilizar fluidos MR constituídos de pós moles ou duros ${ }^{21}$. Os pós moles conferem uma maior susceptibilidade magnética ao fluido, o que resulta numa maior tensão de escoamento comparado aos pós mais duros, para um dado campo magnético. Por outro lado, um fluido MR constituído por pós mais duros apresenta maior durabilidade. O fluido MRF-132AD apresenta um índice $\mathrm{LDE}^{22}$ de aproximadamente $10^{7} \mathrm{~J} / \mathrm{cm}^{3}$, que representa um excelente desempenho em durabilidade.

Um fluido com pós moles pode levar a uma maior saturação no circuito magnético da válvula MR, por apresentar uma maior permeabilidade magnética. Uma maior saturação do núcleo magnético da válvula resulta num campo magnético de menor intensidade sobre o fluido. Este também é um fator importante a se considerar, e que pode ser estudado a partir de análises magnetostáticas realizadas através do método dos elementos finitos (MEF).

\subsection{CÁlCULO DE PARÂMETROS BÁSICOS}

Para a aplicação das formulações da seção 3.2, é necessário o cálculo de mais dois parâmetros adicionais, a vazão volumétrica $(Q)$, o diferencial de pressão controlável $\left(\Delta P_{\tau}\right)$ e a potência mecânica controlável $\left(W_{m}\right)$, dependentes da velocidade do pistão. O importante neste cálculo é manter a mesma velocidade (v) de referência para o pistão (1 m/s), usada para definir os requisitos de força máxima controlável $\left(F_{\max }\right)$ de $2400 \mathrm{~N}$ e a força mínima $\left(F_{\min }\right)$ de $430 \mathrm{~N}$.

Para o cálculo da vazão volumétrica, utiliza-se a área interna da seção transversal do tubo menos a área da seção transversal da haste. Assumindo a parede do tubo de $3 \mathrm{~mm}$, temse uma área resultante $A \cong 6,8 \cdot 10^{-4} \mathrm{~m}^{2}$. Assim, a vazão e a potência mecânica controlável podem ser calculadas conforme segue.

$$
\begin{aligned}
& Q=A \cdot \mathrm{v} \cong 6,8 \cdot 10^{-4} \frac{\mathrm{m}^{3}}{\mathrm{~s}} \\
& \Delta P_{\tau}=\frac{F_{\max }-F_{\min }}{A} \cong 2,98 \mathrm{MPa} \\
& W_{m}=\Delta P_{\tau} \cdot Q \cong 2400 \text { Watts }
\end{aligned}
$$

\footnotetext{
${ }^{21}$ Vide apêndice D.

${ }^{22}$ Vide apêndice $\mathrm{C}$.
} 


\subsection{DEFINIÇÃO DA MAGNETIZAÇÃO MÁXIMA DO FLUIDO}

O próximo passo é definir o ponto de máxima magnetização do fluido magnetoreológico. Para isso é necessário que sejam conhecidas a viscosidade $(\eta)$ e a tensão de escoamento $\left(\tau_{y}\right)$ em função da taxa de cisalhamento $\left(\dot{\gamma} \approx Q / w g^{2}\right)$ e em função do campo magnético, respectivamente. Estas informações podem ser obtidas através de testes em laboratório utilizando um reômetro equipado com gerador de campo magnético, ou através das especificações técnicas fornecidas pelo fabricante do fluido MR. Além disso, estas propriedades do fluido (a viscosidade, em particular) dependem da temperatura. Assim, o projetista deve ter em mente que precisa saber sob que condições o dispositivo vai operar. Para um amortecedor automotivo pode-se considerar uma temperatura de trabalho entre 70 e $100^{\circ} \mathrm{C}$.

Para dar continuidade aos cálculos é preciso obter a viscosidade $(\eta)$ e a sua tensão de escoamento $\left(\tau_{0}\right)$ para a situação de máxima magnetização, identificando através das curvas fornecidas pelo fabricante do fluido o campo magnético $(\mathrm{H})$ e a densidade de fluxo magnético (B) nesta situação.

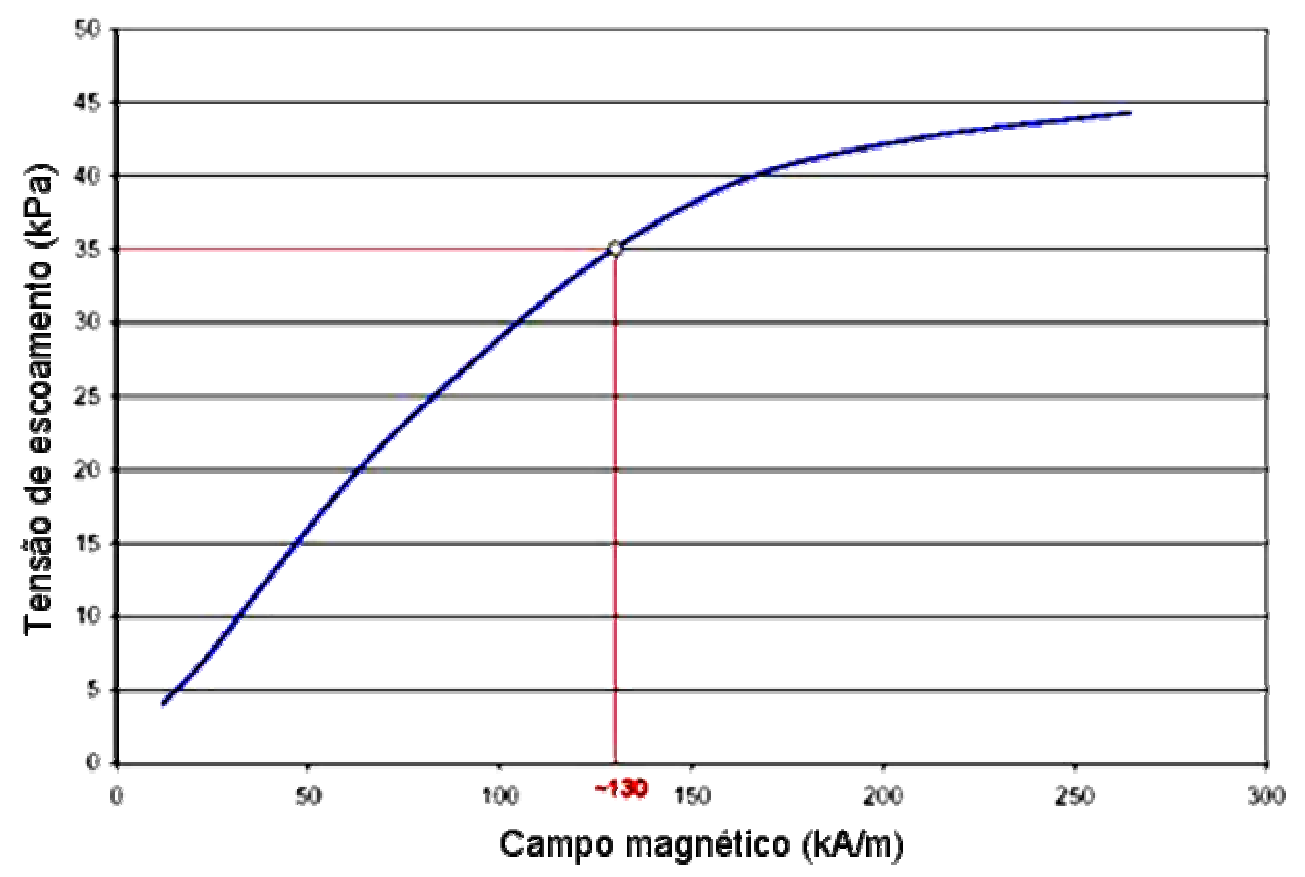

Figura 4.2 - Gráfico do "Product Bulletin" do fluido MRF-132AD 
Para estes cálculos foram utilizados os gráficos disponíveis no boletim técnico ("Product Bulletin") do fluido MRF-132AD da LORD. Desta forma, foram obtidos os seguintes parâmetros:

- $\tau_{0}=35 \mathrm{kPa}$ para $\mathrm{H}=130 \mathrm{kA} / \mathrm{m}$ (vide figura 4.2) e $\mathrm{B}=0,55 \mathrm{~T}$;

- $\quad \eta=0,09$ (+/-0,02) Pa.s (calculado através da inclinação da curva tensão de cisalhamento versus taxa de cisalhamento entre 500 e $800 \mathrm{~s}^{-1}$ numa temperatura de $\left.40^{\circ} \mathrm{C}\right)$

\subsection{CÁLCULO DOS PARÂMETROS GEOMÉTRICOS}

Em seguida, calculam-se os valores do comprimento da válvula (L) e espessura do entreferro (g), utilizando-se as formulações descritas na seção 3.1.3.

Dando continuidade aos cálculos, tem-se:

$$
\begin{aligned}
& w=\pi \cdot d=100,5 \mathrm{~mm} \\
& V=k \cdot\left(\frac{\eta}{\tau_{y}^{2}}\right) \cdot \lambda \cdot W_{m} \cong 2050 \mathrm{~mm}^{3}
\end{aligned}
$$

onde

$$
\begin{aligned}
& k=12 / c^{2} \cong 2,08 \\
& c=2,07+\frac{1}{1+0.4 \lambda} \cong 2,4 \\
& \lambda \text { definido para } v=1 \mathrm{~m} / \mathrm{s} \\
& \left.\begin{array}{ll}
a=\frac{V}{w} \\
b=\frac{\Delta P_{\tau}}{c \cdot \tau_{0}}
\end{array}\right\} \quad \begin{array}{l}
g=\sqrt{\frac{a}{b}}=0,76 \mathrm{~mm} \\
L=\sqrt{a \cdot b}=26,9 \mathrm{~mm}
\end{array}
\end{aligned}
$$

Pode-se, então, calcular os fatores de mérito para verificar se os resultados obtidos são coerentes: 


$$
\begin{aligned}
F_{1}=\frac{\tau_{0}^{2}}{\eta}=14 \cdot 10^{9} \frac{P a}{\mathrm{~s}} & \left(\text { valor referencial: }>\mathbf{1 0}^{\mathbf{9}}\right) \\
F_{2}=\frac{\tau_{0}^{2}}{\eta \cdot \rho}=4,4 \cdot 10^{6} \frac{\mathrm{m}^{2}}{\mathrm{~s}^{3}} & \left(\text { valor referencial: }>\mathbf{1 0}^{\mathbf{6}}\right) \\
F_{3}=\frac{\tau_{0}}{B \cdot H}=0,449 \frac{\mathrm{N} \cdot \mathrm{m}}{\mathrm{Wb} \cdot \mathrm{A}} & (\text { valor referencial: } \sim \mathbf{0 , 5})
\end{aligned}
$$

que são todos satisfatórios (vide seção 3.3, página 74).

\subsection{DEFINIÇÃO DA GEOMETRIA DA VÁLVULA MR}

A definição da geometria da válvula está ligada a uma parte importante no projeto de dispositivos MR que é a concepção do circuito magnético. Fundamentalmente, este processo deve visar à redução ou eliminação das regiões de saturação do núcleo ferromagnético da válvula, respeitando os parâmetros geométricos previamente calculados.

Este trabalho propõe a utilização de um aplicativo de CAE que resolva problemas magnetostáticos com este objetivo. Através dos resultados fornecidos por este aplicativo, é possível identificar as regiões críticas do núcleo onde ocorrem as maiores densidade de fluxo magnético, e assim propor ajustes no desenho da válvula para se obter uma melhor distribuição do fluxo magnético. Trata-se, portanto, de um processo iterativo cujo resultado final é descrito a seguir.

1. Obtenção da menor relutância possível no circuito magnético que envolve o entreferro por onde o fluido passa, para que o núcleo de ferro possa guiar e concentrar o fluxo magnético na região de fluido magneticamente ativo.

2. Maximização da energia do campo magnético no entreferro por onde o fluido passa, através da minimização das perdas de fluxo no núcleo de ferro, evitando que o fluxo se disperse pelo fluido MR fora da região ativa e por outras regiões do dispositivo.

Entretanto, é necessário se propor um desenho inicial para a válvula MR, para que o primeiro ciclo de análise e ajustes seja realizado. Esta é uma fase que depende muito da experiência e criatividade do projetista, pois este primeiro desenho deve a principio respeitar apenas os parâmetros dimensionais calculados na seção anterior e os limites dimensionais 
impostos pelas restrições de projeto. A experiência e a criatividade do projetista podem contribuir para que ele apresente uma primeira proposta que além de atender aos requisitos dimensionais, também possa levá-lo mais rápido a um resultado satisfatório, sem a necessidade de muitas iterações. Para isso os seguintes fatores devem-se ser considerados:

- não-linearidade das propriedades magnéticas do fluido e do material ferromagnético utilizado no circuito magnético;

- fugas de fluxo magnético;

- possíveis perdas em junções e fronteiras;

- limites de tensão, corrente e indutância ${ }^{23}$;

- possível inclusão de imãs permanentes para operações à prova de falha ${ }^{24}$.

De posse dos valores dos parâmetros geométricos, e procurando atender a todos os direcionamentos acima citados, foi proposto o primeiro desenho da válvula MR, que é apresentada na figura 4.3 .

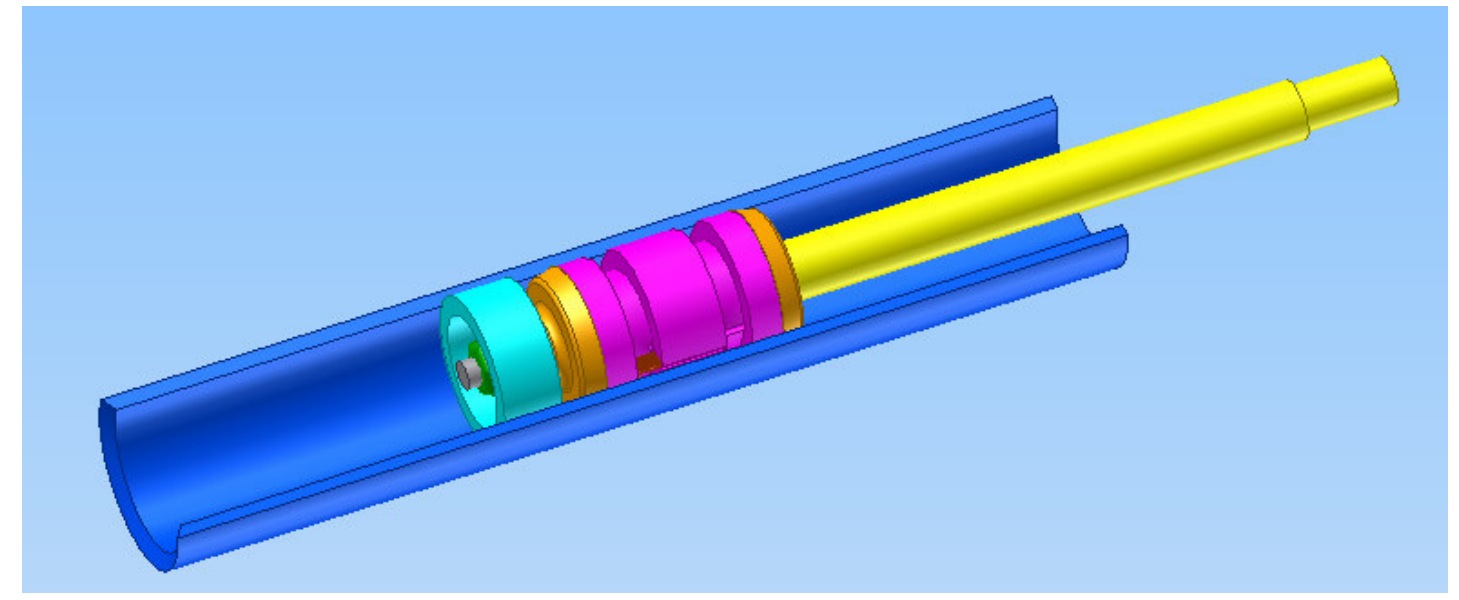

Figura 4.3 - Geometria adotada para a válvula MR.

O comprimento do conjunto válvula MR e pistão, conforme mostrado na figura 4.3, respeitou a restrição de espaço limitada por $L p_{\max }=90 \mathrm{~mm}$.

Observando-se a limitação de espaço, definem-se as dimensões da ranhura para alojar as bobinas. Na geometria adotada a área da seção da ranhura é dada por:

\footnotetext{
${ }^{23}$ As limitações na indutância estão, entre outros aspectos, relacionadas ao tempo de resposta do atuador.

${ }^{24} \mathrm{O}$ uso de imãs permanentes garante um campo magnético constante que evitaria a redução brusca das forças geradas pelo atuador para valores muito baixos, no caso de uma pane nos circuitos elétricos ou na falta de energia elétrica.
} 


$$
S=5,5 \mathrm{~mm} \cdot 4,0 \mathrm{~mm}=22 \mathrm{~mm}^{2}
$$

Considerando-se a intensidade de corrente de pico $\left(I_{p}=3 \mathrm{~A}\right)$, admitiu-se um fio de 26AWG, que apresenta uma área da seção transversal de aproximadamente $0,1671 \mathrm{~mm}^{2}$ (considerando-se o esmalte). Para um fator de empacotamento de $70 \%$, chega-se ao número aproximado de espiras por ranhura:

$$
N_{\max }=22 \cdot 0,70 / 0,1671=92,16
$$

Foi então adotado um enrolamento de 90 espiras, cuja resistência elétrica resultou em $3,5 \Omega$, considerando a resistividade do cobre à $100^{\circ} \mathrm{C}$ e mais a resistência do fio de ligação das bobinas até o circuito de acionamento. Com este valor de resistência e supondo uma alimentação de 12V, a corrente máxima é de aproximadamente 3,4 A. Desta forma verifica-se o circuito elétrico está compatível com o valor da corrente de pico pré-definida.

Esta é a parte do projeto que exige conhecimento e experiência do projetista. Em função da grande quantidade de fatores a serem observados, uma análise eletromagnética é bastante importante para verificar a eficácia do circuito magnético da válvula MR. Com a finalidade de se evitar a construção de protótipos para se testar a geometria adotada, introduz-se nesta fase uma análise de elementos finitos.

\subsection{ANÁLISE ELETROMAGNÉTICA}

Nesta seção é apresentado o uso de um aplicativo de CAE para se encontrar a solução do problema magnetostático em estudo. Assim, uma análise magnetostática através do método dos elementos finitos (MEF) é utilizada para gerar informações sobre o circuito magnético da válvula MR.

O objetivo é verificar se a intensidade do campo magnético $(H)$ que foi utilizada indiretamente nos cálculos dos parâmetros geométricos ( $L$ e $g$ ) pode ser alcançada pela válvula MR com a intensidade de corrente prevista. Além disso, a análise magnetostática indica os pontos de fuga e dispersão do fluxo magnético que ajudarão o projetista a definir corretamente os isolamentos magnéticos necessários. Esta análise também mostra os pontos 
críticos de saturação do núcleo magnético, que precisarão ser revistos no caso de uma saturação excessiva.

Para a simulação deste problema magnetostático por meio de análise de elementos finitos foi utilizado o software FEMM da Berlios (vide Anexo B).

Devido a simetria axial do amortecedor, o problema foi representado por meio de um modelo de elementos finitos 2D axissimétrico. No caso de problemas magnéticos em duas dimensões, o vetor potencial magnético $A$ é sempre normal ao plano do modelo, portanto ele poder ser tratado como um escalar. Além disso, quando o problema magnético é axissimétrico, a condição $A=0$ é forçada na linha $r=0$. Caso uma parte da fronteira do problema passe por essa linha, então uma solução válida pode ser obtida sem a necessidade de uma definição explícita da condição de contorno nesta fronteira.

Nas demais fronteiras do problema foi utilizada a condição de contorno de Dirichlet $(A=0)$. Esta técnica, chamada de truncamento de fronteira, corresponde a forçar para zero o vetor potencial magnético a uma distância suficientemente grande a partir do centro do problema. De acordo com Chen e Konrad (1997), como regra geral, esta distância deve ser pelo menos cinco vezes maior que a maior dimensão da região de interesse. Desta forma obtém-se um problema bem definido com uma região de solução fechada, que é uma condição ideal para solução de problemas MEF. No caso analisado, esta aproximação é bastante boa, uma vez que o fluxo magnético fica praticamente contido dentro do núcleo ferromagnético (ou seja, nenhuma linha de fluxo magnético deve cruzar a fronteira do modelo). As fronteiras do problema magnetostático e suas respectivas condições de contorno são ilustradas na figura 4.4 .

Modelos axissimétricos para problemas magnéticos podem não ser bem postos ("well adressed"), como ocorre com outros modelos de elementos finitos $2 \mathrm{D}$, havendo a dificuldade de se formar expressões fechadas para alguns termos das matrizes de elementos. Atualmente há várias técnicas que propõem uma solução para este problema. O aplicativo FEMM utiliza uma formulação muito similar àquela proposta por Henrotte et al. (1993) para problemas magnéticos axissimétricos, que além de resolver o problema, ainda garante boa precisão nos resultados próximos do eixo $\mathrm{r}=0$. 


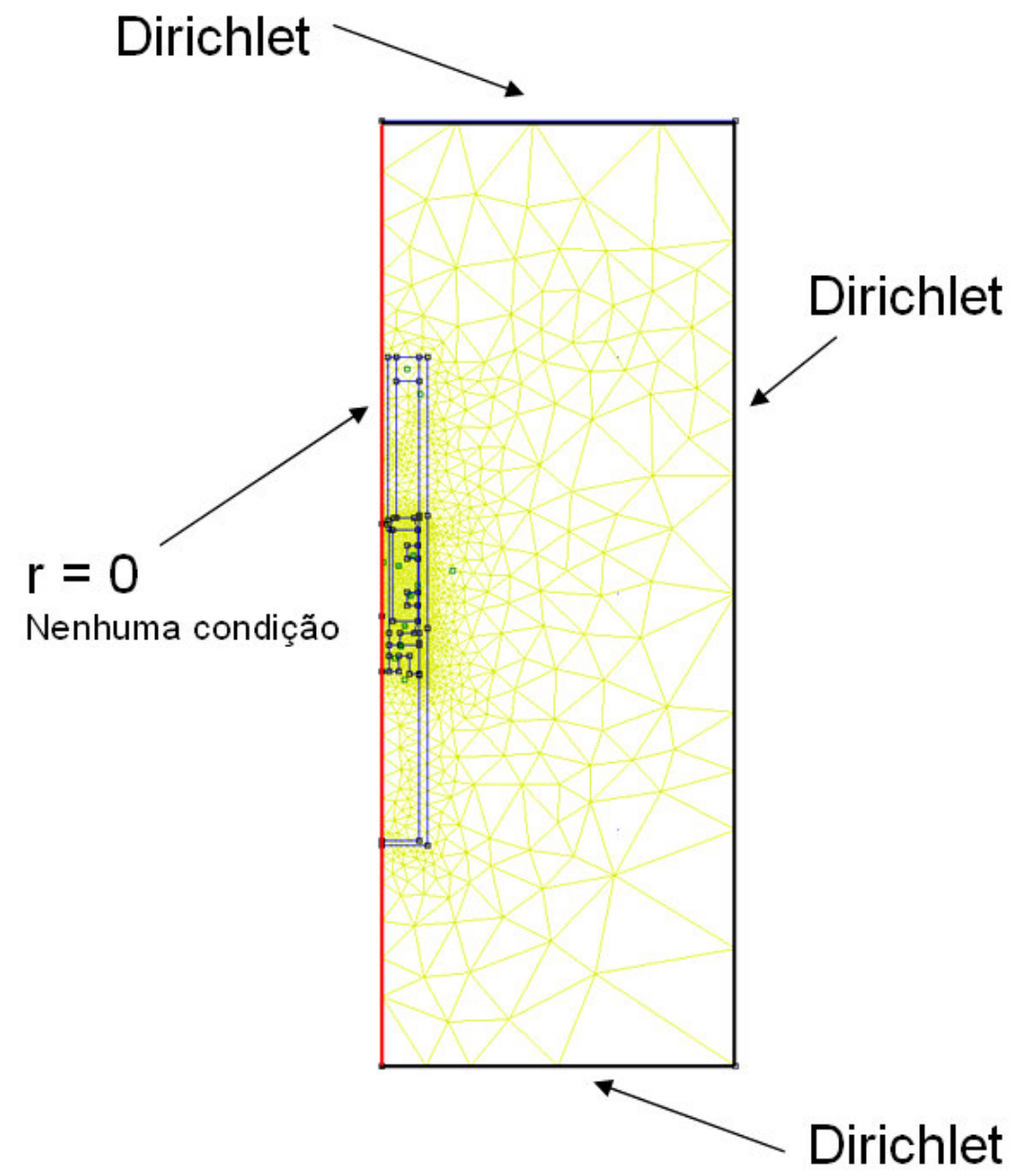

Figura 4.4 - Modelo de elementos finitos e sua condição de contorno.

$\mathrm{Na}$ região das bobinas (identificada na figura 4.7) foi utilizada uma densidade de corrente de $J=90$ espiras $\cdot 3 \mathrm{~A} / 22 \mathrm{~mm}^{2}=12,27 \mathrm{Ae} / \mathrm{mm}^{2}$. As curvas de magnetização dos materiais são apresentadas nas figuras 4.5 e 4.6 . 


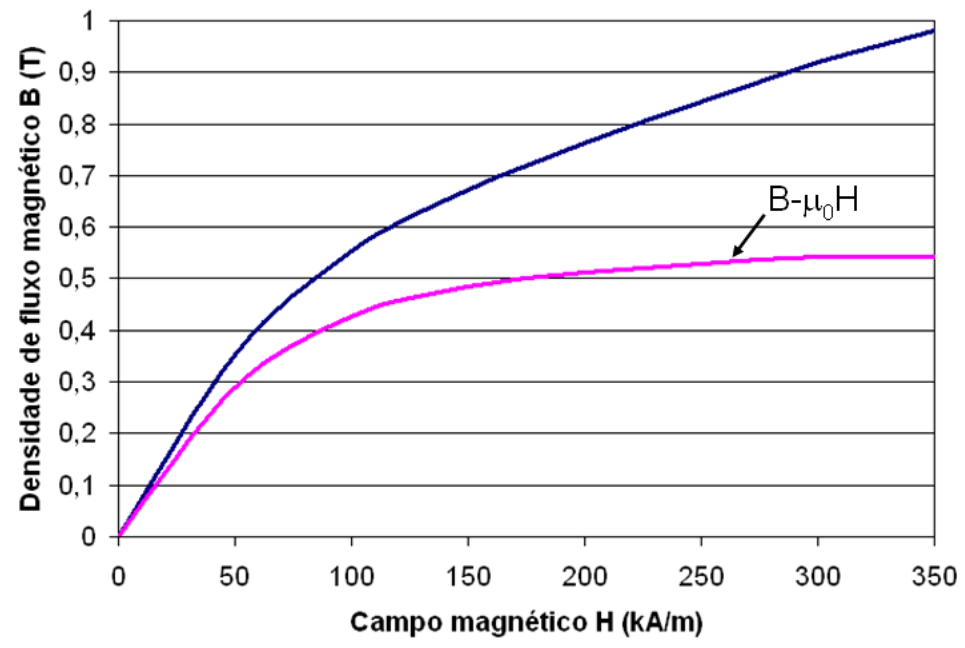

Figura 4.5 - Curva BH do fluido MRF-132AD.

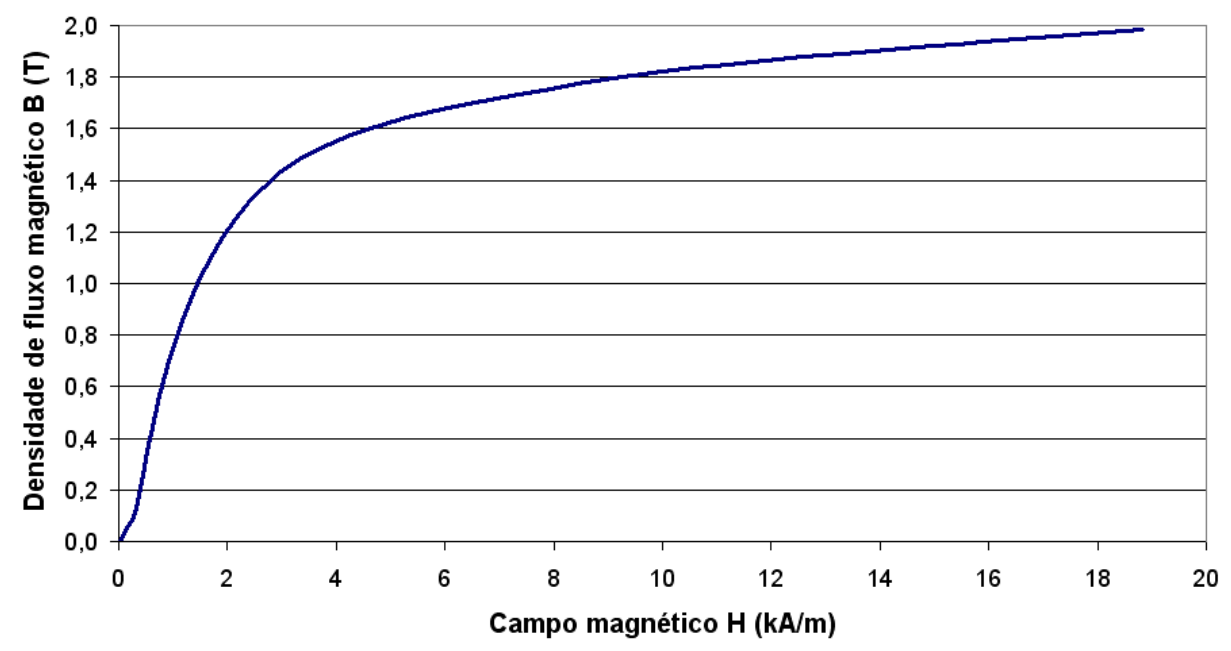

Figura 4.6 - Curva BH do aço SAE1020.

Os resultados encontram-se nas figuras 4.7 e 4.8. Na figura 4.7 também são descritos as partes que compõe a válvula do amortecedor MR. Ainda nesta figura é apresentada em cores a intensidade do vetor densidade de fluxo magnético $B$, cuja legenda está à direita. 


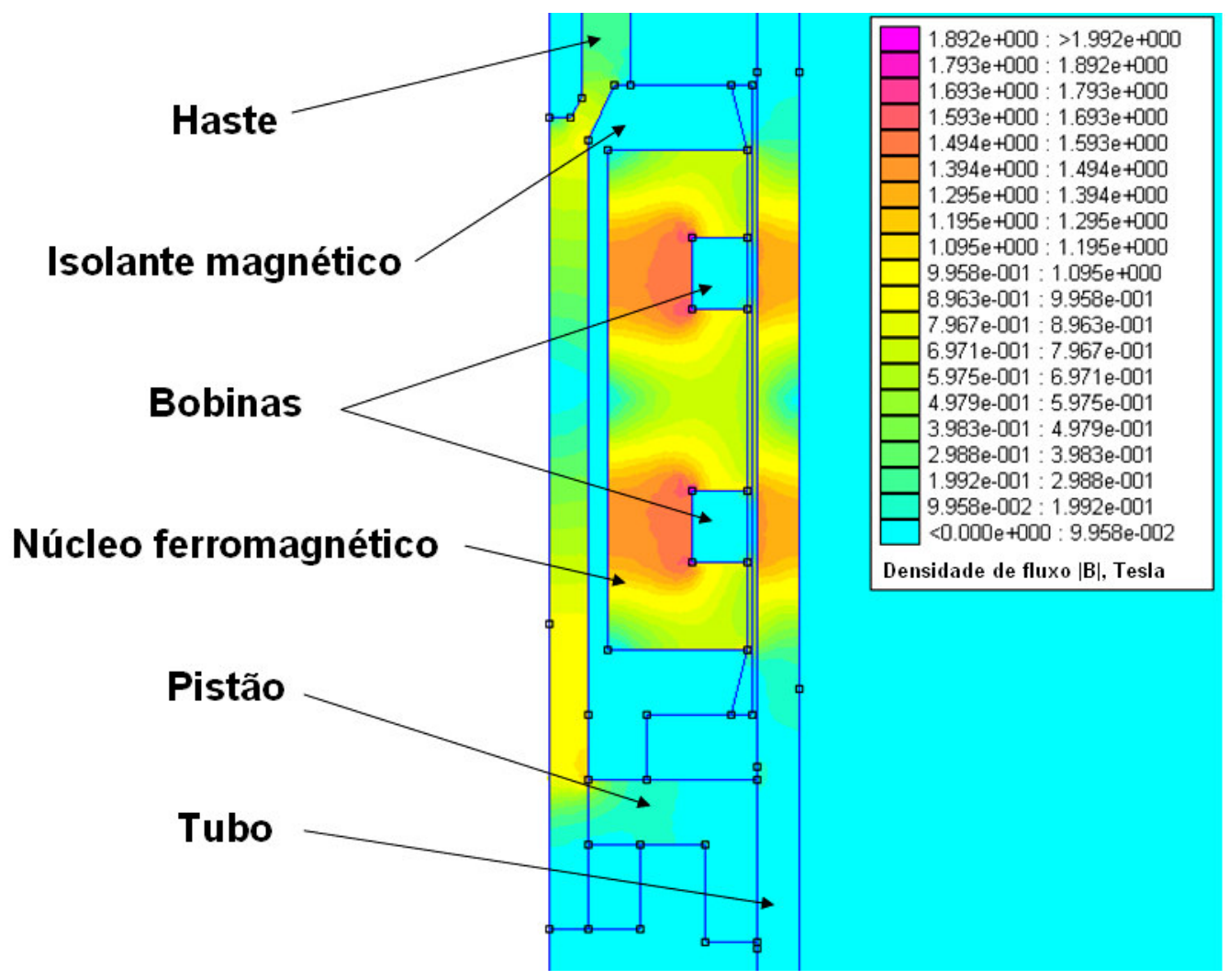

Figura 4.7 - Densidade de fluxo magnético na válvula MR.

Como resultado da análise de elementos finitos, obtêm-se as informações sobre o circuito elétrico, conforme segue:

- Corrente total nas bobinas (ligação em série): $3 \mathrm{~A}$;

- Queda de tensão nas bobinas: $V_{b} \cong 6 \mathrm{~V}$;

- Fluxo magnético: $\phi \cong 87,6 \mathrm{mWb}$;

- Indutância: $L_{b} \cong 29 \mathrm{mH}$

- Resistência elétrica: $R_{b} \cong 2 \Omega$

- Potência dissipada nas bobinas: $P_{b} \cong 17,9 \mathrm{~W}$

Porém, o principal resultado desta análise é o campo magnético que a válvula será capaz de impor ao fluido com uma corrente de 3A. Como foi necessário se pré-estabelecer um ponto de magnetização para o fluido MR para o cálculo das dimensões $L$ e $g$ (seção 4.5), é fundamental nesta fase verificar se a válvula MR proposta é capaz de gerar aquele nível de campo magnético, ou seja, $130 \mathrm{kA} / \mathrm{m}$. 
O gráfico da figura 4.8 ilustra o resultado da análise, mostrando que a intensidade do campo magnético utltrapassou o nível de $130 \mathrm{kA} / \mathrm{m}$ na parte central do núcleo que fica entre as bobinas, e ficou abaixo de 130kA/m nas extremidades da válvula. Devido à curva de tensão de escoamento versus campo magnético do fluido MR (figura 4.2) poder ser aproximada por uma reta no intervalo entre $110 \mathrm{kA} / \mathrm{m}$ até $150 \mathrm{kA} / \mathrm{m}$, admite-se que o ganho de tensão de escoamento no centro do núcleo compensa a perda nas extremidades. Assim, esta situação pode ser considerada equivalente à hipotese de projeto que previu um campo magnético médio de $130 \mathrm{kA} / \mathrm{m}$.

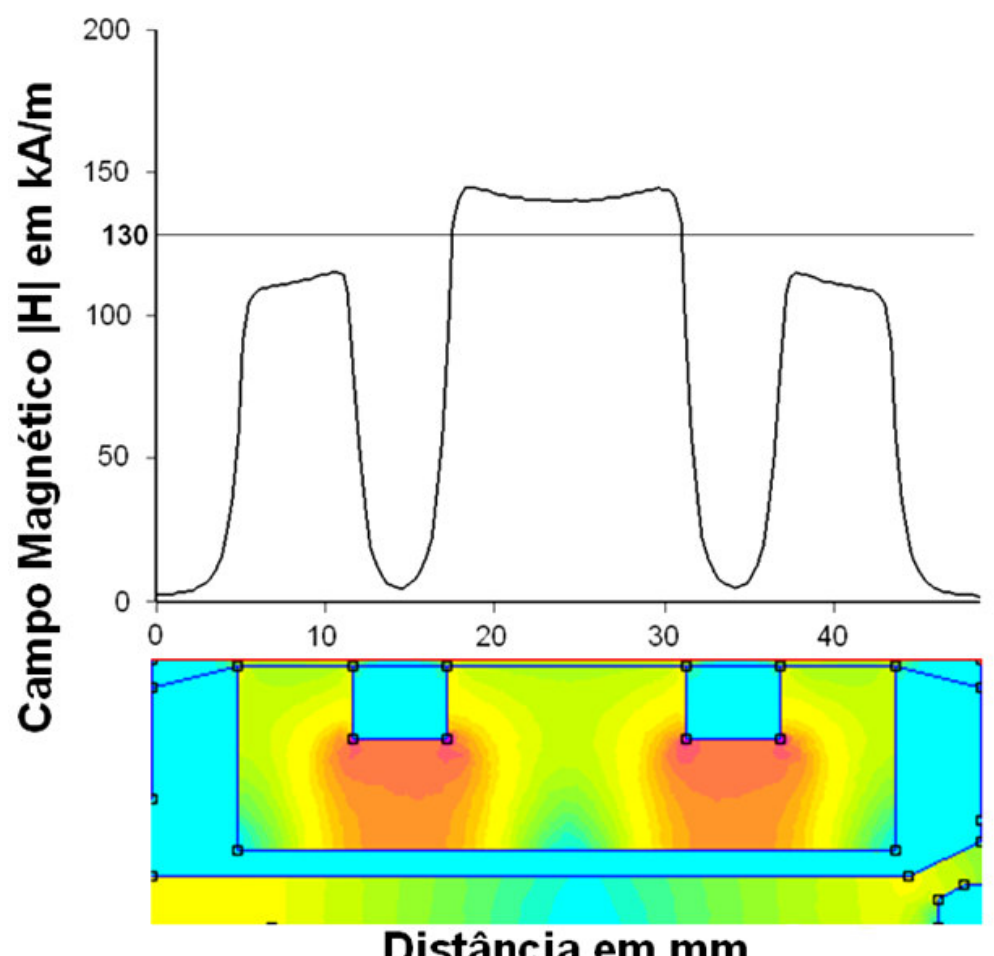

Figura 4.8 - Campo magnético sobre o fluido MR.

Para se chegar a esta proposta que atingiu o campo magnético pré-estabelacido para o cálculo das dimensões $L$ e $g$, foram necessários ajustes no tamanho e posição das ranhuras das bobinas em algumas iterações deste procedimento de análise. Este processo iterativo será abordado pela seção 4.10 .

\subsection{ANÁLISE TERMODINÂMICA}

A análise termodinâmica é necessária para se verificar se a temperatura na válvula MR não vai superar o valor limite definido nas restrições de projeto. 
Para esta análise são necessárias outras informações técnicas sobre o fluido MR. Estas informações do fluido MRF-132AD são apresentadas na tabela 4.2 (LORD, 2001b).

Tabela 4.2: Dados técnicos sobre o fluido MRF-132AD.

\begin{tabular}{|c|c|c|}
\hline Propriedades & Símbolo & Valores / Limites \\
\hline Temperatura de operação & $T_{o p}$ & $-40^{\circ} \mathrm{C}$ até $130^{\circ} \mathrm{C}$ \\
\hline Massa específica & $\rho$ & $3,09 \mathrm{~kg} / 1$ \\
\hline Calor específico & $c_{p}$ & $800 \mathrm{~J} /\left(\mathrm{kg}^{\circ} \mathrm{C}\right)$ \\
\hline Condutibilidade térmica & $\kappa_{f}$ & de 0,25 a $1,06 \mathrm{~W} /\left(\mathrm{m}^{\circ} \mathrm{C}\right)$ \\
\hline
\end{tabular}

Considera-se a condutibilidade térmica do aço igual a $\kappa_{a}=42 \mathrm{~W} /\left(\mathrm{m}{ }^{\circ} \mathrm{C}\right)$, e que o gradiente de temperatura no fluido é desprezível em função da sua constante agitação. Assim adota-se um modelo simplificado de transferência de calor, apresentado na figura 4.9.

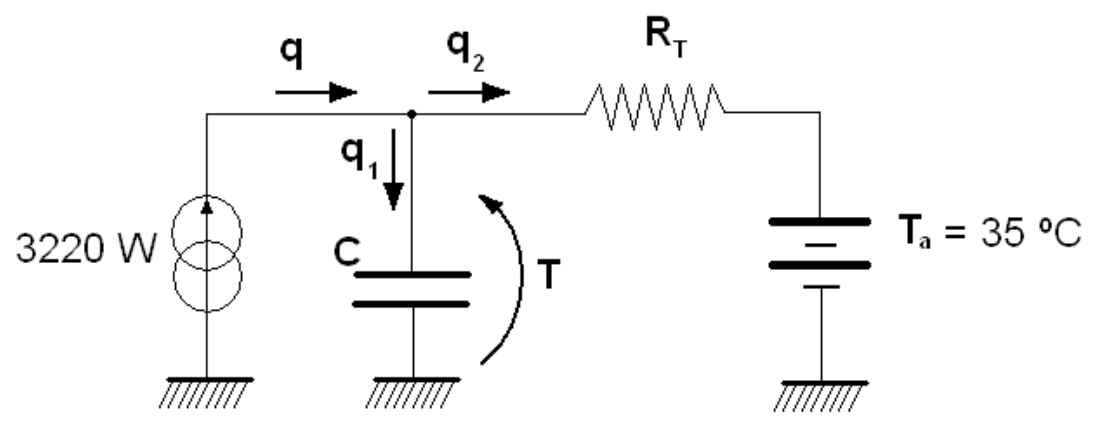

Figura 4.9 - Modelo de transferência de calor.

Associado ao modelo da figura 4.9 há duas equações constitutivas e uma equação de equilíbrio, respectivamente conforme segue:

$$
\begin{gathered}
q_{1}=m \cdot c_{p} \cdot \dot{T}=C_{T} \cdot \dot{T} \\
q_{2}=\frac{T-T_{a}}{R_{T}} \\
q=q_{1}+q_{2}
\end{gathered}
$$


onde $q$ é o fluxo de calor provocado pela dissipação térmica gerada pela passagem do fluido pela válvula MR, $q_{1}$ é o fluxo de calor que é absorvido pelo fluido, $q_{2}$ é o fluxo de calor que atravessa a parede do tubo e vai para o ambiente, $T$ é a temperatura do fluido MR, $T_{a}$ é a temperatura ambiente fora do tubo, $m$ é a massa do fluido $\mathrm{MR}, C_{T}=m \cdot c_{p}$ é a capacitância térmica do fluido MR, e $R_{T}$ é a resistência térmica do tubo, que é calculada como se segue:

$$
R_{T}=\frac{\ln \left(r_{e} / r_{i}\right)}{2 \cdot \pi \cdot l \cdot \kappa_{a}} \cong 0,014{ }^{\circ} \mathrm{C} / \mathrm{W}
$$

onde $r_{e}$ é o raio externo do tubo cilíndrico, $r_{i}$ é o raio interno e $l$ é o comprimento da região do tubo em que está a válvula MR, ou seja, é o próprio comprimento da válvula.

Resolvendo as equações (4.13) a (4.15) verifica-se que se trata de um sistema de $1^{\mathrm{a}}$ ordem cuja constante de tempo é dada por:

$$
\tau_{R C}=R_{T} \cdot C_{T}=R_{T} \cdot m \cdot c \cong 3,6 \mathrm{~s}
$$

Em regime permanente, a temperatura $\mathrm{T}$ do fluido pode ser calculada pela seguinte equação:

$$
T=q \cdot R_{T}+T_{a}
$$

Considera-se que o fluxo de calor é $q=3220 \mathrm{~W}$, a soma da potência controlável (2800W), com a potência dissipada devido ao atrito viscoso do fluido MR na válvula (430 N.s/m) na velocidade máxima do pistão $(2 \mathrm{~m} / \mathrm{s})$, mais a dissipação no circuito elétrico das bobinas $(\sim 20 \mathrm{~W})$. Nesta situação extrema (pior caso), a temperatura do fluido $(T)$ pode chegar a $80^{\circ} \mathrm{C}$, que é bem inferior ao limite de $125^{\circ} \mathrm{C}$ definido no início do projeto.

Apesar do caráter bastante simplificado deste modelo, pode-se aceitar este resultado com boa margem de segurança. A dissipação de calor ocorre na verdade por toda a superfície externa do tubo em que o fluido está em contato, e também há o fluxo de calor por meio de radiação térmica; condições que levam a uma temperatura ainda menor do que a calculada. 
Através deste cálculo é possível perceber que a questão da temperatura do fluido no amortecedor MR não é um fator crítico. Contudo isto não é verdade para outros tipos de dispositivos MR, como os freios e embreagens MR, por exemplo.

\subsection{COMENTÁRIO SOBRE O PROJETO}

Apesar do projeto do $1^{\circ}$ protótipo ter sido apresentado de forma linear por questões didáticas, o procedimento de projeto é na verdade um processo iterativo, como na realidade o foi. A cada iteração, o processo segue linearmente até o momento da avaliação, onde se verifica o atendimento a todas as premissas dos cálculos, das restrições e dos requisitos de projeto.

$\mathrm{Na}$ etapa de avaliação decide-se o que precisará ser revisto a fim de se atingir os objetivos. Neste processo, o projetista dever buscar uma hierarquia de ações, privilegiando as mais simples. Assim criam-se vários níveis de iteração possíveis.

O primeiro nível deve ser a reavaliação da construção do dispositivo, ou necessidade da inclusão de dissipadores, caso o nível de temperatura máxima de operação não seja atingido.

O segundo nível deve ser a reavaliação da forma geométrica adotada para a válvula, buscando reduzir os pontos de saturação do núcleo magnético e bloquear a dispersão do fluxo magnético para fora do circuito.

O terceiro nível deve ser uma opção se as ações tomadas no segundo nível não surtam o efeito desejado. Neste caso deve-se reavaliar o ponto de magnetização máxima do fluido MR.

E o quarto nível de iteração também deve ser uma opção condicionada a não efetividade da iteração do terceiro nível, e só deve ser escolhida em último caso, porque está relacionada à reavaliação dos requisitos de projeto, que muitas vezes não podem ser alterados. 


\subsection{CONSTRUÇÃO DO PRIMEIRO PROTÓTIPO}

O primeiro protótipo foi construído segundo o resultado dos cálculos realizados. A seguir são apresentadas fotos dos componentes e sub-montagens do protótipo do amortecedor MR nas figuras 4.10 até 4.13. A figura 4.13 em especial mostra detalhes da válvula MR desenvolvida.

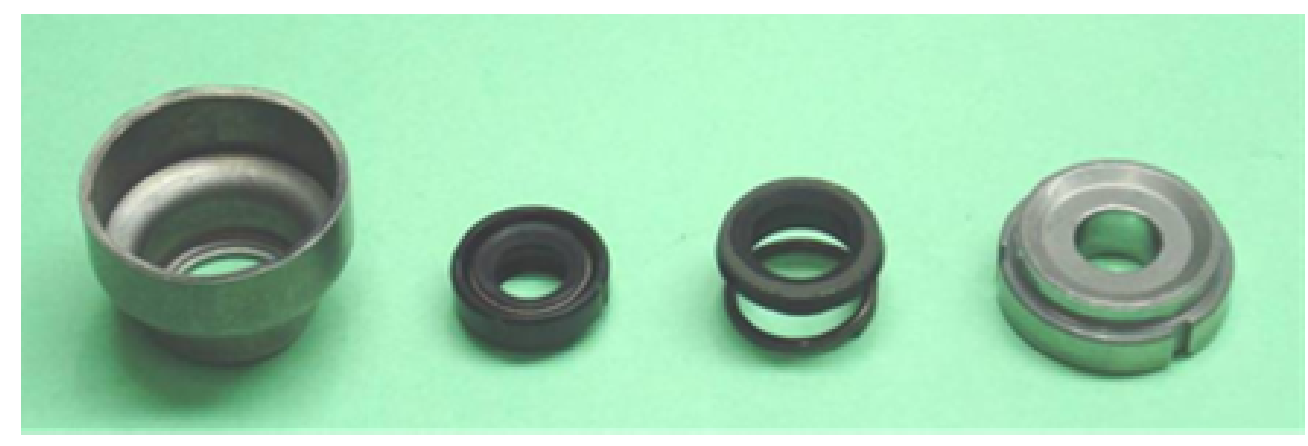

Figura 4.10 - Componentes de vedação e mancal da haste

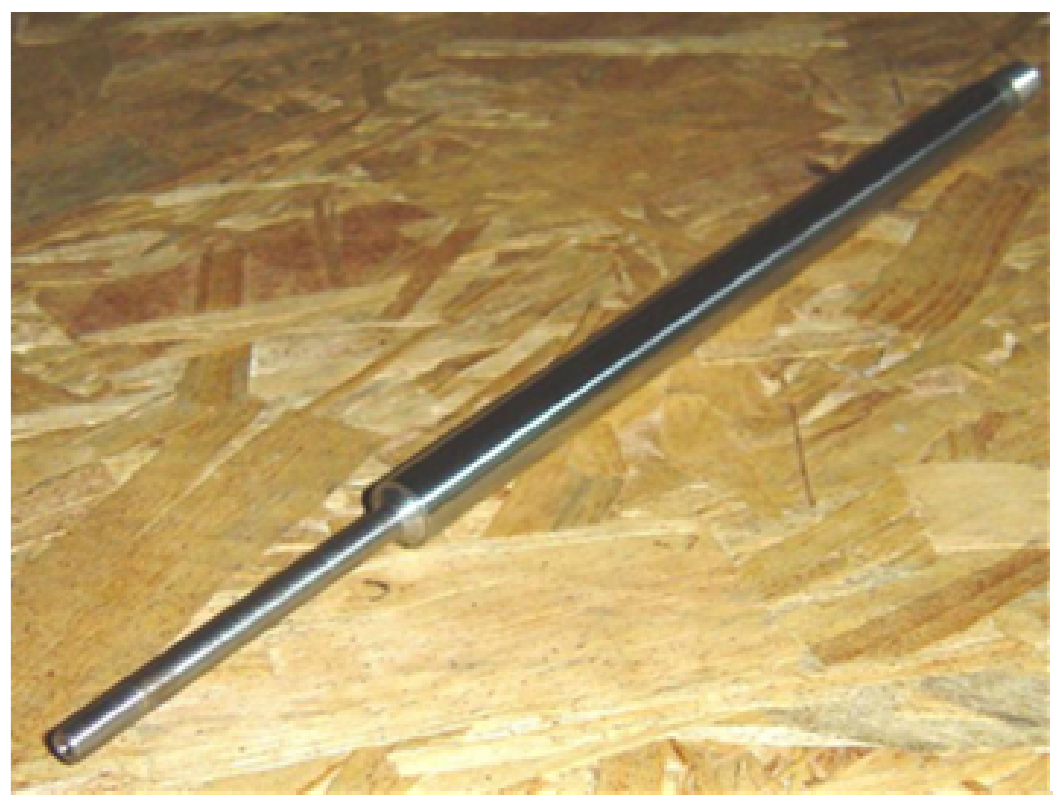

Figura 4.11 - Haste do amortecedor MR 


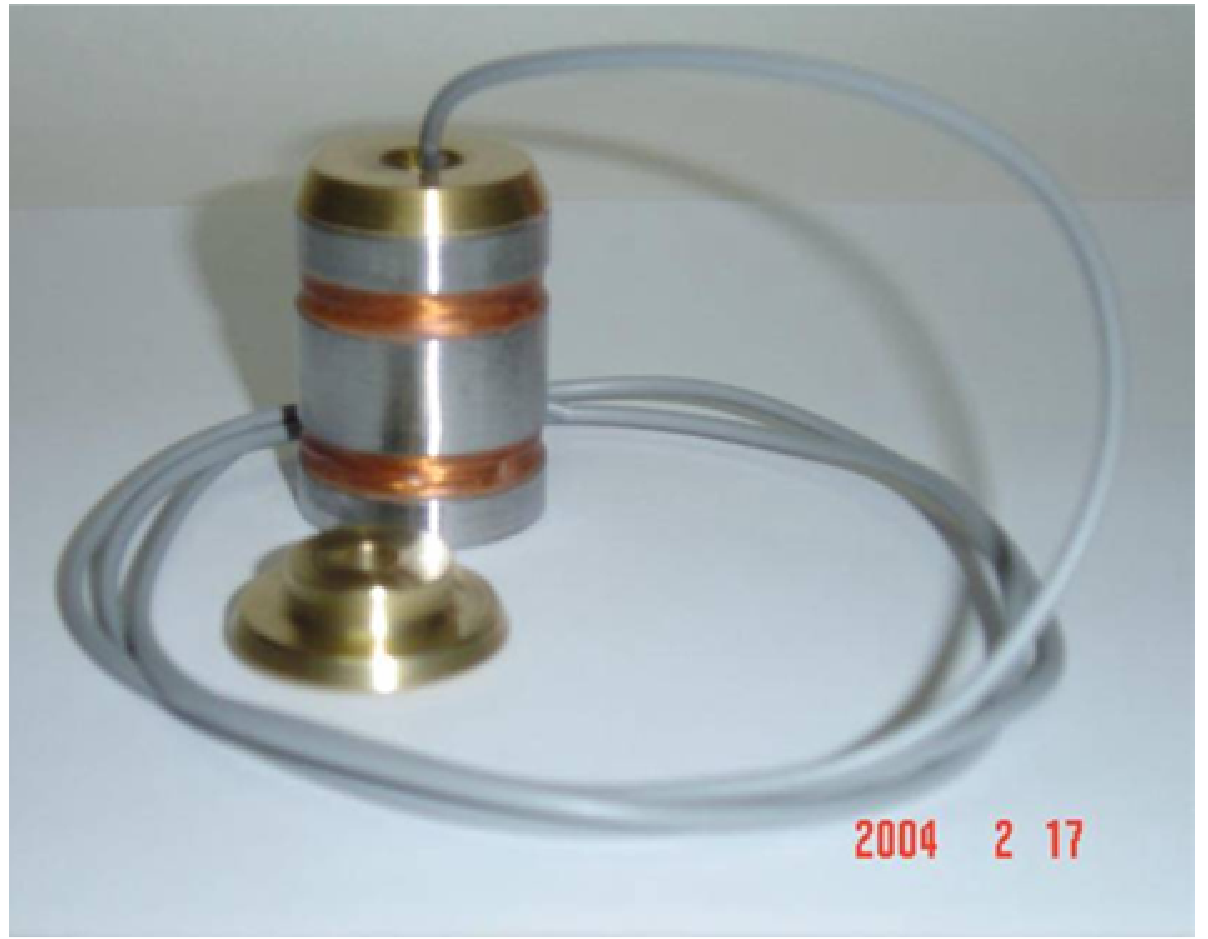

Figura 4.12 - Bobinas da válvula MR

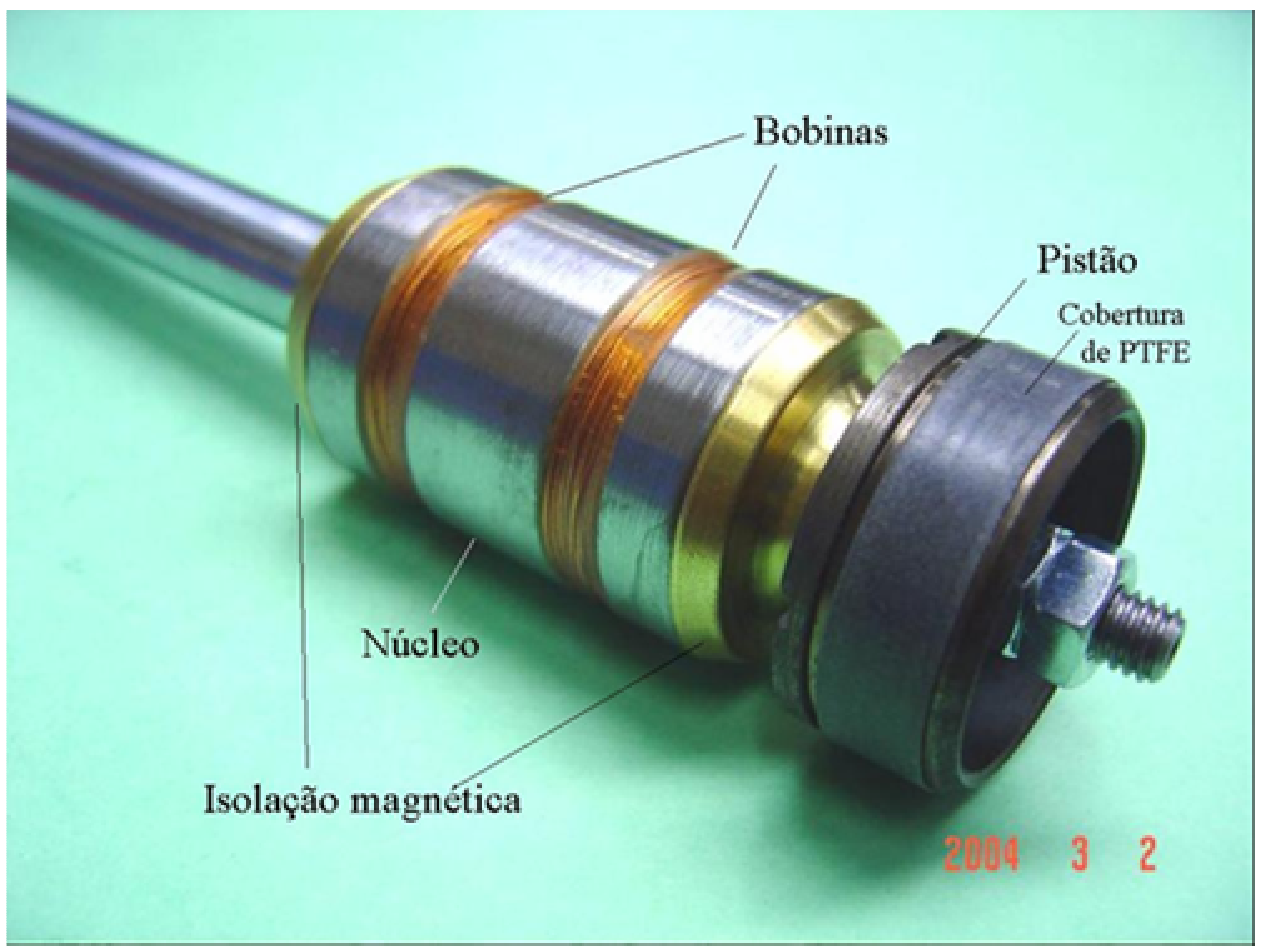

Figura 4.13 - Válvula MR do $1^{\circ}$ protótipo 


\section{RESUlTADOS E DISCUSSÃO - $1^{\circ}$ PROTÓTIPO}

\subsection{DESCRIÇÃO DO EXPERIMENTO}

$\mathrm{O}$ protótipo foi submetido a testes para levantamento das curvas de resposta "força $\mathrm{x}$ deslocamento" (conhecido por gráfico "bolha") e "força x velocidade", ambos para diferentes níveis de corrente elétrica nas bobinas da válvula do amortecedor MR. Na figuras 5.1 é apresentado o amortecedor MR montado no equipamento de teste juntamente com uma célula de carga de $5 \mathrm{kN}$, usada para medição das forças no amortecedor.

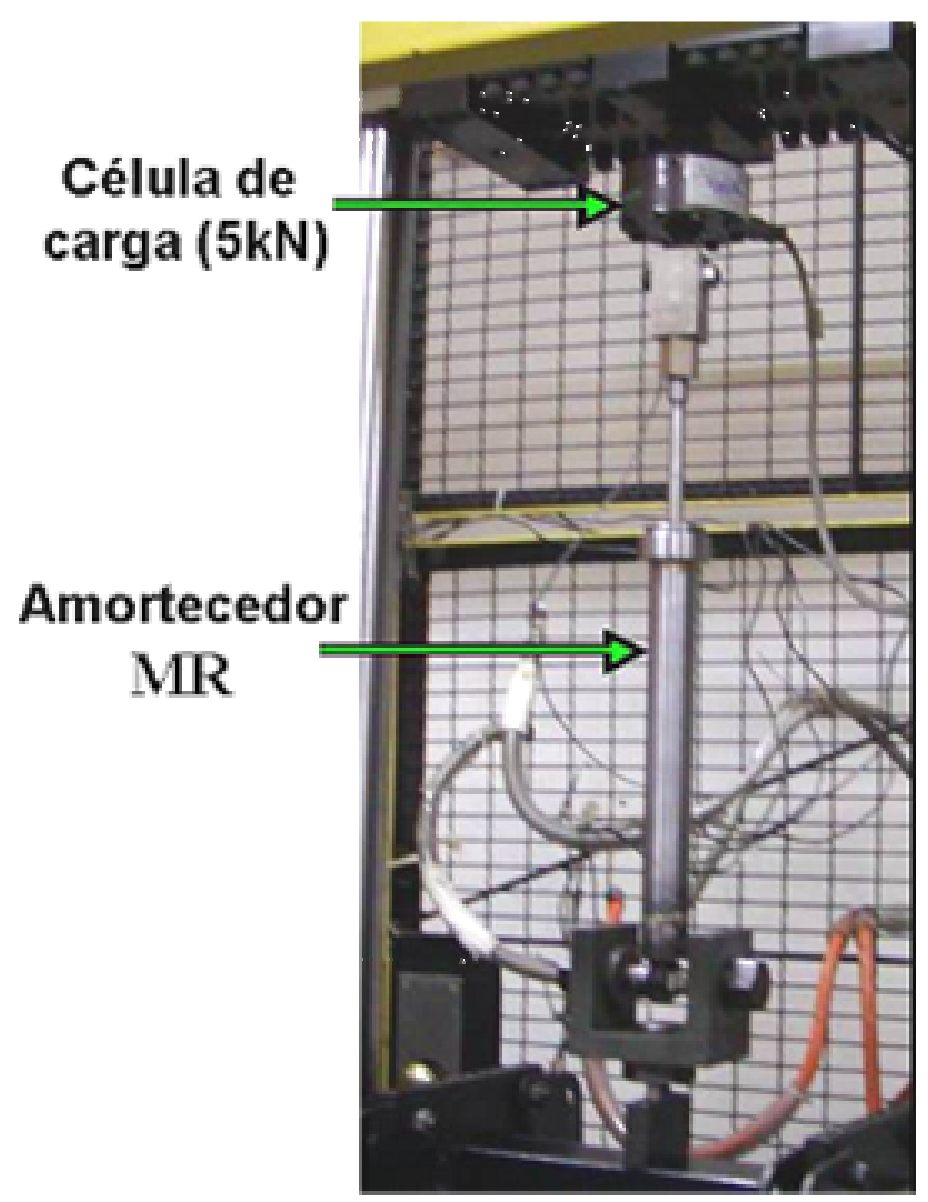

Figura 5.1 - Protótipo montado no equipamento de teste.

Na figura 5.2 são apresentados os equipamentos e a sua disposição para realização do experimento. Além da unidade de teste de amortecedores da MTSTM, modelo 849, também foram utilizados um multímetro digital para medição das correntes elétricas, uma fonte de 
tensão contínua de $12 \mathrm{~V}$ (fazendo o papel de uma bateria de automóvel), e um conversor estático tipo "Buck", trabalhando como uma fonte regulada de corrente elétrica.

Os dados de força, velocidade e deslocamento entre os terminais do amortecedor foram coletados através de uma placa de aquisição de dados e armazenados num computador. $\mathrm{O}$ amortecedor MR foi submetido a um movimento senoidal, com amplitude de $30 \mathrm{~mm}$ e freqüência de $1,3 \mathrm{~Hz}$.

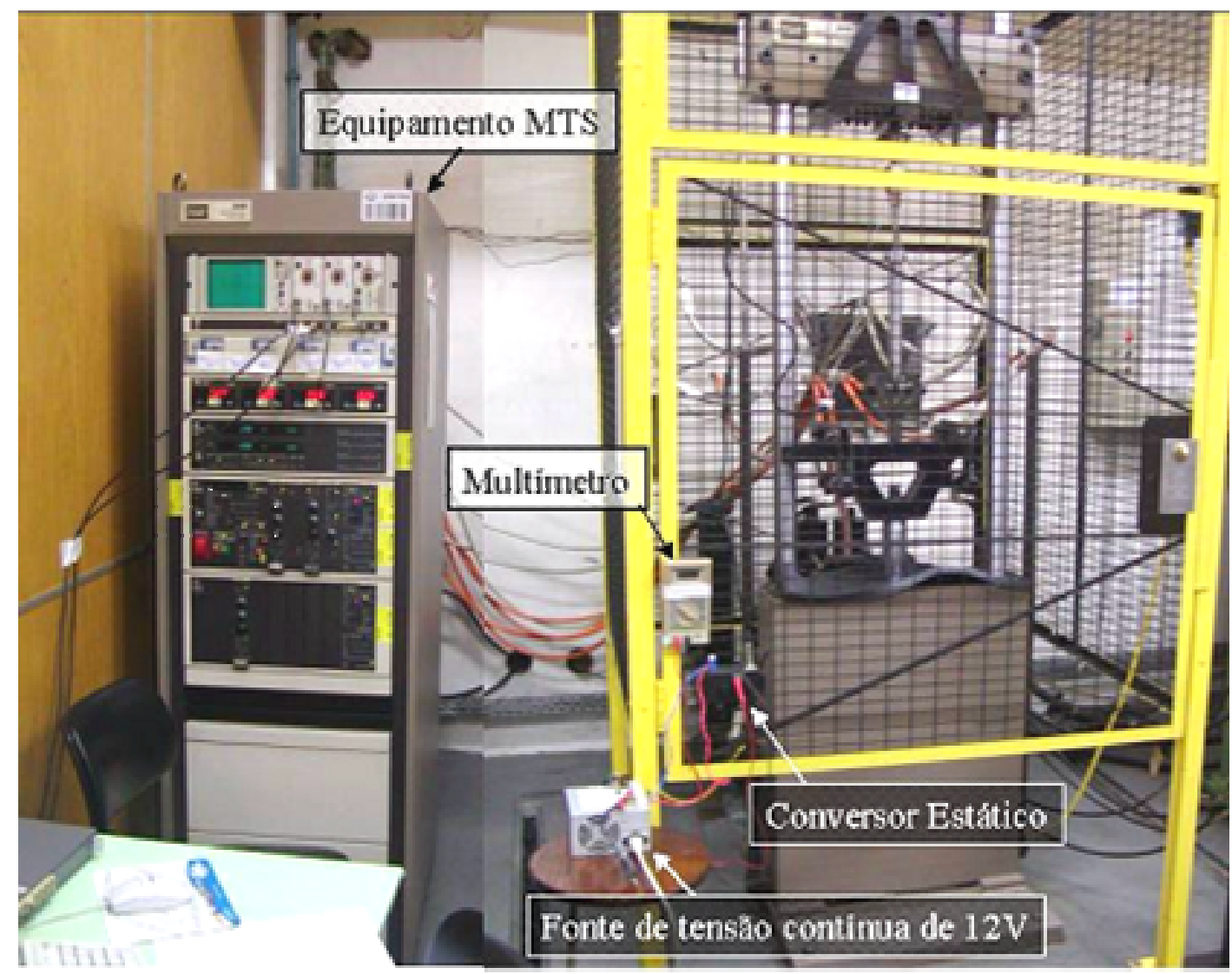

Figura 5.2 - Equipamentos utilizados no experimento. 


\subsection{RESULTADOS EXPERIMENTAIS}

A partir destes dados coletados no teste experimental foi possível construir o gráfico de força versus deslocamento relativo entre os terminais do amortecedor, conforme apresentado na figura 5.3. Na escala de força, o sinal negativo representa a compressão e o positivo a tração.

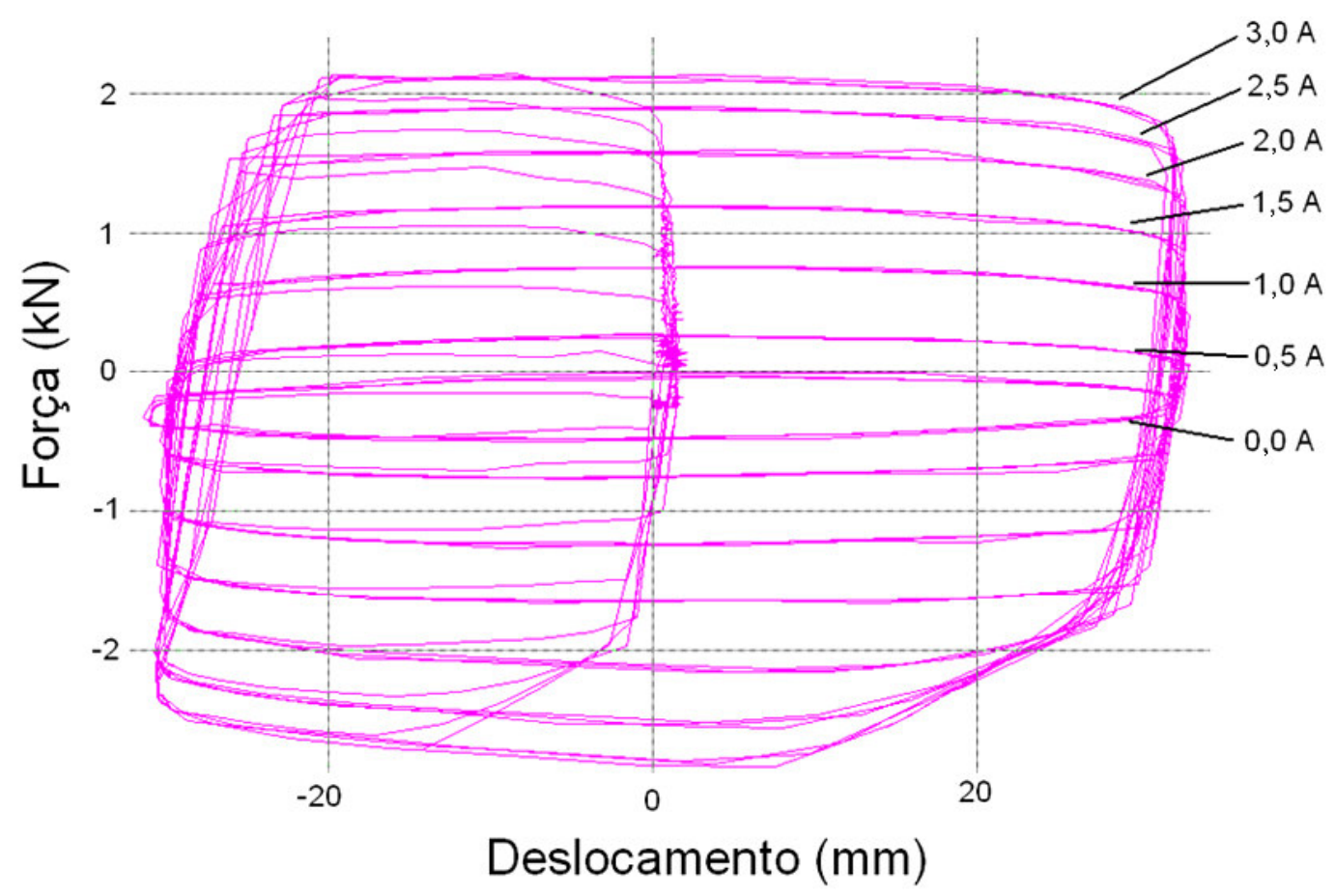

Figura 5.3 - Gráfico Força x Deslocamento.

Cada "bolha" do gráfico da figura 5.3 representa o resultado de força gerada pelo amortecedor para diferentes níveis de corrente elétrica aplicada, variando de zero até três Ampères, com intervalos de 500mA.

Pelo fato de ter sido utilizado o conceito de amortecedor monotubular, onde há um acumulador com nitrogênio em alta pressão ( 20 bar), surge uma força residual entre os terminais do amortecedor. Esta força residual é a razão do deslocamento das curvas de força $\mathrm{x}$ deslocamento para baixo.

Outro resultado do teste experimental foi o gráfico de força versus velocidade relativa entre os terminais do amortecedor, conforme apresentado na figura 5.4. 


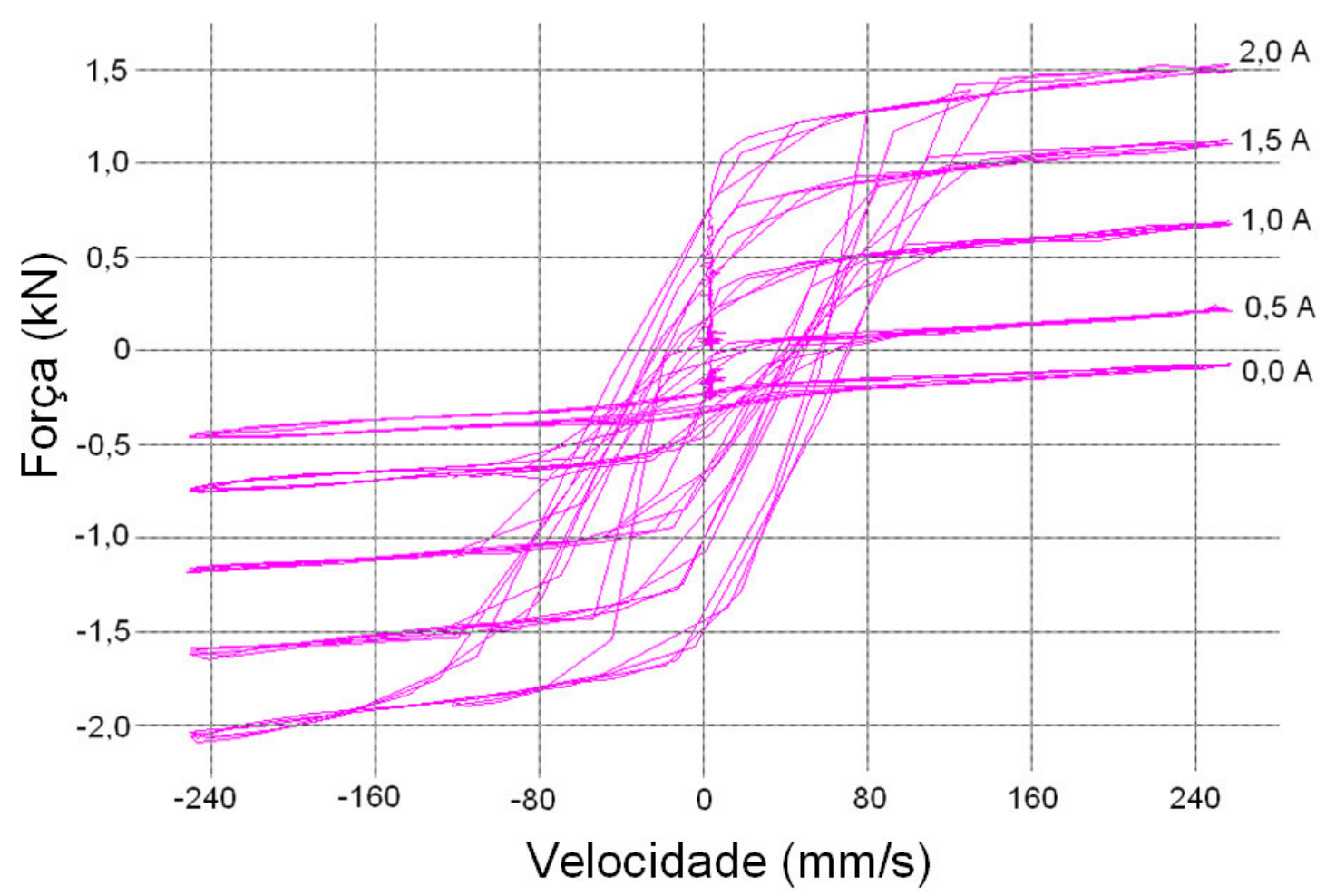

Figura 5.4 - Gráfico Força $(\mathrm{N})$ x Velocidade $(\mathrm{mm} / \mathrm{s})$.

Cada patamar do gráfico da figura 5.4 representa o resultado de força gerada pelo amortecedor para diferentes níveis de corrente elétrica aplicada, variando de zero até dois Ampères, com intervalos de 500mA. Como a movimentação do amortecedor é uma função senoidal, o sinal da velocidade corresponde à derivada desta função, cuja amplitude corresponde à freqüência angular multiplicada pela amplitude do deslocamento. Assim:

$$
\left.\begin{array}{l}
f=1,3 \mathrm{~Hz} \rightarrow \omega=2 \pi f \cong 8,168 \mathrm{rad} / \mathrm{s} \\
A_{\text {desl. }}=30 \mathrm{~mm}
\end{array}\right\} \rightarrow A_{\text {vel. }}=\omega \cdot A_{\text {desl. }}=8,168 \cdot 30 \cong 245 \mathrm{~mm} / \mathrm{s}
$$

\subsection{ANÁLISE DOS RESULTADOS}

Inicia-se por uma análise qualitativa dos resultados, com o objetivo de se verificar nos resultados experimentais o que foi previsto pela teoria. Para isso, utiliza-se o gráfico da força versus velocidade, destacando-se os patamares de força para cada nível de corrente de excitação, o que está ilustrado na figura 5.5. 


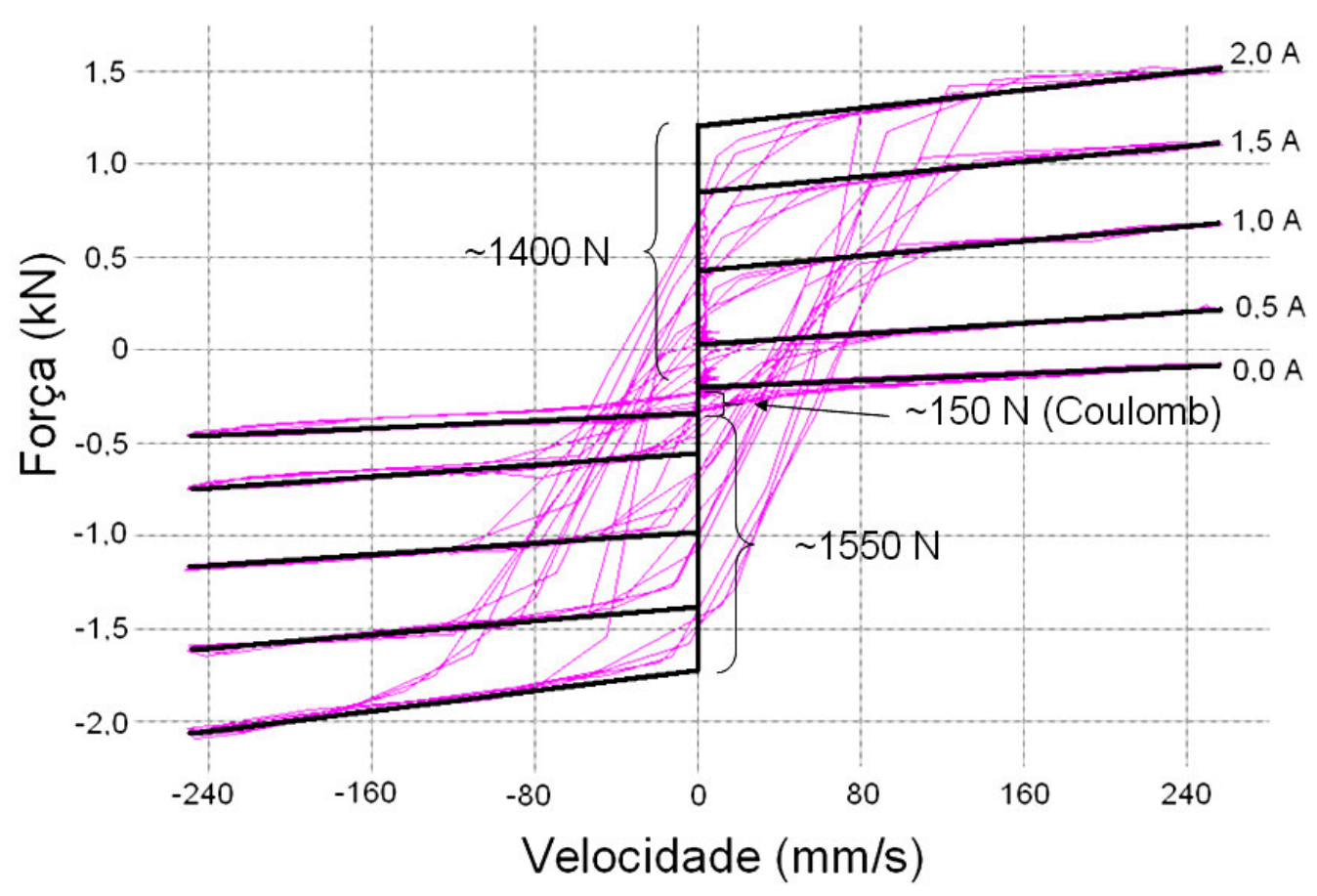

Figura 5.5 - Destaque dos patamares de força para cada nível de tensão de excitação

Percebe-se que o gráfico da figura 5.5 é similar ao da figura 3.5 , de forma que se pode notar a região da força controlável. Preferiu-se apresentar o gráfico com a variação da corrente de controle até $2 \mathrm{~A}$ somente, devido a descaracterizações ocorridas na resposta do amortecedor MR. O motivo destas descaracterizações foi a falta de pressão suficiente no acumulador. A queda da pressão foi provavelmente devido a um vazamento de ar na operação de lacramento da câmara. No gráfico da figura 5.5 foram destacados três valores: um referente ao total de força controlável na tração $\left(f_{c t 2} \cong 1400 \mathrm{~N}\right)$, outro referente ao total de força controlável na compressão ( $f_{c c 2} \cong 1550 \mathrm{~N}$ ), e o valor referente ao atrito de Coulomb devido ao atrito das vedações com a haste e do pistão com a parede interna do tubo ( $f_{a c} \cong 150 \mathrm{~N}$ ).

Como era esperado, a força de tração é menor que a força de compressão para um mesmo nível de corrente de controle, devido à diferença das áreas entre uma extremidade e outra da válvula, uma vez que é necessário se descontar a área da seção transversal da haste em uma das extremidades. As áreas são:

Área sob pressão na compressão: $\mathrm{A}_{\mathrm{c}}=\frac{1}{4} \cdot \pi \cdot D^{2} \cong 804 \mathrm{~mm}^{2}$

Área sob pressão na tração: $\mathrm{A}_{\mathrm{t}}=\frac{1}{4} \cdot \pi \cdot\left(D^{2}-D_{\text {haste }}^{2}\right) \cong 682 \mathrm{~mm}^{2}$ 
A partir do gráfico da figura 5.5, também é possível extrair uma informação aproximada do valor do coeficiente de atrito viscoso do amortecedor MR na ausência de tensão de controle. Entre um extremo e outro das curvas de força para zero volt de excitação há uma diferença de força $\Delta f=400 \mathrm{~N}$, e uma diferença de velocidade $\Delta v=490 \mathrm{~mm} / \mathrm{s}$. O coeficiente de atrito viscoso devido à passagem do fluido MR pela válvula e pelo pistão pode então ser calculado como segue:

$$
b=\frac{\Delta f-f_{a c}}{\Delta v} \cong 510 \mathrm{~N} . \mathrm{s} / \mathrm{m}
$$

Para verificação destes resultados uma nova análise de elementos finitos foi realizada, substituindo-se a corrente das bobinas de 3A para 2A. Todos os cálculos foram refeitos, porém com o objetivo de se chegar aos valores de força e coeficiente de atrito viscoso da válvula a partir dos valores geométricos $(L$ e $g)$, com os quais o protótipo foi construído.

O resultado dos cálculos foi o seguinte:

$\hat{f}_{c t 2}=1381 \mathrm{~N} \quad$ (força controlável de tração com excitação de $2 \mathrm{~A}$ )

$\hat{f}_{c c 2}=1630 \mathrm{~N} \quad$ (força controlável de compressão com excitação de $2 \mathrm{~A}$ )

$\hat{b}_{t}=429 \mathrm{~N} . \mathrm{s} / \mathrm{m} \quad$ (Coeficiente de atrito viscoso na tração)

$\hat{b}_{c}=506 \mathrm{~N} . \mathrm{s} / \mathrm{m} \quad$ (Coeficiente de atrito viscoso na compressão)

Considerando que as diferenças entre o resultado experimental e o teórico foram inferiores a $8 \%$, e que nos resultados experimentais há ainda que se considerar a resistência à passagem do fluxo de fluido pelo pistão, que não entrou no modelo teórico; conclui-se que o resultado do projeto foi satisfatório. 


\subsection{DISCUSSÃO}

A maior dificuldade de projeto de dispositivos MR é a forte interação entre os dois sistemas físicos envolvidos: o sistema mecânico de vazão do fluido e o sistema eletromagnético que gera o campo de controle do fluido MR.

Pela complexidade de se elaborar um processo de síntese direto, em função da dificuldade de modelagem da interação entre os dois sistemas físicos e pela grande variabilidade de geometrias possíveis e aplicáveis, bem como uma grande variedade de restrições físicas (como empacotamento de todo o conjunto, por exemplo), um processo iterativo, conforme o adotado, resultou numa técnica prática e melhor adaptável às aplicações variadas dos atuadores MR.

A seguir é proposto um procedimento sistemático e iterativo de projeto de atuadores MR que faz uso de análise de elementos finitos magnetostática para consolidar uma forma relativamente rápida de projeto, que dispensa a necessidade de construção de muitos protótipos para se obter um resultado capaz de atender a requisitos pré-estabelecidos.

O procedimento de projeto consiste em dez etapas e quatro níveis de iteração possíveis, cuja descrição está apresentada a seguir.

Início: Determinação dos requisitos de projeto, onde a partir de uma análise da aplicação devem ser definidos os parâmetros de força, velocidade, limites de deslocamento, tempo de resposta, freqüência de utilização, que serão utilizados como referências de projeto nas próximas etapas.

Passo 1: Escolha do modelo conceitual do dispositivo MR, ou seja, escolher entre o conceito de placas fixas (modo de fluxo gerado por pressão) ou placas móveis entre si ( modo de cisalhamento direto.).

Passo 2: Escolha do fluido MR, segundo sua viscosidade aparente e curva de magnetização.

Passo 3: Cálculo de parâmetros adicionais, necessários para o projeto baseado no volume de fluido ativo, como a vazão volumétrica $(Q)$, o diferencial de pressão controlável $\left(\Delta P_{\tau}\right)$ e a potência mecânica controlável $\left(W_{m}\right)$, por exemplo. 
Passo 4: Definição do ponto de magnetização máxima desejado para o fluido MR escolhido, o que corresponde a uma intensidade de campo magnético $(H)$ que atua sobre o fluido e a respectiva tensão de escoamento $\left(\tau_{0}\right)$ apresentada pelo fluido sob a ação de tal campo.

Passo 5: Cálculo dos parâmetros geométricos (comprimento $(L)$ e espessura $(g)$ do canal, respectivamente) para o conceito do dispositivo adotado.

Passo 6: Definição da geometria da válvula, quantidade de bobinas, tamanho das ranhuras das bobinas, bitola de fios, e empacotamento do conjunto.

Passo 7: Análise magnetostática via cálculo de elementos finitos, com o objetivo de identificar regiões de saturação de núcleo magnético, campo magnético máximo sobre o fluido, magnetização do fluido e indutância do circuito magnético.

Passo 8: Análise termodinâmica para avaliar a temperatura máxima que o fluido irá atingir dentro da válvula MR.

Passo 9: Tomada de decisão de qual dos níveis de iteração abaixo será escolhido para aprimoramento do projeto, ou verificação de que o projeto está concluído.

Iteração-nível 1: Reavaliação do passo 6 em função do resultado do passo 9, ou seja, reavaliação do projeto da válvula em função da temperatura alcançada pelo fluido e da resistência térmica dos materiais utilizados na isolação, e nos próprios circuitos elétricos.

Iteração-nível 2: Reavaliação do passo 6 em função da densidade de fluxo magnético no fluido não ter atingido o valor definido no passo 4.

Iteração-nível 3: Reavaliação do ponto de magnetização máxima desejado para o fluido MR escolhido no passo 4 em função da não eficácia da iteração de nível 2.

Iteração-nível 4: Reavaliação dos requisitos de projeto: força máxima controlável e alcance dinâmico $(\lambda)$, em função da não eficácia da iteração de nível 3.

A figura 5.6 ilustra o fluxograma deste procedimento. 


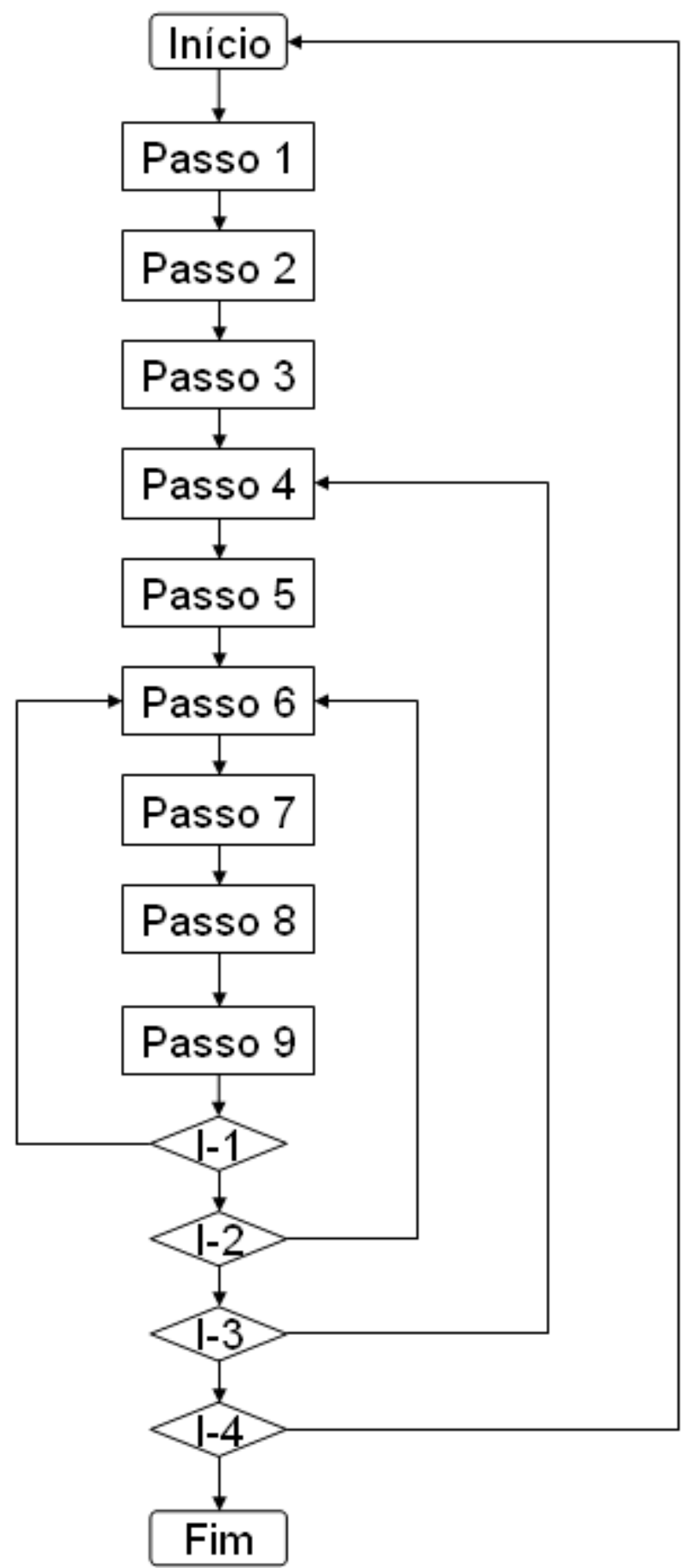

Figura 5.6 - Fluxograma do procedimento de projeto de dispositivos MR. 


\section{NOVO MODELO DINÂMICO DISCRETIZADO}

Um modelo dinâmico de amortecedores MR deve ser capaz de representar a três principais características dinâmicas destes dispositivos, que são: a capacidade de gerar forças apenas no sentido oposto ao movimento do pistão; a dependência da intensidade da força gerada em função da velocidade do pistão e da intensidade do campo magnético na válvula; e a dinâmica do circuito eletromagnético, entre a aplicação de uma entrada de tensão e a formação efetiva do campo magnético na válvula do amortecedor MR. É importante salientar que, na segunda característica citada, a dependência da velocidade do pistão é bastante nãolinear, e apresenta um comportamento histerético entre força e velocidade. Este tipo de comportamento é intensificado pelo efeito elástico dos elementos de borracha presentes nos terminais de conexão do amortecedor com outros componentes do sistema de suspensão.

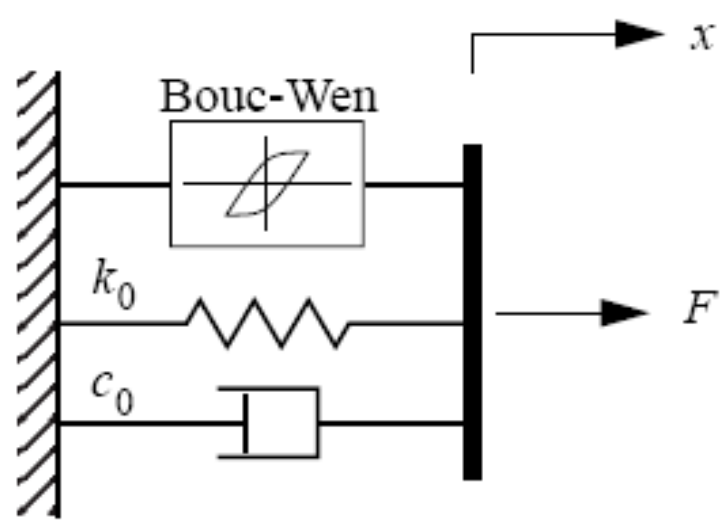

Figura 6.1 - Modelo proposto do amortecedor MR.

O diagrama esquemático de um modelo mecânico que apresenta estas características é apresentado na figura 6.1. Nesta figura, a variável $x$ representa o deslocamento da haste do amortecedor e $F$ é a força de reação do amortecedor em função da imposição do deslocamento $x$ e a velocidade $\dot{x}$. Os parâmetros $k_{0}$ e $c_{0}$ são respectivamente a rigidez da mola a ar do acumulador e do coeficiente de amortecimento resultante do escoamento viscoso do fluido. 
Uma variável $\zeta^{25}$ é usada para emular um modelo de histerese tipo Bouc-Wen, que é um modelo numericamente tratável e tem sido extensivamente usado (SPENCER et al., 1996).

As equações originais deste modelo proposto por Spencer et al. (1996) são reproduzidas a seguir:

$$
\begin{aligned}
& \dot{\zeta}=-\gamma \cdot|\dot{x}| \cdot \zeta \cdot|\zeta|^{n-1}-\beta \cdot \dot{x} \cdot|\zeta|^{n}+A \cdot \dot{x} \\
& \dot{u}=-\eta \cdot(u-v) \\
& F=c_{0}(u) \cdot \dot{x}+k_{0} \cdot\left(x-x_{0}\right)+\alpha(u) \cdot \zeta \\
& \alpha(u)=\alpha_{a}+\alpha_{b} \cdot u \\
& c_{0}(u)=c_{0 a}+c_{0 b} \cdot u
\end{aligned}
$$

As entradas do modelo são $x(t), \dot{x}(t)$ e $v(t)$, e a saída do modelo é a força $F(t)$, e há onze parâmetros: $n, \gamma, \beta, A, \eta, k_{0}, x_{0}, \alpha_{a}, \alpha_{b}, c_{0 a}$ e $c_{0 b}$. A variável $\dot{x}(t)$ equivale à velocidade $U$ na equação apresentada na figura 3.5, página 69. A entrada de controle é a variável $v$ que aparece da equação (6.2), cuja unidade é o volt. Há somente duas variáveis de estado: $\zeta(t)$, que é a variável evolucionária de Bouc-Wen, e $u(t)$, que é uma variável proporcional à corrente elétrica no eletro imã da válvula.

Ajustando-se os parâmetros do modelo (em especial $\gamma, \beta$ e $A$ ), pode-se controlar a linearidade no descarregamento e a suavidade da transição na inversão da velocidade (regiões de pré-carga e pós-carga). Além disso, a força do acumulador, $f_{0}$, pode ser diretamente incorporada neste modelo através de um deslocamento inicial $x_{0}$ na mola linear $k_{0}$.

Embora este modelo em tempo-contínuo seja adequado para desenvolver algoritmos de controle semi-ativo, tirando a máxima vantagem das características únicas do amortecedor MR, ele não é apropriado para uma aplicação de controle digital, por exemplo. Aplicações digitais requerem modelos em tempo-discreto, que podem trabalhar com dados amostrados numa dada freqüência. Além do mais, a aproximação em tempo-discreto pode ser

\footnotetext{
${ }^{25}$ No trabalho original de Spencer et al. 1996, foi utilizada a letra "z" ao invés de " $\zeta$ " para representar a variável evolucionária Bouc-Wen. Aqui esta letra foi modificada para se evitar confusão com o operador "z" nas funções de transformada $\mathrm{z}$ discretas.
} 
implementada num micro-controlador ou DSP (“Digital Signal Processor") e utilizado como um modelo referência em estratégias mais sofisticadas de controle, que consideram o comportamento dinâmico do atuador.

O principal objetivo desta primeira parte do trabalho é propor um novo modelo para amortecedores MR. Este modelo é obtido a partir de uma aproximação do modelo Bouc-Wen em tempo-contínuo por uma representação em tempo discreto.

Para se obter uma versão em tempo discreto deste modelo, a equação (6.1) foi modificada. O parâmetro $n$ foi fixado com o valor 2, e a variável de entrada $\dot{x}$ foi definida como $v_{x}(t)$. Esta equação diferencial é então escrita da seguinte forma:

$$
\dot{\zeta}=\frac{d \zeta}{d t}=-\gamma \cdot\left|v_{x}\right| \cdot \zeta \cdot|\zeta|-\beta \cdot v_{x} \cdot \zeta^{2}+A \cdot v_{x}
$$

Uma maneira simples de converter a equação diferencial acima em uma equação de diferenças é aproximar a derivada da variável de estado por uma diferença. Existem várias formas de se fazer esta aproximação, contudo as formas mais simples são: a diferença para frente, também chamada de método de Euler, que pode ser visto na equação (6.7); ou a diferença para trás, conforme a equação (6.8). Nestas equações, $h$ é o intervalo de tempo entre amostras consecutivas e os instantes de amostragem são $t_{k}=k h$, onde $k$ é um número inteiro positivo.

$$
\begin{aligned}
& \frac{d \zeta(t)}{d t} \approx \frac{\zeta(t+h)-\zeta(t)}{h}=\frac{z-1}{h} \cdot \zeta(k h) \\
& \frac{d \zeta(t)}{d t} \approx \frac{\zeta(t)-\zeta(t-h)}{h}=\frac{1-z^{-1}}{h} \cdot \zeta(k h)
\end{aligned}
$$

A partir de uma aproximação por diferença para frente, é possível que um sistema contínuo no tempo possa ser mapeado em um sistema instável em tempo-discreto. Por outro lado, quando é utilizada a aproximação por diferença para trás, qualquer sistema em tempo contínuo linear e estável sempre resultará num sistema em tempo-discreto também estável.

Então, aplicando-se a aproximação por diferença para trás na equação (6.6), tem-se: 


$$
\begin{gathered}
\frac{\zeta(k h)-\zeta(k h-h)}{h}=-\gamma \cdot\left|v_{x}(k h)\right| \cdot \zeta(k h) \cdot|\zeta(k h)|-\beta v_{x}(k h) \cdot[\zeta(k h)]^{2}+A v_{x}(k h) \\
\Rightarrow \frac{\zeta(k)-\zeta(k-1)}{h}=-\gamma \cdot\left|v_{x}(k)\right| \cdot \zeta(k) \cdot|\zeta(k)|-\beta \cdot v_{x}(k) \cdot[\zeta(k)]^{2}+A \cdot v_{x}(k) \\
\Rightarrow \zeta(k)+\gamma \cdot h \cdot\left|v_{x}(k)\right| \cdot \zeta(k) \cdot|\zeta(k)|+\beta \cdot h \cdot v_{x}(k) \cdot[\zeta(k)]^{2}=A \cdot h \cdot v_{x}(k)+\zeta(k-1)
\end{gathered}
$$

A maior dificuldade na discretização deste modelo está em suas não linearidades. O principal resultado desta primeira parte do trabalho é a proposição de uma nova forma para a equação (6.11) em que o termo quadrático é eliminado. Para isso, um dos fatores da multiplicação foi deslocado um intervalo de tempo, conforme apresentado na equação (6.12):

$$
\zeta(k)+\gamma \cdot h \cdot\left|v_{x}(k)\right| \cdot \zeta(k) \cdot|\zeta(k-1)|+\beta \cdot h \cdot v_{x}(k) \cdot \zeta(k) \cdot \zeta(k-1)=A \cdot h \cdot v_{x}(k)+\zeta(k-1)
$$

Assim, uma nova forma para o modelo de Bouc-Wen é proposta, porém agora na forma de uma equação de diferenças, como é apresentado a seguir:

$$
\zeta(k)=\frac{A \cdot h \cdot v_{x}(k)+\zeta(k-1)}{1+\gamma \cdot h \cdot\left|v_{x}(k)\right| \cdot|\zeta(k-1)|+\beta \cdot h \cdot v_{x}(k) \cdot \zeta(k-1)}
$$

Da mesma forma, a aproximação de diferença para trás pode ser aplicada na equação (6.2), resultando em:

$$
\frac{u(k)-u(k-1)}{h}=-\eta \cdot(u(k)-v(k))
$$

Para aumentar a flexibilidade do modelo e compensar o grau de liberdade perdido no modelo Bouc-Wen (eliminação do parâmetro n), os parâmetros $\gamma, \beta$ e $A$ deixaram de ser constantes, passando a ser dependentes da variável de estado $u(k)$ por meio de funções polinomiais; e os parâmetros $\alpha$ e $c_{0}$ que já eram funções de $u(k)$, tiveram sua ordem aumentada. Além disso, foi introduzido um novo parâmetro $\xi$ no denominador do novo modelo Bouc-Wen proposto, conforme apresentado na equação (6.19). Assim, o novo modelo dinâmico completo para amortecedores MR em tempo discreto, formado por equações de diferenças e polinomiais, está apresentado a seguir: 


$$
\begin{aligned}
& u(k)=\frac{\eta \cdot h \cdot v(k)+u(k-1)}{1+\eta \cdot h} \\
& \gamma(u(k))=\gamma_{a}+\gamma_{b} \cdot u(k)+\gamma_{c} \cdot u(k)^{2} \\
& \beta(u(k))=\beta_{a}+\beta_{b} \cdot u(k) \\
& A(u(k))=A_{a}+A_{b} \cdot u(k)+A_{c} \cdot u(k)^{2} \\
& \zeta(k)=\frac{A(u(k)) \cdot h \cdot v_{x}(k)+\zeta(k-1)}{\xi+\gamma(u(k)) \cdot h \cdot\left|v_{x}(k)\right| \cdot|\zeta(k-1)|+\beta(u(k)) \cdot h \cdot v_{x}(k) \cdot \zeta(k-1)} \\
& \alpha(u(k))=\alpha_{a}+\alpha_{b} \cdot u(k)+\alpha_{c} \cdot u(k)^{2}+\alpha_{d} \cdot u(k)^{3}+\alpha_{e} \cdot u(k)^{4}+\alpha_{f} \cdot u(k)^{5} \\
& c_{0}(u(k))=c_{0 a}+c_{0 b} \cdot u(k)+c_{0 c} \cdot u(k)^{2} \\
& F(k)=c_{0}(u(k)) \cdot v_{x}(k)+k_{0} \cdot\left(x(k)-x_{0}\right)+\alpha(u(k)) \cdot \zeta(k)
\end{aligned}
$$

Este novo modelo apresenta um total de 21 parâmetros. As variáveis de entrada são $x(k)$, $v_{x}(k)$ e $v(k)$, e a saída é a força $F(k)$. 


\section{CONSTRUÇÃO DO $2^{\circ}$ PROTÓTIPO}

Um segundo protótipo de amortecedor MR foi projetado e construído. Este novo projeto, além que introduzir melhorias ao projeto do primeiro protótipo, teve como objetivo obter as mesmas dimensões físicas de um amortecedor convencional frontal de uma caminhonete Ford, modelo Ranger, ano 1998.

A principal melhoria ocorreu na válvula de controle do fluido MR. O conceito da nova válvula é uma combinação do conceito utilizado pela Visteon e do conceito da Delphi, ou seja, a válvula continua tendo duas bobinas como o $1^{\circ}$ protótipo, contudo o campo magnético da válvula não se fecha mais com o tubo do amortecedor, ficando contido na própria válvula. Este novo conceito tem duas vantagens: existe maior controle da precisão e concentricidade do furo anelar, por onde passa o fluido e onde as suas propriedades reológicas são controladas; e o conjunto da válvula é mais curto, permitindo um curso do pistão maior para um mesmo comprimento do amortecedor. As três fotos da figura 7.1 mostram a nova válvula, que também recebeu aprimoramentos construtivos, no sentido de facilitar a sua montagem e melhorar a sua robustez, uma vez que o objetivo final deste protótipo é ser testado num veículo real. Como exemplo destas melhorias pode-se citar a cobertura das bobinas com um revestimento a base de PTFE e grafite, que reduz o atrito sobre as bobinas, evitando que elas sejam destruídas pelo fluxo do fluido, que pode atingir localmente temperaturas e forças de arrasto bastante elevadas.

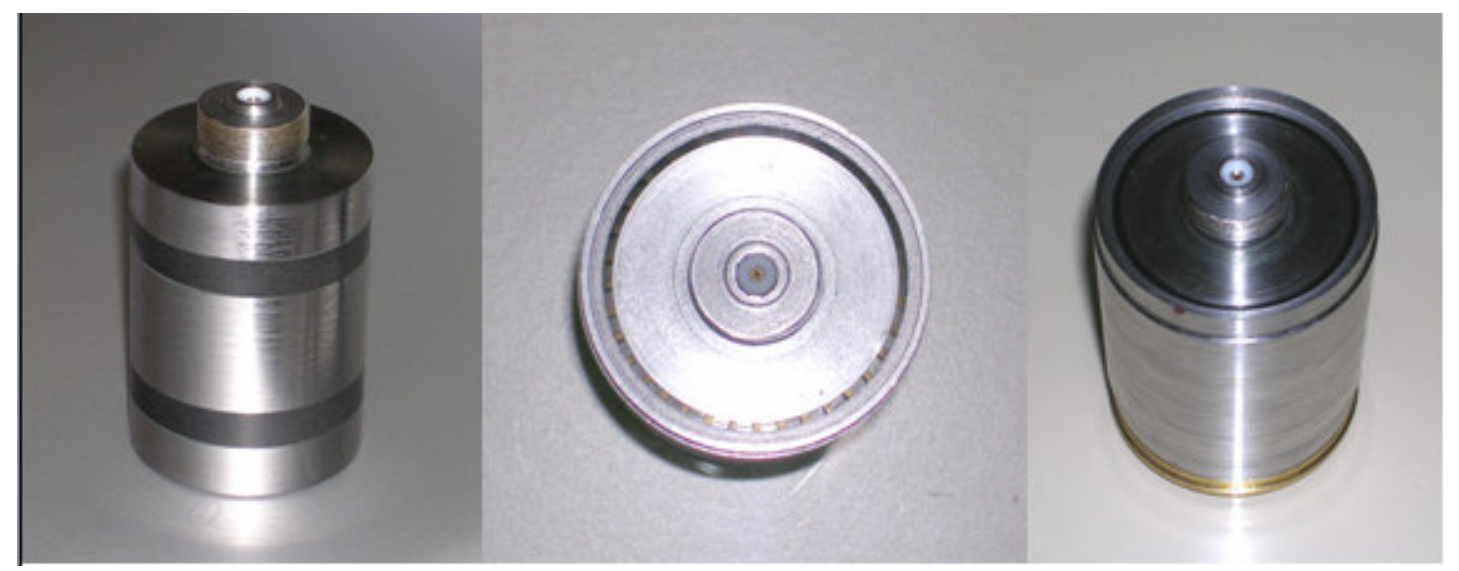

Figura 7.1 - Válvula magnética do $2^{\circ}$ protótipo. 
Outras melhorias ocorreram nas vedações, no pistão flutuante que recebeu um elemento de vedação "o-ring” adicional, no acréscimo de uma válvula de retenção na câmara de ar que facilita a pressurização e despressurização da mesma, e de uma tampa rosqueável que permite a troca do fluido MR.

O projeto do protótipo seguiu restrições dimensionais impostas pelas dimensões da suspensão frontal da caminhonete Ranger, que são:

- comprimento máximo (do amortecedor): $474 \pm 3 \mathrm{~mm}$;

- comprimento mínimo (do amortecedor): $350 \pm 3 \mathrm{~mm}$;

- curso total: $124 \pm 3 \mathrm{~mm}$ ( aproximadamente $\pm 62 \mathrm{~mm}$ ).

As características do amortecedor original também impõem restrições de projeto, uma vez que o amortecedor MR que o substituirá deverá ter um alcance dinâmico tal que sua força máxima seja maior ou igual a força máxima do amortecedor convencional e a sua força mínima (estado "off”) seja menor que a menor força do amortecedor convencional. Como a força do amortecedor convencional varia com a velocidade de movimentação do seu pistão, tomou-se como referência a velocidade de $1 \mathrm{~m} / \mathrm{s}$. Segundo as especificações do amortecedor original da caminhonete Ranger, sabe-se:

- força de compressão $(1 \mathrm{~m} / \mathrm{s}): 950 \pm 90 \mathrm{~N}$;

- força de tração $(1 \mathrm{~m} / \mathrm{s}): 3000 \pm 220 \mathrm{~N}$.

Portanto, foi especificado que na velocidade do pistão de $1 \mathrm{~m} / \mathrm{s}$ o amortecedor MR deve apresentar um alcance dinâmico de 4 e uma força inferior a $950 \mathrm{~N}$ (a 1m/s) quando desligado.

Neste protótipo, o projeto da válvula magnética seguiu o procedimento sistemático desenvolvido na seção 4 deste trabalho, e o desenho do amortecedor e empacotamento do mesmo dentro das restrições dimensionais do veículo foram feitos com o auxílio do CAD Inventor $^{\circledR}$ da Autodesk. O modelo 3D completo do $2^{\circ}$ protótipo é apresentado da figura 7.2. Como pode ser observado o desenho do amortecedor MR seguiu o conceito monotubular, ao invés de bitubular como é o amortecedor original da caminhonete Ranger. 


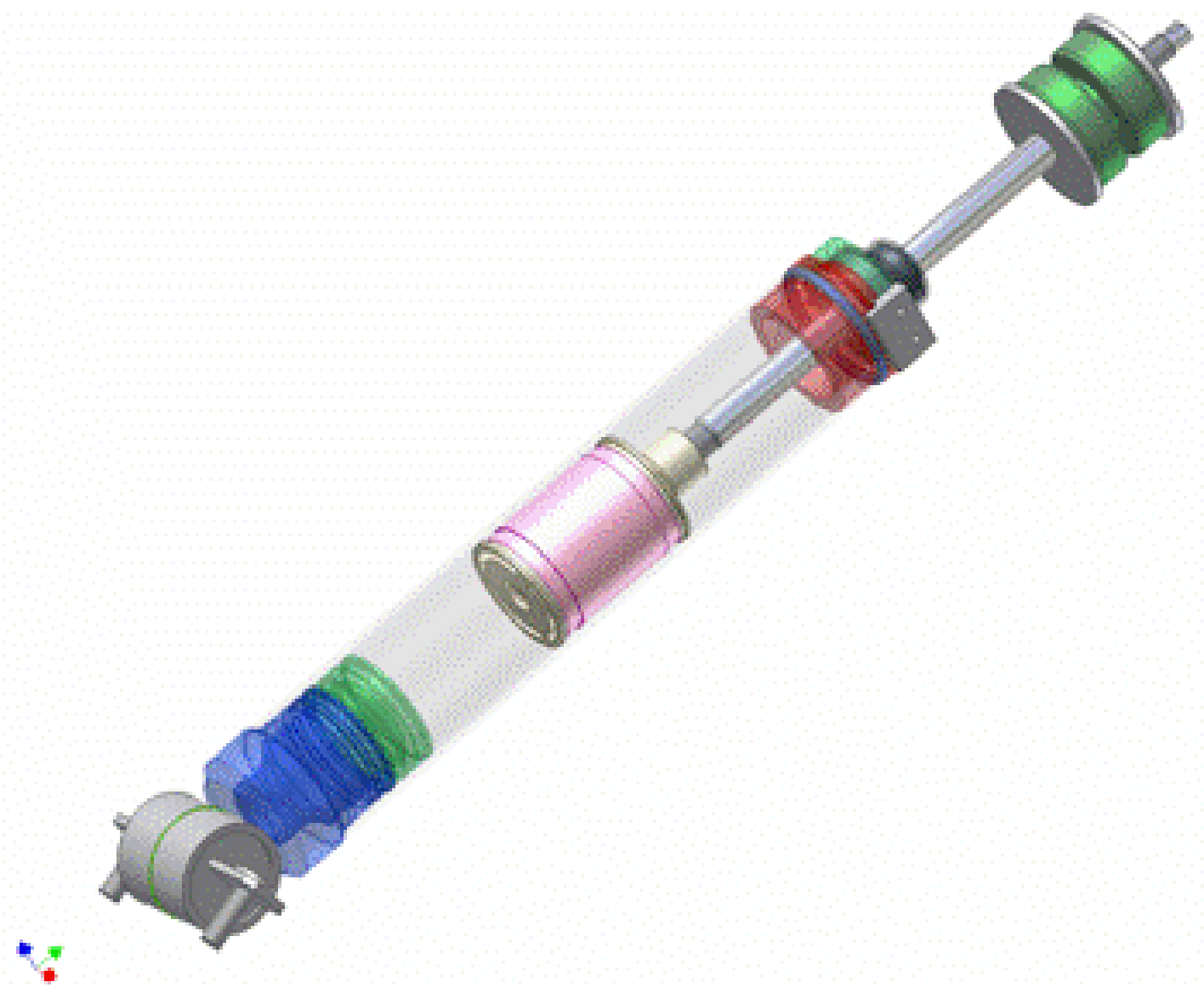

Figura 7.2 - Modelo em CAD 3D do amortecedor MR para caminhonete Ranger.

Na figura 7.3 estão apresentadas todas as peças que foram utilizadas na montagem do amortecedor, que foram construídas a partir do modelo em CAD.
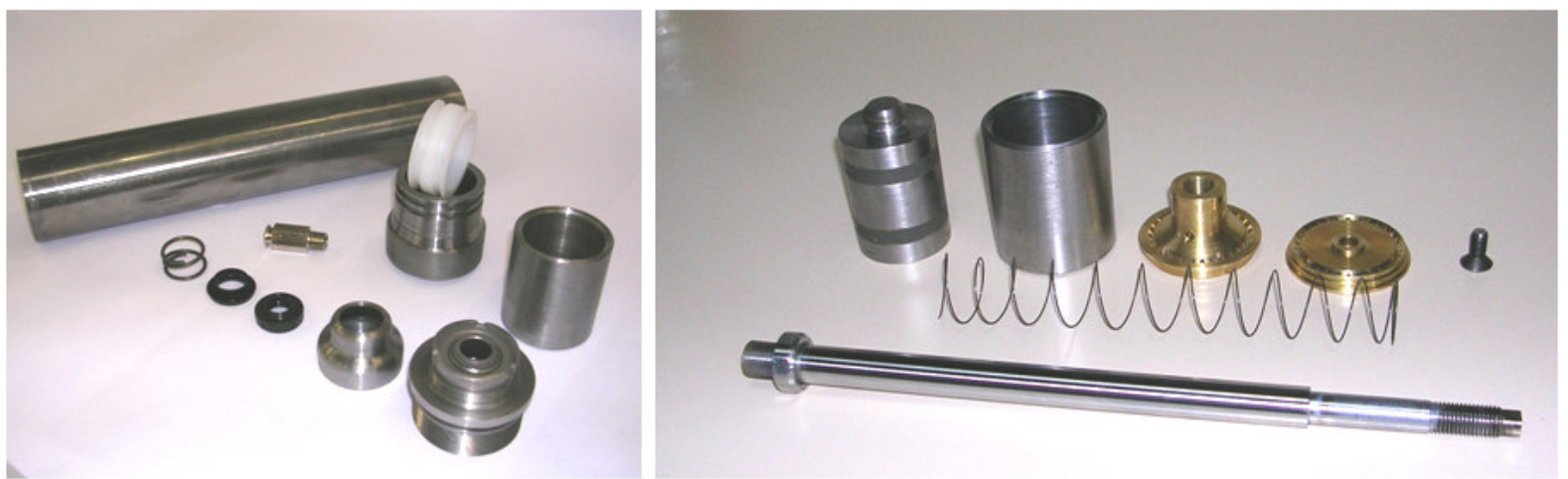

Figura 7.3 - Modelo Conjunto de peças do $2^{\circ}$ protótipo do amortecedor MR.

Uma comparação visual entre o amortecedor original frontal da caminhonete Ford Ranger é apresentado na figura 7.4. Pode-se notar que o amortecedor MR ficou mais longo. 
Isto se deveu basicamente a existência do acumulador na versão monotubular, que não existe no original, e o fato da válvula MR ocupar um espaço maior que o pistão do amortecedor convencional. Felizmente as dimensões da suspensão da caminhonete permitiram este alongamento do amortecedor.

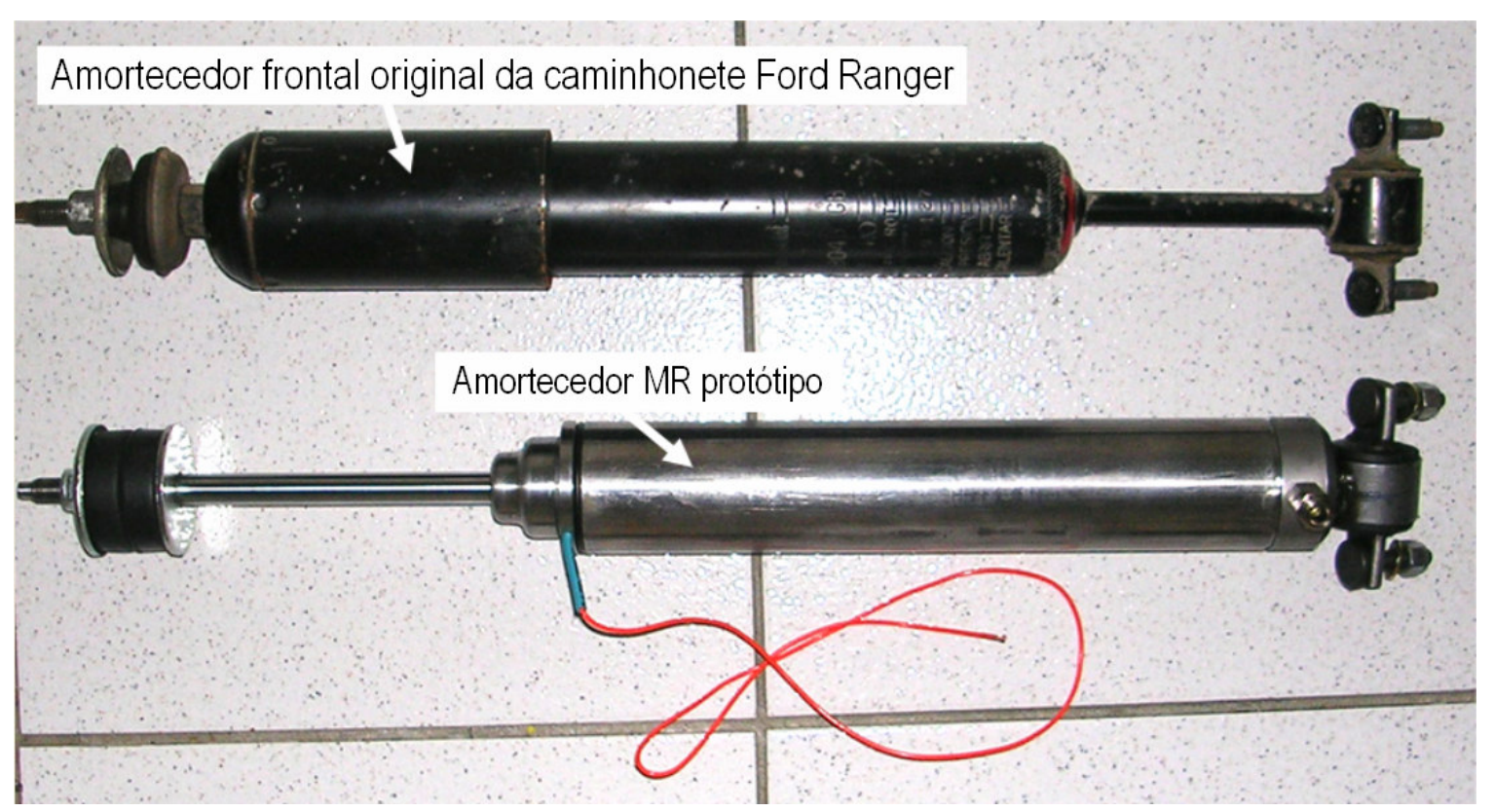

Figura 7.4 - Comparação do amortecedor original com o novo amortecedor MR. 


\section{TESTE EXPERIMENTAL DO $2^{\circ}$ PROTÓTIPO}

\subsection{DESCRIÇÃO DO EXPERIMENTO}

Uma estrutura de carga foi construída para se realizar os testes experimentais no $2^{\circ}$ protótipo. O desenho esquemático desta estrutura, bem como os sinais e equipamentos utilizados estão descritos na figura 8.1.

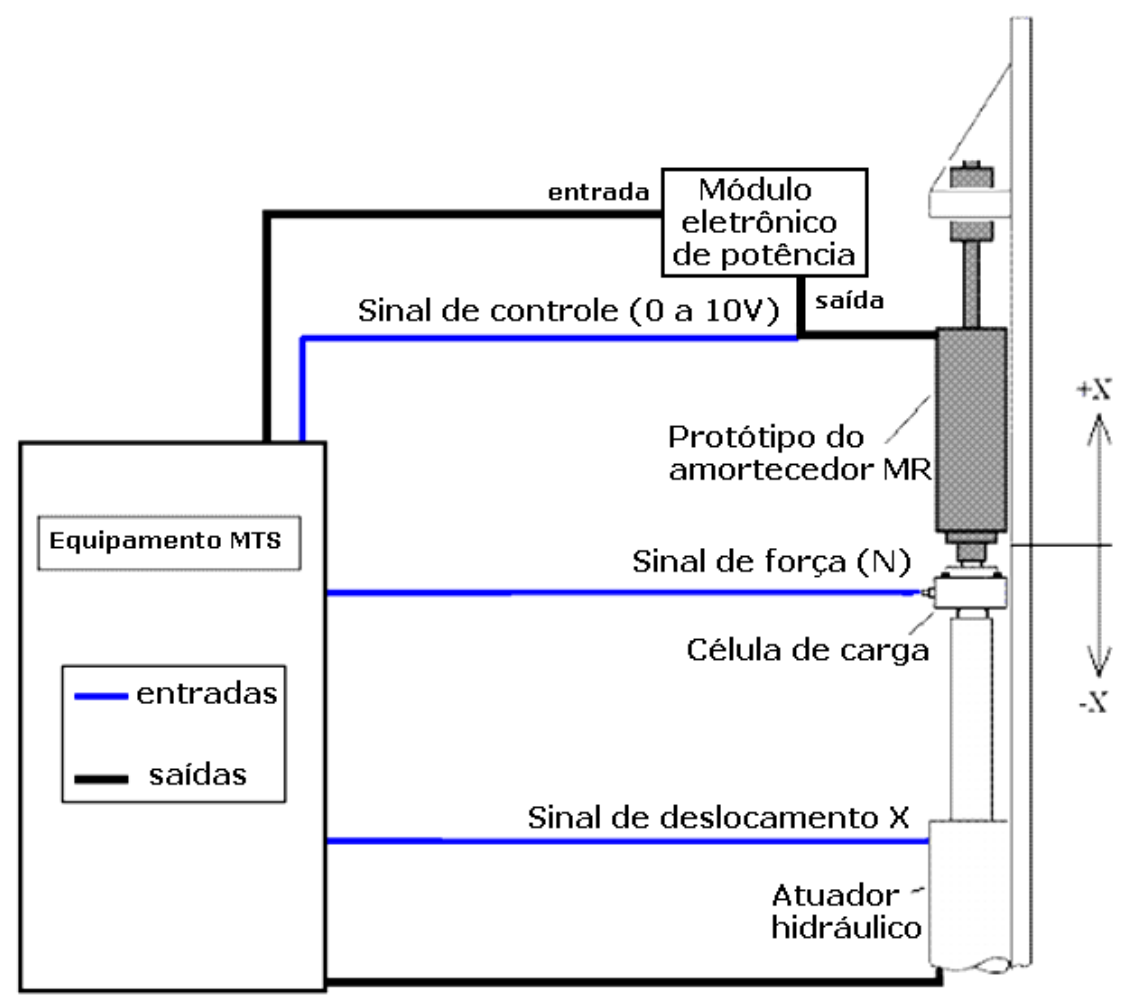

Figura 8.1 - Diagrama esquemático da estrutura de teste.

Nesta preparação, um atuador hidráulico da MTS foi empregado para movimentar o amortecedor. Este atuador apresenta um dispositivo para medição do seu deslocamento linear, que é utilizado para medir o deslocamento do conjunto haste/pistão do amortecedor MR. Em série com o cilindro hidráulico e o amortecedor MR foi montada uma célula de carga de $\pm 15 \mathrm{kN}$, para a medida da resposta de força do amortecedor MR em função dos movimentos aplicados pelo atuador hidráulico e pela variação da tensão nas bobinas da válvula MR. O 
sinal de tensão elétrica (de 0 a 10V) aplicado a entrada do amortecedor MR é amplificado por um circuito eletrônico de potência, que é capaz de suprir correntes acima de $3 \mathrm{~A}$, sem variação da tensão aplicada.

Os três sinais: força, deslocamento da haste/pistão, e tensão de controle do amortecedor MR foram amostrados a uma freqüência de $1024 \mathrm{~Hz}$ por uma unidade de aquisição de dados MTS.

Foram realizados dois experimentos: um com amplitude de deslocamento de $\pm 15 \mathrm{~mm}$, e outro com amplitude de $\pm 30 \mathrm{~mm}$. Em ambos, o deslocamento imposto seguiu uma função senoidal com freqüência de $2,5 \mathrm{~Hz}$.

A figura 8.2 apresenta a implementação física da estrutura de testes. Um MTS FlexTest GT foi o equipamento utilizado para gerar e monitorar os sinais. Um sensor de temperatura foi utilizado para medir a temperatura na superfície externa do amortecedor. Toda a aquisição de dados foi realizada com o amortecedor a uma temperatura de $60{ }^{\circ} \mathrm{C}\left( \pm 5^{\circ} \mathrm{C}\right)$. Este cuidado foi necessário para reduzir a dependência da temperatura entre o resultado de experimentos distintos.

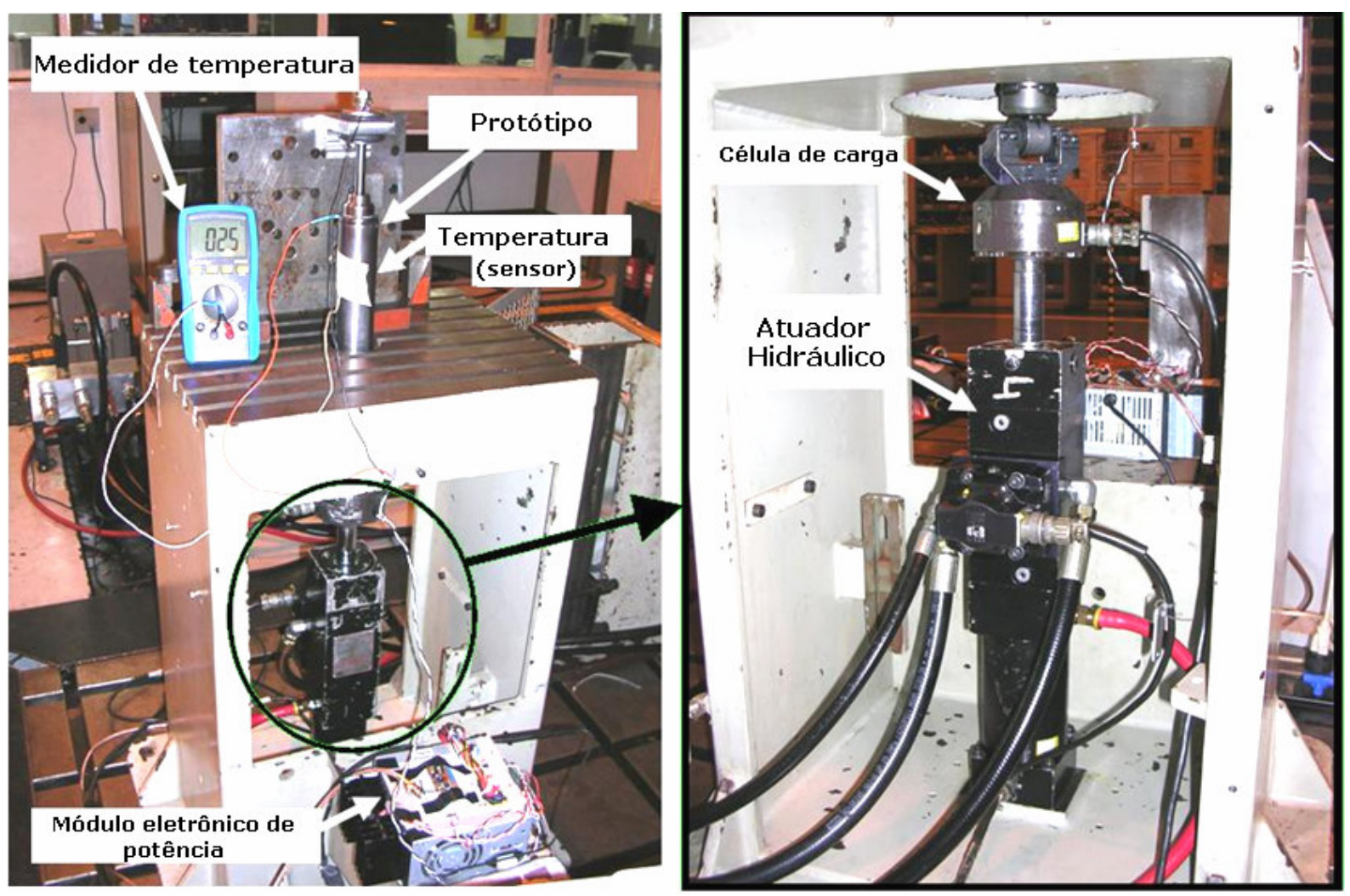

Figura 8.2 - Realização física da estrutura de teste (Laboratório da Dana Nakata). 
O equipamento de servo controle utilizado na realização dos testes no segundo protótipo está apresentado na figura 8.3.

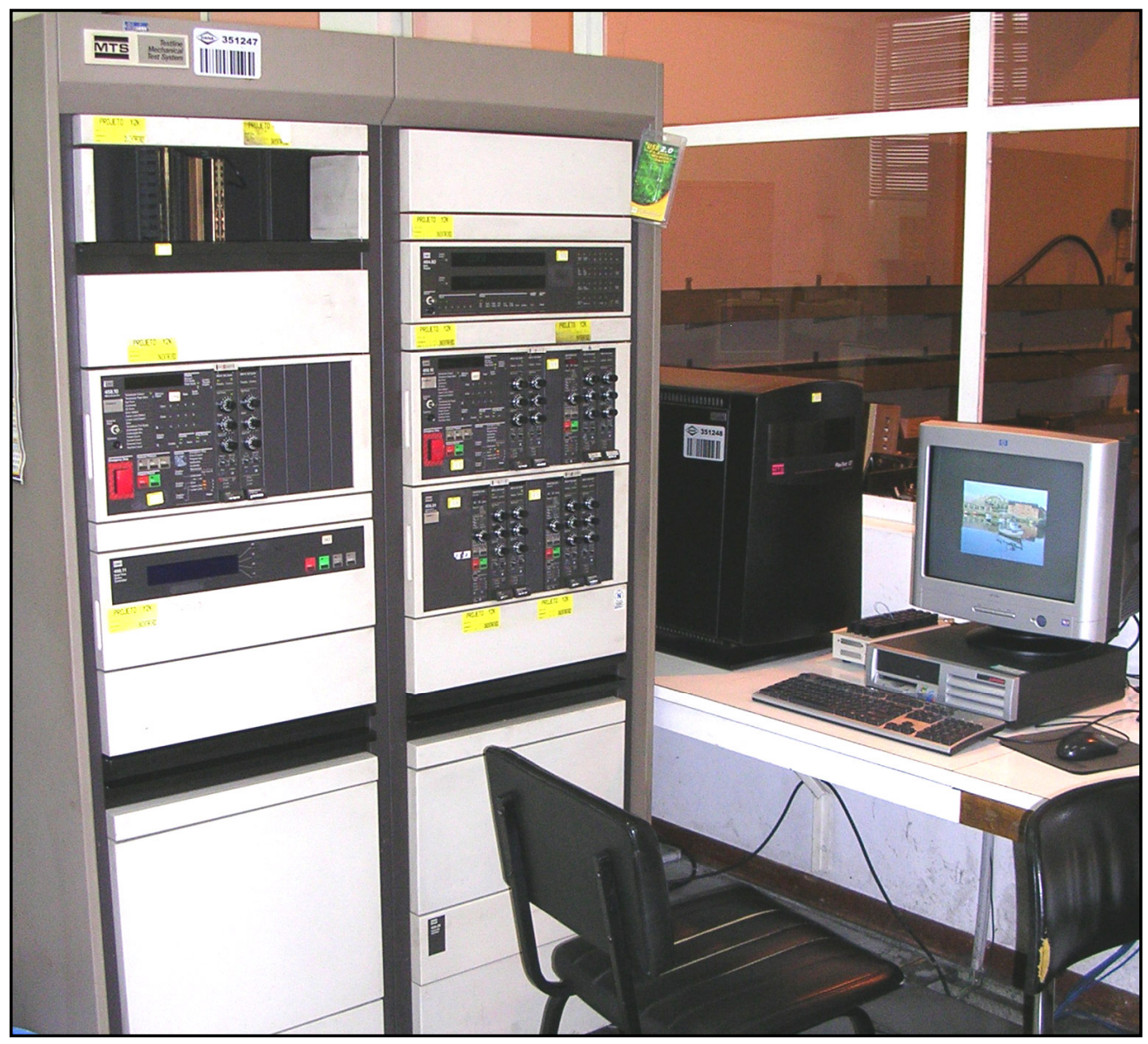

Figura 8.3 - Equipamentos MTS utilizado no experimento. 


\subsection{RESULTADOS EXPERIMENTAIS}

Foram propostos três diferentes experimentos para se tentar abranger o máximo possível os principais aspectos dinâmicos do atuador MR. No primeiro experimento, foi imposto ao amortecedor um deslocamento com amplitude $\pm 30 \mathrm{~mm}$ na forma de uma onda senoidal de 1Hz. Durante este deslocamento senoidal foram aplicados degraus consecutivos e acumulativos de 2 volts de amplitude na entrada de controle do amortecedor, variando a tensão desde 0 até 10 volts. O sinal de força foi medido pela célula de carga e armazenado num arquivo de computador. Estes sinais do primeiro experimento estão apresentados na figura 8.4 , e mostram principalmente a relação entre a tensão de controle e a intensidade da força controlável do amortecedor.

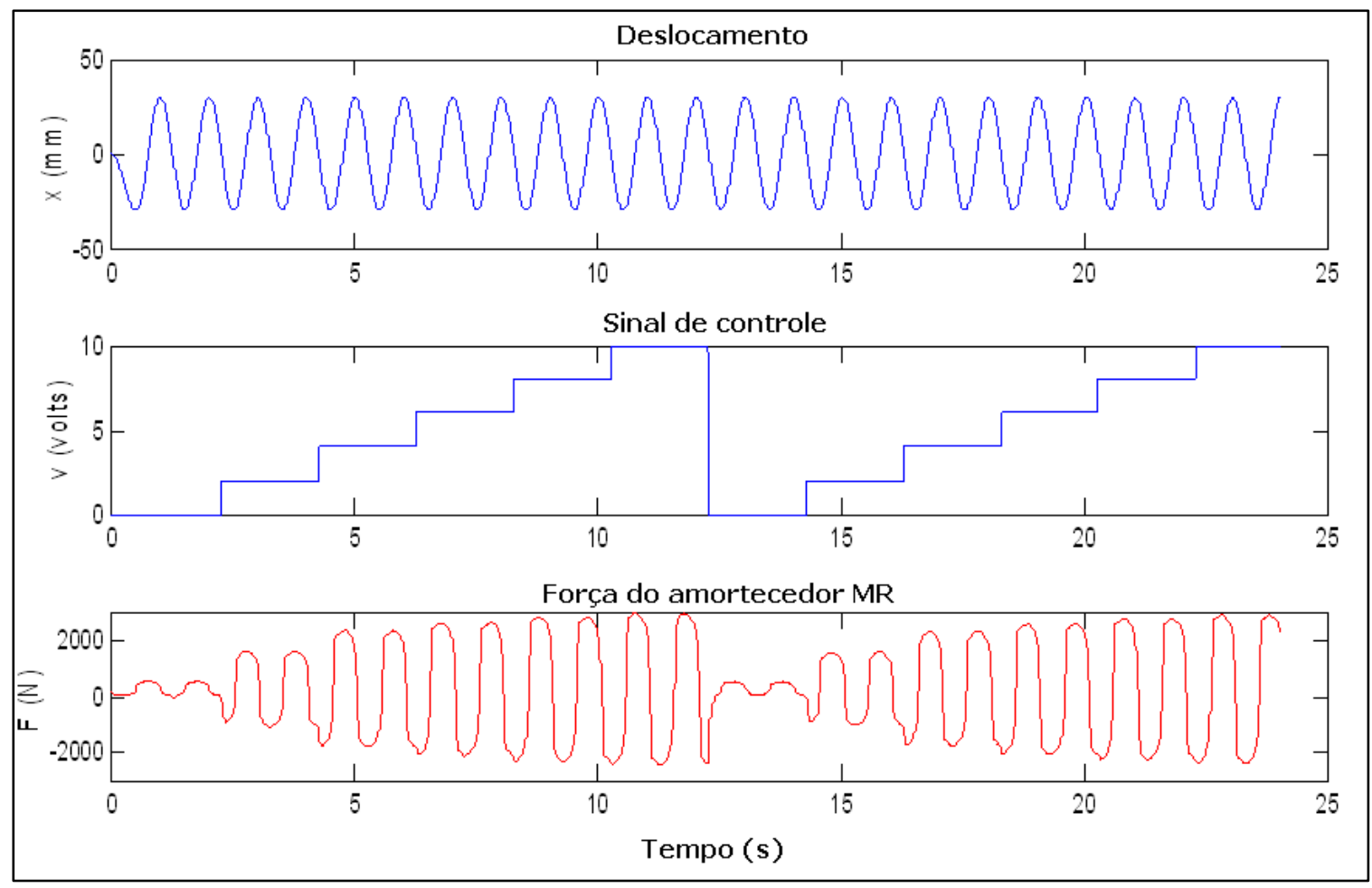

Figura 8.4 - Dados do primeiro experimento.

No segundo experimento foi imposto um deslocamento em onda triangular com amplitude de $15 \mathrm{~mm}$ e freqüência de $1 \mathrm{~Hz}$, e no meio de algumas rampas deste movimento foram aplicados degraus de amplitude 8 volts, conforme apresentado na figura 8.4. Como em cada rampa do deslocamento a velocidade do pistão do amortecedor é praticamente constante, este experimento produz informações importantes sobre o tempo de resposta do amortecedor MR para excitações em degrau. 


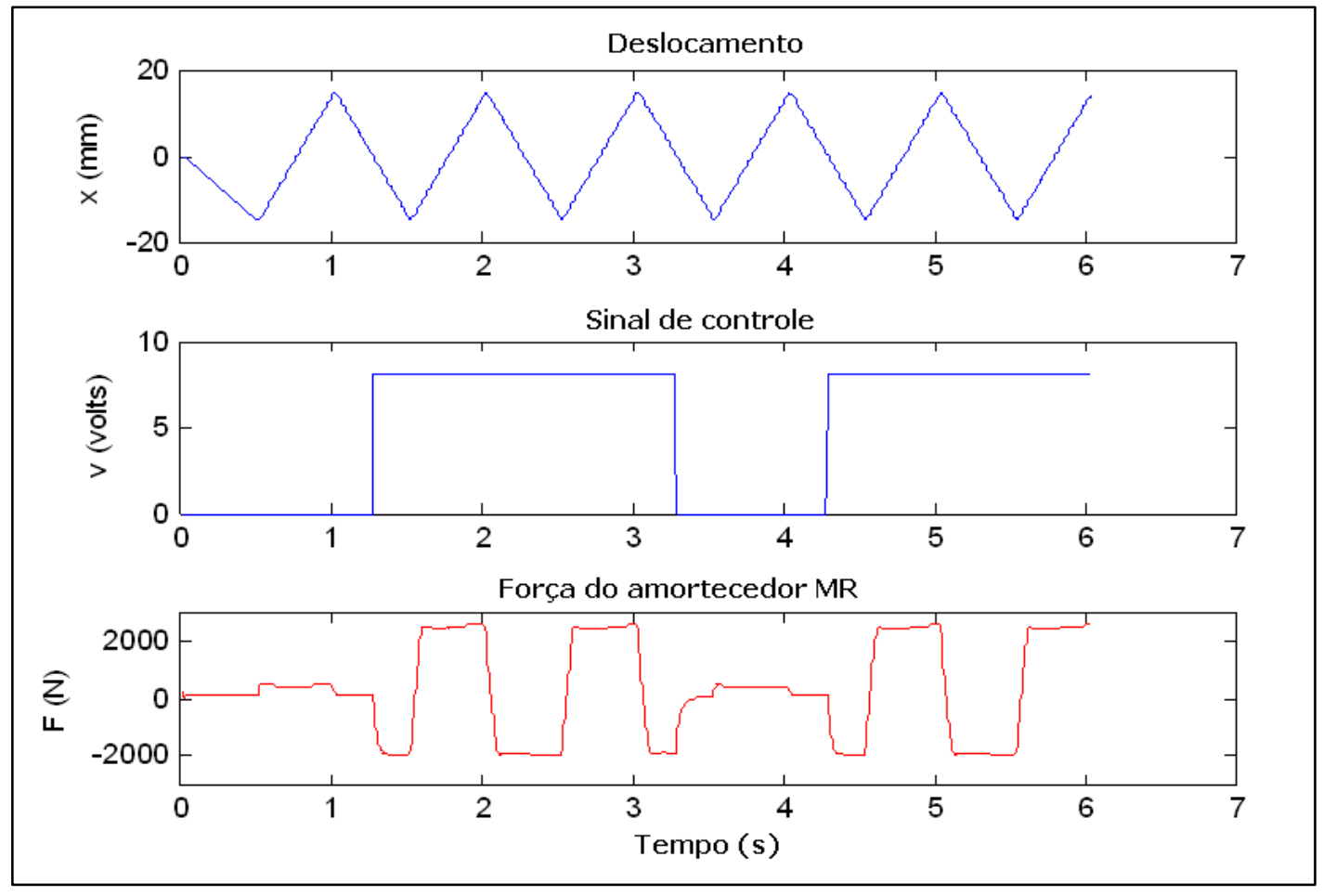

Figura 8.5 - Dados do segundo experimento.

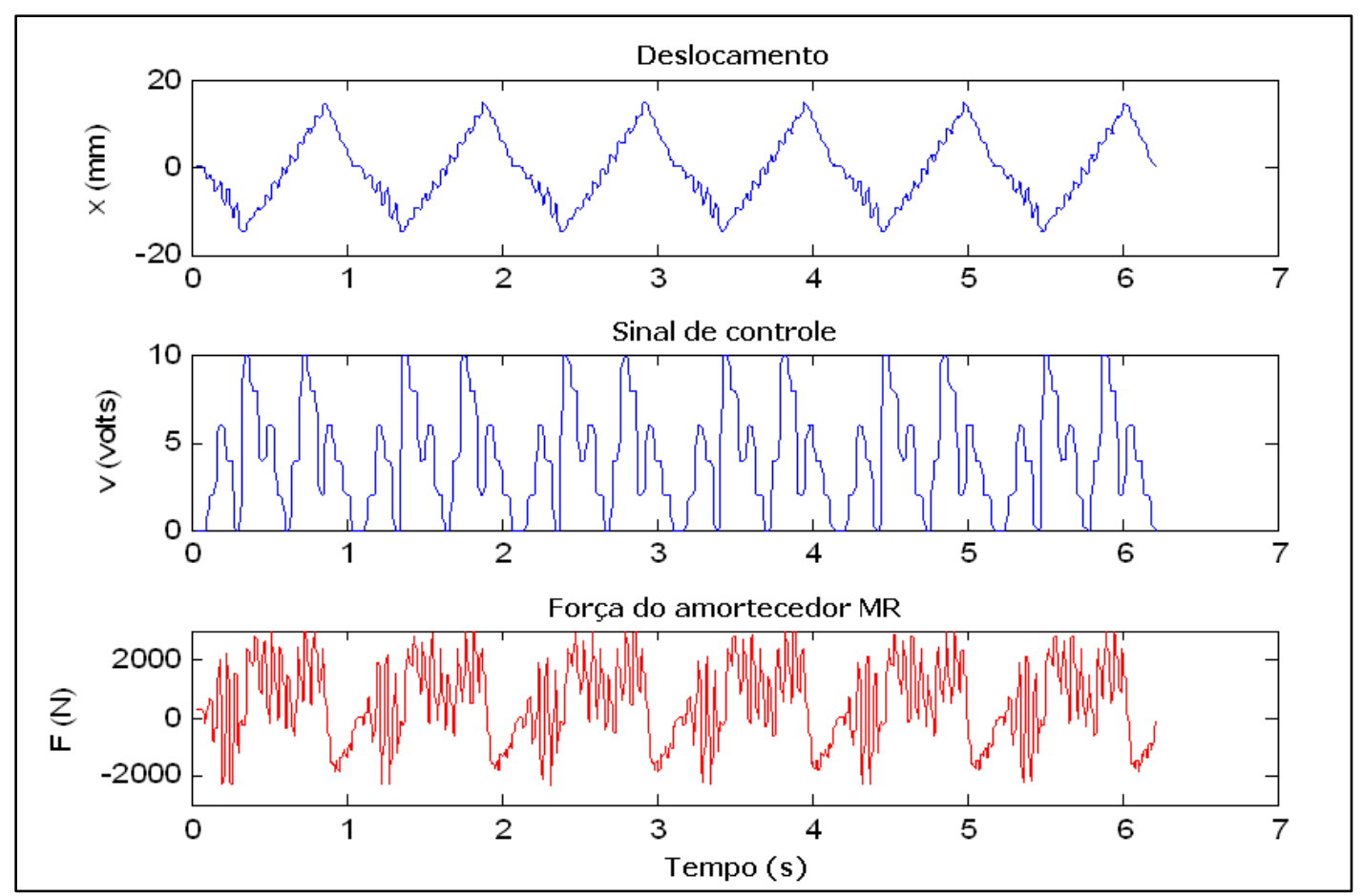

Figura 8.6 - Dados do terceiro experimento. 
No terceiro experimento também foi aplicado um deslocamento em onda triangular com amplitude $15 \mathrm{~mm}$ e freqüência de $1 \mathrm{~Hz}$, porém foi adicionado ao sinal de deslocamento uma harmônica de $10 \mathrm{~Hz}$ com amplitude de $3 \mathrm{~mm}$ na forma senoidal. Além disso, um sinal "aleatório" de tensão foi aplicado na entrada de controle, conforme mostra a figura 8.6. Este experimento visa dar informações focadas no comportamento do amortecedor MR próximo da sua condição de trabalho real.

Todos os sinais foram amostrados a uma freqüência de $1024 \mathrm{~Hz}$, porém a freqüência de amostragem foi reduzida tomando-se apenas um dado a cada quatro amostras dos sinais. Este dado foi calculado a partir da média aritimética das quatro amostras, com a finalidade de filtrar os ruidos do sinal medido. O novo intervalo de amostragem resultou em $h=3,906 \mathrm{~ms}$. Por fim, os sinais de velocidade foram calculados a partir de uma diferenciação numérica do sinal de deslocamento, como segue:

$$
v_{x}(k)=\frac{x(k+1)-x(k-1)}{2 h}
$$

Como o sinal deslocamento medido já havia sido filtrado, este sinal de velocidade manteve um nível de ruído aceitável para a análise.

\subsection{ESTIMAÇÃO DOS PARÂMETROS DO MODELO}

Um algoritmo de otimização baseado em programação quadrática seqüencial (PQS) foi utilizado para identificar os parâmetros do modelo do amortecedor MR. A cada iteração do processo de otimização é realizada uma simulação do comportamento do amortecedor utilizando o modelo em tempo discreto proposto. Para isso, foram introduzidos no modelo os sinais de deslocamento e velocidade (gerado a partir do sinal de deslocamento) para se obter um sinal de força, o qual foi comparado com o dado experimental. A função de custo que foi minimizada correspondeu a uma medida de erro entre os sinais de força experimental e simulado, que foi reavaliado a cada passo do processo de otimização.

Um processo de otimização não linear com restrição foi utilizado para obter os 21 parâmetros do modelo proposto a partir da minimização dos erros entre os dados experimentais e os dados estimados pelo modelo. Esta otimização foi executada utilizando-se um algoritmo de programação quadrática seqüencial (PQS) disponível no aplicativo Matlab ${ }^{\circledR}$ através da função “fminimax”. Esta função do Matlab resolve o seguinte problema: 


$$
\underset{x}{\operatorname{Min}}\{\operatorname{Max}\{F U N(x)\}\}
$$

Na equação (8.2), FUN é uma função em linguagem Matlab especialmente criada para este trabalho, que resolve as equações de diferenças do modelo pelo período de tempo da amostragem dos dados. Esta função retorna um vetor com as normas 1 e 2 do erro entre o sinal de força medido e o sinal de força estimado. O processo de identificação do modelo consiste no ajuste dos parâmetros para minimizar o custo, ou seja, as normas do vetor de erros.

A tabela 8.1 mostra os valores iniciais e os valores limite para cada parâmetro. As duas últimas colunas da tabela 8.1 mostram os valores finais de cada parâmetro e sua respectiva unidade.

Tabela 8.1: Parâmetros estimados.

\begin{tabular}{|c|c|c|c|c|c|}
\hline Parâmetros & $\begin{array}{c}\text { Valor } \\
\text { inicial }\end{array}$ & $\begin{array}{c}\text { Limite } \\
\text { inferior }\end{array}$ & $\begin{array}{c}\text { Limite } \\
\text { superior }\end{array}$ & $\begin{array}{c}\text { Valor } \\
\text { ajustado }\end{array}$ & Unidade \\
\hline$\eta$ & 40 & 4 & 200 & $\mathbf{3 8 , 6 6}$ & $\mathrm{Hz}$ \\
\hline$\gamma_{\mathrm{a}}$ & 180000 & 20000 & 1500000 & $\mathbf{4 9 9 0 5}$ & $1 / \mathrm{m}^{2}$ \\
\hline$\gamma_{\mathrm{b}}$ & 0 & -10000 & 10000 & $\mathbf{- 5 1 5 1}$ & $1 /\left(\mathrm{m}^{2} . \mathrm{V}^{2}\right)$ \\
\hline$\gamma_{\mathrm{c}}$ & 0 & -500 & 500 & $\mathbf{1 5 2 , 1}$ & $1 /\left(\mathrm{m}^{2} . \mathrm{V}^{3}\right)$ \\
\hline$\beta_{\mathrm{a}}$ & 80000 & -400000 & 1500000 & $\mathbf{- 8 9 0 5}$ & $1 / \mathrm{m}^{2}$ \\
\hline$\beta_{\mathrm{b}}$ & 0 & -1000 & 1000 & $\mathbf{6 2 4 , 2}$ & $1 /\left(\mathrm{m}^{2} . \mathrm{V}^{2}\right)$ \\
\hline $\mathrm{A}_{\mathrm{a}}$ & 50 & 1 & 1000 & $\mathbf{2 1 , 6 2}$ & -- \\
\hline $\mathrm{A}_{\mathrm{b}}$ & 0 & -1000 & 1000 & $\mathbf{- 1 , 5 7 8}$ & $1 / \mathrm{V}$ \\
\hline $\mathrm{A}_{\mathrm{c}}$ & 0 & -100 & 100 & $\mathbf{0 , 0 7 8 6}$ & $1 / \mathrm{V}^{2}$ \\
\hline$\xi$ & 1 & 0,9 & 5 & $\mathbf{1 , 0 1 2}$ & -- \\
\hline$\alpha_{\mathrm{a}}$ & 3500 & -10000 & 500000 & $\mathbf{4 7 5 5}$ & $\mathrm{N} / \mathrm{m}$ \\
\hline$\alpha_{\mathrm{b}}$ & 10000 & -35000 & 35000 & $\mathbf{1 5 7 1 7}$ & $\mathrm{N} /(\mathrm{m} . \mathrm{V})$ \\
\hline$\alpha_{\mathrm{c}}$ & 3000 & -1000 & 50000 & $\mathbf{3 6 9 5}$ & $\mathrm{N} /\left(\mathrm{m} . \mathrm{V}^{2}\right)$ \\
\hline$\alpha_{\mathrm{d}}$ & -500 & -9500 & 9500 & $\mathbf{- 1 6 7 7}$ & $\mathrm{N} /\left(\mathrm{m} . \mathrm{V}^{3}\right)$ \\
\hline$\alpha_{\mathrm{e}}$ & -100 & -300 & 300 & $\mathbf{2 0 0 , 8}$ & $\mathrm{N} /\left(\mathrm{m} . \mathrm{V}^{4}\right)$ \\
\hline$\alpha_{\mathrm{f}}$ & 7 & -20 & 20 & $\mathbf{- 7 , 9 7 2}$ & $\mathrm{N} /\left(\mathrm{m} . \mathrm{V}^{5}\right)$ \\
\hline $\mathrm{C}_{\mathrm{oa}}$ & 1500 & 50 & 5000 & $\mathbf{8 6 8 , 0}$ & $\mathrm{N} . \mathrm{s} / \mathrm{m}$ \\
\hline $\mathrm{C}_{\mathrm{ob}}$ & 500 & -1000 & 2000 & $\mathbf{4 8 6 , 3}$ & $\mathrm{N} . \mathrm{s} /(\mathrm{m} . \mathrm{V})$ \\
\hline $\mathrm{C}_{\mathrm{oc}}$ & 0 & -500 & 500 & $\mathbf{- 3 7 , 1 3}$ & $\mathrm{N} . \mathrm{s} /\left(\mathrm{m} . \mathrm{V}^{2}\right)$ \\
\hline $\mathrm{k}_{\mathrm{o}}$ & -100 & -500 & 120 & $\mathbf{4 3 , 2 6}$ & $\mathrm{N} / \mathrm{mm}$ \\
\hline $\mathrm{x}_{\mathrm{o}}$ & 10 & 1 & 30 & $\mathbf{6 , 3 3 0}$ & $\mathrm{mm}$ \\
\hline & & & & & \\
\hline
\end{tabular}


Para se melhorar a convergência do método, procurando-se evitar um mínimo local, alguns valores iniciais e limites foram definidos de forma arbitrária longe do seu valor "ótimo" mais provável. Por exemplo, o limite inferior de $\mathrm{k}_{\mathrm{o}}$ foi definido com valor negativo e o limite superior do parâmetro $\xi$ foi colocado em um valor relativamente elevado.

O processo de otimização foi executado em um computador PC com processador Intel ${ }^{\mathrm{TM}}$ Centrino $^{\mathrm{TM}}$ Duo Core ${ }^{\mathrm{TM}} \mathrm{T} 2300$, com 1,66 GHz de freqüência de clock, e 1Gbytes de RAM. Nestas condições o processamento levou apenas 1 min e 18s para ser concluído.

O processo de identificação foi aplicado a todos os dados dos três experimentos de forma simultânea a fim de se obter um modelo com o melhor desempenho possível nas diferentes situações exploradas em cada experimento. O modelo assim obtido foi chamado de modelo generalista. É claro que este mesmo processo de identificação pode ser aplicado aos dados de cada experimento individualmente, o que leva a aproximações melhores entre os dados experimentais e os dados estimados pelo modelo, contudo a generalidade do modelo é perdida.

\subsection{ANÁLISE DOS RESULTADOS}

Nas figura de 8.7 a 8.15 são apresentados comparações entre os dados obtidos nos experimentos e o resultado simulado pelo modelo que foi identificado pelo método proposto. As figuras mostram quatro tipos de gráficos para cada experimento: força versus deslocamento; força versus velocidade; força versus tempo; e erro absoluto entre os sinais de força: experimental e simulado. Nestes gráficos o sinal experimental aparece em cor mais clara (azul ciano) e o resultado das simulações em cor mais escura (azul marinho). 


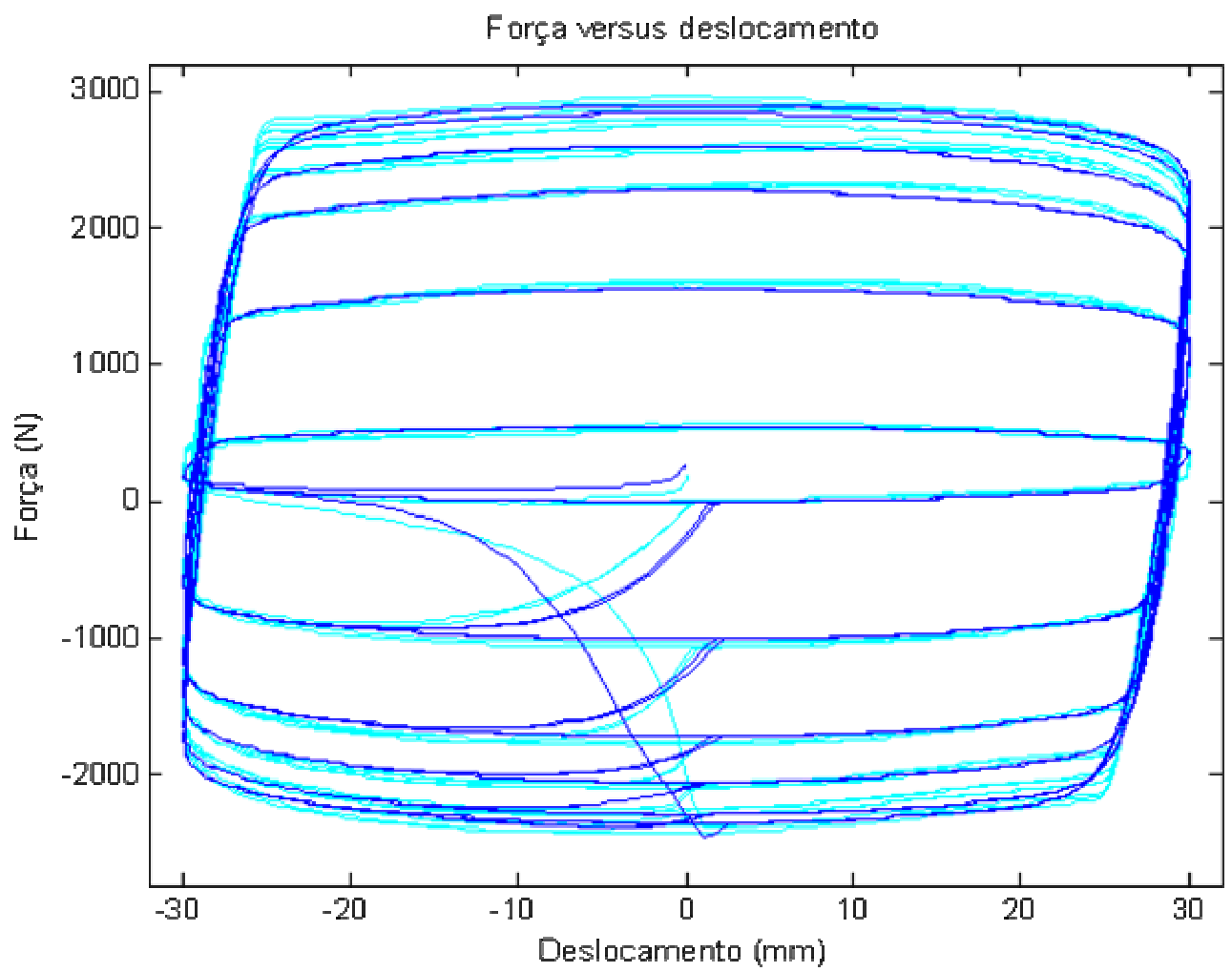

Figura 8.7 - Gráfico de Força x Deslocamento - $1^{\circ}$ experimento.

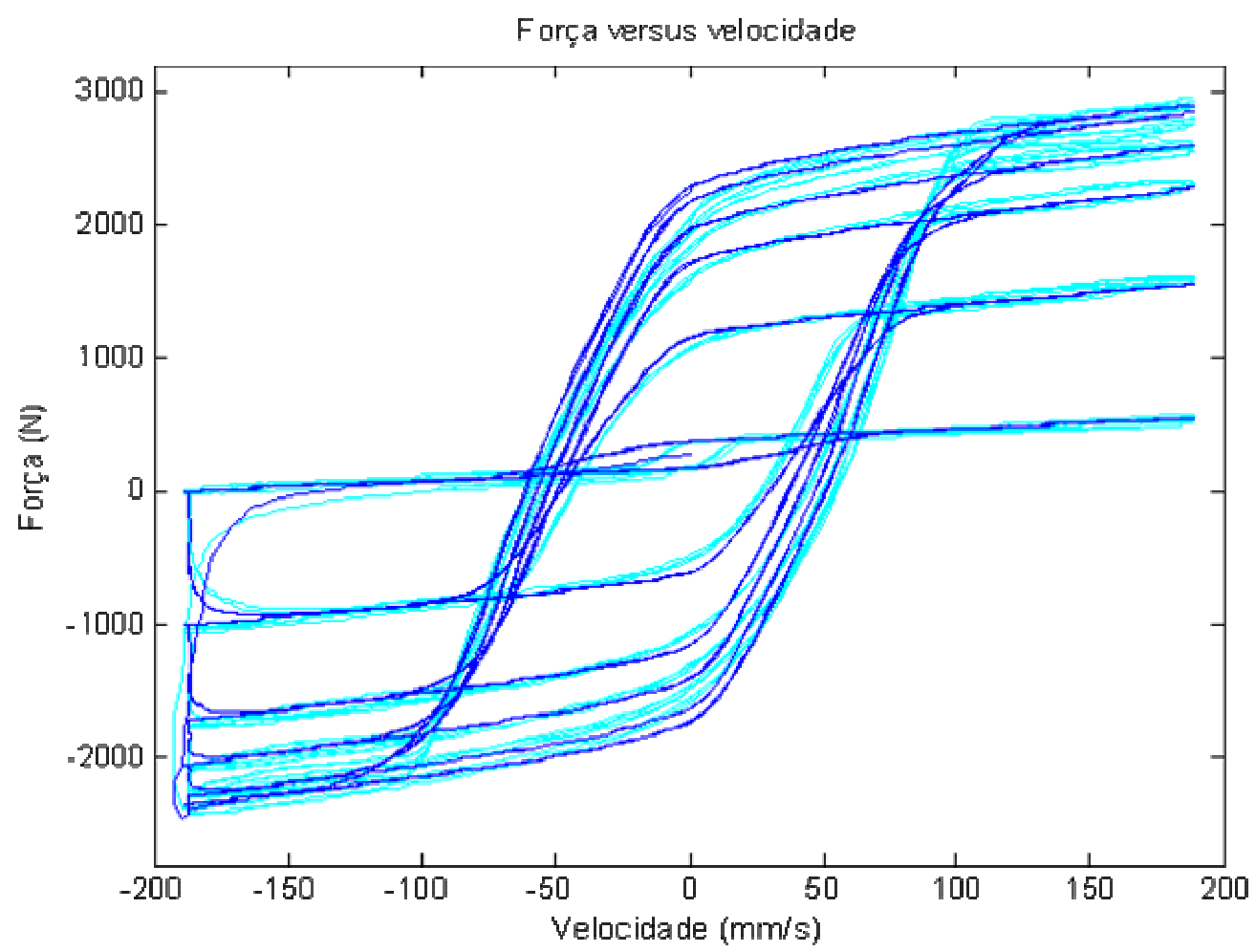

Figura 8.8 - Gráfico de Força x Velocidade $-1^{\circ}$ experimento. 

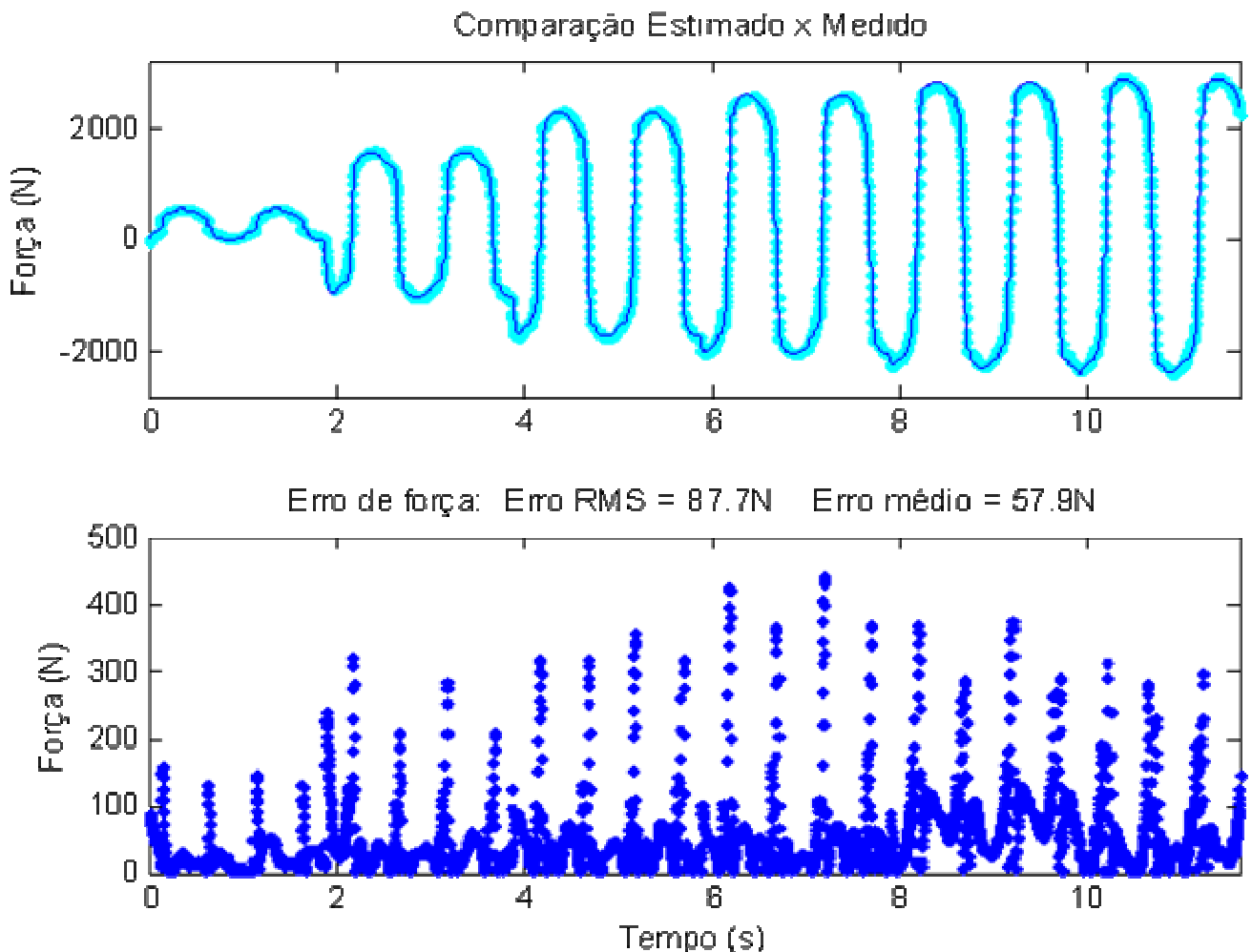

Figura 8.9 - Gráficos de Força x Tempo e Erro de força - $1^{\circ}$ experimento.

Força versus deslocamento

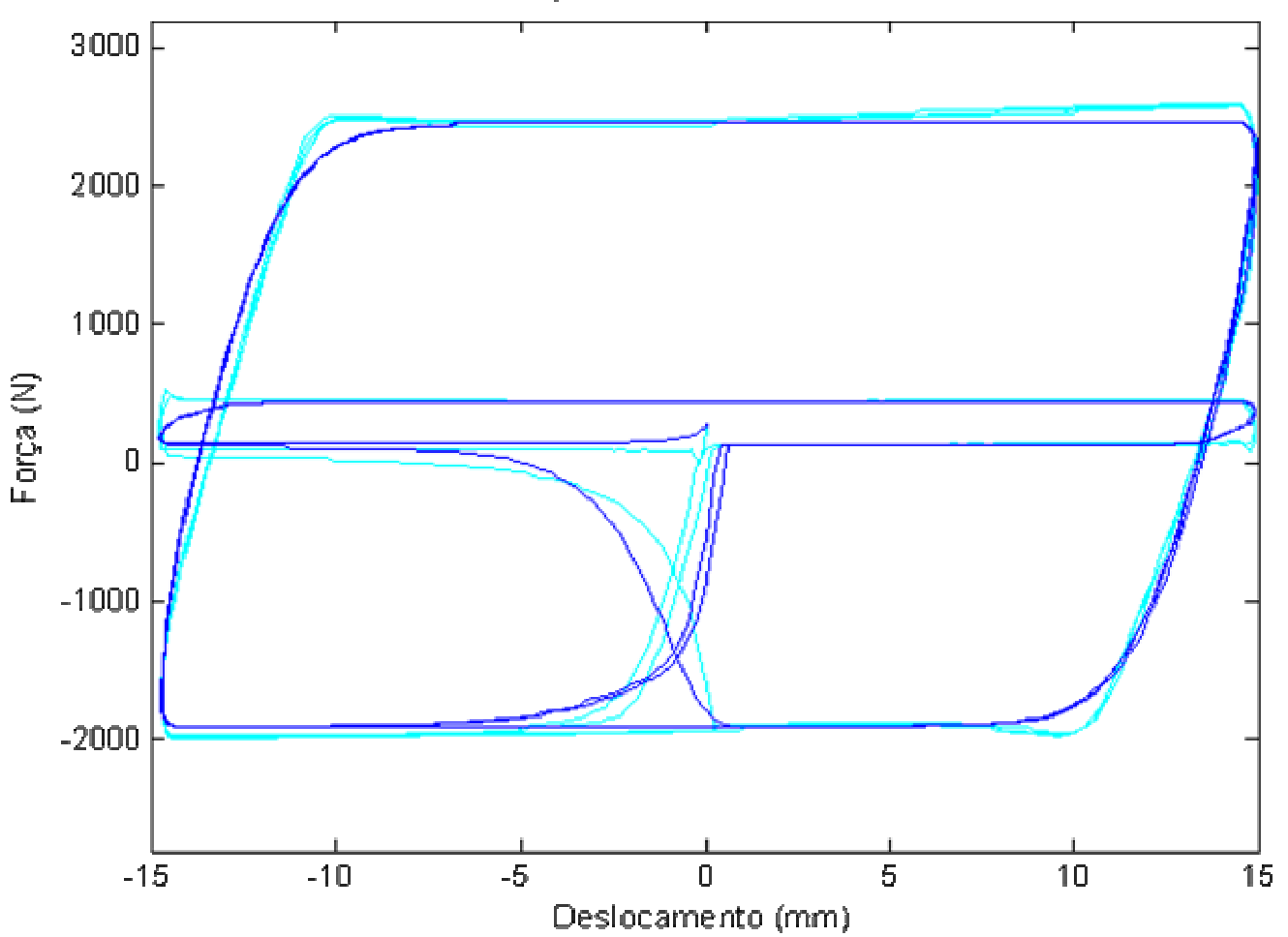

Figura 8.10 - Gráfico de Força x Deslocamento - 2º experimento. 


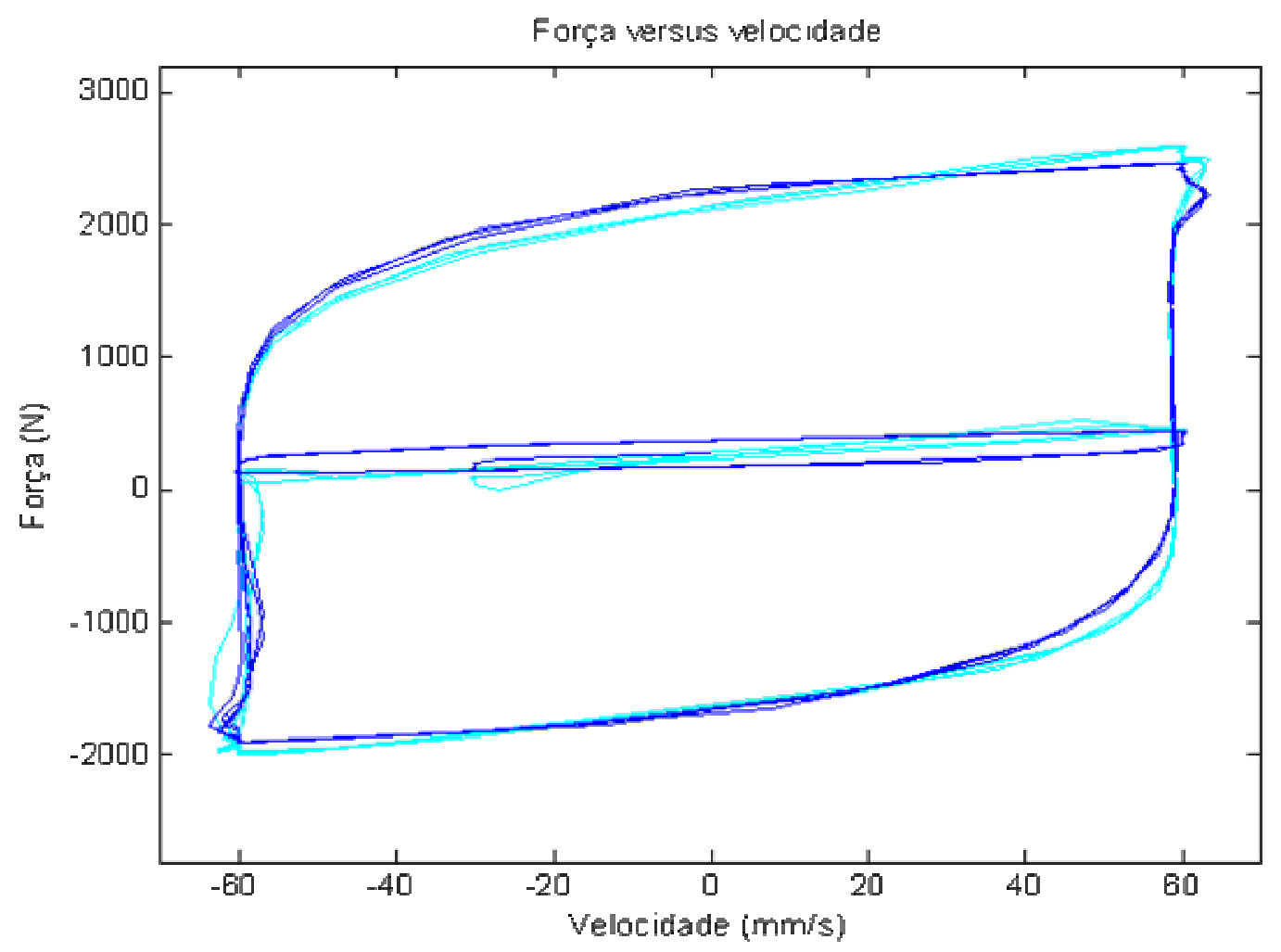

Figura 8.11 - Gráfico de Força x Velocidade - $2^{\circ}$ experimento.
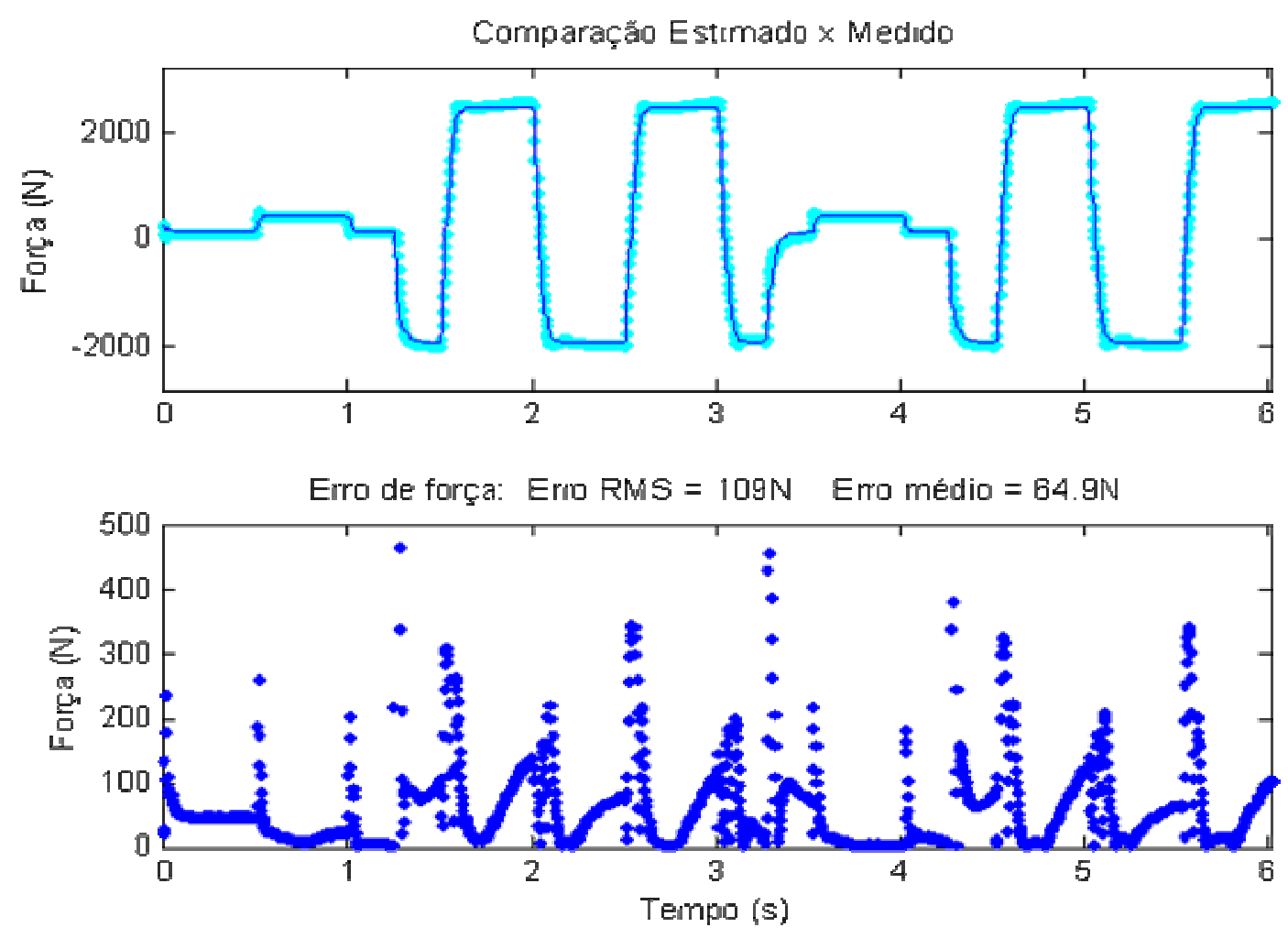

Figura 8.12 - Gráficos de Força x Tempo e Erro de força - $2^{\circ}$ experimento. 


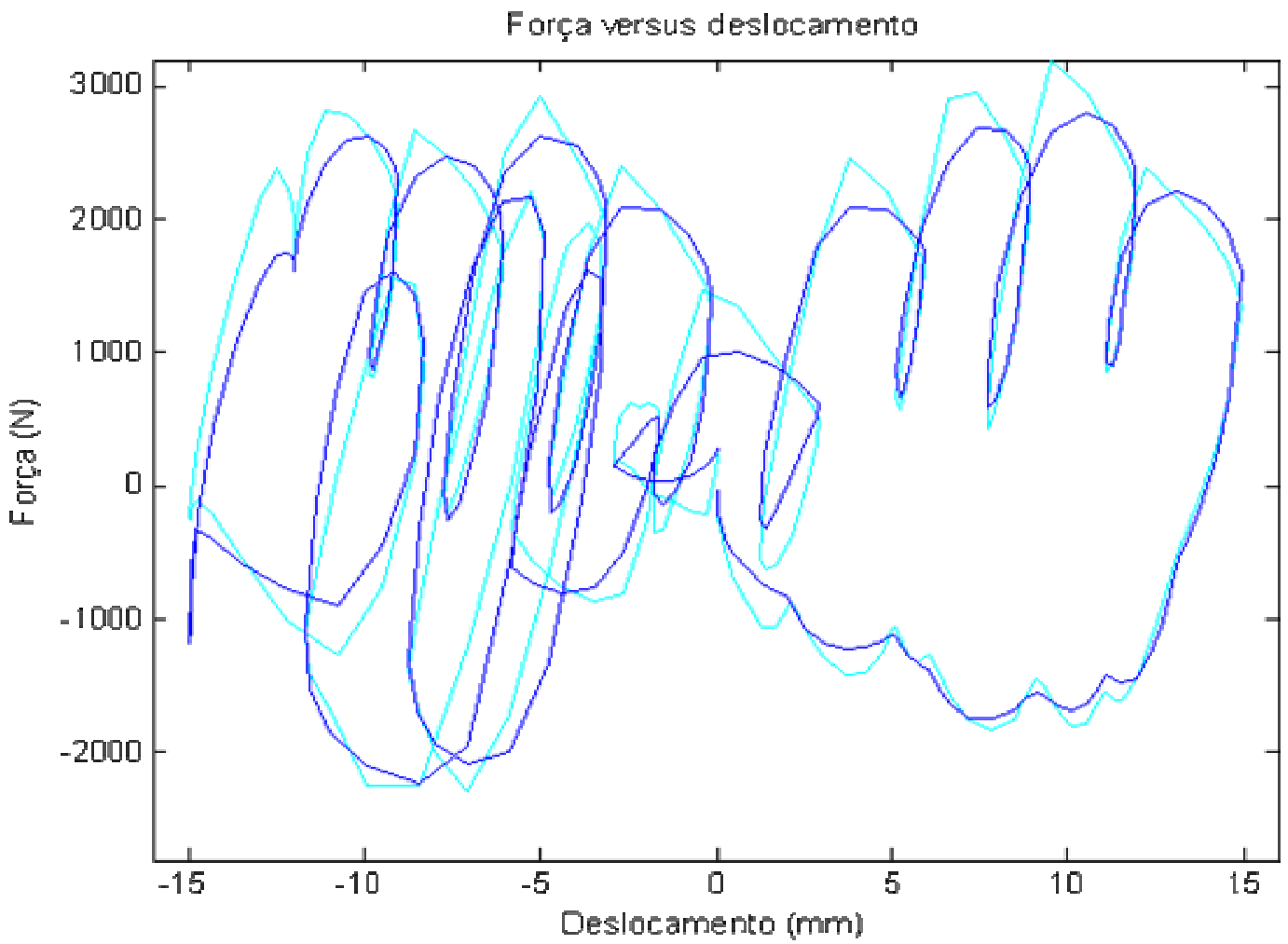

Figura 8.13 - Gráfico de Força x Deslocamento - $3^{\circ}$ experimento.

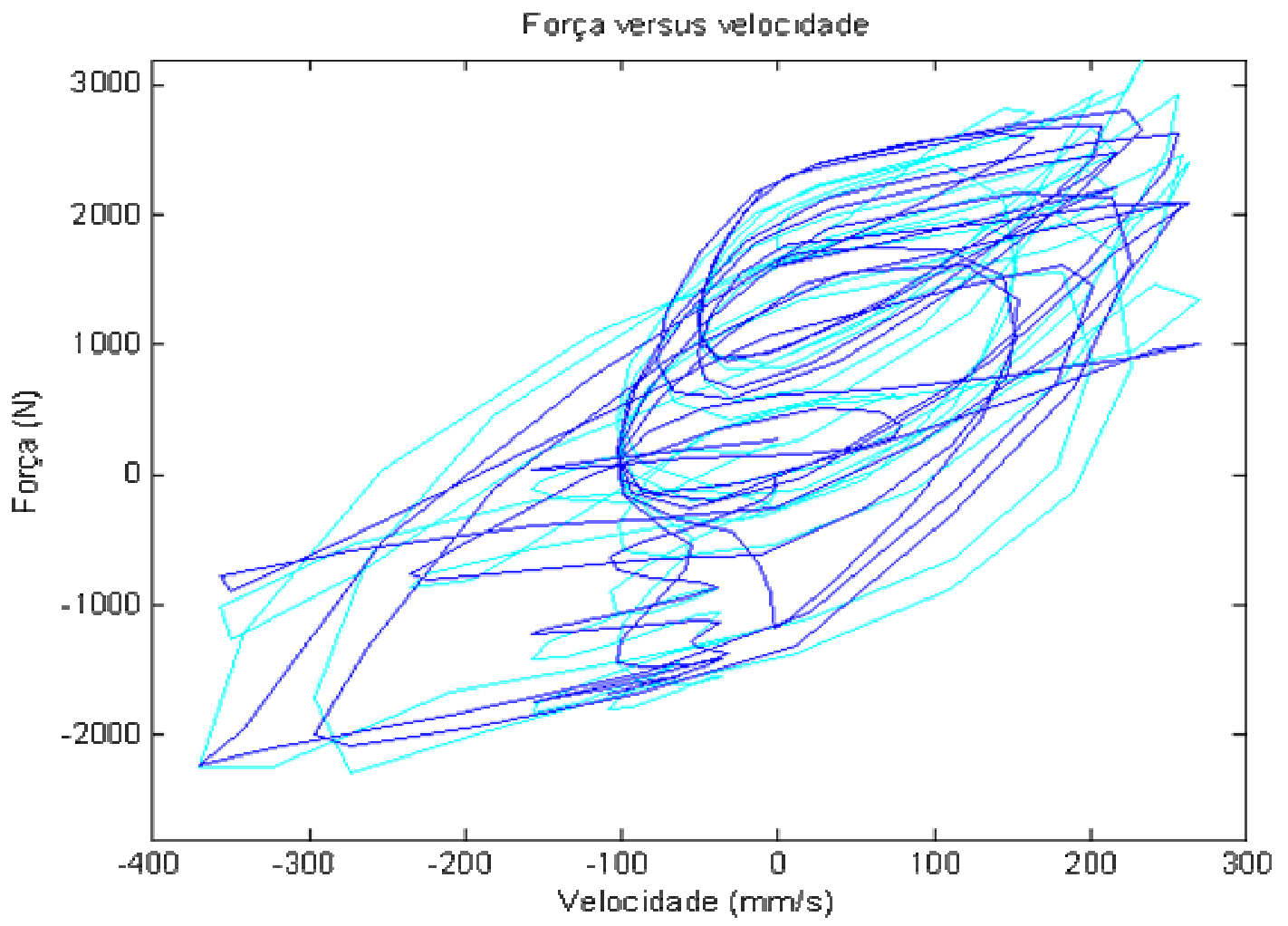

Figura 8.14 - Gráfico de Força x Velocidade - $3^{\circ}$ experimento. 

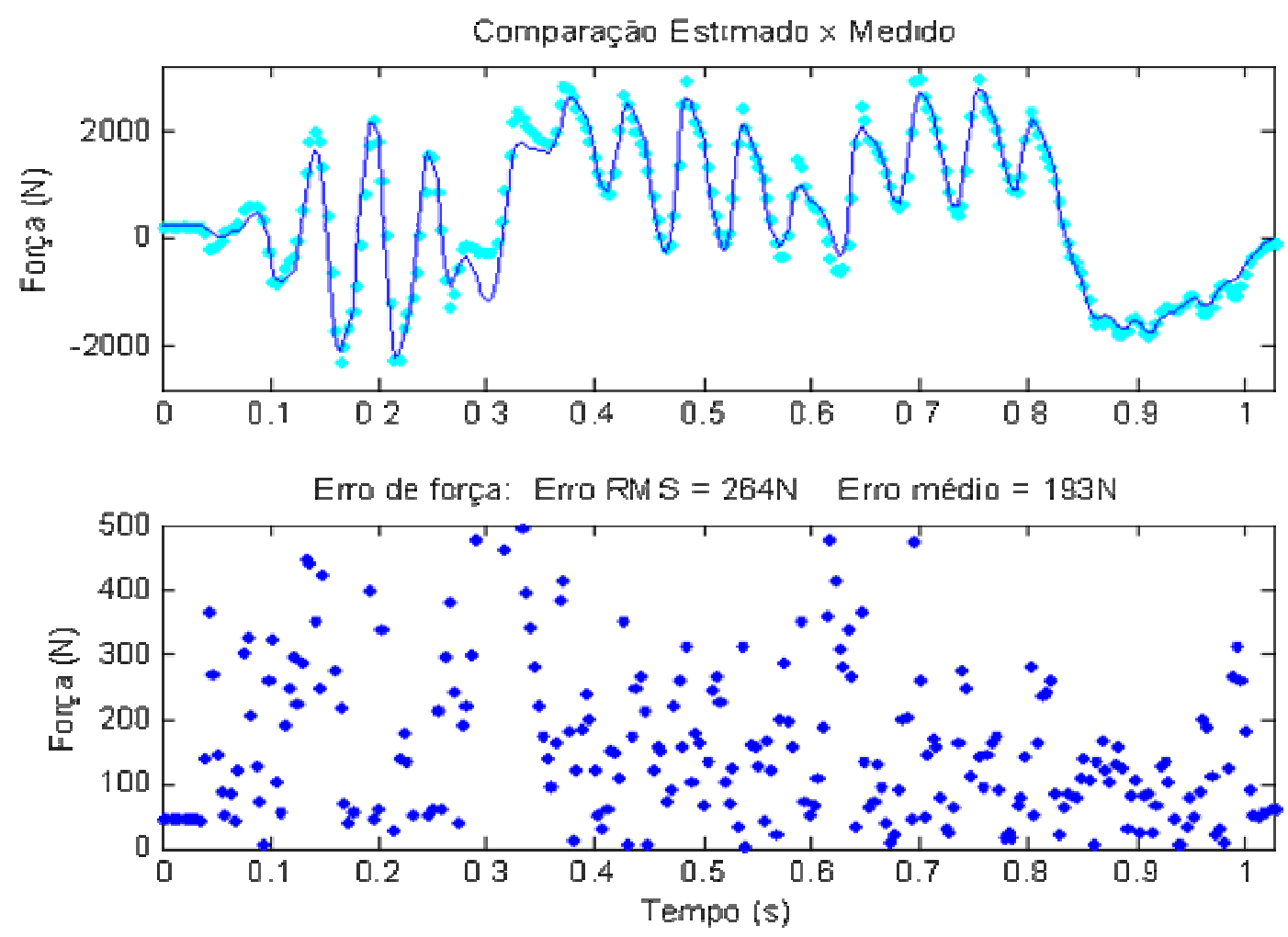

Figura 8.15 - Gráficos de Força x Tempo e Erro de força - $3^{\circ}$ experimento.

Nos gráficos das figuras 8.9, 8.12 e 8.15 são apresentados o módulo dos erros entre os dados experimentais e simulados. Também nestes gráficos são apresentados dois valores para avaliação do erro representativo de todo o período de simulação. Um destes valores é o valor RMS ("root mean square") do erro, e o outro é o valor médio do erro absoluto.

Conforme apresentado nestes gráficos, o modelo proposto pode representar de forma efetiva o comportamento real do amortecedor MR testado. Embora os picos de erro entre o simulado e o experimental terem alcançado até $900 \mathrm{~N}$, estes picos ocorreram em um curto intervalo de tempo e não prejudicam significativamente o desempenho do modelo, o qual apresenta somente $264 \mathrm{~N}$ de erro RMS no pior caso, o que equivale a menos de $10 \%$ da maior força que o atuador pode gerar. 


\subsection{DISCUSSÃO}

O procedimento proposto para a identificação do modelo do amortecedor MR mostrouse bastante eficaz na identificação dos 21 parâmetros deste modelo, o que não é uma tarefa trivial, dadas as suas características não lineares. Além disso, o fato de se utilizar um modelo discreto ao invés de um modelo contínuo trouxe uma estabilidade numérica maior e um processamento mais rápido deste processo de identificação.

Contudo este procedimento apresenta alguns pontos críticos que devem ser observados para o seu sucesso na identificação do modelo do amortecedor MR. O primeiro ponto é a escolha adequada dos experimentos. Cada experimento visa fornecer dados relacionados a um certo grupo de parâmetros. Por exemplo, o primeiro experimento traz a informação necessária para o ajuste dos parâmetros responsáveis pela relação entre a tensão de controle e a força final do atuador. Este experimento também fornece a informação do comportamento mais geral do atuador, sendo importante também no ajuste dos parâmetros relacionados ao comportamento histerético do modelo. Por outro lado, o segundo experimento fornece informação mais direcionada aos parâmetros relacionados ao tempo de resposta do atuador, e o terceiro experimento enfatiza o comportamento dinâmico mais rápido, complementando as informações para ajuste dos parâmetros relacionados ao modelo Bouc-Wen discreto.

Outro fator crítico é a escolha da medida de erro. O fato de se utilizar um algoritmo "minimax" de otimização permite a definição de mais de uma forma de medir o erro a ser considerada no processo de ajuste de parâmetros. Com a utilização das normas 1 e 2 do vetor de erros, foi possível conseguir uma boa convergência do algoritmo para o ponto ótimo, uma vez que enquanto uma medida de erro pode estar mostrando uma condição de vale, a outra pode indicar uma tendência para fora deste ponto de mínimo local. É possível ainda refinar ainda mais a medida do erro, privilegiando uma característica específica do atuador, o que em certas aplicações pode ser bastante útil.

Deve-se destacar também a importância do valor inicial de cada parâmetro do modelo. Os valores iniciais devem ser escolhidos de forma que o comportamento do modelo apresente um mínimo de similaridade com o comportamento real do amortecedor MR e que o modelo seja estável. Para isso, é possível contar com várias informações oriundas do projeto do atuador e dos dados experimentais. Por exemplo, os parâmetros $\eta$ e $c_{o a}$ vêm direto dos requisitos de projeto de tempo de resposta e coeficiente de amortecimento viscoso residual (ou mínimo), respectivamente. O parâmetro $c_{o b}$ deve estar entre 10 e $30 \%$ do valor de $c_{o a}$, e 
o parâmetro $c_{o c}$ inicia com o valor zero, da mesma forma que vários outros parâmetros relacionados a termos de segunda e terceira ordem, como é o caso de $\gamma_{b}, \gamma_{c}, \beta_{b}, A_{b}$, e $A_{c}$. O parâmetro $\xi$ inicia-se sempre com o valor 1, pois seu valor final sempre estará muito próximo disso, e os parâmetros $\gamma_{a}, \beta_{a}$, e $A_{a}$ devem ser sempre positivos. Os dados do primeiro experimento podem orientar a escolha dos parâmetros $\alpha_{a}, \alpha_{b}, \alpha_{c}, \alpha_{d}, \alpha_{e}$, e $\alpha_{f}$, que estão ligados à relação entre corrente elétrica de controle e força no atuador, contudo sua contribuição final é influenciada pelos valores iniciais escolhidos para $\gamma_{a}, \beta_{a}$, e $A_{a}$. O parâmetro $x_{o}$ inicia sempre com valores entre 10 e $50 \mathrm{~mm}$, que corresponde fisicamente ao deslocamento do pistão flutuante do acumulador. Já o parâmetro $k_{o}$ é propositalmente iniciado com um valor negativo, pois ele é rapidamente ajustado pelo algoritmo para o seu valor positivo ótimo, contudo esta prática resulta num valor de erro inicial elevado, o que proporciona uma maior velocidade de convergência do processo de identificação dos parâmetros.

Os limites superior e inferior de cada parâmetro, tem como objetivo evitar que o modelo entre numa situação em que ele seja instável, e ao mesmo tempo estes limites devem ser amplos os suficiente para permitir uma boa convergência do algoritmo. Limites muito estreitos podem conduzir o modelo a um ponto de mínimo local.

Tomados estes cuidados tem-se em mãos uma excelente ferramenta para o ajuste de modelos de amortecedores MR. De forma geral, o funcionamento do algoritmo é representado pelo diagrama da figura 8.16. Com exceção dos três primeiros blocos, que são basicamente: a atribuição dos valores iniciais, a simulação das equações de diferenças do modelo no período de tempo equivalente ao dos dados experimentais, e o cálculo dos erros entre o sinal de força simulado e o experimental; todo o resto do algoritmo já está implementado na função "fminimax" do Matlab ${ }^{\circledR}$. 


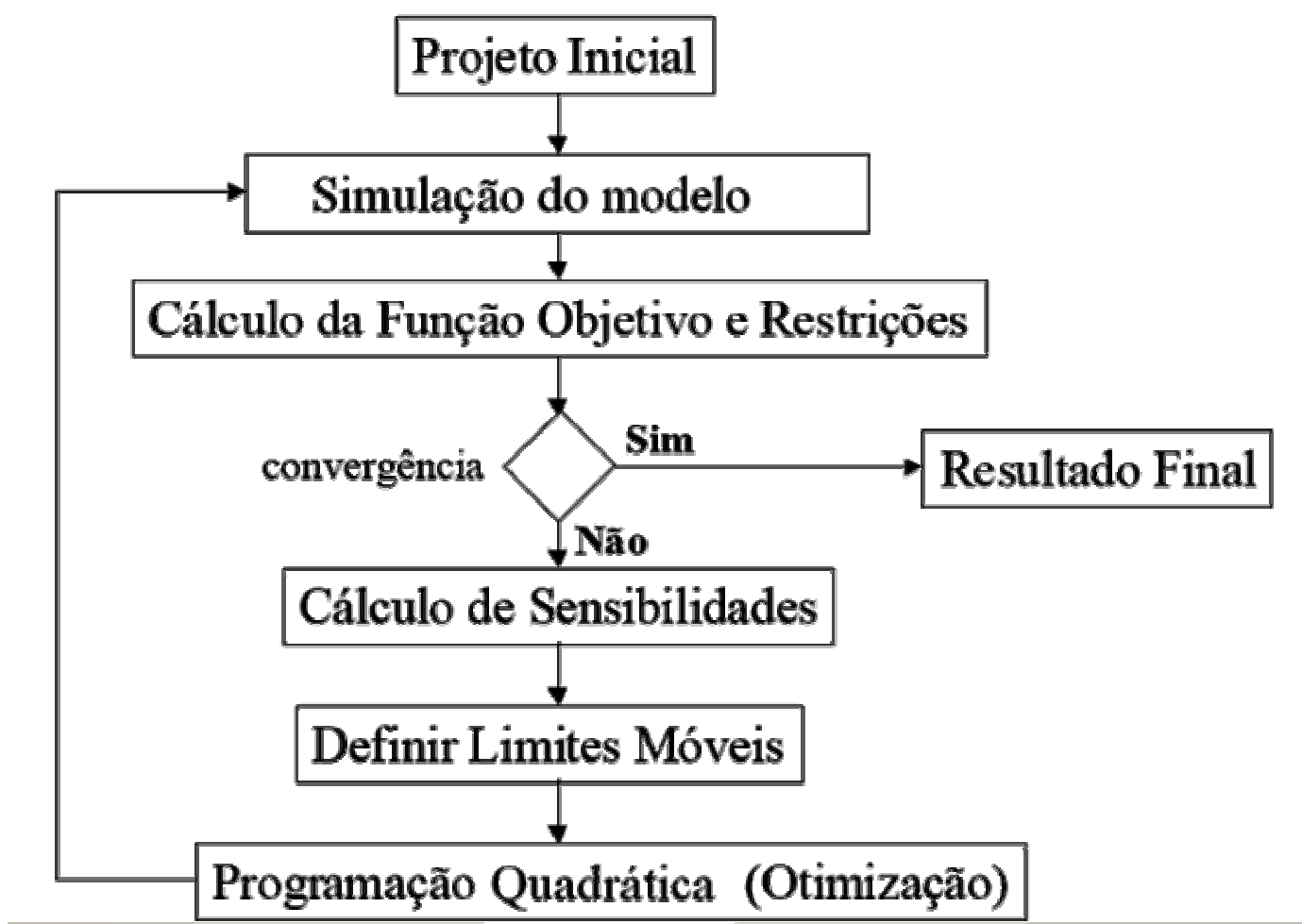

Figura 8.16 - Processo proposto para identificação do modelo.

Uma característica importante do modelo proposto é que alguns de seus parâmetros apresentam relação direta com características físicas do atuador MR. Para exemplificar, podese analisar a característica de tempo de resposta que tem relação direta com o parâmetro $\eta$. A constante de tempo do filtro de primeira ordem que modela esta característica é calculada como $\Delta T=1 / \eta$, que resulta em $\Delta T=25,87 \mathrm{~ms}$, conforme o valor estimado pelo processo d identificação proposto. Esta resultado poderia ser obtido também a partir da análise dos dados do segundo experimento, conforme o gráfico da figura 8.17. Nele é possível observar uma comparação da resposta do atuador real com uma resposta ao degrau de um sistema de primeira ordem com constante de tempo $\Delta T=25,0 \mathrm{~ms}$. Percebe-se que este é um valor muito próximo daquele obtido diretamente a partir do parâmetro do modelo, o que leva a conclusão de que o novo modelo e o processo de ajuste dos parâmetros propostos podem substituir análise secundárias, que seriam necessárias se fossem utilizados outros modelos e processo de identificação. Além disso, quando o valor de uma característica resulta diretamente do modelo que foi identificado a partir de vários experimentos, pode-se assumir que éste valor é a melhor 
aproximação para uma ampla faixa de situações, e não apenas para um experimento específico.

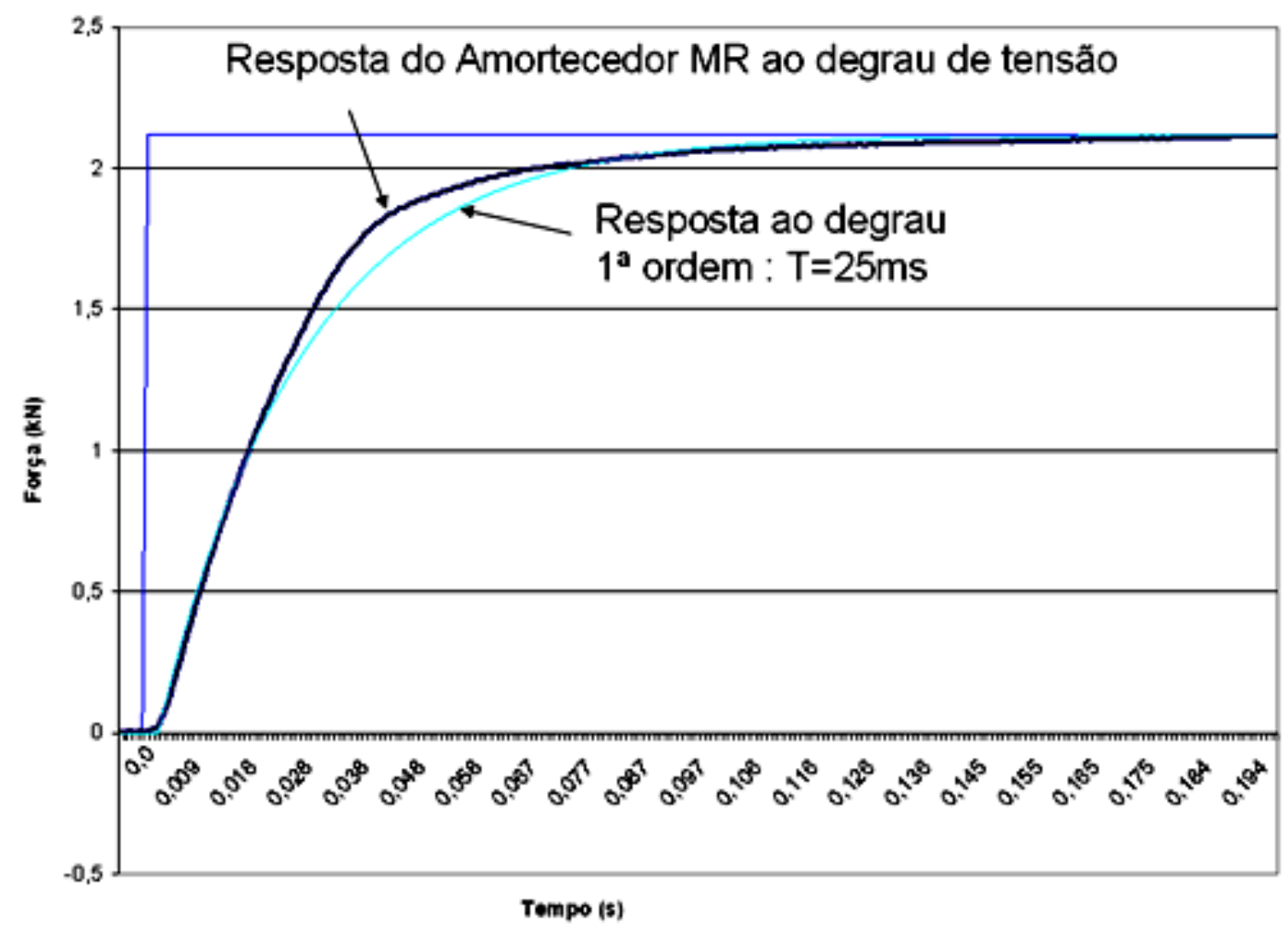

Figura 8.17 - Estimativa do tempo de resposta a partir dos dados do segundo experimento. 


\section{CONCLUSÕES}

O amortecedor MR é um dispositivo atrativo para utilização em sistemas de controle semi-ativo, apresentando um grande potencial para sua aplicação em muitas áreas, especialmente em controles de vibração em grandes estruturas civis e aplicações automobilísticas, entre muitas outras.

A primeira necessidade ao se imaginar uma aplicação para os atuadores semi-ativos é saber quais são os requisitos que devem ser especificados na definição do atuador mais apropriado, e também, se for o caso, como se projeta um novo atuador MR para um determinada aplicação. Neste sentido, este trabalho apresenta um grande contribuição, mostrando um completo embasamento teórico sobre o assunto, destacando as considerações e simplificações que levam a modelos mais práticos para utilização em novos projetos. Também é definido todo um procedimento sistematizado de projeto, exemplificado e validado pela construção e teste de protótipos.

Uma vez com o atuador em mãos, é necessário se tirar o máximo proveito das características únicas dos atuadores MR, em particular dos amortecedores MR. E, portanto, um modelo de alta fidelidade é necessário para o projeto e simulação de sistemas de controle. Um dos objetivos deste trabalho foi desenvolver um modelo em tempo discreto para os amortecedores MR para uso em implementações digitais de aplicações de controle.

Numa revisão de vários modelos mecânicos idealizados para este tipo de atuador, escolheu-se um modelo Bouc-Wen utilizado por Spencer et al. (1996) para ser a base do novo modelo em tempo-discreto. O modelo Bouc-Wen é especialmente adequado a esta aplicação por ser numericamente tratável e ser capaz de exibir uma ampla variedade de comportamentos histeréticos, como os que ocorrem neste tipo de atuador. Contudo o modelo de Spencer (op. cit) ainda apresenta algumas limitações, como a dificuldade de estimação de seus parâmetros por ser uma equação complexa e não-linear em tempo-contínuo, e o fato de não poder ser diretamente implementada em sistemas digitais.

Conseqüentemente, um novo modelo em tempo-discreto foi proposto utilizando uma representação discretizada do modelo de histerese Bouc-Wen. A transformação do sistema original em tempo-contínuo num sistema discreto estável foi realizada pela aplicação do 
método da diferença para trás ("backward-difference"), além da aplicação de certos artifícios matemáticos para tornar as equações mais tratáveis. Para se obter um modelo que reproduz mais fielmente o comportamento do amortecedor MR com campo magnético flutuante, foi admitido que cinco parâmetros pudessem variar conforme a corrente elétrica no atuador segundo funções polinomiais. Este aumento de complexidade do modelo somente foi possível em razão da maior estabilidade numérica dada pela nova forma do sistema descrita por equações de diferenças. Adicionalmente, de maneira similar ao modelo original em tempocontínuo, a forma em tempo-discreto de um filtro de primeira ordem foi incorporada ao modelo para se considerar a dinâmica envolvida comportamento do fluido MR buscando o seu equilíbrio reológico.

Para que um modelo matemático da dinâmica de amortecedores MR seja realmente útil, é necessária uma metodologia eficiente para fazer com que este modelo tenha uma grande aderência ao comportamento real de um amortecedor MR. Isto pode ser feito a partir de processos de estimação de parâmetros que buscam a redução das diferenças entre o comportamento do modelo e o comportamento de um amortecedor real, a partir de ajustes graduais destes mesmos parâmetros.

Outro resultado importante desta primeira parte do trabalho é a proposta de um método extremamente eficiente e robusto para a estimação dos 21 parâmetros do novo modelo proposto para estes dispositivos MR, que utiliza um processo de otimização baseado num algoritmo de Programação Quadrática Seqüencial (PQS) disponível no software Matlab®. Quando comparado com dados experimentais, o modelo com parâmetros estimados pelo método proposto mostrou ser capaz de predizer de forma precisa a resposta de um amortecedor MR real, que foi submetido a uma ampla variedade de condições de trabalho e excitações, incluindo degrau de tensão e um deslocamento multi-periódico combinado com variações "aleatórias" de tensão.

Estes resultados puderam mostrar a efetividade do modelo proposto em representar um amortecedor MR real, e a robustez, velocidade e precisão do método proposto para estimação dos parâmetros do modelo dinâmico. Embora o modelo proposto tenha uma grande quantidade de parâmetros, ele converge mais rápido e de forma mais suave do que outros modelos baseados em equações diferenciais, um vez que estas últimas exigem integrações numéricas (como Runge-Kuta, por exemplo) a cada passo do processo de estimação e ajuste dos parâmetros, que além de representar um uma tarefa computacional mais pesada, pode gerar mais problemas de instabilidades numéricas, ou dificuldade de convergência. 


\subsection{SUGESTÕES PARA TRABALHOS FUTUROS}

Seguem algumas sugestões para trabalhos futuros.

- Desenvolvimento de novos conceitos de válvulas magneto-reológicas, utilizando novas geometrias e materiais magnéticos mais nobres aplicados de forma racional.

- Desenvolvimentos de outros tipos de dispositivos magneto-reológicos utilizando o processo iterativo de projeto proposto neste trabalho.

- Estudo do efeito das correntes parasitas ("eddy currents") na eficiência do dispositivo MR.

- Desenvolver "software" para solução dos fenômenos eletromagnético, hidrodinâmico, termodinâmico e mecânico acoplados em dispositivos baseados em fluidos MR por meio de análise de elementos finitos.

- Desenvolvimento de um "software" específico para a otimização topológica da geometria da válvula magneto-reológica baseado na solução do problema acoplado através de análise de elementos finitos e na consideração de restrições como força nominal, vazão de fluido, temperatura máxima, corrente elétrica máxima, etc.

- Criar formas alternativas para redução da histerese na relação entre força e velocidade do pistão. Há patentes que mostram o uso de um orifício que permite a passagem do fluido pela válvula sem a ação do campo magnético, fazendo com que as forças fiquem baixas quando a velocidade do pistão está proxima de zero.

- Estudo de outros tipo de materiais para o núcleo ferromagnético da válvula dos amortecedores MR.

- Estudo de outras aplicações para o modelo Bouc-Wen discreto proposto por este trabalho. 


\section{REFERÊNCIAS}

ANFLOR, C. T. M. Estudo da transmissibilidade da vibração no corpo humano na direção vertical e desenvolvimento de um modelo biodinâmico de quatro graus de liberdade. 1998. 105 p. Dissertação (Mestrado)- Escola de Engenharia da Universidade Federal do Rio Grande do Sul, Porto Alegre, 1998.

ÁSTRÖM, K. J. Control System Design. Lecture notes for ME 155 A, Department of Mechanical and Environmental Engineering. University of California, Santa Barbara, 2002. Disponível em:

$<$ http://www.cds.caltech.edu/ murray/courses/cds101/fa02/caltech/astrom.html $>$. Acesso em 12 out. 2008.

BARBIERI, F. A. A.; COSTA NETO, A.; BARROS, R. M. Virtual prototyping: a vehicle model for integrated motion control studies. In: INTERNATIONAL CONGRESS OF MECHANICAL ENGINEERING, 18., 2005, Ouro Preto. Proceedings of COBEM 2005. Rio de Janeiro: ABCM, 2005.

BARBOSA, R. S. Aplicação de sistemas multicorpos na dinâmica de veículos guiados. 1999. 273 p. Tese (Doutorado)- Escola de Engenharia de São Carlos, São Carlos, 1999.

BASTOW, D. Aspects of car rear suspension. Proceedings of the Institution of Mechanical Engineers. Part D. Journal of automobile engineering, London , v. 190, p. 53-76, 1976.

BENDER, E. K. Optimum linear preview control with application to vehicle suspension. Journal of Basic Engineering, New York, v. 90, n. 2, p. 213-221, Jun. 1968.

BIGGS, M.C. Constrained minimization using recursive quadratic programming. In: Dixon, L.C.W.; Szergo, G.P. (Ed) Towards global optimization. Amsterdam: North-Holland, 1975. p. 341-349.

BIRCH, S. Audi TT Roadster, soft-top is given harder edge by Audi. Times on Line, Mar. 2th, 2007. Disponível em:

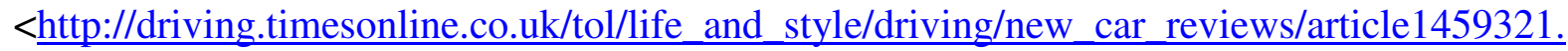
ece>. Acesso em 28 jun. 2008.

BODIE, M. O.; HAC, A. Closed loop yaw control of vehicles using magneto-rheological dampers. In: WORLD CONGRESS, Detroit, 2000. SAE 2000 [S.l.: s.n] , 2000.

BOKOR, J.; PALKOVICS, L. Modern control theory applies to vehicle dynamics. In: MINI CONFERENCE ON VEHICLE SYSTEM DYNAMICS, 4., 1994, Budapest. Proceedings. Budapest: Technical University of Budapest, 1994. p. 74-87. 
BOMBARD, A. J. F. Fluidos eletroreológicos: suspensão de IVA em óleo de milho. 1996. 74 p. Dissertação (Mestrado) - Instituto de Química da Universidade Estadual de Campinas, Campinas, SP, 1996.

Suspensões magneto-reológicas de pós de ferro carbonilo: um estudo da influência das propriedades magnéticas e do tamanho das partículas. 2005. 144 p. Tese (Doutorado) - Instituto de Química da Universidade Estadual de Campinas, Campinas, SP, 2005 .

; KNOBEL, M.; ALCÂNTARA, M. R.; JOEKES, I. Evaluation of magnetorheological suspensions based on carbonil iron powders. Journal of Intelligent Material Systems and Structures, Lancaster, v. 3, jul/ago 2002.

BOURMISTROVA, A.; STOREY, I.; SUBIC, A. Multiobjective optimization of active and semi-active suspension system with application of evolutionary algorithm. [S.1.]: RMIT , 2005. p. 1217-1223 (Mechanical and Aerospace Engineering Report)

BREESE, D. G.; GORDANINEJAD, F. Semi-active, fail-safe magneto-rheological fluid dampers for mountain bicycles. International Journal Vehicle Design, Geneve, v. 33, n. 1/3, p. 128-138, 2003.

BROGE, J.L Valveless damping suspension system. Automotive Engineering International Online, p. 4, Dec. 1999. Disponivel em $<$ http://www.sae.org/automag/techbriefs_12-99/04.htm> Acesso em: 12 out. 2008.

BS - British \& International Standards. BS 6841: Guide to measurement and evaluation of human expesure to whole-body mechanical vibration and repeated shock, 1987.

BUTSUEN, T.; HEDRICK, J. K. Optimal semi-active suspensions for automotive vehicles: the 1/4 car model. Advanced Automotive Technology, DSC-3, p. 305-319, 1989.

CANALE, A. C.; FERREIRA, H. T. Estudo de 'ride' de um caminhão de dois eixos usando Matlab-Simulink. In: SIMPOSIO BRASILEIRO DE ACUSTICA VEICULAR, 7., São Paulo, 2003. SIBRAV 2003. São Paulo: [s.n.], 2003.

CARLSON, J. D. What makes a good MR fluid. In: INTERNATIONAL CONFERENCE ON ELECTROHREOLOGICAL FLUIDS AND MAGNETO-RHEOLOGICAL SUSPENSIONS AND THEIR APPLICATIONS, 8., 2001, Nice. Proceedings. New Jersey: World Scientific, 2002.

; CATANZARITE, D. M.; CLAIR, K. A. St. Commercial magneto-rheological fluid devices. In: INTERNATIONAL CONFERENCE ON ELECTRORHEOLOGICAL FLUIDS AND MAGNETO-RHEOLOGICAL SUSPENSIONS AND THEIR APPLICATIONS, 5., 1995, Sheffield. Proceedings. Singapore: World Scientific, 1996. p. $20-28$

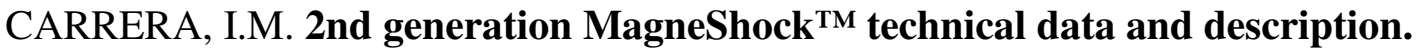

Disponível em: <http://carrerashocks.com/MSGen2TechData.htm>. Acesso em: 04 ago. 2003. 
CHANTRANUWATHANA, S.; PENG, H. Practical adaptive robust controllers for active suspensions. In: ASME INTERNATIONAL MECHANICAL ENGINEERING CONGRESS AND EXPOSITION (IMECE), Orlando, FL, 2000. Proceedings. New York: American Society of Mechanical Engineers, 2000.

CHEN, Q.; KONRAD, A. A review of finite element open boundary techniques for static and quasistatic electromagnetic field problems. IEEE Transactions on Magnetics, New York, v. 33, n. 1, p. 663-676, Jan. 1997.

CHOI, S. B.; BANG, J. H.; CHO, M. S.; LEE Y. S. Sliding mode control for anti-lock brake system of passenger vehicles featuring electrorheological valves. Proceedings of the Institution of Mechanical Engineers. Part D. Journal of automobile engineering, London, v. 216, p. 897-908, 2002.

CHRZAN, M.J.; CARLSON, J. D. MR fluid sponge devices and their use in vibration control of washing machines. In: ANNUAL SYMPOSIUM ON SMART STRUCTURES AND MATERIALS, 8., 2001, New Beach. Proceedings. [S.1.: s.n.] 2001.

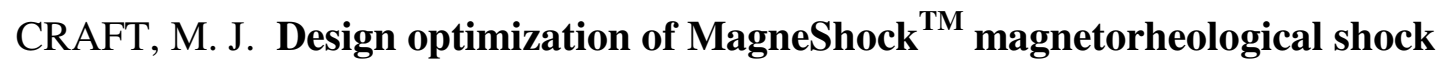
absorbers and development of fuzzy logic control algorithms for semi-active vehicle suspensions. 2003. 94 p. Thesis (Degree of Master os Science) - Graduate Faculty of North Carolina State University, Raleigh, 2003.

CRIVELLARO, C. Estudo do aprimoramento do conforto e dirigibilidade de caminhonetes utilizando projeto de suspensão semi-ativa baseado em dispositivos magneto-reológicos. In: CONGRESSO E EXPOSIÇÃO INTERNACIONAL DA TECNOLOGIA DA MOBILIDADE, 12., 2003, São Paulo. SAE 2003. São Paulo: SAE Brasil, 2003. (Paper Series 2003-01-46)

; SANTOS, E. C. A. Projeto de um amortecedor magneto-reológico. In: CONGRESSO E EXPOSIÇÃO INTERNACIONAL DA TECNOLOGIA DA MOBILIDADE, 13., 2004, São Paulo. SAE Technical Paper Series. São Paulo: SAE Brasil, 2004. (Paper, 2004-01-3279)

; TAMAI, E. H. Study of ride and handling improvement of pickup light truck vehicles using robust semi-active suspension control based on magneto-rheological dampers. In: INTERNATIONAL CONGRESS OF MECHANICAL ENGINEERING , 17., 2003, São Paulo. Proceedings of COBEM 2003. São Paulo: ABCM, 2003 .

CROSBY, M.; KARNOPP. The active damper : a new concept for shock and vibration control. Shock and Vibration Bulletin, Washington, 1973.

CRUZ, J. J. da. Controle robusto multivariável. São Paulo: Edusp, 1996. 163 p. ; BITTAR, A.; COSTA, E. A. da; SALES, R. M. Control and optimization of the electromagnetic suspension operation of a maglev vehicle. In: INTERNATIONAL CONGRESS OF MECHANICAL ENGINEERING , 17., 2003, São Paulo. Proceedings of COBEM 2003. São Paulo: ABCM, 2003.

CULLITY, B. D. Introduction to magnetic materials. Reading: Addison-Wesley, 1972. 
DATA, S.; FRIGERIO, F. Objective evaluation of handling quality. Proceedings of the Institution of Mechanical Engineers. Part D. Journal of automobile engineering, London, v. 216, p. 297-305, 2002.

DELPHI TECHNOLOGY, Inc. S. Lun, R. L. Hofmann, I. Lisenker. Magnetorheological piston and damper. Int. Cl..F61F 9/53, US Patent 6.612.409 B2. Sept. 2, 2003.

DELPHI CHASSIS SYSTEMS. Thinking ahead. New Haven: Mason \& Madison, 1999. v. 4, n. 2/3, 1999.

DE JAGER, A. G. Comparison of two methods for the design of active suspension systems. Optimal Control Appl. \& Methods, Chichester, v. 12, p. 173-188, 1991.

DE MAN, P.; LEMERLE, P.; MISTROT, P.; VERSCHUEREN, J-Ph.; PREUMONT, A. An investigation of a semi-active suspension for a lift truck. Vehicle System Dynamics, Amsterdam, v. 43, n. 2, p. 107-119, Feb. 2005.

DOYLE, J. C.; STEIN, G. Multivariable feedback design: concepts for a classical/modern synthesis. IEEE Transactions on Automatic Control, New York, v. AC-26, n. 1, p. 4-16, Feb. 1981.

DYKE, S. J; SPENCER Jr., B. F.; CARLSON, J. D. Seismic response reduction using magneto-rheological dampers. In: IFAC WORLD CONGRESS, 1996, San Francisco. Proceedings. New York: Published for the International Federation of Automatic Control by Pergamon, 1997.

EHRGOTT, R. C.; MASRI, S. F. Structural control applications of an eletrorheological device. In: INTERNATIONAL WORKSHOP ON STRUCTURAL CONTROL, 1993, Honolulu. Proceedings. Los Angeles: University of Southern California, 1994. p.115-129

ELBEHEIRY, E.; KARNOPP, D. C. Optimal control of vehicle random vibration with constrained suspension deflection. Journal of Sound and Vibration, London, v. 189, n. 5, p. 547-564, 1996.

FLETCHER, R. Practical methods of optimization. Chichester: John Wiley \& Sons, 1987.

FOX, R. W.; MCDONALD, A. T. Introduction to fluid mechanics. New York: John Wiley \& Sons, 1985.

GEAR, C. W. Differential-algebraic equations. In: Haug, E. D. ed. Computer aided analysis and optimization of mechanical system dynamics. Berlin: Springer-Verlag, 1984. p. 323-334.

GEHM, R. Delphi improves cadillac's ride. Automotive Engineering International, v. 109, n. 10, p. 32-33, Oct. 2001. Disponível em:

<http://www.sae.org/automag/techbriefs/10-2001> Acesso em: 28 jun. 2008. 
GENÇ, S. Synthesis and properties of magnetorheological (MR) fluids. 2002. 168 p. Tese (Doutorado) -School of Engineering of University of Pittsburgh, Pittsburg, 2002.

GILBERT, R.; JACKSON, M. Magnetic ride control. GM Tech Link, GM Dealership Service Professionals, v. 4, n. 1, Jan. 2002.

GILL, P.E.; MURRAY, W.; WRIGTH , M.H. Practical optimization. London: Academic Press, 1981.

GILLESPIE, T. D. Fundamentals of vehicle dynamics. Warrendale: Society of Automotive Engineers, 1994.

GIORGETTI, N.; BEMPORAD, A.; TSENG, H. E.; HROVAT, D. Hybrid model predictive control application towards optimal semi-active suspension. In : PROCEEDINGS OF THE INTERNATIONAL SYMPOSIUM ON INDUSTRIAL ELECTRONICS, 2005, Dubrovnik, 2005. ISIE 2005. Zagreb: Institute of Electrical and Electronics Engineers, 2005. v. 1, p. 391-398.

GIUA, A.; MELAS, M.; SEATZU, C.; USAI, G. Design of a predictive semiactive suspension system. Vehicle System Dynamics, Amsterdam, v. 41, n. 4, p. 277-300, Apr. 2004.

GLOVER, K.; DOYLE, J.C. A state-space approach on $\mathbf{H}_{\infty}$ optimal control. Berlin: Springer-Verlag, 1989. (Lecture Notes in Control and Information Sciences, v. 135)

GONÇALVES, A. J.; MEIRELLES, P. S. Damping control in hydropneumatic suspension. In : INTERNATIONAL CONGRESS OF MECHANICAL ENGINEERING, 18., 2005, Ouro Preto. Proceedings of COBEM 2005. Rio de Janeiro: ABCM, 2005.

GONÇALVES, F. D. Dynamic analysis of semi-active control techniques for vehicle applications. 2001. 180 p. Dissertação (Mestrado) - Faculty of the Virginia Polytechnic Institute and State University, Blacksburg, 2001.

GONCALVES, F. D.; AHMADIAN, M. In search of a suitable control policy for intelligent vehicle suspensions, intelligent systems - III. In : ASME INTERNATIONAL MECHANICAL ENGINEERING CONGRESS AND EXPOSITION, 17., 2002, New Orleans. Proceedings. New York: American Society of Mechanical Engineers, 2002.

GRIFFIN, M.J. Handbook of human vibration. London: Academic Press, 1990.

GUO, D. L.; HU, H. Y.; YI, J. Q. Neural network control for a semi-active vehicle suspension with a magnetorheological damper. Journal of Vibration and Control, Thousand Oaks, v.10, p. 461-471, 2004.

HAĆ, A. Adaptive control of vehicle suspension. Vehicle System Dynamics, Amsterdam, v.16, p. 57-74, 1987.

HAĆ, A.; YOUN, I.; CHEN, H. H. Control of suspensions for vehicles with flexible bodies Part I: active suspensions. Journal of Dynamic Systems Measurement and Control, New York, v. 118, n. 3, p. 508-517, 1996. 
HAĆ, A.; YOUN, I.; CHEN, H. H. Control of suspensions for vehicles with flexible bodies Part II: semi-active suspensions. Journal of Dynamic Systems Measurement and Control, New York, v. 118, n. 3, p. 518-525, 1996.

HALL, N. Ferrari 599 GTB Fiorano. Revista Quatro Rodas, ago. 2006. Disponível em: $<$ http://quatrorodas.abril.com.br/carros/impressoes/conteudo_166081.shtml > Acesso em: 28 jun. 2008.

HALVERSON, H. Magnetic ride - star wars meets the $50^{\text {th }}$ car. Disponível em: $<$ http://www.corvetteactioncenter.com/kb/question.php?qstId=503 > Acesso em: 14 set. 2003.

HAN, S.P. A globally convergent method for nonlinear programming. Journal of the Optimization Theory and Applications, New York, v. 22, p. 297, 1977.

HAYT Jr, W. H. Engineering eletromagnetics. 4 ed. New York: McGraw-Hill, 1981. 403 p.

HENROTTE, F.; HEDIA, H.; BAMPS, N.; GENON, A.; NICOLET, A.; LEGROS, W. A new method for axisymmetric linear and nonlinear problems. IEEE Transactions on Magnetics, New York, v. 29, n. 2, p. 1352-1355, Mar. 1993.

HERR, H. M.; WILKENFELD, A. User-adaptive control of a magnetorheological prosthetic knee. Industrial Robot, Bradford, v. 30, n. 1, p. 42-55, 2003.

; WILKENFELD, A.; BLECK, O. Speed-adaptive and patient-adaptive prosthetic knee. US Patent \#6.610.101 B2 - 26 Ago. 2003.

HOCK, W.; SCHITTKOWSKI, K. A comparative performance evaluation of 27 nonlinear programming codes. Computing, New York, v. 30, n. 4, p. 335-358, 1983.

HROVAT, D. Applications of optimal control to advanced automotive suspension design. Journal Dynamic Systems, Measurement and Control, New York, v. 115, n. 2(B), p. 328342, 1993. (Special Issue commemorating 50 years for the DSC division)

Influence of unsprung weight on vehicle ride quality. Journal of Sound and Vibration, London, v. 124, n. 4, p. 497-516, 1988.

Survey of advanced suspension development and related optimal control applications. Automatica, New York, v. 33, n. 10, p. 1781-1817, 1997.

; HUBBARD, M. Optimum vehicle suspension minimizing RMS rattlespace, sprungmass acceleration and jerk. Journal of Dynamic Systems, Measurement, and Control, New York, v. 103, n. 3, p. 228-236, Sept. 1981.

; MARGOLIS, D. L. An experimental comparison between semi-active and passive suspension for air-cushion vehicles. International Journal of Vehicle Design, Geneve, v. 2, n. 3, p. 308-321, 1981. 
ISO - International Organization for Standardization. ISO 2631: Guide for the evaluation of human exposure to whole body vibration, 1978.

ISO - International Organization for Standardization. ISO/DP 8608: Draft proposal: road surface profile - reporting measured data, 1984.

IVERS, D. E.; MILLER, L. R. Experimental comparison of passive, semi-active on/off, and semi-active continuous suspensions. Warrendale: Society of Automotive Engineers, 1989. (SAE Paper, no. 892484)

JANSEN, L. M.; DYKE, S. J. Semi-active control strategies for MR dampers: a comparative study. Journal of Engineering Mechanics, New York, v. 126, n. 8 , p. 795-803, 2000.

JOLLY, M. R. Pneumatic motion control using magnetorheological fluid technology.

Proceedings of the SPIE, Bellingham, n. 4332, p. 300-307, 2001.

.; BENDER, J.W.; CARLSON, J. D. Properties and applications of commercial magneto-rheological fluids. In: INTERNATIONAL SYMPOSIUM ON SMART STRUCTURES AND MATERIALS, 5., 1998, San Diego. Smart structures and materials 1998. Bellingham: SPIE, 1998.

JUANG, J.; LONGMAN, R. W. Optimized system identification. Hampton: National Aeronautics and Space Administration/Langley Research Center, 1999

; MAGHAMI, P. G. Optimal frequency-domain system realization with.

Hampton: National Aeronautics and Space Administration/Langley Research Center, 1999.

KAILATH, T. Linear systems. Englewood Cliffs: Prentice-Hall, 1980. 682 p.

KANE, T. R.; LEVINSON, D. A. Dynamics, theory and applications. Englewood Cliffs: Prentice-Hall, 1985. 379 p. (Series in Mechanical Engineering)

KARNOPP, D. C. Theoretical limitations in active vehicle suspensions. Vehicle System Dynamics, Amsterdam, v. 15, p. 41-54, 1986.

; CROSBY, N. J System for controlling the transmission of energy between spaced members. US Patent 3.807.678, 1974.

; HARWOOD, R. A. Vibration control using semi-active force generators.

Journal of Engineering for Industry, New York, v. 96, n. 2, 1974.

KAWAGOE, K.; IGUCHI, M. Semi-active control and optimum preview control applications to vehicle suspension. JSAE Review, Tokyo, n. 17, p. 24-31, Aug. 1985.

KELSO, S. P. Experimental characterization of commercially practical magnetorheological fluid damper. In: PROCEEDINGS OF SPIE CONFERENCE ON SMART STRUCTURES MATERIALS, Newport Beach, 2001. Proceedings. Bellingham: The International Society for Optical Engineering, 2001. (Paper n. 4332-34) 
KIM, C.; RO, P. I.; KIM, H. Effect of the suspension structure on equivalent suspension parameters. Proceedings of the Institution of Mechanical Engineers. Part D. Journal of automobile engineering, London, v. 213, p. 457-470, 1999.

KIMBROUGH, S. Bilinear modeling and regulator of variable component suspension. [S.1: s.n] , 1986. (ASME Monograph, AMD-80, DSC-2)

KIRICZI, S.; KASHANI, R. Control of active suspension with parameter uncertainty and non-white road unevenness disturbance input. Warrendale: Society of Automotive Engineers, 1990. (SAE Paper, no. 902283)

KO, J. M.; NI, Y. Q.; CHEN, Z. Q.; SPENCER, B. F. Implementation of MR dampers to Dongting Lake Bridge for cable vibration mitigation. In: WORLD CONFERENCE ON STRUCTURAL CONTROL, 3., Como. Proceedings. Chichester: John Wiley \& Sons, 2003. v. 3, p. 767-775.

KRASNICKI, E. J. The experimental performance of an ON-OFF active damper. Shock and Vibration Bulletin, Washington, v. 51, 1981.

KWAKERNAAK, H.; SIVAN, R. Linear optimal control system. New York: Wiley, 1972.

KWAKERNAAK, H.; SIVAN, R. The maximally achievable accuracy of linear optimal regulators and linear optimal filters. IEEE Transactions on Automatic Control, New York, v. AC-17, n. 1, p. 79-86, Feb. 1972.

LAMPE, D.; GRUNDMANN, R. Transitional and solid state behavior of a magnetorheological clutch. Dresden: Dresden University of Technology, 2000.

LIM, R. K.; PHAN, M. Q.; LONGMAN, R. W. State-space system identification with identifies hankel matrix. [S.1.]: Department of Mechanical and Aerospace Engineering, 1998. (Technical Report no. 3045)

LISENKER, I.; HOFMANN, R. L.; HURTT, M. W. Magnetorheological piston and damper assembly. US Patent 6.874.603, Apr. 2005.

LIU, Y., MATSUHISA, H.; UTSUNO, H.; GYU, J. Controllable vibration of the car-body using magnetorheological fluid damper. Vehicle System Dynamics, Amsterdam, v. 41, p. 627-636, 2004. Suplemento

LORD MATERIALS DIVISION. ENGINEERING NOTE. Designing with MR fluids. [S.1.]: Lord Corporation, 1999.

Magnetic circuit design. [S.1.]: Lord Corporation, Cary, NC, 1999.

Technical Spec.; Rheonetic ${ }^{\mathrm{TM}}$ MR Fluid - MRF 132LD. Lord Corporation, Cary, NC, 2001. NC, 2001.

Technical Spec.; Rheonetic ${ }^{\mathrm{TM}}$ MR Fluid - MRF 132AD. Lord Corporation, Cary, 
NC, 2001.

Technical Spec.; Rheonetic ${ }^{\mathrm{TM}}$ MR Fluid - MRF 240BS. Lord Corporation, Cary,

LOZIA, Z. An analysis of vehicle behavior during lane-change maneuver on an uneven road surface. In: IAVST SYMPOSIUM, 12., 1992, Lyon. Proceedings. Lisse, Swets and Zeitlinger, 1992, p. 417-431

MAEDA, T.; TOYODA, H.; IGARASHI, N.; HIROSE, K.; MIMURA, K.; NISHIOKA, T.; IKEGAYA, A. Development of super low iron-loss P/M soft magnetic material. SEI

Technical Review: New Materials, Sumitomo, n. 60, p. 3-9, Jun. 2005.

MAILAT, F.; DONESCU, S.; CHIROIU, V. On the automotive semi-active suspensions, Proceedings of the Romanian Academy. Series A, Bucureşti, v. 5, n. 1, 2004.

MARGOLIS, D. L.; HROVAT, D. Semi-active heave and pitch control of a high speed tracked air cushion vehicle. In: INTERSOCIETY CONFERENCE ON

TRANSPORTATION, 4., 1976, Los Angeles. Proceedings. New York: ASME, 1976.

MARGOLIS, D. L.; TYLEE, J. L.; HROVAT, D. Heave mode dynamics of a tracked air cushion vehicle with semiactive airbag secondary suspension. Journal of Dynamic Systems, Measurement, and Control, New York, v. 97, n. 4, p. 399-407, 1975.

MEDICAL PRODUCT MANUFACTURING NEWS. State-of-the-art prosthetic leg incorporates magneto-rheological technology. November 2000. Disponível em: $<<$ http://devicelink.com/mpmn/archive/00/11/profile.html $>$. Acesso em: 15 out. 2008.

MELLO, L. F. P. Projeto de fontes chaveadas. São Paulo: Ed. Érica, 1987. 292 p.

MENDES, E. S. Propriedades eletroreológicas de suspensões de sulfato de hidrazinalítio em óleo de silicone. 1996. Tese (Doutorado) - Faculdade de Engenharia Química da Universidade de Campinas, Campinas, 1996.

MILLER, L. R. The efect of hardware limitations on an on/off semi-active suspension. In: INTERNATIONAL CONFERENCE ON ADVANCED SUSPENSIONS, 1988, London. Proceedings. [S.1.]: Institution of Mechanical Engineers/Institution of Electrical Engineers, 1988. ( Paper no. C442/88)

MILLMAN, J.; HALKIAS, C.C. Eletrônica - dispositivos e circuitos. São Paulo: McGraw-Hill do Brasil, 1981. 877 p. v. 2.

MOORE, B. Principal component analysis in linear systems: controllability, observability, and model reduction. IEEE Transactions on Automatic Control, New York, v. 26, n.1, Feb. 1981.

MOKHIAMAR, O.; ABE, M. Active wheel steering and yaw moment control combination to maximize stability as well as vehicle responsiveness during quick lane change for active vehicle handling safety. Proceedings of the Institution of Mechanical Engineers. Part D. Journal of automobile engineering, London, v. 216, p. 115-124, 2002.

MORAN, A.; HASEGAWA, T.; NAGAI, M. Continuously controlled semi-active suspension 
using neural networks. In: INTERNATIONAL SYMPOSIUM ON ADVANCED VEHICLE CONTROL, Tsukuba. Proceedings. [S.1.:s.n.] 1994, p. 305-310

MORRISH, A. H. The physical principles of magnetism. New York: John Wiley \& Sons, 1965. $411 \mathrm{p}$.

MOTTA, D. da S.; ZAMPIERI, D. E. Modeling of a vehicle suspension with non-linear elements and performance comparison to a semi-active. In: INTERNATIONAL CONGRESS OF MECHANICAL ENGINEERING, 18., 2005, Ouro Preto. Proceedings of COBEM 2005. Rio de Janeiro: ABCM, 2005.

MOURA, E. D. A. Estudo de suspensões passiva, semi-ativa MR e ativa. 2003. 143 p. Dissertação (Mestrado) - Universidade Federal de Itajubá, Itajubá, 2003.

NOVAK, M.; VALASEK, M. A new concept of semi-active control of truck's suspension. In: INTERNATIONAL SYMPOSIUM ON ADVANCED VEHICLE CONTROL, 1996, Aachen. Proceedings. [S.1]: AVEC, 1996. p. 141-151.

OGATA, K. Engenharia de controle moderno. Rio de Janeiro: Prentice Hall, 1982. 929 p.

OLIVEIRA, J. de; TROFINO, A.; SOUZA, C. E. Análise e síntese $\mathcal{H}_{\infty}$ para sistemas LPV. SBA: Controle \& Automação, Campinas, v. 13, n. 1, p. 6-12, Jan./Abr. 2002.

PACKARD, A. K.; FAN, M.; DOYLE, J. A power method for the structured singular value. IEEE CONFERENCE ON CONTROL AND DECISION, 27, 1988, Austin. Proceedings. New York, IEEE, 1988, p. 2132-2137.

PERRELLA, N. Laboratório de controle utilizando processador digital de sinal (DSP). 2005. 94 p. Dissertação (Mestrado) - Escola Politécnica da Universidade de São Paulo, São Paulo, 2005.

PERSEGUIM, O. T. Dinâmica veicular relativa ao ride de veículos e métricas para sua avaliação. 2005. 221 . Tese (Doutorado) - Escola de Engenharia de São Carlos da Universidade de São Paulo, São Carlos, 2005.

PHILLIPS, T. Amazing magnetic fluids: uma co-produção entre "exploration systems mission directorate" e "science@NASA" publicado em 2 de abril de 2003. Disponível em: $<$ http://exploration.nasa.gov/articles/23aug_MRfluids_lite.html>. Acesso em: 10 de set. 2006.

PICADO, R. M. Controle semi-ativo em suspensões automotivas. 1998. 100 p. Dissertação (Mestrado) - Faculdade de Engenharia Mecânica da Universidade Estadual de Campinas, Campinas, 1998.

PINKOS, A.; SHTARKMAN, E.; FITZGERALD, T. An actively damped passenger car suspension system with low voltage electro-rheological magnetic fluid. In: INTERNATIONAL SYMPOSIUM ON ADVANCED VEHICLE CONTROL, Tsukuba, 1994. Proceedings. Tokyo, JSAE, 1994. p. 311-317.

POTTER, M.C.; WIGGERT, D.,C. Mechanics of fluids. 2.ed. Upper Saddle River: Prentice Hall, 1997. 
POUSSOT-VASSAL, C.; SENAME, O.; DUGARD, L.; GÁSPAR, P.; SZABÓ, Z.; BOKOR, J. A $\quad \mathbf{L P V} / \mathcal{H}_{\infty}$ semi-active suspension controller design. In: WORKSHOP ON ADVANCED CONTROL AND DIAGNOSIS, Nancy, Nov. 2006. Disponível em: $<<$ http://www.acd-2006.cran.uhp-nancy.fr/>. Acesso em: 12 out. 2008

POWELL, M.J.D. The convergence of variable metric methods for nonlinearly constrained optimization calculations. In: MANGASARIAN, O.L.; MEYER, R. R. ; ROBINSON, S.M. (Ed). Nonlinear programming 3. New York: Academic Press, 1978.

A fast algorithm for nonlinearly constrained optimization calculations. In: Watson, G.A. (Ed) Numerical analysis . Berlin: Springer-Verlag, 1978 . (Lecture notes in mathematics ; 630 )

Variable metric methods for constrained optimization. In: KORTE, Bernhard H. ; BACHEM, Achim (Ed) Mathematical programming: the state of the art. Berlin: Springer, 1983. p. 288-311.

RAO, M. V. C.; PRAHLAD, V. A tunable fuzzy logic controller for vehicle-active suspension systems. In: Fuzzy Sets and Systems 85. New York: Elsevier Science, 1997. p. $11-21$

REGAZZI, R. D.; XIMENES, G. M. A importância da avaliação da vibração no corpo humano, 3R Brasil tecnologia ambiental. Rio de Janeiro: INMETRO, 2000.

SANCHEZ, J. P. de A. Estudo de desempenho entre suspensões passiva, semi-ativa, e totalmente ativa utilizando modelo completo do veículo. 1997. 123 p. Dissertação (Mestrado) - Escola de Engenharia de São Carlos da Universidade de São Paulo, São Carlos, 1997.

SANTOS, I. F. Dinâmica de sistemas mecânicos. São Paulo: Makron Books, 2001.

SAYERS, M. W. Symbolic computer methods to automatically formulate vehicle simulation codes. 1990. 316 p. Dissertation (Doctor) - The University of Michigan, Michigan, 1990.

SCHELFHOUT, G. Model reduction for control design. 1996. 294 p. Thesis (PHD) Faculteit der Toegepast Wetenschappen. Katholieke Universiteit Leuven, Heverlee, 1996.

SCHITTKOWSKI, K. NLQPL: a Fortran-subroutine solving constrained nonlinear programming problems. Annals of Operations Research, Amsterdam, v. 5, p. 485-500, 1985.

SHARP, R. S. Wheelbase filtering and automobile suspension tuning for minimizing motions in pitch. Proceedings of the Institution of Mechanical Engineers. Part D. Journal of automobile engineering, London, v. 216, p. 933-946, 2002.

SHIMADA, Y.; MATSUNUMA, K.; NISHIOKA, T.; IKEGAYA, A.; ITOU, Y; KOISO, T. Development of a high-magnetic performance P/M soft magnetic material. SEI Technical Review, Sumitomo, n. 56, p. 46-53, Jun. 2003. 
SILVA, P. F. Motor viscoso de fluxo laminar com fendas circunferenciais. 1998. 197 p. Tese (Doutorado) - Escola Politécnica da Universidade de São Paulo, São Paulo, 1998.

SILVA, W. M. da; PAULA, P. P. de. $12 \mathrm{~V} / 14 \mathrm{~V}$ to $36 \mathrm{~V} / 42 \mathrm{~V}$ automotive system supply voltage change and the new technologies. In: CONGRESSO E EXPOSIÇÃO INTERNACIONAIS DA TECNOLOGIA DA MOBILIDADE, 11., 2002, São Paulo. SAE Brasil 2002. São Paulo: SAE Brasil, 2002.

SIMON, D. E.; AHMADIAN, M. An alternative semi-active control method for sport utility vehicles. Proceedings of the Institution of Mechanical Engineers. Part D. Journal of automobile engineering, London, v. 216, p. 125-139, 2002.

SINNECKER, J. P. Materiais magnéticos doces e materiais ferromagnéticos amorfos. Revista Brasileira de Ensino de Física, São Paulo, v. 22, n. 3, Set. 2000.

SOCIETY OF AUTOMOTIVE ENGINEERS. SAE J1490: Measurement and presentation of truck ride vibrations. Warrendale, SAE, 1987.

SONG, X.; AHMADIAN, M.; SOUTHWARD, S. C. Eliminating the unwanted dynamics from the controllable suspension for vehicle applications. In: ASME INTERNATIONAL INTERNATIONAL MECHANICAL ENGINEERING CONFERENCE, New Orleans, 2002. Proceedings. New York: American Society of Mechanical Engineers, 2002.

SPENCER Jr., B. F.; DYKE, S. J.; SAIN M. K.; CARLSON J. D. Phenomenological model of a magneto-rheological damper. Journal of Engineering Mechanics, New York, v. 122, n. 3, Mar. 1996.

; YANG, G.; CARLSON, J. D.; SAIN, M. K. "Smart" dampers for seismic protection of structures: a full-scale study. In: WORLD CONFERENCE ON STRUCTURAL CONTROL, 2., Kyoto, Japan, 1998. Proceedings. Chichester/ New York: Wiley, 1999.

STONE, R.; BALL, J. K. Automotive engineering fundamentals. Warrendale: SAE INTERNATIONAL, 2004

STURK, M. ; WU, X. M., WONG, J. Y. Development and evaluation of a high voltage supply unit for eletrorheological fluid dampers. Vehicle System Dynamics, Amsterdam, v. 24, p. 101-121, 1995.

STUTS, L.T.; ROCHINHA, F. A. A comparison of control strategies for magnetorheological vehicle suspension systems. In: INTERNATIONAL SYMPOSIUM ON DYNAMIC PROBLEMS OF MECHANICS, 11., Ouro Preto, 2005. Proceedings of DINAME. Ouro Preto: [s.n.], 2005

SZELAG, W. Finite element analysis of the magnetorheological fluid brake transients. In: INTERNATIONAL SYMPOSIUM ON ELETROMAGNETIC FILDS IN ELECTTICAL ENGINEERING, 11., Maribor, 2003. ISEF 2003. Bradford: Emerald Group, 2004. p. 835840.

TAMAI, E. H. Estudo do problema de controle da suspensão de trens de alta velocidade 
levitados magneticamente. 1995. 234 p. Tese (Doutorado) - Escola Politécnica da Universidade de São Paulo, São Paulo, 1995.

THOMPSON, A. G. Design of active suspensions. Proceedings of the Institution of Mechanical Engineers, v. 185 , n. 36, p. 553-563, 1971.

THOMPSON, A. G. An optimal suspension for an automobile on a random road. [S.1.:s.n.], 1979. (SAE Paper No. 790478)

TSAO, Y. J.; CHEN, R. The design of an active suspension force controller using genetic algorithms with maximum stroke constraints. Proceedings of the Institution of Mechanical Engineers. Part D. Journal of automobile engineering, London, v. 215, p. 317-327, 2001.

TSENG, H. E.; HEDRICK, J. K. Semi-active control laws - optimal and sub-optimal. Vehicle System Dynamics, Amsterdam, v. 23, n. 7, p. 545-569, 1993.

TSENG, H. E.; HROVAT, D. Some additional characteristics of optimal active suspensions for quarter-car models. Dearborn: Ford Motor Company Reserch, 1989. (Report SR-89-95)

ULSOY, A. G; HROVAT, D.; TSENG, T. Stability robustness of LQ and LQG active suspensions. Journal of Dynamic Systems, Measurement and Control, New York, v. 116, n. 1, p. 123-131, 1994.

VANNUCCI, S. N. Variable damping suspension with electronic control. In: FISITA CONGRESS, 26., London, 1992. The vehicle and the environment: technical papers. London: Automotive Technology Serving Society, 1992.

VIEIRA, S. L. Caracterização das propriedades mecânicas e reológicas de fluidos eletroreológicos. 1996. 158p. Tese (Doutorado) - Faculdade de Engenharia Mecânica da Universidade Estadual de Campinas, Campinas, 1996.

WATTON, J.; HOLFORD, K. M.; SURAWATTANAWAN, P. Electrohydraulic effects on the modeling of a vehicle active suspension. Proceedings of the Institution of Mechanical Engineers. Part D. Journal of automobile engineering, London, v. 215, p. 1077-1092, 2001.

WOERNLE, C. Position and force control of multibody systems by feedback linearization. In: Flexible Mechanisms, Dynamics, and Analysis: Presented at the 1992 ASME Design Technical Conferences, 1992, Scottsdale. Proceedings. v. 47, p. 11-18, 1992.

WOODBURY, M. A. Inverting modified matrices. Princeton: Princeton University, 1950. ( Memorandum Report 42, Statistical Research Group)

YAMAMURA, S.; OHNISHI, K; MASADA, E. Theory of control system of electromagnetically levitated bogie truck. Electrical Engineering in Japan, New York, v. 99 , n. 6, p. 62-69, 1979.

YAMASHITA, M.; FUJIMOTI, K.; UHLIK, C.; KAWATANI, R.; KUMURA, H. $H_{\infty}$ control of an automotive active suspension. In: IEEE CONFERENCE ON DECISION 
CONTROL,29., 1990, Honolulu. Proceedings. New York: Institute of Electrical and Electronics Engineers, 1990. p. 2244-2250.

YEH, E. C.; LU, S. H.; CHEN, C. C. A genetic algorithm based fuzzy system for semi-active suspension system design. In: INTERNATIONAL SYMPOSIUM ON ADVANCED VEHICLE CONTROL, Tsukuba. Proceedings. Tokyo, Japan: JSAE, 1994. p. 189-194.

YOO, J. H.; WERELEY, N. M. Design of a high efficiency magnetorheological valve. Journal of Intelligent Material Systems and Structures, Lancaster, v. 13, p. 679-685, Oct. 2002.

YOSHIOKA, H.; RAMALLO, J. C.; SPENCER Jr., B. F. "Smart" base isolation strategies employing magneto-rheological dampers. Journal of Engineering Mechanics, New York, p. 540-551, May 2002.

YUE, C. ; BUTSUEN, T.; HEDRICK, J. K. Alternative control laws for automotive active suspensions. In: AMERICAN CONTROL CONFERENCE, Philadelphia. Proceedings. Evanston: American Automatic Control Council, 1988. p. 2373-2376. 


\section{APÊNDICE A - Revisão sobre Viscosidade}

\section{A.1 - Introdução}

Da teoria de mecânica dos fluidos (FOX e MCDONALD, 1985) tem-se a definição de fluido como uma substância que se deforma continuamente sob a ação de uma tensão de cisalhamento. Na ausência de uma tensão de cisalhamento, não haverá deformação. Fluidos podem ser de classificados, modo geral, de acordo com a relação entre a tensão de cisalhamento aplicada e a sua taxa de deformação, a que chamamos de viscosidade.

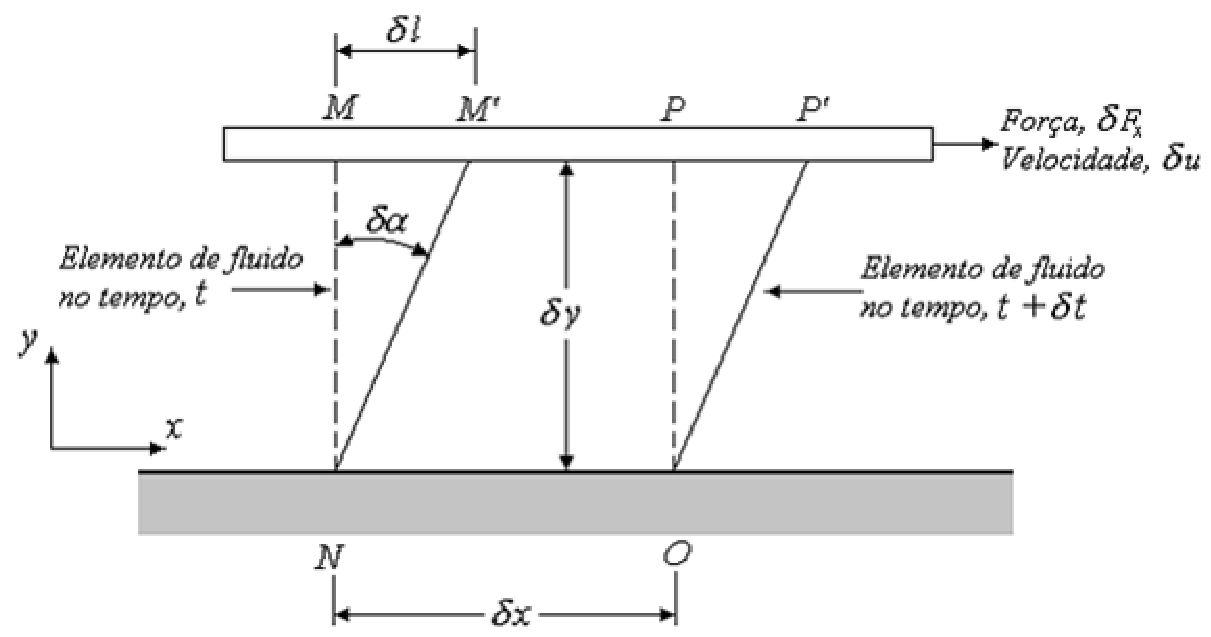

Figura A.1 - Deformação de um elemento de fluido

Considerando o comportamento de um elemento de fluido entre dois planos infinitos, mostrado na figura A.1. Tem-se que a placa superior (um dos planos) move-se a uma velocidade constante, $\delta u$, sob a influência de uma força constante aplicada $\left(\delta F_{x}\right)$. A tensão de cisalhamento, $\tau_{y x}$, aplicada ao elemento de fluido é dada por:

$$
\tau_{y x}=\lim _{\delta A_{y} \rightarrow 0} \frac{\delta F_{x}}{\delta A_{y}}=\frac{d F_{x}}{d A_{y}}
$$

onde $\delta A_{y}$ é a área de contato do elemento de fluido com a placa. 
Durante o intervalo de tempo, $\delta t$, o fluido é deformado da posição MNOP para a posição M'NOP'. A taxa de deformação do fluido é dada por:

$$
\varsigma=\lim _{\delta t \rightarrow 0} \frac{\delta \alpha}{\delta t}=\frac{d \alpha}{d t}
$$

A tensão de cisalhamento, $\tau_{y x}$, deve ser expressa através de grandezas facilmente mensuráveis. Assim, usando-se a distância, $\delta l$, entre os pontos M e M' que é dada por:

$$
\delta l=\delta u \cdot \delta t
$$

ou alternativamente, para ângulos pequenos,

$$
\delta l=\delta y \cdot \delta \alpha
$$

Igualando estas duas últimas expressões para um dado $\delta l$, tem-se:

$$
\frac{\delta \alpha}{\delta t}=\frac{\delta u}{\delta y}
$$

Tomando-se o limite de ambos os lados da equação, obtém-se:

$$
\frac{d \alpha}{d t}=\frac{d u}{d y}
$$

Assim, o elemento de fluido da figura A.1 quando sujeito a uma tensão de cisalhamento, $\tau_{y x}$, experimenta uma taxa de deformação ( ou taxa de cisalhamento que vem do termo em inglês "shear rate") dada por $d u / d y$. Fluidos para os quais a tensão de escoamento é diretamente proporcional à taxa de deformação são denominados fluidos newtonianos. $\mathrm{O}$ termo não-newtoniano é usado para classificar todos os fluidos para os quais a tensão de escoamento não é diretamente proporcional à taxa de deformação.

\section{A.2 - Fluidos Newtonianos}

Os fluidos comuns como água, ar, e gasolina são newtonianos sob condições normais (CNTP). Se o fluido da figura A.1 é newtoniano, então: 


$$
\tau_{y x}=\mu \frac{d u}{d y}
$$

onde constante de proporcionalidade, $\mu$, é a viscosidade absoluta (ou dinâmica). A tensão de cisalhamento, $\tau_{y x}$, age no plano normal ao eixo $y$. Se fossem consideradas as deformações de dois fluidos newtonianos diferentes, por exemplo glicerina e água, seria possível reconhecer que estes dois fluidos iriam deformar-se em taxas diferentes sob a ação de uma mesma tensão de cisalhamento aplicada. A glicerina apresenta uma resistência muito maior à deformação do que a água. Desta forma, pode-se dizer que a glicerina é muito mais viscosa.

Nota-se que, como as dimensão de $\tau$ é $\left[F / L^{2}\right]$ e que a dimensão de $d u / d y$ é [1/t],então a dimensão de $\mu$ é $\left[F t / L^{2}\right]$. Como as dimensões de força, $F$, massa, $M$, comprimento, $L$, e tempo, $t$, são relacionadas pela segunda lei de Newton do movimento, as dimensões de $\mu$ podem também ser expressas como $[M / L t]$. No sistema "Gravitacional Britânico", as unidades de viscosidade são lbf $\mathrm{s} / \mathrm{ft}^{2}$ ou slug/ft's. No sistema "Métrico Absoluto", a unidade básica de viscosidade é chamada de poise (poise $\equiv \mathrm{g} / \mathrm{cm} / \mathrm{s}$ ); no sistema SI as unidades de viscosidade são $\mathrm{kg} / \mathrm{m} \cdot \mathrm{s}$ ou Pa $\mathrm{s}\left(=\mathrm{N} \cdot \mathrm{s} / \mathrm{m}^{2}\right)$.

Em mecânica dos fluidos a razão entre viscosidade absoluta, $\mu$, e densidade, $\rho$, é utilizado com frequiência. Desta forma, a está razão é dado o nome de viscosidade cinemática e é em geral representada pelo símbolo v. Uma vez que a densidade tem dimensão $\left[\mathrm{M} / \mathrm{L}^{3}\right]$, a dimensão de $v$ é $\left[\mathrm{L}^{2} / \mathrm{t}\right]$. No sistema "Métrico Absoluto" de unidades, a unidade de $v$ é um stoke (stoke $\equiv \mathrm{cm}^{2} / \mathrm{s}$ ), e no "SI" é $\mathrm{m}^{2} / \mathrm{s}$.

\section{A.3 - Fluidos Não-Newtonianos}

Muitos fluidos comuns exibem comportamento não-newtoniano. Um exemplo familiar é o creme-dental, que se comporta como um "fluido" quando o tubo de creme-dental é espremido, expulsando o creme para fora. Contudo, o creme não escorre para fora do tubo por si próprio quando a tampa é removida. Há neste caso um limiar de tensão ou uma tensão limite para o escoamento, abaixo do qual o creme-dental comporta-se como um sólido. Estritamente falando, a definição de fluido citada em A.1 é válida somente para materiais que têm tensão de limite de escoamento igual a zero. O termo não-Newtoniano é utilizado para classificar todos os fluidos cuja tensão de cisalhamento não é diretamente proporcional a sua taxa de deformação. Tais fluidos são comumente classificados como tendo comportamentos 
independentes do tempo, dependentes do tempo, ou viscoelático. Quatro exemplos de comportamento independente do tempo são apresentados no diagrama reológico da figura A.2.
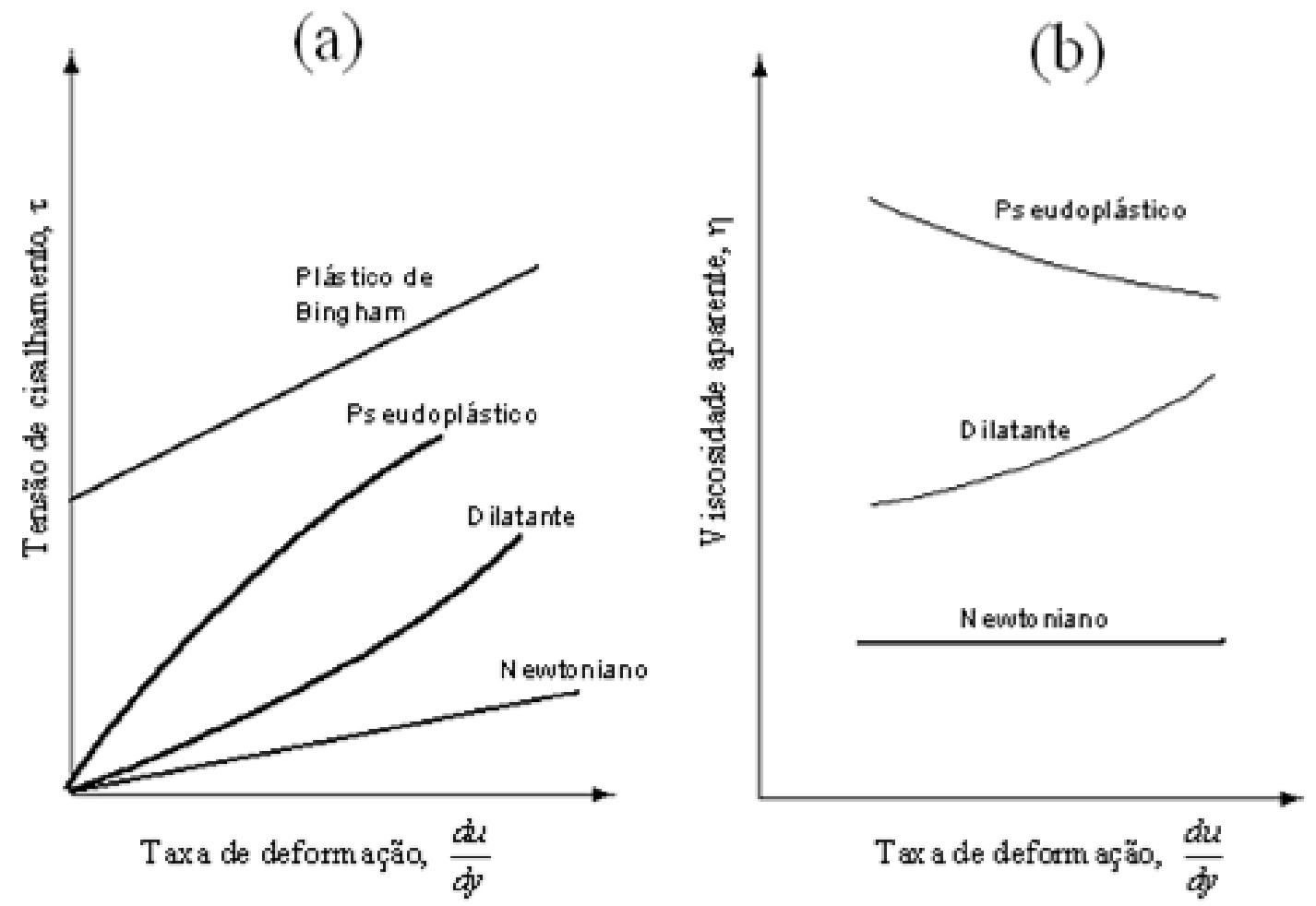

Figura A.2 - (a) Tensão de cisalhamento, $\tau$, e (b) viscosidade aparente, $\eta$, como função da taxa de deformação para fluxo unidimensional de vários fluídos não Newtonianos.

Numerosas equações empíricas foram propostas para modelar as relações observadas entre $\tau_{y x}$ e $d u / d y$ para fluidos independentes do tempo. Eles podem ser adequadamente representados na maioria das aplicações de engenharia pelo modelo de potenciação, o qual para fluxo unidimensional resume-se na equação (A.8), onde o expoente, $n$, é chamado de índice de comportamento de fluxo e $k$ é o índice de consistência. Esta equação reduz-se à lei de Newton da viscosidade para $n=1 \operatorname{com} k=\mu$.

$$
\tau_{y x}=k \cdot\left(\frac{d u}{d y}\right)^{n}
$$

Caso a equação equação (A.8) possa ser representada na forma da equação (A.9), então o termo $\eta=k|d u / d y|^{n-1}$ é definido como viscosidade aparente de um fluido nãonewtoniano. 


$$
\tau_{y x}=k \cdot\left|\frac{d u}{d y}\right|^{n-1} \cdot \frac{d u}{d y}=\eta \cdot \frac{d u}{d y}
$$

Fluidos cuja viscosidade aparente decresce com o incremento da taxa de deformação $(\mathrm{n}<1)$ são chamados de fluidos pseudo-plásticos ("shear thinning"). A maioria dos fluidos não-newtonianos se enquadra neste grupo. Exemplos incluem soluções poliméricas, suspensões coloidais e polpa de papel na água. Se a viscosidade aparente cresce com o incremento da taxa de deformação (n>1) o fluido é chamado de dilatante ("shear thickening"). Suspensões de fécula e de areia são exemplos de fluidos dilatantes.

Um "fluido" que se comporta como um sólido até que uma tensão de escoamento mínima, $\tau_{y}$, seja ultrapassada e subseqüentemente exibe uma relação linear (ou muito próximo de linear) entre a tensão de cisalhamento e a taxa de deformação é conhecido como plástico de Bingham. O modelo de tensão de cisalhamento deste tipo de fluido é apresentado na eq.(A.10).

$$
\tau_{y x}=\tau_{y}+\eta \frac{d u}{d y}
$$

Fluidos magneto-reológicos e creme-dental são exemplos de substâncias que exibem este tipo de comportamento. 


\section{APÊNDICE B - MR versus ER}

Apesar dos fluidos ER terem tido mais atenção dos pesquisadores entre as décadas de 50 e 80, os fluidos MR modernos são superiores em vários aspectos e atualmente são os mais utilizados. Abaixo são citadas as quatro grandes desvantagens dos fluidos ER (CARRERA, 2003):

- fluidos ER requerem tensões acima de $1 \mathrm{kV}$, que exigem fontes de alta tensão relativamente caras, requerem maiores cuidados com isolação e apresentam maiores riscos, principalmente em veículos onde circuitos de alta-tensão teriam que compartilhar espaço com dutos de combustível;

- dispositivos que utilizam fluidos ER apresentam um alcance dinâmico em média dez vezes menor que os fluidos MR, o que resulta em dispositivos menos eficientes. Segundo Genç (2002) esta diferença ocorre devido às tensões de escoamento do fluido MR alcançarem valores mais elevados, o que está relacionado ao fato de que a densidade de energia magnetostática, $\mu_{0} H_{0}^{2}$, nos fluidos MR é maior que a densidade de energia eletrostática, $\varepsilon_{0} E_{0}^{2}$, nos fluidos ER;

- fluidos ER são altamente susceptíveis a contaminantes externos ( por exemplo, a umidade), porque o seu comportamento reológico depende em última instância do movimento dos íons ou cargas elétricas, facilmente afetado por pequenas quantidades contaminantes externos; e

- fluidos ER só podem operar numa faixa estreita de temperatura, pois sua viscosidade apresenta grande dependência da temperatura. Por outro lado, os fluidos MR apresentam uma estabilidade relativa entre -40 e $150{ }^{\circ} \mathrm{C}$, portanto, são mais adequados a aplicações como amortecedores de automóveis que experimentam uma grande variação térmica em uma situação normal de operação. 


\section{APÊNDICE C - Características de um Fluido MR}

Segundo Carlson (2001), os fluidos elaborados por Winslow já no final década de 40, que alcançavam até $100 \mathrm{kPa}$ de resistência ao escoamento quando magnetizados, consistiam basicamente de 9 partes por peso de ferro carbonilo suspensos em 1 parte de óleo mineral. Para manter esta mistura em suspensão, Winslow adicionava naftanatos ferrosos ou oleatos ferrosos como dispersantes e "sabão" metálico como estearato de lítio ou de sódio como um aditivo tixotrópico ${ }^{26}$.

Esta formulação, além de ser relativamente fácil de elaborar, atende razoavelmente bem às necessidades básicas da maioria dos dispositivos MR. Entretanto, para se obter dispositivos MR altamente eficientes, as pesquisas mais atuais sobre os fluidos MR buscam aprimorar algumas de suas características de forma a se atingir desempenhos cada vez melhores (BOMBARD, 2005; GENÇ, 2002). Basicamente são quatro as características fundamentais dos fluidos MR:

- tensão de escoamento;

- viscosidade aparente;

- estabilidade e

- durabilidade

As duas primeiras características estão diretamente ligadas ao alcance dinâmico (“dynamic range") ou razão de controle do dispositivo MR, que nada mais é do que a razão entre a força máxima (totalmente magnetizado) e a força mínima (desmagnetizado) que o dispositivo é capaz de gerar. Para um bom dispositivo MR é interessante que o alcance dinâmico seja o maior possível. É claro que isso depende muito da aplicação. No caso de amortecedores automobilísticos é interessante que o alcance dinâmico seja pelo menos igual a cinco na velocidade máxima de operação, ou seja, que a parcela de força gerada pela resistência ao movimento imposto pela tensão de escoamento do fluido magnetizado seja cinco vezes maior que a força de resistência devido ao atrito viscoso gerado pela viscosidade

\footnotetext{
${ }^{26}$ Termo técnico de Química: substância que se transforma em líquido quando da mistura ou agitação.
} 
plástica do fluído. Para que isto seja possível, é importante que o fluido MR apresente tensões de escoamento superiores a $30 \mathrm{kPa}$, quando sob um campo magnético de aproximadamente $150 \mathrm{kA} / \mathrm{m}$, e ainda que o coeficiente de viscosidade plástica seja menor que $0,1 \mathrm{~Pa}$ s na temperatura de operação do fluido.

A estabilidade também é um fator importante para um fluido MR. À medida que o fluido MR é composto por dois componentes mais abundantes: partículas ferro-carbonilo bem pequenas, com diâmetro entre 2 e $5 \mu \mathrm{m}$ e formato arredondado e regular, que compõem de 70 a $90 \%$ do peso do fluido, ou $20 \%$ a $40 \%$ do volume, e um líquido base que pode ser óleo mineral, óleo de silicone ou até mesmo água, é natural perceber que vai se tratar de uma mistura bastante instável. As partículas de ferro-carbonilo são bem mais densas que o líquido base, e tenderão a se precipitar com facilidade. Esta instabilidade é prejudicial, uma vez que o fluido depois de um certo tempo deixa de ser homogêneo e perde sua característica de reologia dependente do campo magnético. Para resolver este problema são adicionados alguns aditivos à mistura de forma a aumentar sua estabilidade. Um fluido que demore em média de 5 a 10 dias para que se perceba visualmente sua decantação é considerado estável o suficiente para aplicações automobilísticas, o mais importante é que ele apresente uma grande facilidade de redispersão, isto é, que consiga restabelecer suas propriedades com pouca energia de agitação. Em aplicações destes dispositivos no controle de edifícios sujeitos a abalos sísmicos, a estabilidade é um fator crítico, pois o dispositivo MR pode ficar longos períodos sem ser utilizado e ainda as baixas freqüências em que ele atua podem não movimentar o fluido o suficiente para que suas propriedades sejam restabelecidas (CARLSON, 2001, p. 2).

A durabilidade de um fluido MR também é uma propriedade importante de fluidos MR, principalmente quando aplicados em atuadores de ação contínua como no controle de vibração de máquinas e em suspensão automobilística. Este já foi um fator limitante da aplicação dos fluidos MR, porém os fluidos comerciais atualmente apresentam uma durabilidade satisfatória. Segundo Carlson (2001), mesmo em aplicações em dispositivos comuns como o amortecedor de um assento de motorista de caminhão pesado, os fluidos MR são expostos a condições bastante extremas. Este tipo de amortecedor é projetado para gerar forças resistivas da ordem de $1.200 \mathrm{~N}$ a uma corrente de $1 \mathrm{~A}$. A taxa de cisalhamento do fluido na válvula deste dispositivo, quando operando na faixa de 0,05 a $0,2 \mathrm{~m} / \mathrm{s}$ é de 1 a $4 \mathrm{x}$ $10^{4} \mathrm{~s}^{-1}$. Sob condições extremas este amortecedor pode experimentar velocidades que excedem $1 \mathrm{~m} / \mathrm{s}$ ou taxas de cisalhamento superiores a $2 \times 10^{5} \mathrm{~s}^{-1}$. Em amortecedores de suspensões primárias de automóveis as taxas de cisalhamento do fluido MR nas válvulas pode ser da ordem de $10^{6} \mathrm{~s}^{-1}$. Além disso, os picos de dissipação de potência podem ultrapassar 
2.000 watts ou $20 \mathrm{~W} / \mathrm{cm}^{3}$. Situações como estas geram um efeito de degradação do fluido MR conhecido por IUT ("In-Use-Thickening") ou "espessamento pelo uso", que se caracteriza pela segmentação das partículas ferromagnéticas do fluido em partículas ainda menores, porém com formato irregular que provocam um espessamento da mistura e por conseqüência um aumento da viscosidade aparente. No extremo, o comportamento do fluido MR pode ficar similar ao de uma graxa. O aumento da viscosidade do fluido MR faz com que o alcance dinâmico do dispositivo MR diminua, degradando a sua efetividade como atuador em sistemas de controle.

A durabilidade dos fluidos MR é testada a partir de ensaios cíclicos, no entanto, um mesmo fluido MR pode apresentar diferentes graus de deterioração, dependendo do tipo de dispositivo em que ele foi aplicado e a que nível de trabalho este fluido foi submetido. De forma geral, a durabilidade de um fluido MR depende da taxa de cisalhamento, da temperatura e do tempo a que o fluido está submetido a estas condições. Assim uma medida útil na predição da expectativa de vida de um fluido MR é a energia dissipada no tempo de vida ou LDE (“Lifetime Dissipated Energy”), definida por Carlson (2001):

$$
L D E=\frac{1}{V} \int_{o}^{T} P \cdot d t
$$

Onde P é a potência instantânea sendo convertida em calor no dispositivo MR, V é o volume de fluido utilizado no dispositivo e T é o tempo de vida do fluido.

Assim o LDE é simplesmente o total de energia mecânica dissipada por unidade de volume do fluido MR durante toda sua vida. No estado da arte atual dos fluidos MR comerciais, o LDE chega a aproximadamente $10^{7} \mathrm{~J} / \mathrm{cm}^{3}$. Numa aplicação de amortecedor de suspensão primária para automóveis de passeio, onde se tem uma potência média de $450 \mathrm{~W}$ e um volume típico de $120 \mathrm{~cm}^{3}$, isto equivaleria a uma vida útil de aproximadamente 740 horas, onde a uma velocidade média de $50 \mathrm{~km} / \mathrm{h}$ resultaria num total de aproximadamente 37.000 $\mathrm{km}$. Como um amortecedor convencional atualmente deve ser trocado a cada $40.000 \mathrm{~km}$, a durabilidade dos atuais fluidos MR é satisfatória para esta aplicação. Considerando que um amortecedor MR não apresenta desgaste significativo em suas partes mecânicas, como é o caso dos amortecedores convencionais, é possível que depois de atingida a quilometragem limite que sejam trocados apenas o fluido MR e as vedações, mantendo-se todo o conjunto mecânico e elétrico, e assim reduzindo-se os custos de manutenção. 
Outro aspecto importante dos fluidos magneto-reológicos, e que não pode ser deixado de lado, são as demandas da sua produção em larga escala. Tomando-se uma única plataforma de automóvel de passeio no mercado americano, a quantidade de fluido MR utilizada para equipar os amortecedores destes veículos seria da ordem de $10^{5}$ litros/ano. Dependendo da carga de partículas de ferro na composição do fluido pode-se chegar a um montante de 2 a 4 x $10^{5} \mathrm{~kg} / \mathrm{ano}$ ou 1 a 2 toneladas de fluido MR por dia. Além disso, um barril de fluido MR de 50 galões (185 litros) pesaria entre meia e uma tonelada, e assim, para uma aplicação automobilística típica, um produtor de fluido MR deveria ter capacidade e confiabilidade para produzir vários barris de fluido por dia, considerando-se que esta empresa terá que lidar com grandes quantidades de matérias-primas pesadas e pirofosfóricas, o que exige razoáveis investimentos em transportadores e sistemas de segurança (CARLSON, 2001). 


\section{APÊNDICE D - Materiais Ferromagnéticos}

Este apêndice traz um resumo das propriedades dos materiais magnéticos, e também quais são as propriedades mais importantes para algumas aplicações.

A magnetização $(M)$ é o total de momento magnético dos dipolos por unidade de volume, em unidade $\mathrm{A}^{\cdot} \mathrm{m}^{2}$ por $\mathrm{m}^{3}$. Indução magnética ou densidade de fluxo magnético $(B)$, é o fluxo por área expresso em unidades de $\mathrm{Wb} / \mathrm{m}^{2}$ ou Tesla. No vácuo a indução magnética é dada por (CULLITY, 1972, apud GENÇ, 2002):

$$
B=\mu_{0} \cdot H
$$

onde $\mu_{0}$ é a permeabilidade magnética do vácuo $\left(4 \pi \times 10^{-7} \mathrm{H} / \mathrm{m}\right)$ e $H$ é a intensidade de campo magnético. Se o espaço é preenchido com qualquer substância magnética, cuja magnetização induzida é $\mu_{0} M$, então a indução total torna-se (CULLITY, 1972, apud GENÇ, 2002):

$$
B=\mu_{0} \cdot(H+M)
$$

Assim sendo, define-se suscetibilidade como:

$$
\chi=\frac{M}{H}
$$

e a permeabilidade é definida por:

$$
\mu=\frac{B}{H}=\frac{\mu_{0} \cdot(H+M)}{H}=\mu_{0} \cdot(1+\chi)
$$

A razão entre a permeabilidade do material e a permeabilidade no vácuo é chamada de permeabilidade relativa, $\mu_{r}$, e é dada por $\mu / \mu_{0}$, ou seja: 


$$
\mu_{r}=1+\chi
$$

A resposta magnética de vários materiais é comparada através de seus valores de suscetibilidade e permeabilidade relativa conforme mostra a tabela D.1.

Tabela D.1: Suscetibilidade e permeabilidade relativa dos materiais.

\begin{tabular}{l|ccc}
\hline & Diamagnéticos & Paramagnéticos & $\begin{array}{c}\text { Ferro- ou Ferri- } \\
\text { magnéticos }\end{array}$ \\
\hline Suscetibilidade, $\chi$ & $<0$ & $\geq 0$ & $>>0$ \\
Permeabilidade relativa, $\mu_{\mathrm{r}}$ & $<1$ & $\geq 1$ & $>>1$ \\
\hline
\end{tabular}

A figura D.1 apresenta um curva BxH típica de materiais ferromagnéticos, onde são indicados as principais propriedades destes materiais.

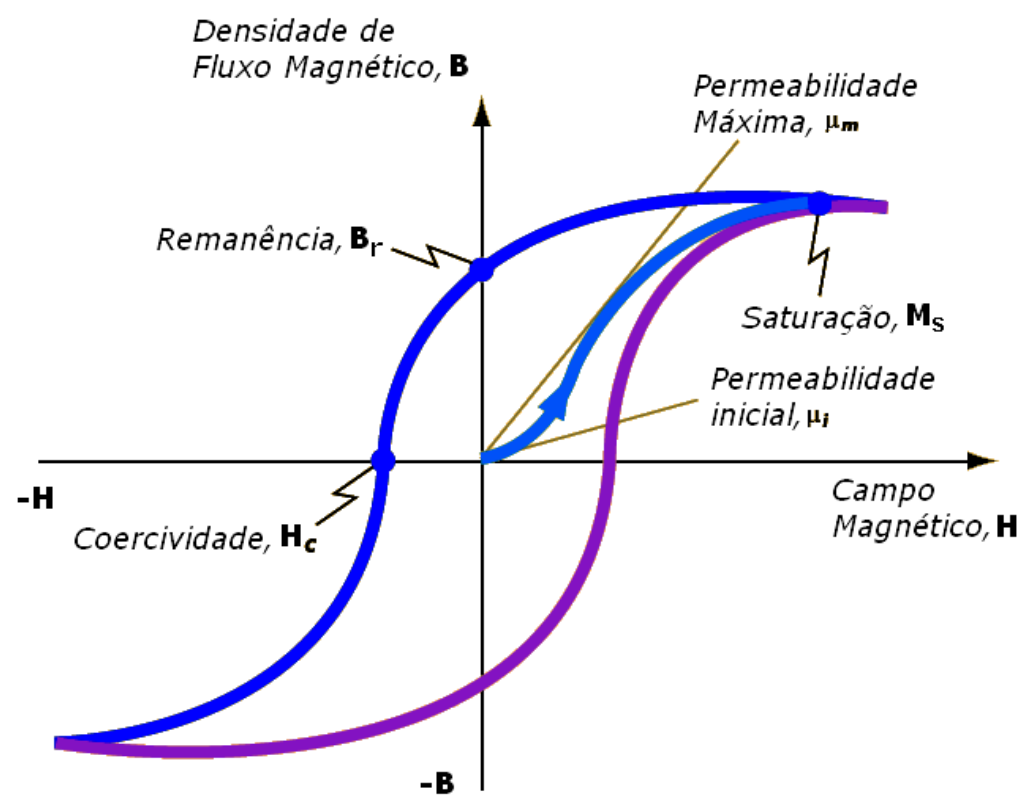

Figura D.1 - Curva BxH típica, descrevendo as propriedades principais dos materiais

Além do $\mathrm{Fe}$, Co, e $\mathrm{Ni}$ que são os materiais ferromagnéticos tradicionais, alguns elementos da série dos lantanídeos ( $\mathrm{Gd}, \mathrm{Td}$, Dy, Ho, Er e Tm) exibem comportamento ferromagnético em temperatura ambiente. Entretanto, a lista dos materiais ferromagnéticos é 
muito grande uma vez que é possível formar um número ilimitado de soluções sólidas e outros compostos, contendo materiais ferromagnéticos e não magnéticos.

Segundo Sinnecker (2000), os processos de magnetização em materiais ferromagnéticos podem ocorrer de duas formas: por deslocamento das paredes de domínios magnéticos e/ou por rotação da magnetização local dentro dos domínios. As mudanças na magnetização em ambos os casos dependem fortemente de imperfeições no material. Diversos modelos têm sido propostos e aplicados para calcular a coercividade, a permeabilidade inicial, a remanência, etc. (vide figura D.1)

Em um monocristal ferromagnético sem nenhuma imperfeição, um campo aplicado ao material pode levar as paredes de domínio existentes a se deslocarem através do material sem encontrar nenhuma resistência. Portanto, a intensidade de campo necessária para causar o movimento pode ser muito pequena e, no caso de uma parede ${ }^{27}$ de $180^{\circ}$, a alteração da magnetização será muito grande. Assim, esperam-se coercividades muito pequenas, e permeabilidade e suscetibilidades muito grandes neste tipo de material.

Entretanto, até os monocristais podem possuir imperfeições de algum tipo, e isso leva a um bloqueio parcial das paredes de domínio e conseqüentemente a uma diminuição da permeabilidade e a um aumento da coercividade. Este efeito é ainda maior em se tratando de materiais policristalinos, onde as fronteiras de grãos são um obstáculo a mais para o movimento das paredes. A posição das paredes depende de um estado mínimo de energia do material. Quando todos os domínios magnéticos de um material se anulam, deixando-o sem magnetização, há um estado com nível de energia nulo. O campo magnético necessário para ultrapassar um ponto máximo de energia e mover a barreira para outra posição é a coercividade. Quando da aplicação de um campo magnético pode haver o deslocamento da barreira para outro mínimo local de energia que não é nulo. Neste caso, quando o campo magnético for retirado, ainda permanecerá uma magnetização residual no material que é chamada de remanência, e sua unidade dimensional é o Tesla.

Para aplicações como: transformadores, motores, geradores:

- alta magnetização de saturação;

- baixa coercividade;

- alta permeabilidade inicial; e

- baixas perdas energéticas por histerese.

\footnotetext{
${ }^{27}$ A fronteira entre dois domínios também é chamada de parede de domínio. No caso de dois domínios adjacentes apresentarem direções opostas de magnetização, a parede entre eles é chamada parede de $180^{\circ}$.
} 
Estas em geral são as características típicas de um material ferromagnético mole ou doce. Por outro lado, materiais com alta coercividade são chamados de materiais magnéticos duros, e são utilizados principalmente na confecção de imãs permanentes. Os materiais magnéticos mais duros apresentam maiores perdas energéticas por histerese.

Altas magnetizações de saturação podem ser obtidas utilizando-se metais com alto momento magnético, tais como o ferro ou ligas de ferro-cobalto. As outras propriedades podem ser obtidas impondo-se de alguma maneira uma alta mobilidade das paredes de domínio. Isto pode ser obtido reduzindo-se os defeitos tais como inclusões, cavidades, fronteira de grãos, tensões internas, etc. Inclusões podem ser reduzidas removendo-se impurezas. Tensões internas de origem mecânica podem ser reduzidas por tratamentos térmicos adequados.

As características de um material magnético doce também podem ser melhoradas através de tratamentos metalúrgicos. Duas das mais importantes técnicas metalúrgicas neste sentido são a de orientação de grão e de tratamentos termo-magnéticos ("magnetic annealing”). $\mathrm{Na}$ orientação de grão, o material é submetido a um processo de laminação a frio. Este procedimento faz com que os grãos do material se alinhem e se tornem orientados ao longo de uma orientação preferencial. Se um campo é aplicado nesta direção, as curvas de histerese são praticamente retangulares, com uma permeabilidade bastante alta, coercividade baixa e baixas perdas por histerese. No tratamento termo-magnético, o material é submetido a altas temperaturas na presença de campos magnéticos. Isso também leva a indução de uma anisotropia uniaxial que resulta numa curva de histerese retangular, com altas permeabilidades e baixas perdas.

Tabela D.2: Materiais ferromagnéticos doces típicos (MORRISH,1965).

\begin{tabular}{|c|c|c|c|c|c|c|}
\hline Material & Observações & Composição & $\mu_{I}$ & $\mu_{m}$ & $H_{c}[\mathbf{A} / \mathbf{m}]$ & $M_{S}[\mathbf{T}]$ \\
\hline Ferro & Comercial & $\mathrm{Fe}_{99}$ & 200 & 6.000 & 72 & 2,16 \\
Ferro & Puro & $\mathrm{Fe}_{99.9}$ & 25.000 & 350.000 & 0,8 & 2,16 \\
FeSi & -- & $\mathrm{Fe}_{96} \mathrm{Si}_{4}$ & 1200 & 6.500 & 40 & 1,95 \\
FeSi & Hypersil & $\mathrm{Fe}_{97} \mathrm{Si}_{3}$ & 9.000 & 40.000 & 12 & 2,01 \\
Permalloy 50 & Hypernik & $\mathrm{Ni}_{50} \mathrm{Fe}_{50}$ & --- & $10^{5}$ & 4 & 1,60 \\
Permalloy 78 & --- & $\mathrm{Ni}_{78} \mathrm{Fe}_{22}$ & 4.000 & $10^{5}$ & 4 & 1,05 \\
Mumetal & --- & $\mathrm{Ni}_{75} \mathrm{Fe}_{18} \mathrm{Cu}_{5} \mathrm{Cr}_{2}$ & 20.000 & $10^{5}$ & 4 & 0,75 \\
Supermaloy & --- & $\mathrm{Ni}_{79} \mathrm{Fe}_{15} \mathrm{Mo}_{5} \mathrm{Mn}_{2}$ & 90.000 & $10^{6}$ & --- & 0,32 \\
Permendur & --- & $\mathrm{Fe}_{50} \mathrm{Co}_{50}$ & 500 & 6.000 & 16 & 2,4 \\
FeCoV & -- & $\mathrm{Fe}_{49} \mathrm{Co}_{49} \mathrm{~V}_{2}$ & --- & $10^{5}$ & 16 & 2,3 \\
Perminvar & Tratamento & $\mathrm{Fe}_{34} \mathrm{Ni}_{43} \mathrm{Co}_{23}$ & --- & $4 \times 10^{5}$ & 2,4 & 1,5 \\
FeSiAl & termomagnético & $\mathrm{Fe}_{85} \mathrm{Si}_{9.5} \mathrm{Al}_{5.5}$ & 35.000 & 120.000 & 2,4 & 1,2 \\
\hline
\end{tabular}


$\mathrm{Na}$ tabela D.2, são apresentadas as propriedades típicas de vários materiais ferromagnéticos doces, que podem ser utilizadas na construção de dispositivos MR. Nesta tabela $\mu_{I}$ é a permeabilidade inicial (ou seja, permeabilidade sob campos magnéticos de baixa intensidade), $\mu_{m}$ é a permeabilidade relativa máxima, $H_{c}$ é a coercividade e $M_{S}$ é a magnetização de saturação (conforme figura D.1).

O ferro possui uma magnetização de saturação relativamente alta, o que é bastante interessante no projeto de atuadores MR, porque permite a aplicação de altas densidades de fluxo magnético sobre os fluidos MR. Além disso, o ferro, por ser abundante na crosta terrestre $(3,3 \%)$, é o material ferromagnético mais barato. O ferro comercial disponível alcança permeabilidades relativas máximas da ordem de 5000 e coercividade da ordem de 70 $\mathrm{A} / \mathrm{m}$. Dentro destas características encaixam-se também os aços carbono com baixo teor de carbono, os SAE 1008 e SAE 1010, por exemplo. Os aços SAE 1020 laminados também apresentam boas propriedades magnéticas, como a alta magnetização de saturação e baixa coercividade, e sua permeabilidade é um pouco menor que a do ferro comercial. Pela sua boa resistência mecânica e boa usinabilidade, o SAE 1020 é um material bastante adequado à construção de válvulas MR (CRAFT, 2003).

De maneira geral a desvantagem do uso de Fe é a sua baixa resistividade elétrica. A baixa resistividade é ruim para aplicações em altas freqüências por causa de correntes parasitas ("eddy currents") conforme a lei de Faraday ${ }^{28}$. Contudo este não é um fator limitante para os dispositivos MR dado que as frequiências de trabalho não são tão elevadas.

Outros materiais doces podem ser obtidos por ligas de ferro com outros metais. As ligas de FeSi são muito utilizadas por apresentar baixas perdas por correntes induzidas. A sua formulação conhecida por Hyspersil (vide tabela D.2) pode ser interessante para uso em dispositivos MR. Um dos materiais doces mais conhecidos é o chamado Permalloy, que são ligas de $\mathrm{NiFe}$, contudo apresentam magnetização de saturação cerca de 70 a $80 \%$ mais baixas que a do ferro, o que não é interessante para a aplicação estudada. Outra liga interessante para dispositivos MR é a FeCo, que apresenta magnetização de saturação de até 2,4 Tesla, contudo seu custo é muito superior ao custo do ferro e dos aços comuns.

\footnotetext{
${ }^{28}$ A lei de Faraday (1831) é estabelecida por $f e m=-\frac{d \phi}{d t}$, que é comumente confundida com a lei de Lenz (1834), que afirma somente que a voltagem induzida age de modo a produzir um fluxo de oposição ao fluxo gerador da indução. Ou seja, a lei de Lenz só dá uma interpretação física da lei de Faraday e justifica o sinal de menos da fórmula.
} 
As ferritas, compostos contendo $\mathrm{FeO}$, são materiais utilizados em altas freqüências por sua característica de alta resistência elétrica ${ }^{29}$, o que reduz drasticamente a indução de correntes parasitas, reduzindo as perdas de potência. Contudo, devido a sua baixa magnetização de saturação (em relação ao ferro) e fragilidade, elas são inadequadas ao uso em dispositivos para controle de fluidos MR.

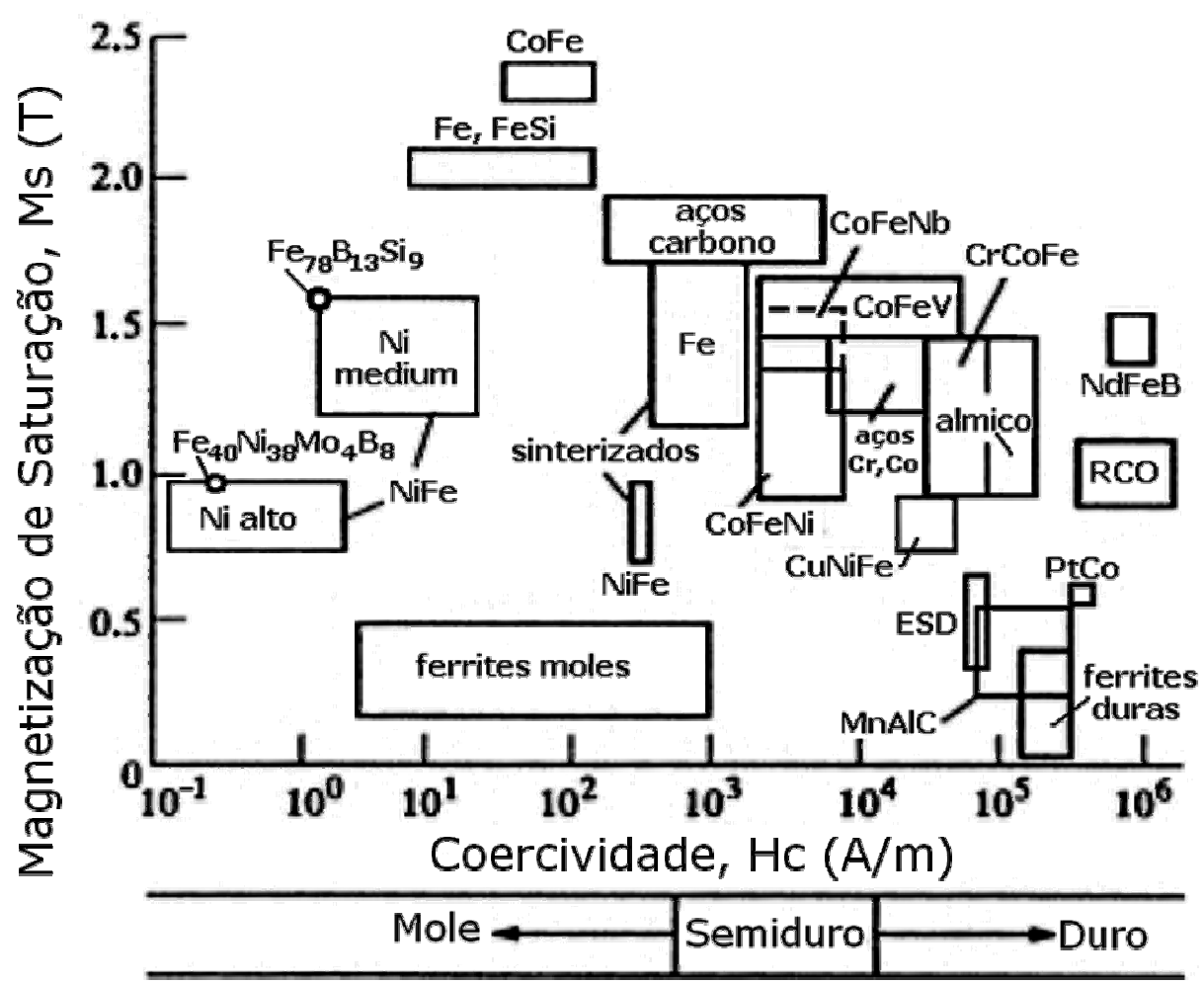

Figura D.2 - Coercividade e magnetização de saturação de materiais magnéticos (Chin apud GENÇ, 2002 ).

Um gráfico que compara diversos tipos de materiais com relação a sua magnetização de saturação $\left(M_{S}\right)$ e coercividade $\left(H_{c}\right)$ é apresentado na figura D.2. Para aplicação em dispositivos MR deve-se procurar utilizar materiais com características de baixa coercividade e alta magnetização de saturação, porém sempre se levando em conta a relação de custobenefício.

\footnotetext{
${ }^{29}$ As ferritas podem alcançar resistividade elétrica da oredem de $10^{3}$ até $10^{7} \Omega \mathrm{m}$.
} 


\section{APÊNDICE E - Equações das tensões sobre um fluido}

Para fluidos newtonianos e isotrópicos é possível relacionar as componentes de tensão (vide figura 2.5, página 49) e os gradientes da velocidade usando apenas duas propriedades do fluido, a viscosidade $\mu$ e o segundo coeficiente da viscosidade, $\lambda$, As relações tensãogradiente da velocidade, também conhecido por equações constitutivas, são enunciadas como segue (POTTER e WIGGERT, 2002):

$$
\begin{array}{ll}
\sigma_{x x}=-p+2 \mu \frac{\partial u}{\partial x}+\lambda \nabla \cdot \vec{V} & \tau_{x y}=\mu\left(\frac{\partial u}{\partial y}+\frac{\partial v}{\partial x}\right) \\
\sigma_{y y}=-p+2 \mu \frac{\partial v}{\partial y}+\lambda \nabla \cdot \vec{V} & \tau_{x z}=\mu\left(\frac{\partial u}{\partial z}+\frac{\partial w}{\partial x}\right) \\
\sigma_{z z}=-p+2 \mu \frac{\partial w}{\partial z}+\lambda \nabla \cdot \vec{V} & \tau_{y z}=\mu\left(\frac{\partial v}{\partial z}+\frac{\partial w}{\partial y}\right)
\end{array}
$$

onde $p$ é a pressão e $\vec{V}^{T}=\{u, v, w\}$ é o vetor de velocidade do volume infinitesimal de fluido, respectivamente nas direções dos eixos $\mathrm{x}$, y e z. Considerando a expressão do gradiente deste vetor:

$$
\nabla \vec{V}=\left[\begin{array}{lll}
\frac{\partial u}{\partial x} & \frac{\partial v}{\partial x} & \frac{\partial w}{\partial x} \\
\frac{\partial u}{\partial y} & \frac{\partial v}{\partial y} & \frac{\partial w}{\partial y} \\
\frac{\partial u}{\partial z} & \frac{\partial v}{\partial z} & \frac{\partial w}{\partial z}
\end{array}\right]
$$

O tensor P pode ser escrito numa forma mais compacta, conforme apresentado na equação E.3, onde I é a matriz identidade. 


$$
\mathbf{P}=\left[\begin{array}{lll}
\sigma_{x x} & \tau_{x y} & \tau_{x z} \\
\tau_{y x} & \sigma_{y y} & \tau_{y z} \\
\tau_{z x} & \tau_{z y} & \sigma_{z z}
\end{array}\right]=-p \cdot \mathbf{I}+\mu\left(\nabla \vec{V}+(\nabla \vec{V})^{T}\right)+\lambda(\nabla \cdot \vec{V}) \cdot \mathbf{I}
$$

Para muitos gases e principalmente para gases monoatômicos, o segundo coeficiente da viscosidade $(\lambda)$ é relacionado à viscosidade por:

$$
\lambda=-\frac{2}{3} \mu
$$

que é uma hipótese conhecida como a hipótese de Stokes. Com essa relação, a média negativa das três tensões normais é igual à pressão, isto é:

$$
-\frac{1}{3}\left(\sigma_{x x}+\sigma_{y y}+\sigma_{z z}\right)=p
$$

Utilizando as equações E.1 pode-se mostrar que isso é sempre verdade para um líquido no qual $\nabla \cdot \vec{V}=0$ e, com a hipótese de Stokes, é também verdade para um gás. Substituindose as equações constitutivas (E.1) nas equações diferenciais da quantidade de movimento (equação 3.1, página 53), aplicando-se a hipótese de Stokes, e supondo um fluido homogêneo em escoamento incompressível, chega-se a seguinte expressão:

$$
\rho \frac{D \vec{V}}{D t}=-\nabla p+\mu \nabla^{2} \vec{V}+\rho \vec{g}
$$




\title{
APÊNDICE F - Revisão sobre PQS
}

\author{
PROBLEMA DE OTIMIZAÇÃO GERAL
}

Técnicas de Otimização são utilizadas para se encontrar um conjunto de parâmetros de projeto, $x=\left\{x_{1}, x_{2}, \ldots, x_{n}\right\}$, que, sob certas condições, podem ser definidos como ótimos. Num caso simples, a condição pode ser a minimização ou a maximização de alguma característica do sistema que é dependente de $x$. Em casos mais complexos, a função objetivo, $\mathrm{f}(\mathrm{x})$, a ser minimizada ou maximizada, pode estar sujeita a restrições que se apresentam da seguinte forma:

- restrições de igualdade, $G_{i}(x)=0\left(i=1,2, \ldots, m_{e}\right)$;

- restrições de desigualdade, $G_{i}(x) \leq 0\left(i=m_{e}+1, \ldots, m\right)$;

- e/ou parâmetros de contorno.

O Problema Geral (PG) é posto da seguinte forma:

$$
\underset{\mathrm{x}}{\operatorname{minimizar}} f(x)
$$

sujeito à

$$
\begin{aligned}
G_{i}(x) & =0, \quad i=1,2, \ldots, m_{e} \\
G_{i}(x) & \leq 0, \quad i=m_{e}+1, \ldots, m
\end{aligned}
$$

onde $x$ é o vetor de parâmetros de projeto de dimensão $n, f(x)$ é a função objetivo, cujo contradomínio $\in \mathfrak{R}$, e a função vetorial $G(x)$ que retorna um vetor de dimensão $m$ contendo os valores das restrições de igualdade e de desigualdade avaliadas em $x$.

Uma solução eficiente e acurada para este problema não depende do tamanho do problema em termos de número de restrições e variáveis de projeto, mas sim de características da função objetivo e das restrições. Quando a função objetivo e as restrições são funções 
lineares das variáveis de projeto, o problema é conhecido como problema de Programação Linear (PL). A Programação Quadrática (PQ), por sua vez, trata da minimização ou maximização de uma função-objetivo quadrática linearmente restrita. Para ambos os problemas PL e PQ há soluções confiáveis disponíveis.

Por outro lado, problemas de Programação Não-linear (PN), nos quais a função objetivo e as restrições podem ser funções não-lineares das variáveis de projeto, são mais difíceis de resolver. A solução de um problema de PN geralmente requer um procedimento mais complexo para estabelecer a direção de busca de cada iteração subseqüente. Isto é usualmente atingido pela solução de um problema LP, um QP, de um sub-problema não restrito.

\section{PROGRAMAÇÃO QUADRÁTICA SEQUENCIAL (PQS)}

As metodologias PQS representam o estado da arte em métodos de PN. Shittkowski (1985), por exemplo, programou e testou uma versão com desempenho superior a todos os outros métodos testados até então, sendo mais eficiente, preciso e com muito mais soluções bem sucedidas, além de ter passado em um grande número de problemas de teste.

Baseado nos trabalhos de Biggs (1975), Han (1977), e Powell (1978a,1978b), o método desenvolvido por Schittkowski permite imitar localmente o método de Newton para otimização com restrição, da mesma forma que é feito para otimização sem restrição. A cada ciclo maior do processo iterativo, uma aproximação da matriz hessiana da função lagrangeana é feita através de um método quasi-Newton de atualização. Este resultado é então utilizado para gerar um sub-problema de programação quadrática (PQ), cuja solução é utilizada para definir a direção de busca no processo de encontrar o ponto de mínimo. Uma visão geral do PQS pode ser encontrada em Fletcher (1987), Gill et al. (1981), Powell (1983), e Hock e Schittkowski (1983). O problema geral é posto como segue: dado a descrição do PG (eq. (F.1)) a principal idéia é a formulação de um sub-problema de $\mathrm{PQ}$, baseado na aproximação quadrática da seguinte função lagrangeana:

$$
L(x, \lambda)=f(x)+\sum_{i=1}^{m} \lambda_{i} \cdot G_{i}(x)
$$

onde $\lambda_{i}$ são os multiplicadores de Lagrange. 
Neste ponto, a equação (F.1) é simplificada através da consideração de restrições de fronteira como restrições de desigualdade. Obtém-se um sub-problema de PQ através da linearização das restrições não-lineares.

SUBPROBLEMA DE PROGRAMAÇÃO QUADRÁTICA

$$
\begin{aligned}
\underset{d \in \mathfrak{Y}^{n}}{\operatorname{minimizar}} & \frac{1}{2} d^{T} H_{k} d+\nabla f\left(x_{k}\right)^{T} d \\
\nabla g_{i}\left(x_{k}\right)^{T} d+g_{i}\left(x_{k}\right)=0, & i=1,2, \ldots, m_{e} \\
\nabla g_{i}\left(x_{k}\right)^{T} d+g_{i}\left(x_{k}\right) \leq 0, & i=m_{e}+1, \ldots, m
\end{aligned}
$$

Este sub-problema pode ser resolvido utilizando-se qualquer algoritmo de PQ. A solução é, então, utilizada numa nova iteração

$$
x_{k+1}=x_{k}+\alpha_{k} d_{k}
$$

O parâmetro que define o passo, $\alpha_{k}$, é determinado por procedimento apropriado de busca, de tal forma que um decréscimo suficiente na função de custo seja obtido. A matriz $H_{k}$ é uma aproximação positiva definida da matriz hessiana da função lagrangeana (eq. (F.2)). $H_{k}$ pode ser atualizada por qualquer dos métodos quasi-Newton existentes, embora o método BFGS pareça ser o mais popular. 


\section{ANEXO A - Exemplo de fluidos MR comerciais}

No trabalho de JOLLY et al. (1999) encontra-se o comparativo entre quatro fluidos MR comerciais da Lord Co., são eles: MRX-126PD, MRX-140ND, MRX-242AS e o MRX336AG. O primeiro algarismo da numeração do fluido significa o tipo de fluido base, e os dois últimos algarismos significam o percentual de ferro por volume na composição do fluido, conforme a tabela An.1:

Tabela An.1:Composição básica e densidade de fluidos MR comerciais (1998).

\begin{tabular}{|c|c|c|c|}
\hline $\begin{array}{c}\text { Fluido MR } \\
\text { comercial }\end{array}$ & $\begin{array}{c}\text { Percentual de ferro } \\
\text { por volume }\end{array}$ & Fluido Base & Densidade $(\mathrm{g} / \mathrm{ml})$ \\
\hline MRX-126PD & 26 & Óleo orgânico & 2,66 \\
\hline MRX-140ND & 40 & Óleo orgânico & 3,64 \\
\hline MRX-242AS & 42 & Água & 3,88 \\
\hline MRX-336AG & 36 & Óleo de Silicone & 3,47 \\
\hline
\end{tabular}

As propriedades magneto-reológicas destes fluidos foram medidas com um aparelho chamado reômetro, usando uma geometria de placa paralela circular com diâmetro de $46 \mathrm{~mm}$ e posicionada com um espaçamento ("gap" ou entreferro) de $1 \mathrm{~mm}$. Na geometria de placas paralelas, a taxa de cisalhamento varia linearmente cruzando-se a amostra de fluido a partir do centro da placa até o seu raio externo, onde ocorre a máxima taxa de cisalhamento. O reômetro é capaz de aplicar fluxo magnético com densidade superior a 1 Tesla através da amostra de fluido. Como a tensão de cisalhamento é proporcional à densidade de fluxo magnético e a máxima taxa de cisalhamento, o experimento foi feito com uma rotação baixa de forma que esta taxa ficasse em torno de apenas $26 \mathrm{~s}^{-1}$. Portanto, a tensão de cisalhamento medida pelo equipamento foi aproximadamente igual à tensão de escoamento do fluido. Outro experimento foi medir a viscosidade do fluido variando-se a taxa de cisalhamento até um valor bem significativo (1000 s $\left.\mathrm{s}^{-1}\right)$ mantendo o campo magnético desligado. Os valores de viscosidade em torno de $1000 \mathrm{~s}^{-1}$ podem ser considerados aproximadamente iguais a 
viscosidade plástica do modelo de Bingham. Os resultados destes experimentos são mostrados na tabela An.2:

Tabela An.2: Tensão de escoamento e viscosidade aparente de fluidos MR comerciais.

\begin{tabular}{|c|c|c|}
\hline Fluido MR comercial & $\begin{array}{c}\text { Tensão de escoamento sob } \\
\text { densidade de fluxo } \\
\text { magnético de 1 Tesla. }\end{array}$ & $\begin{array}{c}\text { Viscosidade medida a uma } \\
\text { taxa de cisalhamento de } \\
1000 \mathrm{~s}^{-1}\left(25^{\circ} \mathrm{C}\right) .\end{array}$ \\
\hline MRX-126PD & $45 \mathrm{kPa}$ & 0,1 \\
\hline MRX-140ND & $70 \mathrm{kPa}$ & 1,0 \\
\hline MRX-242AS & $100 \mathrm{kPa}$ & 0,35 \\
\hline MRX-336AG & $60 \mathrm{kPa}$ & 0,65 \\
\hline
\end{tabular}

Como conclusão, tem-se que a tensão de escoamento máxima do fluido sob campo magnético é proporcional à fração de volume de ferro na composição do fluido MR. Por outro lado, a viscosidade plástica depende tanto do fluido como do tipo de fluido-base. Considerando-se as duas primeiras linhas da tabela An.2, onde se tem dois fluidos MR que utilizam óleos orgânicos como líquido-base, pode-se observar que um aumento de $54 \%$ no percentual de volume das partículas de ferro na composição do fluido resultou em uma variação de dez vezes, para maior, no valor da viscosidade plástica e somente $55 \%$ de aumento na tensão de escoamento máxima. Isto quer dizer que quando se adiciona mais partículas de ferro ao fluido, apesar de se aumentar sua tensão máxima de escoamento, diminuiu-se o alcance dinâmico que ele pode proporcionar a um dispositivo MR, numa proporção muito maior. 


\section{ANEXO B - Exemplos de ferramentas de CAE}

Segue abaixo uma lista de aplicativos para análise de elementos finitos eletromagnética:

- "Maxwell" 2D e 3D da Ansoft Corporation, utilizado pela Lord Corporation.

- "Magnet" da Infolytica.

- "Flux" 2D e 3D da CEDRAT utilizado pelo laboratório LMAG do departamento de Engenharia Elétrica da Universidade de São Paulo.

- "FEMM" da Berlios, um aplicativo aberto padrão GNU, que pode ser baixado gratuitamente na Internet pelo site: http://femm.berlios.de. As limitações deste programa são que ele só resolve problemas planos ou axissimétricos e os seus elementos são de primeira ordem, entretanto isto é suficiente para $80 \%$ das aplicações. A falta de precisão dos elementos pode ser compensada utilizando-se uma quantidade grande de elementos bem pequenos, o que aumentará o tempo de processamento, que para um computador Pentium III não irá além de alguns minutos de processamento para problemas típicos. 


\section{ANEXO C - Dimensionamento de circuitos magnéticos}

Para o projeto de circuitos magnéticos simples ou para se ter uma idéia inicial das grandezas dos parâmetros de projeto, pode se seguir o procedimento descrito abaixo.

1. Selecionar o ponto de operação $\left(\mathbf{H}_{\mathbf{f}}, \mathbf{B}_{\mathbf{f}}\right)$ do fluido $\mathbf{M R}$ visando alcançar os níveis de tensão de escoamento $\left(\tau_{\mathrm{y}}\right)$ desejados.

- O fluxo magnético total é dado por $\phi_{f l u i d}=\mathrm{B}_{\mathrm{f}} \cdot \mathrm{A}_{\mathrm{f}}$, onde $\mathrm{A}_{\mathrm{f}}$, é a área efetiva do pólo devido ao espalhamento do fluxo $\left(\mathrm{A}_{\mathrm{f}},>\mathrm{A}_{\mathrm{f}}\right)$.

2. Aplicar o princípio da Continuidade do Fluxo Magnético para determinar a densidade de fluxo (B) ao longo do núcleo de ferro do circuito magnético:

- $\phi_{\text {fluid }}=\phi_{\text {steel } 1}=\phi_{\text {steel } 2}=\ldots$

3. Determinar o ponto de operação do núcleo de ferro. (Notar que este pode não se o mesmo em diferentes partes do circuito magnético caso a seção transversal varie):

- $\mathrm{B}_{\mathrm{s}}=\phi_{\text {steel }} / \mathrm{A}_{\mathrm{s}}=\mathrm{B}_{\mathrm{f}} \cdot \mathrm{A}_{\mathrm{f}} / \mathrm{A}_{\mathrm{s}}$

- Determinar $\mathrm{H}_{\mathrm{s}}$, a partir da curva BH do material ferromagnético do núcleo.

4. Aplicar a Lei de Kirchoff para Circuitos Magnéticos para determinar a necessidade de ampère-espira (NI).

- NI $=\oint H \cdot d l$

$\mathrm{ou}$

- $\mathrm{NI}=\Sigma \mathrm{Hi} \cdot \mathrm{Li}$

ou

- $\mathrm{NI}=\mathrm{Hf} \cdot \mathrm{g}+\mathrm{Hs} \cdot \mathrm{L}$ 